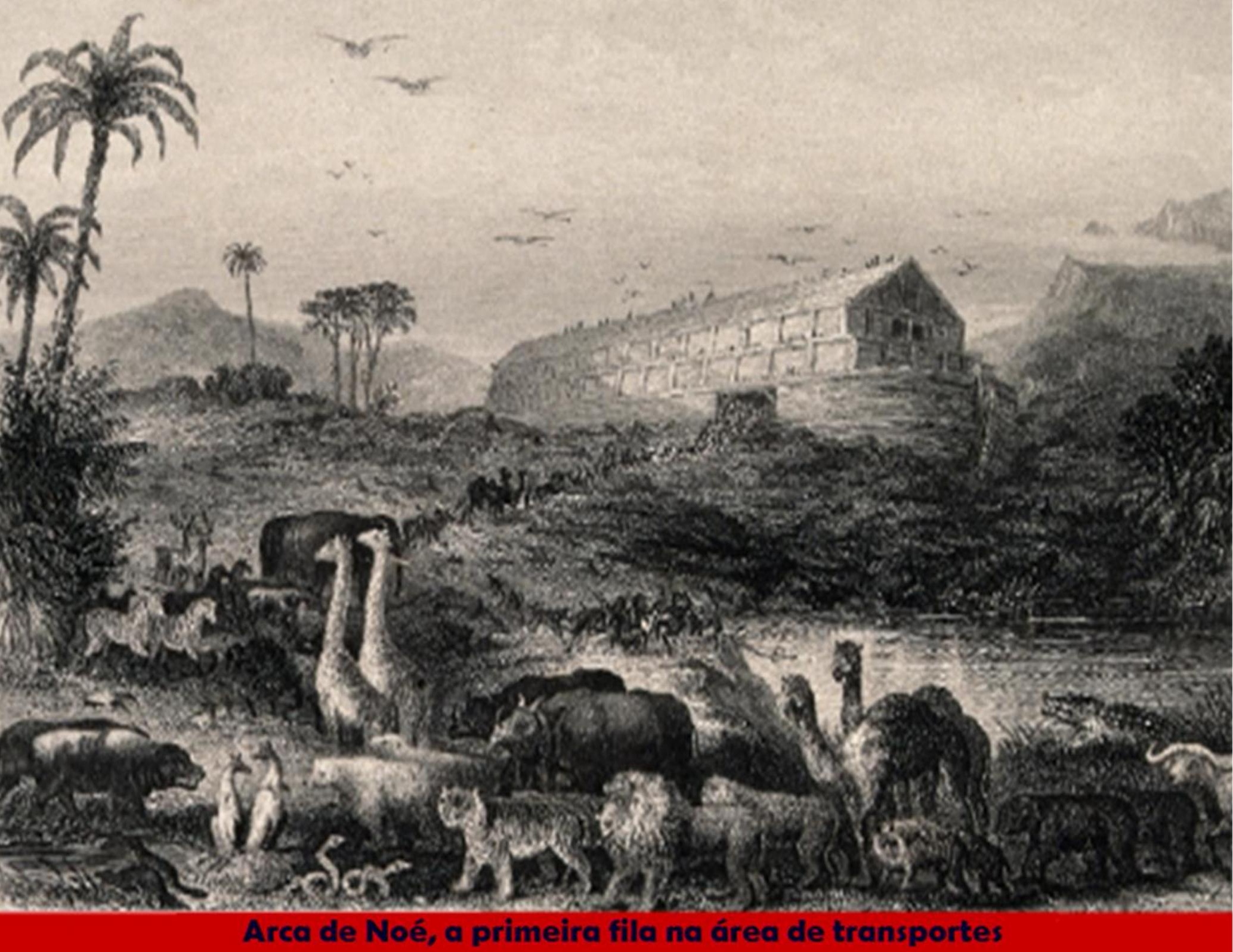

Arca de Noé, a primeira fila na área de transportes

\title{
FILAS
}

CONCEITOS, NOVOS ENFOQUES DE ABORDAGEM E APLICAÇÖES EM TRANSPORTES 


\section{Filas: conceitos, novos enfoques de abordagem e aplicações em Transportes}

\section{AUTORES}

Professor e alunos do Mestrado

em Engenharia de Transportes do Instituto Militar de Engenharia

- PAUlo AFONSO LOPES DA SILVA (organizador e revisor) - Cel QEM/Com (Refm) pauloafonsolopes@uol.com.br

- AdONIS CARNEIRO DA SILVA

adoniscarneiro@gmail.com

- FABIRE SOARES REZENDE - Cap QEM/FC

engfcfabirerezende@gmail.com

- FELIPE PEREIRA ROSA PIERROTTI

Pierrotti.felipe@gmail.com

- LUCAS DE CASTRO VALENTE

valente.lucas@engenharia.ufjf.br

- MARCOS VINÍCIOS GONÇALVES

marcos4758@gmail.com

- MARION GOMES DE MORAES FERNANDES - Cap QEM/FC

eng.marionfernandes@gmail.com

- MELQUiSEDEQUE DAMASCENO DO NASCIMENTO

mdn.melqui@gmail.com

- NEWTON CARLOS DE OLIVEIRA PORTELLA - Maj QMB

newtoncarlos99@gmail.com

- ERNESTO RADEMAKER MARTINS - Capitão-de-Fragata radmart@yahoo.com.br

- RAFAEL FERREIRA ALMEIDA

rafaelfalme@yahoo.com.br

- SAMILLE CRISTINA RODRIGUES

samillecr@gmail.com

- VITOR NUNES CRUZ

vitorncruz@hotmail.com

- YURI MARINHO DE CARVALHO - 10 Ten Int

yuri.marinho@eb.mil.br 


\section{CRÉDITOS}

- Arte da capa: Cel QEM/Com (Refm) Paulo Afonso Lopes da Silva

- Imagem da capa: Os animais entram na Arca (The Entry Into the Ark). Gravura. Wellcome Collection(https://wellcomecollection.org/works/zj7j2n4n). CC BY (https://creativecommons.org/licenses/by/4.0/deed.pt_BR)

- Figuras:

a) Ernesto Rademaker Martins: 11.4.

b) Fabire Soares Rezende: 2.4, 3.1, 7.2.

c) Felipe Pereira Rosa Pierrotti: 1.5, 2.15 e 2.17 .

d) Marion Gomes de Moraes Fernandes: 11.3.

e) Michał Parzuchowski em Unsplash (https://unsplash.com): 2.5

f) Paulo Afonso Lopes da Silva: 1.4, 2.1, 2.2, 2.3. 2.5 (com o ícone das pessoas obtido de https://www.flaticon.com/free-icon/people-sitting_10933, CC BY ( https://creativecommons.org/licenses/by/3.0/)), 2.7 a 2.14, 2.16, 2.18 a 2.25, 5.1, 5.2, 7.5, 8.6, 8.7, 11.1, 11.2 e Desfecho-1.

g) Samille Cristina Rodrigues: 1.1, 1.2 e 1.3.

h) Vitor Nunes Cruz: 1.7, 1.8, 1.9. 1.10, 4.19 e 4.20.

i) Yuri Marinho de Carvalho: 1.6, 2.6 e 9.2. 


\section{INFORMAÇÃO ADICIONAL}

Todo esse texto passou nos testes dos seguintes softwares disponíveis na Web:

a. Grammarly

Verifica erros de ortografia e testa para plágio.

Disponível em https://www.grammarly.com/plagiarism-checker

b. Plagiarism

Testa para plágio.

Disponível em http://plagiarisma.net

Para ambos os softwares, houve o registro no portal para ter acesso completo e a submissão do trecho de texto para detecção de possível plágio. 0 texto era aceito se o resultado fosse superior a " $85 \%$ unique".

Os nomes dos autores dos capítulos foram colocados em ordem alfabética.

\section{DECLARAÇÃo}

Esta publicação contém informações obtidas de autênticas e altamente respeitadas fontes, tendo sido feitos esforços no sentido de as trazerem confiáveis. Entretanto, pode haver, ainda, erros que, naturalmente, ocorrem em qualquer trabalho intelectual, pelo que se pede aos leitores que os apontem no sentido de serem corrigidos.

Os Autores não têm qualquer controle sobre o uso deste material e não podem assumir responsabilidade de qualquer espécie pela validade de todas as informações ou pelas consequências dos seus usos. O material apresentado nesta publicação destina-se ao aprendizado geral do leitor, do qual se espera exercer um julgamento profissional sólido na utilização das informações apresentadas.

Todas as referências a produtos comerciais citados no livro são restritas a exemplos. Quaisquer marcas ou nomes comerciais referenciados pertencem aos respectivos proprietários, e os Autores não endossam qualquer uma delas em nenhum momento.

As instruções do fabricante sobre a utilização de qualquer produto comercial devem ser seguidas sempre, mesmo em conflito com qualquer informação contida neste livro.

Este material está em processo de registro na Biblioteca Nacional.

(C)2019 - Os Autores 


\section{PREFÁCIO Como foi feito \\ e o porquê deste livro ${ }^{1}$}

PAULO AFONSO LOPES DA SILVA

A ideia surgiu quando eu preparava as aulas de Teoria das Filas para o Mestrado em Engenharia de Transportes do Instituto Militar de Engenharia em 2019. Observei que, mesmo com o uso de modernos enfoques de aprendizagem, expõem-se da maneira tradicional os assuntos constantes da ementa que se supõe os alunos devam adquirir, exigindo deles um desempenho avaliado essencialmente por provas escritas com os problemas clássicos, constantes dos livros-textos. Finda a disciplina, todo o trabalho feito se encerra naquele momento, perdendo-se a contribuição dos alunos, e o ciclo recomeça no oferecimento da mesma disciplina nos anos seguintes.

Durante o meu planejamento, verifiquei que, na maioria das universidades brasileiras, adotam-se livros ou em inglês (os clássicos) ou os poucos em português, ou mesmo o capítulo daqueles de Pesquisa Operacional. Embora havendo um livro nacional sobre teoria das filas com aplicações em Transportes, esse é datado de 1975, há quase 45 anos, hoje esgotado e considerado raro².

No ensino de uma disciplina, enfatizo a aquisição do conhecimento mais que a realização de provas, o que os alunos precisam saber para executarem uma determinada tarefa, tornando-os competentes por terem conceitos e habilidades que resultam em um elevado desempenho profissional.

Por essas razões, lancei um desafio para os matriculados no segundo período: fazer um livro em um tempo reduzido e com um enfoque completamente novo, e o resultado aí está, realizado em um período de dois meses, a partir do zero, inclusive em termos de conhecimentos dos alunos, com apenas seis aulas presenciais e extensiva comunicação pelo WhatsApp, independentemente de dias e de horários. Para minha agradável surpresa, o interesse superou as minhas expectativas, chegando até a alertá-los para não esquecerem as demais disciplinas. Todos tinham um propósito bem definido!

Este livro apresenta uma nova concepção de ensino da Teoria das Filas, aplicada realmente para a área de Planejamento e Operações de Transportes do Instituto Militar de Engenharia, na qual o aprendizado ocorre mediante o desenvolvimento, pela ordem, das seguintes etapas, que resultam na aquisição do conhecimento:

\footnotetext{
1 "This chapter might have been called "Introduction," but nobody reads the introduction, and we wanted you to read this. We feel safe admitting this here, in the footnote, because nobody reads footnotes either." (Este capítulo poderia ter sido chamado de "Introdução", mas ninguém lê a introdução, e nós queríamos que você lesse isto. Sentimo-nos seguros em admitir isso aqui, na nota de rodapé, porque também ninguém lê as notas de rodapé.) (em Bock, David E., Velleman, Paul F. e De Veaux, Richard D. (2010) Stats : modeling the world, 3rd ed., 769 p., ISBN 13: 978-0-13-135958-1, ISBN 10: 0-13-135958-4, p. 2)

22 NOVAES, Antonio Galvão. Pesquisa Operacional e Transportes: modelos probabilísticos. São Paulo: USP e McGraw-Hill do Brasil, 1975.
} 
1. Conceito.

2. Habilidade.

3. Fundamentação teórica.

4. Aplicativos computacionais.

5. Aplicações reais específicas.

6. Interpretação dos resultados.

Diferentemente dos cursos usuais que enfatizam as habilidades matemáticas, quais sejam a resolução de problemas clássicos, neste livro tem-se um material didático novo, enfatizando o valor das ideias e suas aplicações, essas passíveis de serem encontradas em situações reais, com o enfoque do engenheiro, o qual necessita, prioritariamente, interpretar adequadamente os resultados para tomar a decisão correta no contexto em que se encontra.

No trabalho de construção do livro, formaram-se equipes que podem ser consideradas multidisciplinares com os assuntos da Estatística (conceitos fundamentais), Engenharia (aplicações específicas) e Gestão (tomada de decisão). No seu término, e após uma decisão por consenso, cada um dos autores achou por bem declarar que, se o leitor ou a leitora encontrar algum erro, esse foi devido a um dos outros treze; nesse caso, solicitam que mandem suas críticas (principalmente!) e observações para o endereço eletrônico pauloafonsolopes@uol.com.br.

Entrega-se um produto para a sociedade, especificamente para o setor dos transportes, resultado do provocar, na pós-graduação, mudanças no ensino e na pesquisa.

Esta é uma edição que poderá ser revista e expandida, principalmente porque, de acordo com a citação Non omnia possumus omnes, de Virgílio ${ }^{3}$, "Todos nós não podemos fazer tudo" e também que, segundo Ricardo Jordão Magalhães ${ }^{4}$, "O projeto imperfeito com ação sempre vence o projeto perfeito sem ação."

\footnotetext{
${ }^{3}$ Públio Virgílio Maro (70 a.C.- 19 a.C.) considerado um dos maiores poetas de Roma, e expoente da literatura latina.

${ }^{4} \mathrm{https}: / /$ blogdojordao.com/
} 


\section{Sumário}

\begin{tabular}{|c|c|c|}
\hline Capítulo & & Pág, \\
\hline UM & Uma conversa inicial, uma gentil introdução & 8 \\
\hline DOIS & $\begin{array}{c}\text { A estrutura básica da fila, alicerce de todos os modelos, } \\
\text { e a matemática dos principais tipos de filas }\end{array}$ & 15 \\
\hline TRÊS & $\begin{array}{l}\text { Exemplos, exercícios resolvidos e algo mais: } \\
\text { aquecendo os neurônios }\end{array}$ & 37 \\
\hline QUATRO & Aplicativos computacionais & 50 \\
\hline CINCO & $\begin{array}{c}\text { Determinando l e e a distribuição de probabilidades } \\
\text { modelo dos dados coletados }\end{array}$ & 66 \\
\hline SEIS & $\begin{array}{l}\text { Aplicação da teoria das filas } \\
\text { no transporte rodoviário }\end{array}$ & 83 \\
\hline SETE & $\begin{array}{l}\text { Aplicação da teoria das filas } \\
\text { no transporte ferroviário }\end{array}$ & 94 \\
\hline OITO & $\begin{array}{l}\text { Aplicação da teoria das filas } \\
\text { no transporte aquático }\end{array}$ & 103 \\
\hline NOVE & $\begin{array}{l}\text { Aplicação da teoria das filas } \\
\text { no transporte aéreo }\end{array}$ & 113 \\
\hline DEZ & $\begin{array}{l}\text { Aplicação da teoria das filas } \\
\text { no transporte dutoviário }\end{array}$ & 116 \\
\hline ONZE & $\begin{array}{l}\text { Breve introdução ao transporte } \\
\text { por bicicletas de aluguel }\end{array}$ & 121 \\
\hline DOZE & Desfecho & 125 \\
\hline ANEXO 1 & $\begin{array}{l}\text { Tutorial para o uso do ARENA, } \\
\text { incluindo exemplo de filas }\end{array}$ & 128 \\
\hline ANEXO 2 & $\begin{array}{l}50 \text { ou mais } \\
\text { vídeos sobre teoria das filas }\end{array}$ & 151 \\
\hline ANEXO 3 & $\begin{array}{c}\text { Teoria das Filas } \\
\text { em três universidades estrangeiras }\end{array}$ & 154 \\
\hline REFERÊNCIAS & Referências adicionais & 156 \\
\hline
\end{tabular}




\section{Capítulo \\ Uma conversa inicial, \\ uma gentil introdução}

\section{SAMILLE CRISTINA RODRIGUES VITOR NUNES CRUZ}

Para muitas pessoas, as filas de um determinado lugar são critérios de escolha para avaliar se um estabelecimento é bom ou ruim, preferindo mudar para um concorrente para não enfrentar filas. Para as empresas, tal atitude significa que haverá perda de negócios, consequentemente resultando em uma redução nos lucros ou nos serviços. O mesmo ocorre com os meios de transportes que, embora com um público cativo, esse escolhe aquele com menor tempo de espera ou maior conforto, se não houver mais opções, ou migra para os alternativos, mesmo ilegais.

Para evitar o problema das extensas filas, muitos estabelecimentos adotam medidas para amenizar o tempo de espera dos clientes pelo serviço, ou até mesmo melhorar o humor daqueles que a vão enfrentar. Por exemplo, uma rede de supermercados tem um atendimento diferenciado para os clientes que optam por fazerem suas compras nas suas lojas. $O$ cliente que quiser ter um atendimento diferenciado e sem muita espera nas filas para o pagamento, faz um cadastro no aplicativo da rede que, além de vários benefícios, como descontos em determinados produtos, permite marcar o horário para ser atendido no caixa, e o cliente pode programar-se para fazer suas compras em menor tempo. Figura 1.1.

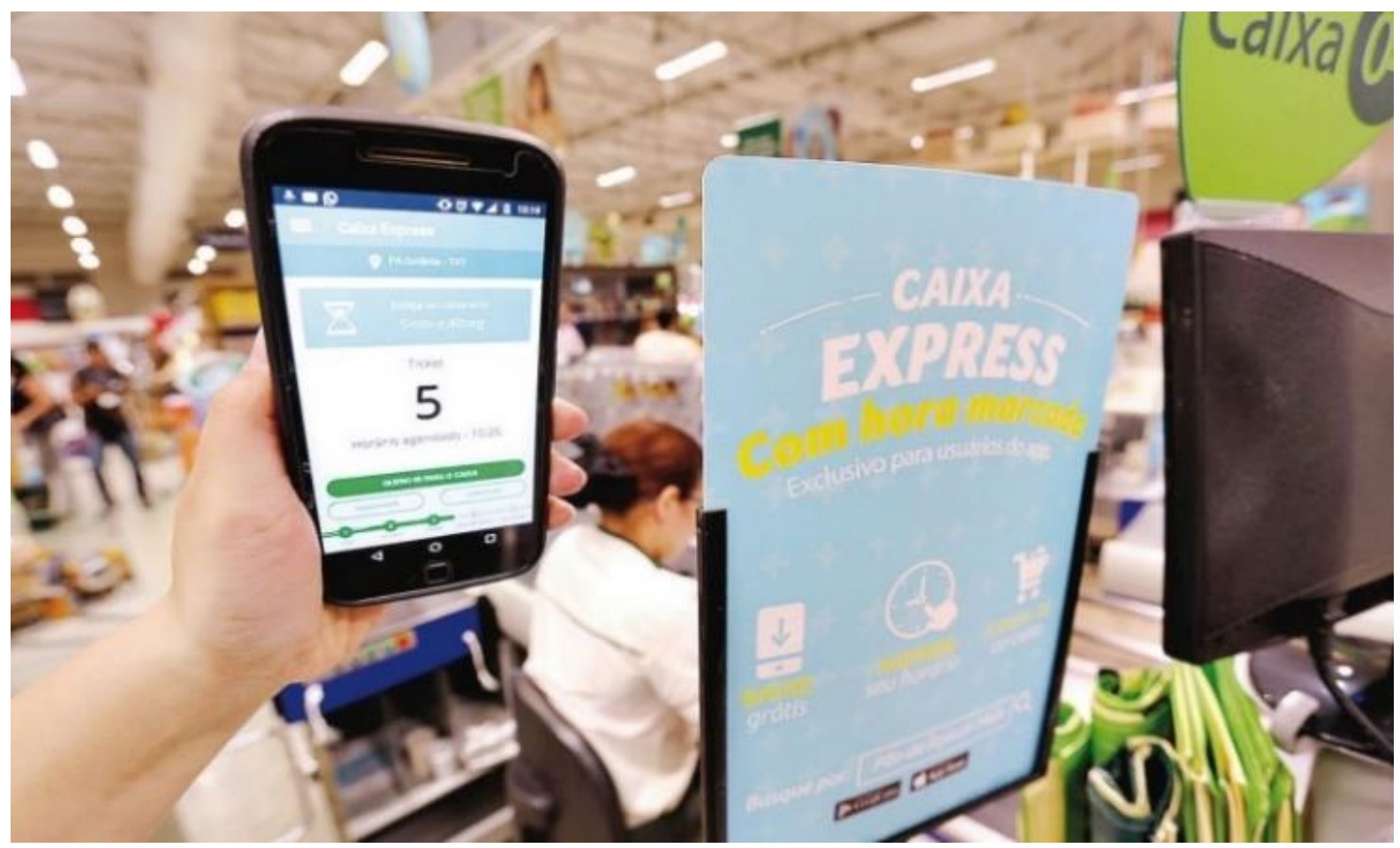

Figura 1.1. Caixa Express com hora marcada em um supermercado. 
Outra maneira que supermercados, agências e estabelecimentos estão aperfeiçoando, e que se tem expandido cada vez mais, são os aplicativos de entrega que, além de evitarem filas, ajudam os clientes a não se deslocarem do local em que estejam, seja para fazerem compras ou mesmo pedirem um remédio de determinada farmácia.

Já em alguns bancos, para amenizarem o tamanho da fila, fazem parcerias com casas lotéricas ou estabelecimentos, que representam as agências, para atenderem os clientes que desejam pagar apenas uma conta, por exemplo. A implantação de caixas de autoatendimento também é um método utilizado para priorizar aqueles que têm um volume menor necessidades a resolver. Além disso, a internet proporciona, com os aplicativos, uma redução na demanda de transportes, porque as pessoas não precisam se deslocar até os estabelecimentos para resolverem os seus problemas, reduzindo o tráfego, se o deslocamento for por veículo próprio.

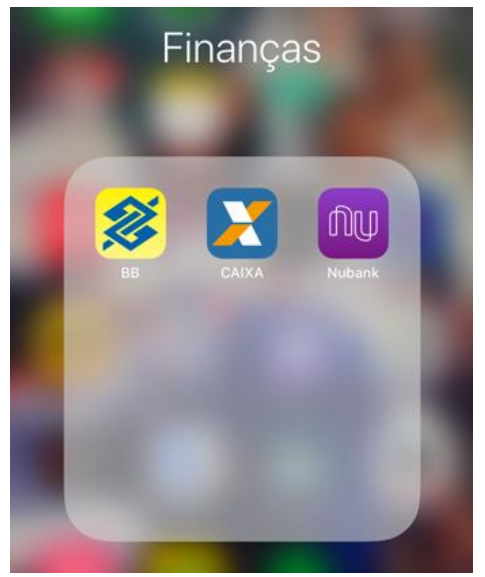

Figura 1.2. Aplicativos de bancos.

No Brasil, o tempo de espera nas filas de banco ultrapassava o limite do razoável, o que conduziu a que os municípios (não existe lei federal) estabelecessem um tempo máximo de espera dos seus clientes nas filas, a chamada "Lei dos 15 minutos", ou "Lei da Fila do Banco", que limita o tempo máximo de espera na fila em dias precedentes ou posteriores a feriados prolongados (usualmente 15 minutos, e 30 minutos nos dias de alta demanda. No estado do Rio de Janeiro, a lei é a 5.254 de 25 de março de 2011.

O método de distribuição de senhas também é um modo de amenizar a espera dos clientes nas filas, possibilitando programar o seu tempo de espera. Como exemplo, se um estabelecimento tem uma fila com um tempo de atendimento em torno de 5 minutos por cliente, e você é o décimo quinto a ser atendido, provavelmente você será atendido em $1 \mathrm{~h} 15 \mathrm{~min}$ quando, na prática, não é bem assim que funcionam as filas, porque outros fatores interferem no tempo de espera para atendimento, como a presteza ou o humor do atendente, e até mesmo a quantidade de serviços.

Nos transportes, pode ser observada a modelagem de filas em diferentes sistemas, como o rodoviário, o ferroviário e o marítimo. No transporte rodoviário as filas estão presentes nos pontos de pedágios, semáforos, túneis e pontes; no ferroviário, as filas no pátios de manutenção e de serviços e, no transporte marítimo, na espera das embarcações nos portos para atracarem ou serem carregadas. 
FILAS: conceitos, novos enfoques de abordagem e aplicações em Transportes

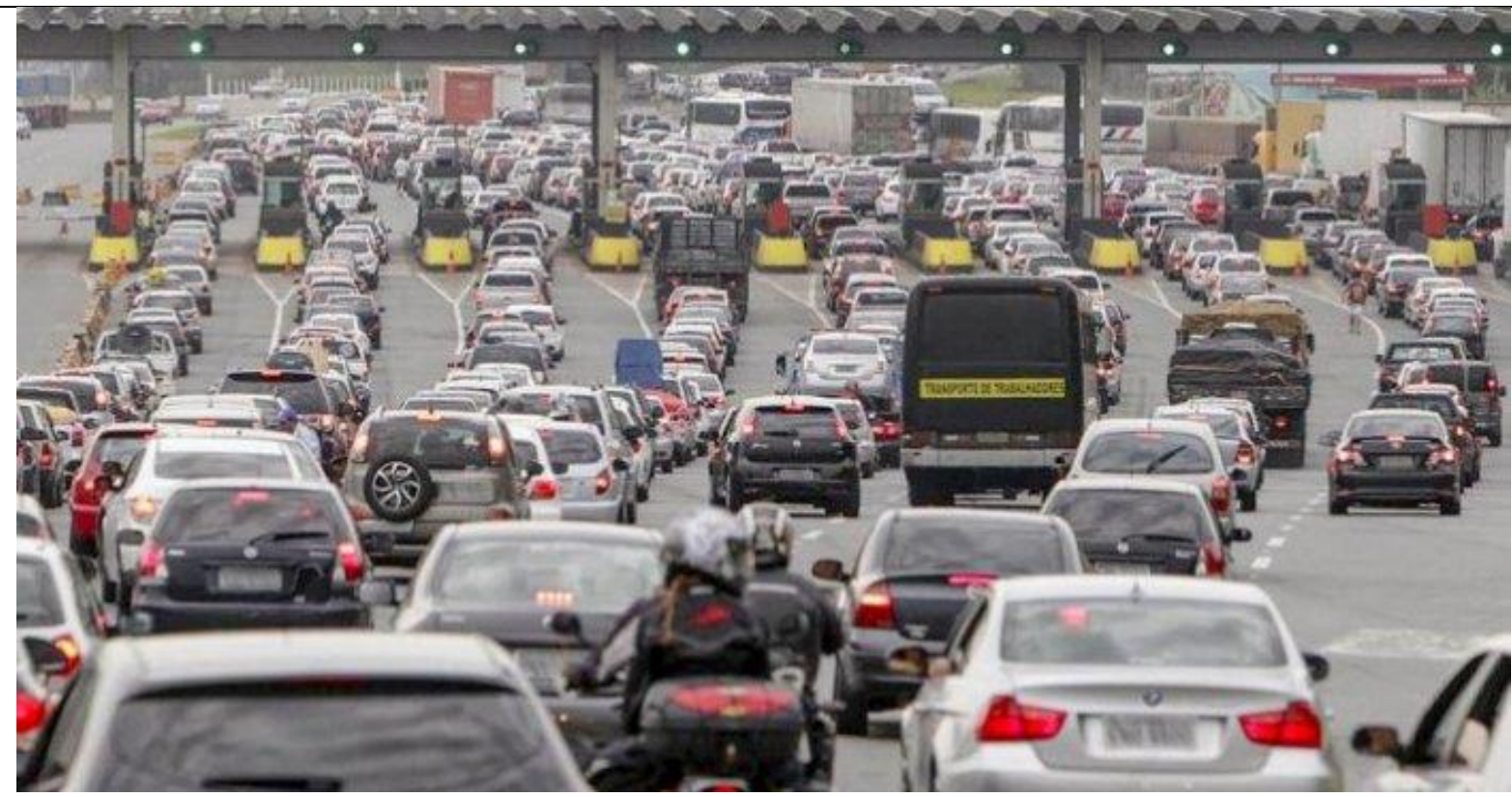

Figura 1.3. Filas em postos de pedágios nas rodovias.

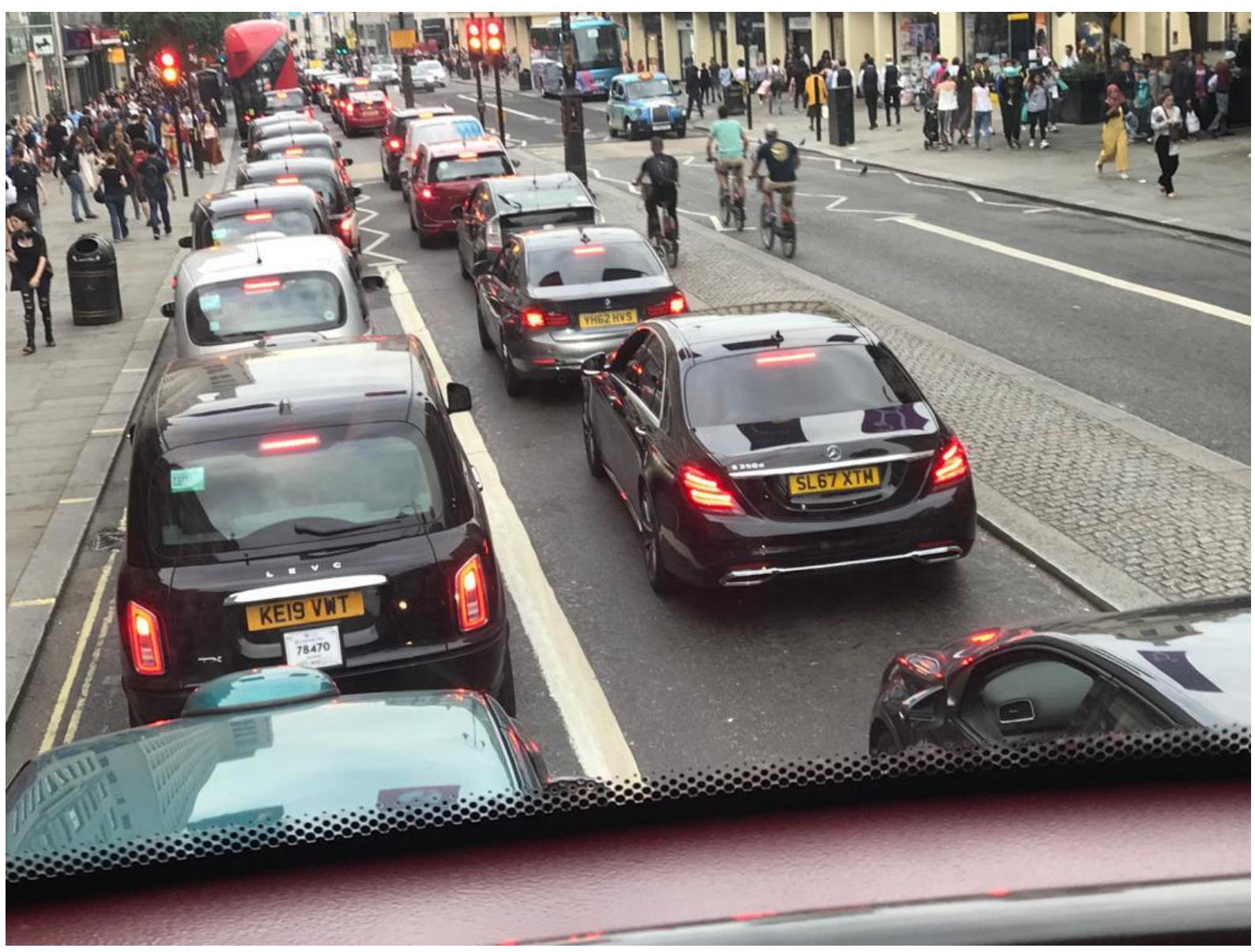

Figura 1.4. Filas de veículos nas vias urbanas. 
FILAS: conceitos, novos enfoques de abordagem e aplicações em Transportes

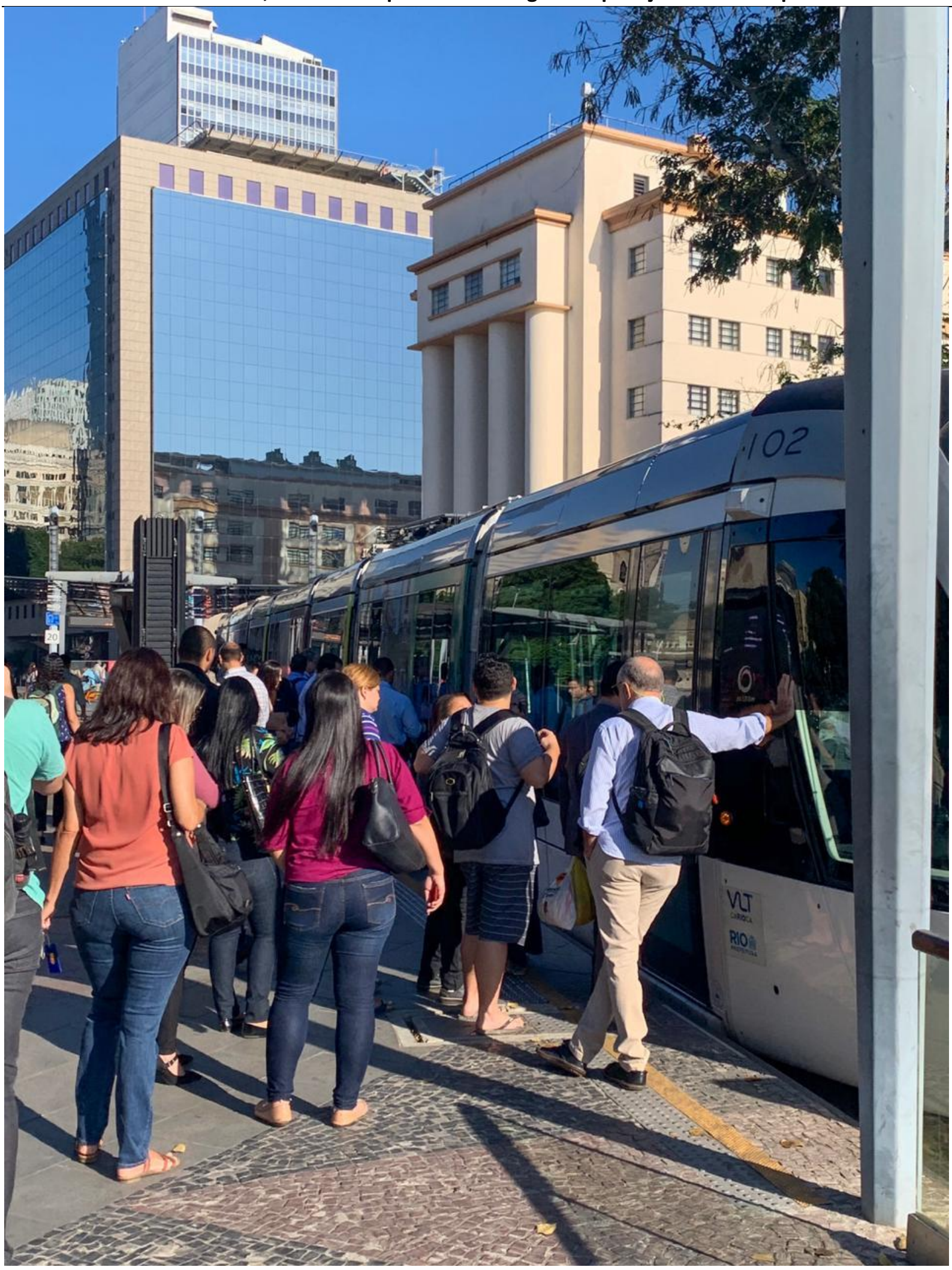

Figura 1.5. Filas de passageiros no VLT, Rio de Janeiro, RJ. 


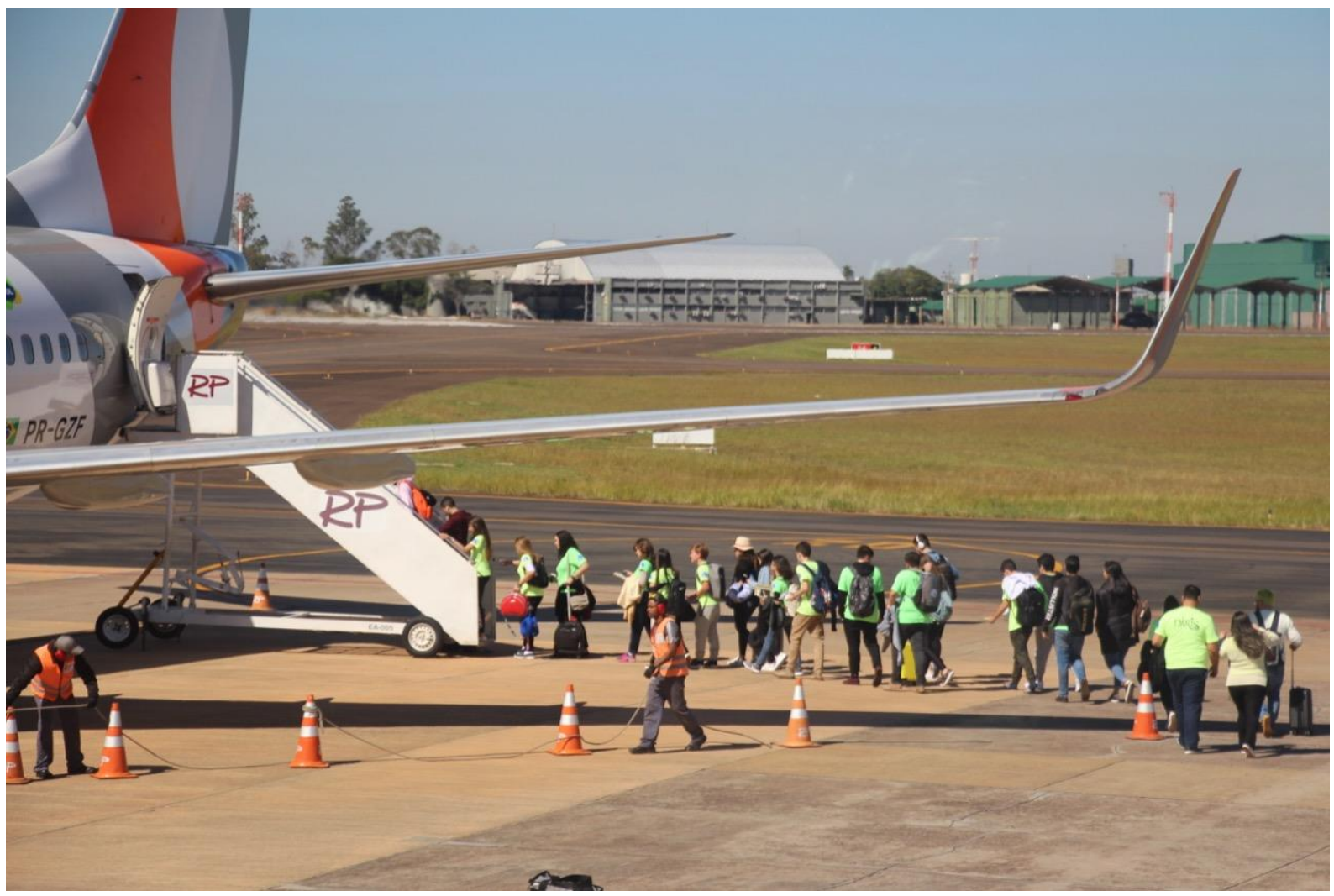

Figura 1.6. Filas de passageiros para embarque em uma aeronave no aeroporto de Campo Grande MS.

Há também situações em que a teoria das filas é utilizada como auxílio para maximizar a de um processo como, por exemplo, a capacidade ferroviária de uma via férrea singela (Figura 1.7), onde os deslocamentos dos trens de um sentido para outro concorrem entre si. No planejamento, entre os critérios que influenciam na determinação dos coeficientes da capacidade ferroviária, ressalta-se o uso da teoria das filas para que um segmento crítico de uma ferrovia seja utilizado em $100 \%$ do tempo.

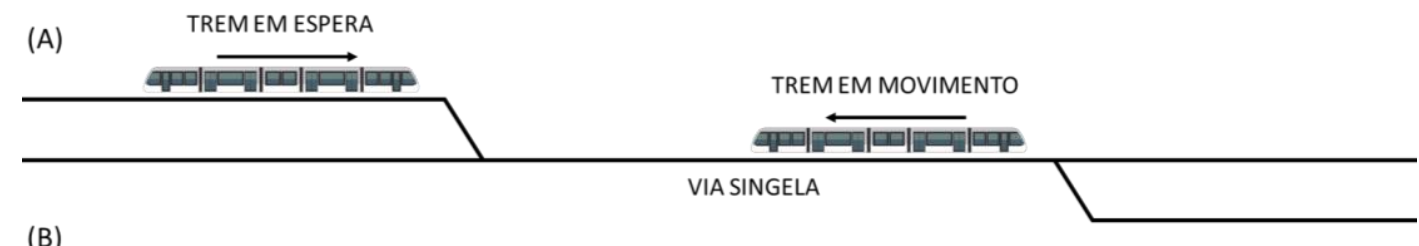

(B)

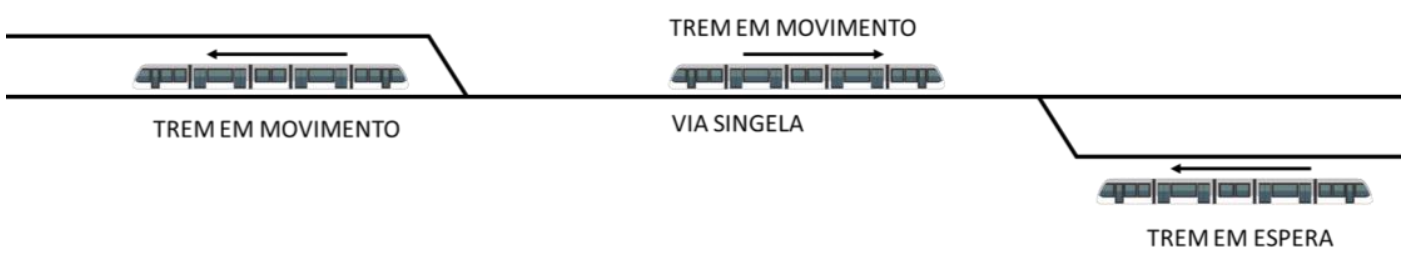

Figura 1.7. Cruzamento de trens em linha singela. Utilização máxima da capacidade ferroviária. 
Embora os problemas de filas sejam estudados há muito, e usadas diversas ferramentas práticas para a obtenção de soluções, ainda hoje é possível identificar organizações que utilizam métodos empíricos. Durante o desenvolvimento deste livro, foi realizada uma pesquisa simples, respostas múltiplas, com 16 profissionais da área de transportes, em que 7 responderam sobre os métodos utilizados para solução dos problemas de filas em suas empresas, cujo resultado está na Figura 1.8.

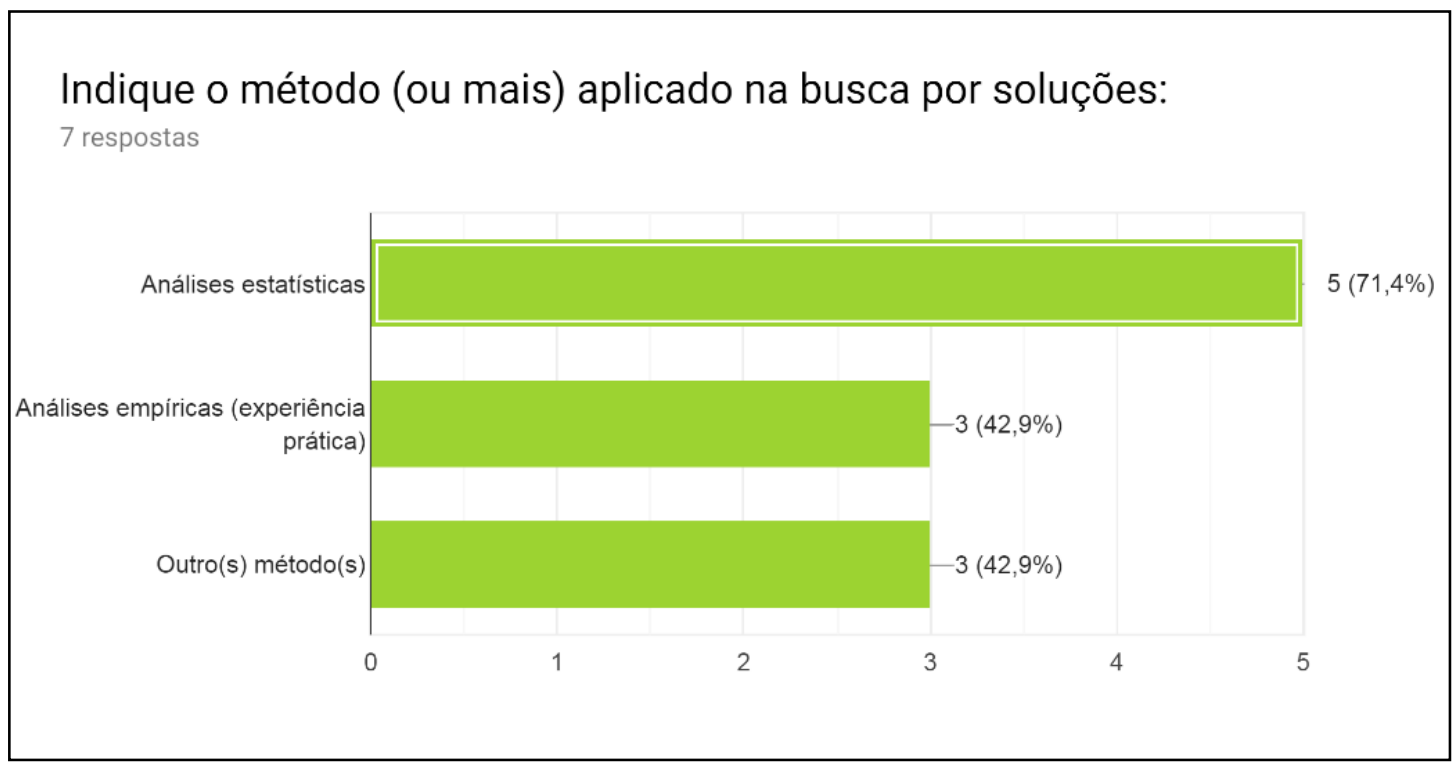

Figura 1.8. Métodos aplicados em problemas de filas.

Com base nas respostas, verificou-se que $42,9 \%$ dos entrevistados utilizam métodos empíricos, considerando também os outros métodos, um número relativamente elevado, evidenciando que os problemas são resolvidos com base na observação e na experiência dos responsáveis e, em alguns casos, utilizando análises estatísticas, mas sem se obter uma otimização dos resultados. Entretanto, os entrevistados que trabalham em grandes operações logísticas, como distribuições de combustíveis, bem como em ferrovias e portos, citaram os métodos de simulação como sendo a ferramenta utilizada em problemas mais complexos.

Para finalizar este capítulo, ressalte-se que, embora as filas sejam representadas nos livros texto, usualmente, em um arranjo linear, esse nem sempre acontece na área dos transportes, conforme ilustram as Figuras 1.9 e 1.10. 
FILAS: conceitos, novos enfoques de abordagem e aplicações em Transportes

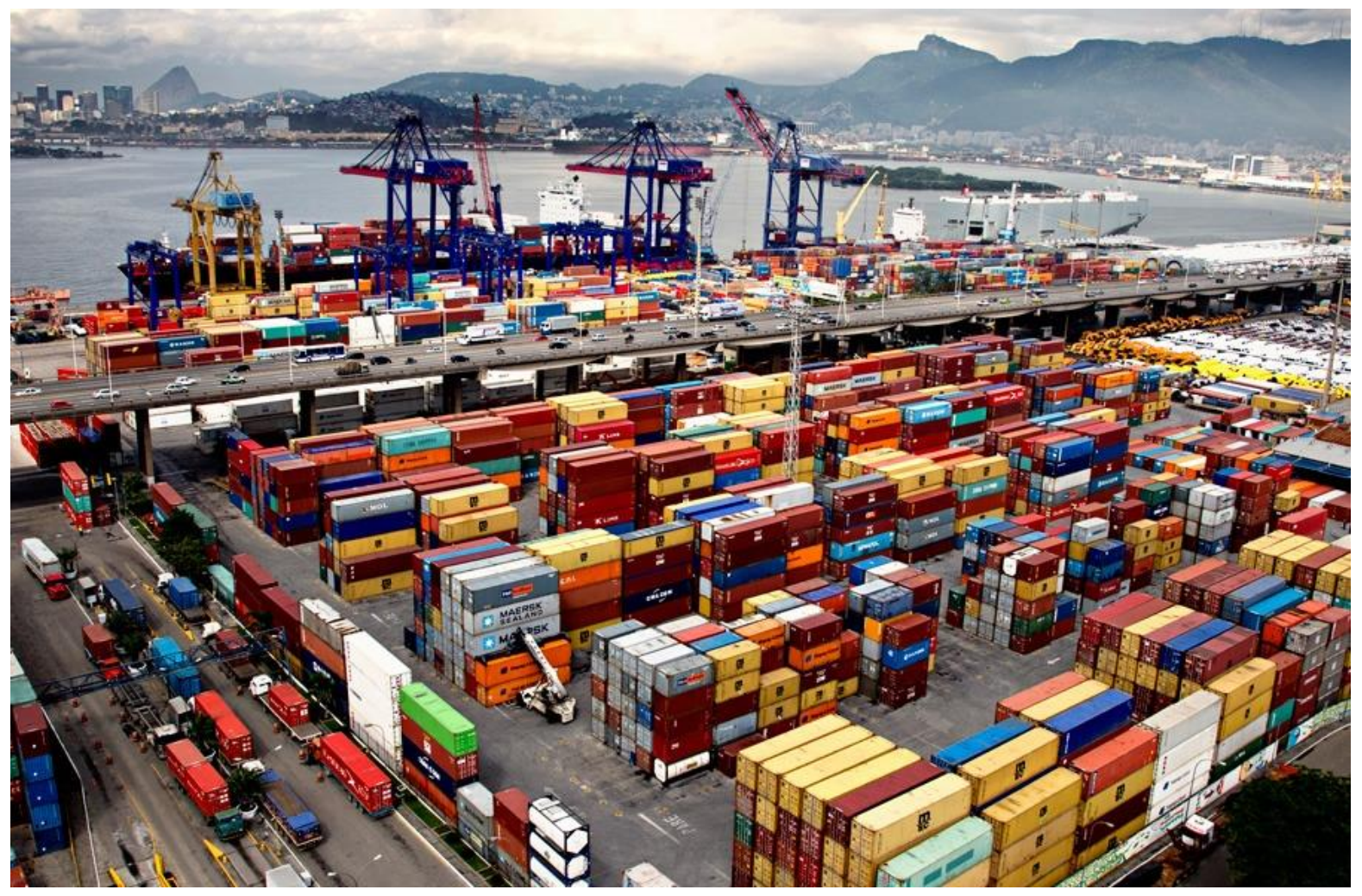

Figura 1.9. Fila de contêineres em um terminal portuário.

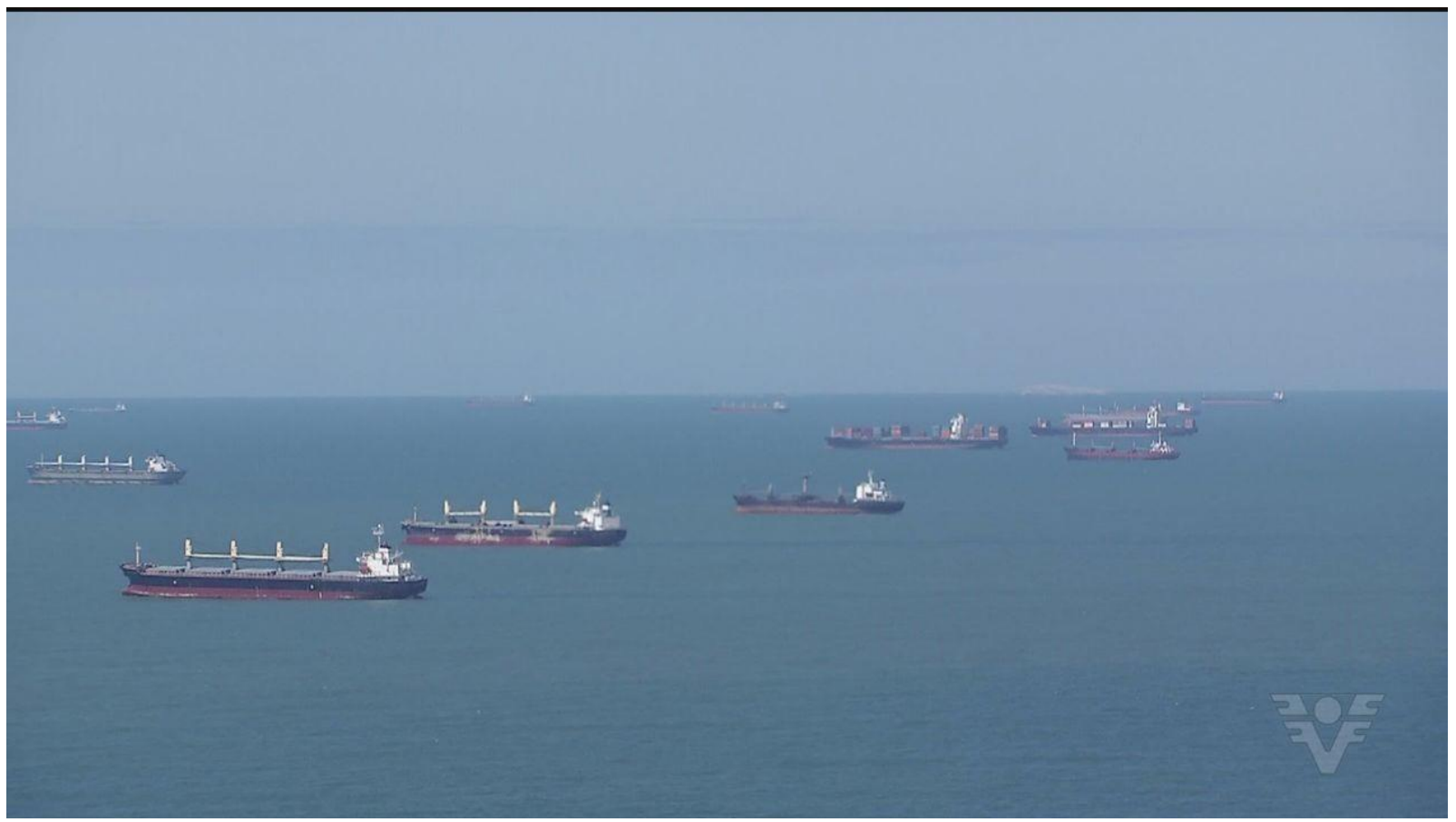

Figura 1.10. Fila de navios aguardando atracação. 


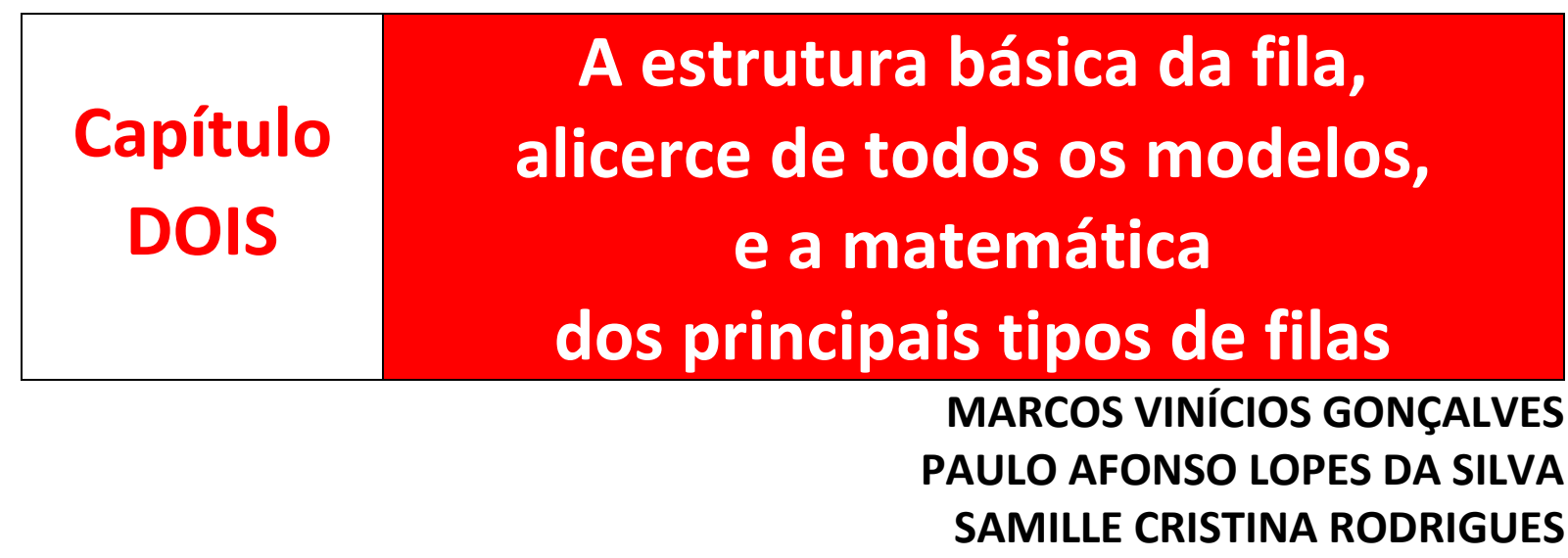

\section{A partir deste capítulo, onde estiver a palavra passageiro, entenda-se também que, onde pertinente, pode referir-se a cargas.}

O problema de filas começou a ser estudado quando o matemático dinamarquês Agner Erlang começou a aplicar conceitos probabilísticos em redes de telecomunicações, mais precisamente em problemas de tráfego de telefonia, tendo publicado, em 1909, o artigo "The Theory of Probabilities and Telephone Conversations", o primeiro sobre esse assunto ${ }^{5}$, sendo por isso considerado o pai da Teoria das Filas.

A Teoria de Filas é um dos estudos da Pesquisa Operacional no que se refere às relações entre as demandas de sistemas de transportes e os atrasos sofridos pelos passageiros. Os serviços ofertados são limitados por restrições intrínsecas dos sistemas, que causam as indesejadas filas, cuja teoria é um método estatístico que permite estimar o comportamento delas quando um serviço tem de ser proporcionado a passageiros cujas chegadas sejam aleatórias.

No caso típico, cada passageiro tem que esperar por determinado serviço para ser atendido. Como a chegada deles é aleatória, a teoria das filas usa conceitos probabilísticos para fornecer informações que proporcionam, tanto para o passageiro quanto para o provedor do meio de transporte, uma otimização de todo o sistema. O Quadro 2.1 apresenta exemplos reais de sistemas de filas no dia a dia.

Quadro 2.1. Exemplos de sistemas de filas

\begin{tabular}{|c|c|c|}
\hline Sistema & Entrada & Atendimento \\
\hline Metrô ou trem & Passageiros & Vagões \\
\hline Rodoviário & Produtos & Caminhões \\
\hline Pedágio & Automóveis & Cabinas de cobrança \\
\hline
\end{tabular}

\footnotetext{
${ }^{5}$ Erlang, A.K. (1909). The Theory of Probabilities and Telephone Conversations. Nyt Tidsskrift for Matematik B, $20,33$.
} 
FILAS: conceitos, novos enfoques de abordagem e aplicações em Transportes

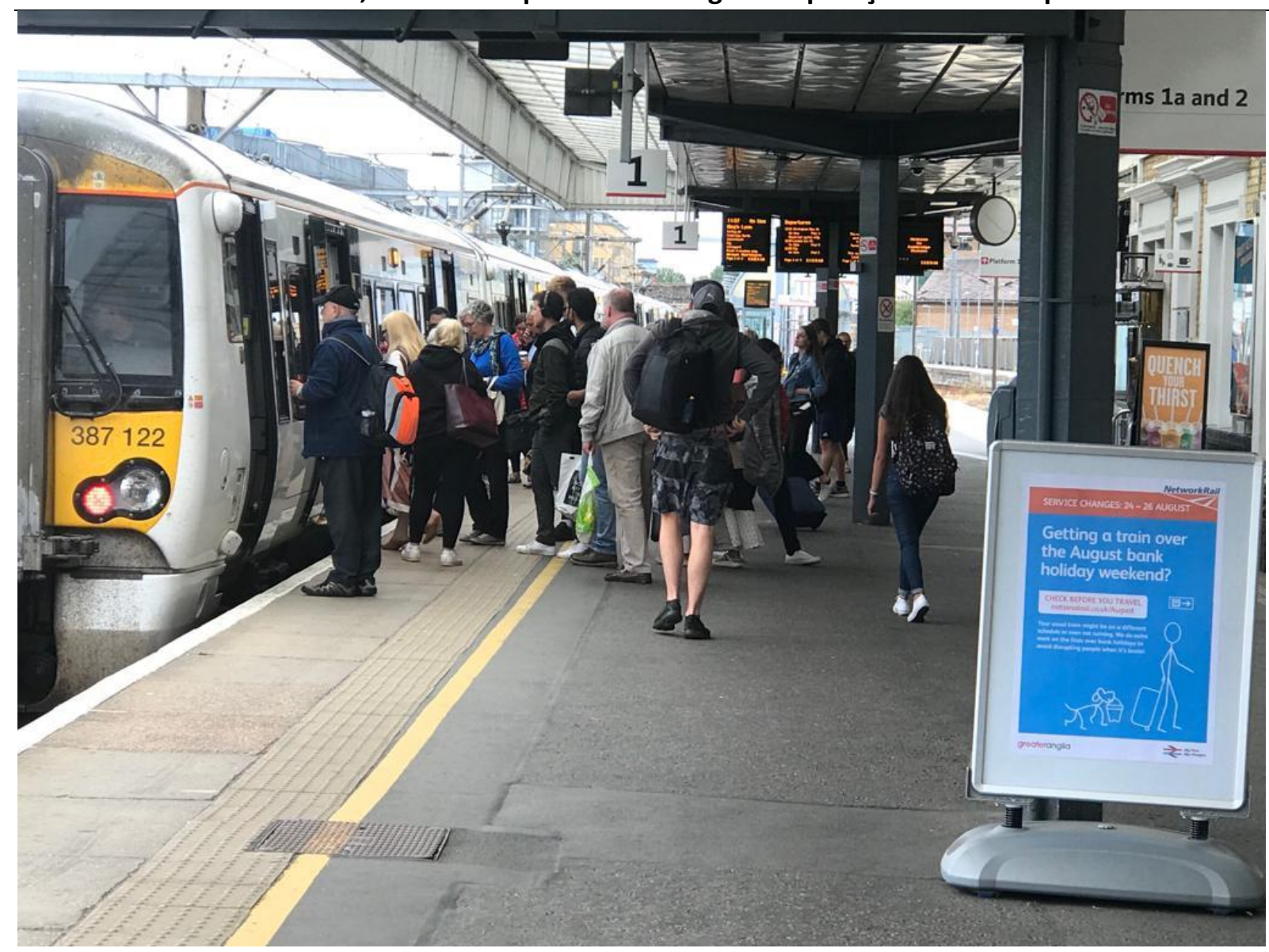

Figura 2.1 Embarque em ordem aleatória em trem de passageiros

A Teoria das Filas ajuda a encontrar um ponto de equilíbrio entre a satisfação do passageiro e a viabilidade econômica do provedor dos meios de transporte. Os termos passageiros e meios de transporte são usados com sentido amplo: podem ser veículos (em um congestionamento ou em um posto de pedágio), pessoas (aguardando embarque) e produtos (em um pátio, antes do carregamento).

A Figura 2.2 ilustra como funciona o sistema de filas e seus componentes.

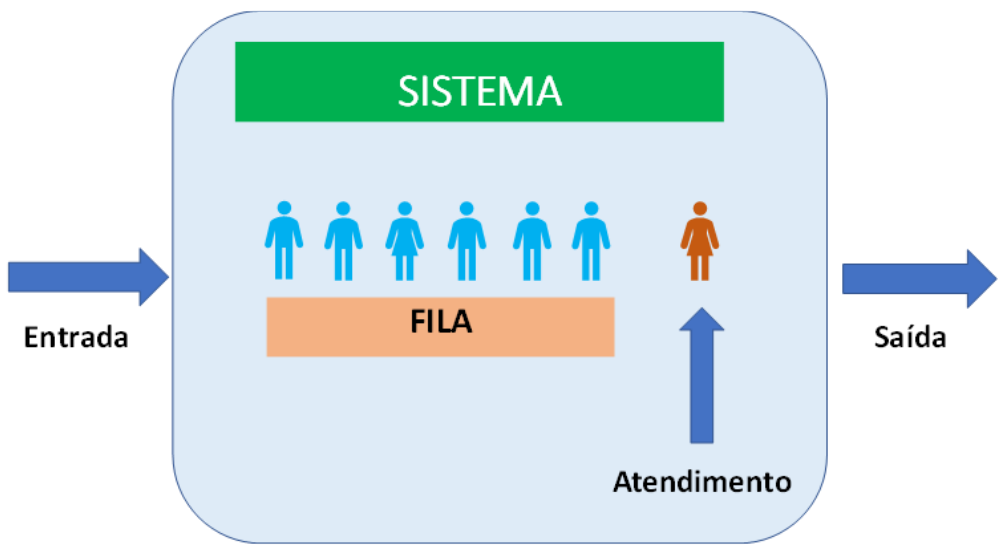

Figura 2.2. Diferença entre sistema de filas e filas propriamente dito. 
Entretanto, por que estudar a teoria das filas?

O objetivo é otimizar o desempenho dos sistemas de transportes, buscado um ponto de equilíbrio entre a satisfação do passageiro com menor tempo de espera e a melhor utilização dos recursos de serviços disponíveis para o provedor desses transportes, atuando no planejamento das operações para balancear adequadamente os custos de oferecer serviços de qualidade e os da insatisfação dos passageiros.

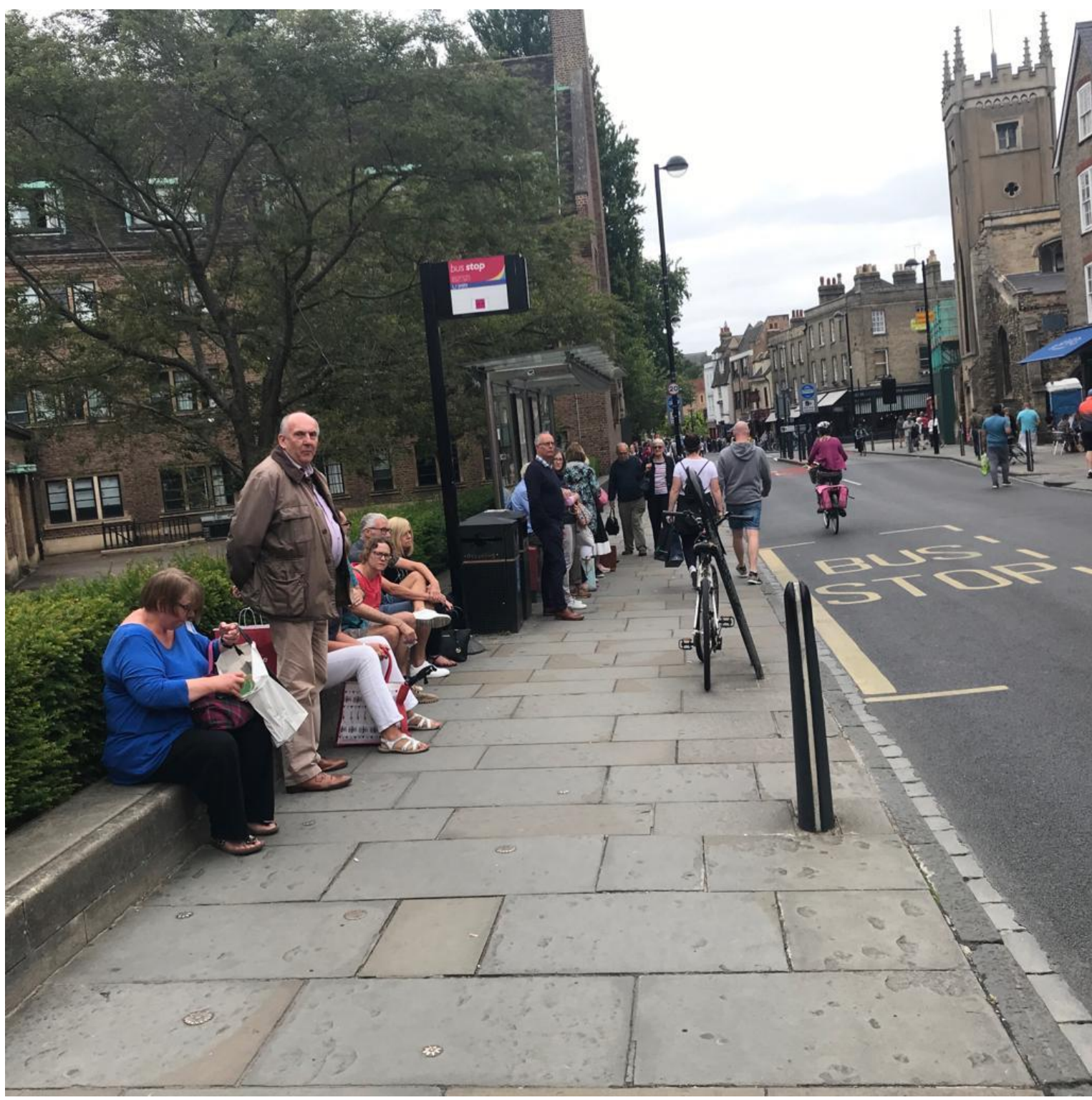

Figura 2.3. Fila de espera de ônibus

De um modo geral, os principais elementos de uma fila são os passageiros que chegam ao sistema procurando um determinado transporte e os servidores deles.

Tamanho da população: refere-se ao tamanho do grupo que fornece os passageiros.

Fila: número de passageiros que esperam por um atendimento, não incluindo o passageiro que está sendo atendido.

Unidade de atendimento: realiza o atendimento ao passageiro, podendo ser uma única ou múltipla. 
Taxa de chegada: frequência em que os passageiros entram no sistema, e cujo valor médio é representado pela letra grega $\lambda$ (lambda), Figura 2.4 .

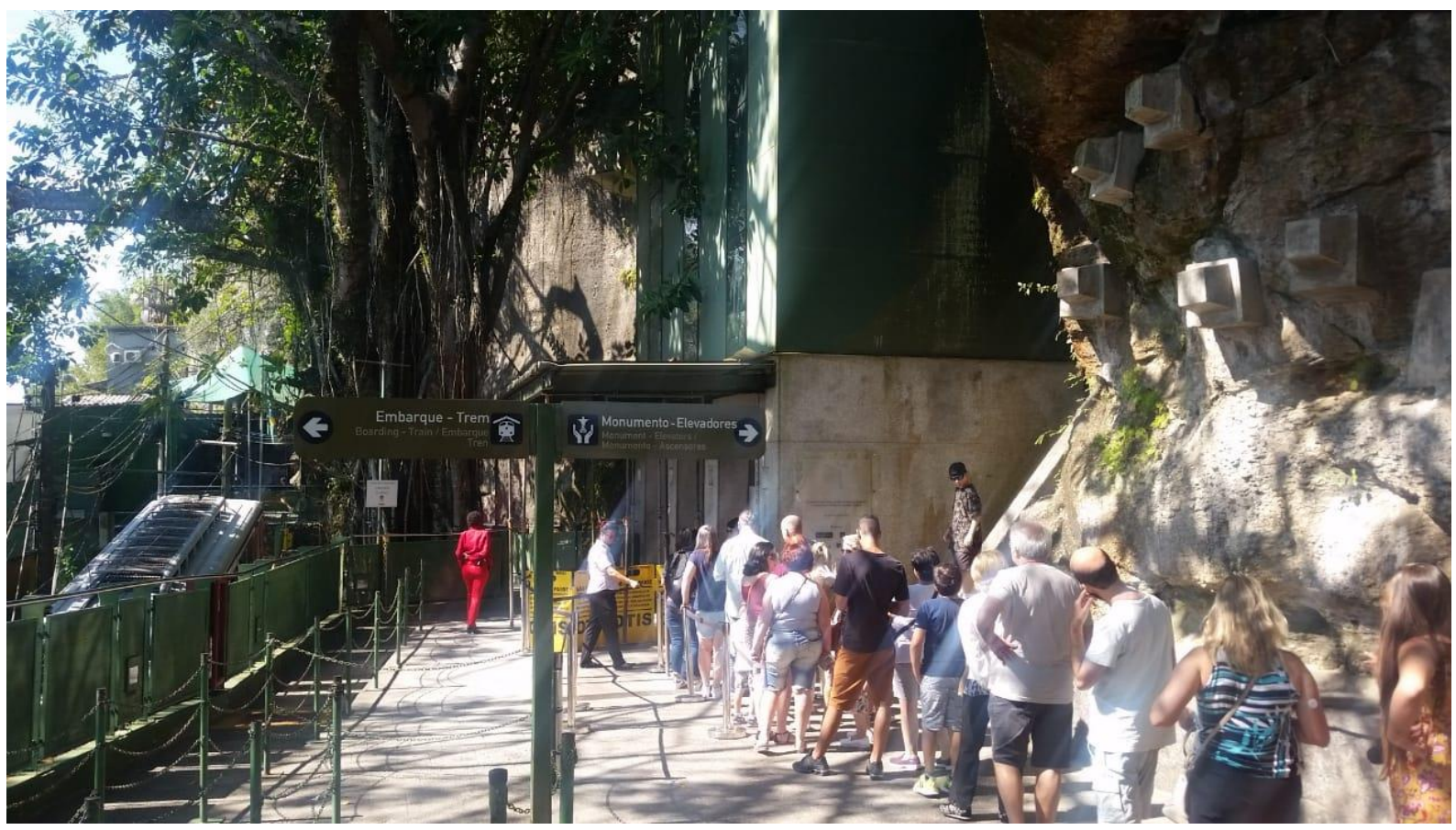

Figura 2.4. Fila para o elevador de acesso à estátua do Cristo Redentor, Rio de Janeiro, RJ.

Se os passageiros chegam em intervalos fixos de tempo, o processo de chegadas é dito ser constante ou determinístico. Se essas chegadas são aleatórias no tempo, é necessário identificar seus modelos probabilísticos, os mais comuns sendo o de Poisson e o exponencial.

Taxa de atendimento: frequência com que um servidor pode efetuar o atendimento de determinado passageiro, e cujo valor médio é representado pela letra grega $\mu$ (mi), Figura 2.5.

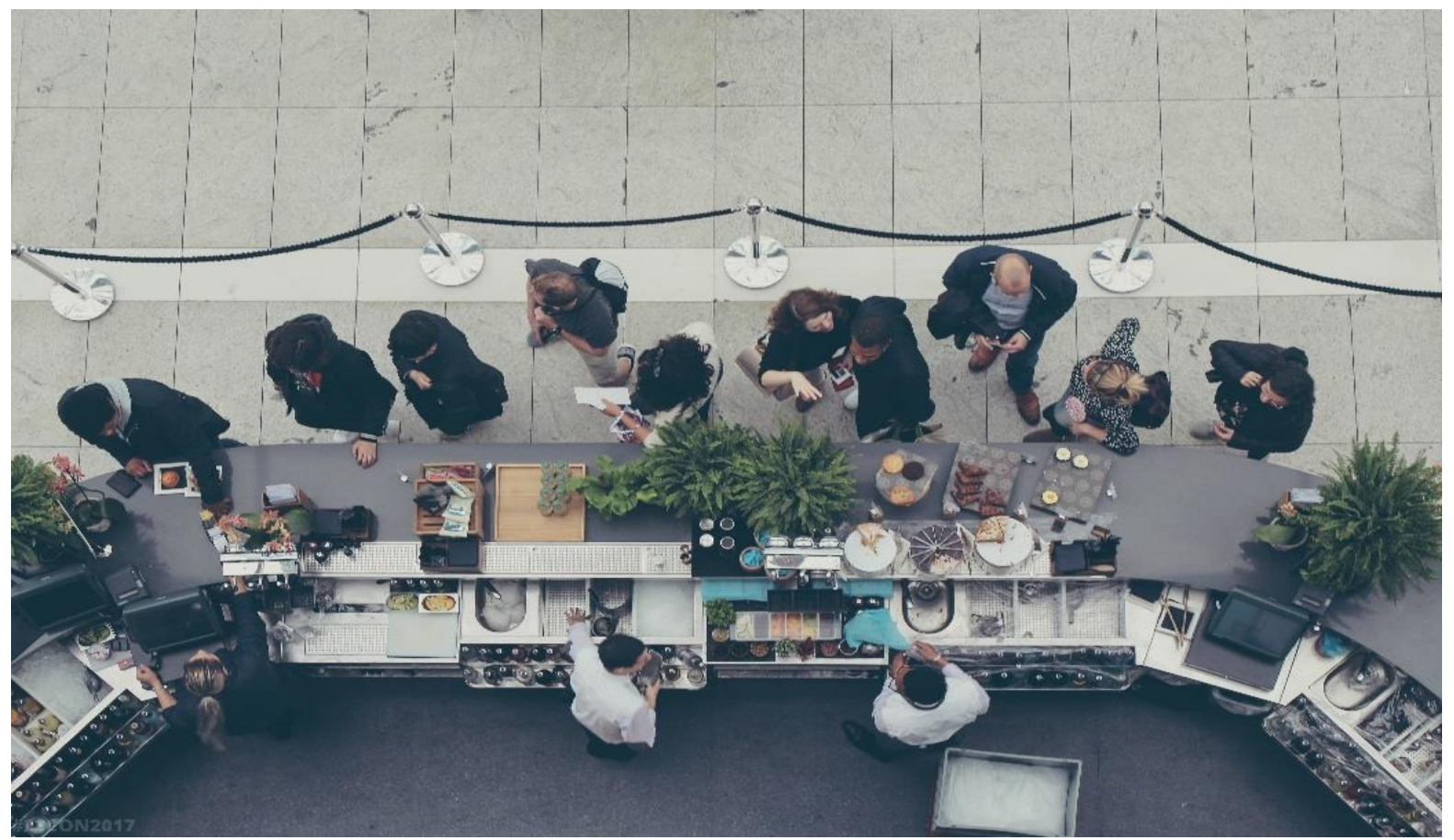

Figura 2.5. Atendimento a passageiros em um terminal de transportes 
Disciplinas das filas: refere-se a maneira como os usuários serão selecionados para receber o serviço. Em geral. os atendimentos são feitos pela ordem de chegada, denominado FCFS, em inglês: First come, First served, traduzido para o português como: Primeiro a chegar, Primeiro a ser atendido. O Quadro 2.2 exemplifica esse e outros tipos de disciplinas de filas.

Quadro 2.2. Disciplinas das filas

\begin{tabular}{|c|c|}
\hline Disciplina de Serviço & Descrição \\
\hline $\begin{array}{c}\text { FCFS - First Come First Served } \\
\text { ou FIFO - First In First Out }\end{array}$ & $\begin{array}{c}\text { Primeiro a chegar, Primeiro a ser atendido } \\
\text { Ou Primeiro a entrar, Primeiro a sair }\end{array}$ \\
\hline $\begin{array}{c}\text { LCFS - Last Come, First Served } \\
\text { Ou LIFO - Last In Last Out }\end{array}$ & $\begin{array}{c}\text { Último a chegar, Primeiro a ser atendido } \\
\text { Ou Último a chegar, Primeiro a sair }\end{array}$ \\
\hline SIRO - Select in Random Order & Selecionado em ordem aleatória \\
\hline Priority & $\begin{array}{c}\text { Prioridade: pode ser preemptivo (interrompe serviços) } \\
\text { ou não preemptivo (aguarda o término dos serviços) }\end{array}$ \\
\hline
\end{tabular}

Curiosidade: Há um curta-metragem que aborda o uso da disciplina de fila FIFO em um supermercado sob o aspecto da ética. Pode ser visto em https://vimeo.com/271642838.

Um exemplo de FCFS com barreira física está na Figura 2.6, no acesso aos portões de embarque em um aeroporto. Outro exemplo está na Figura 2.7

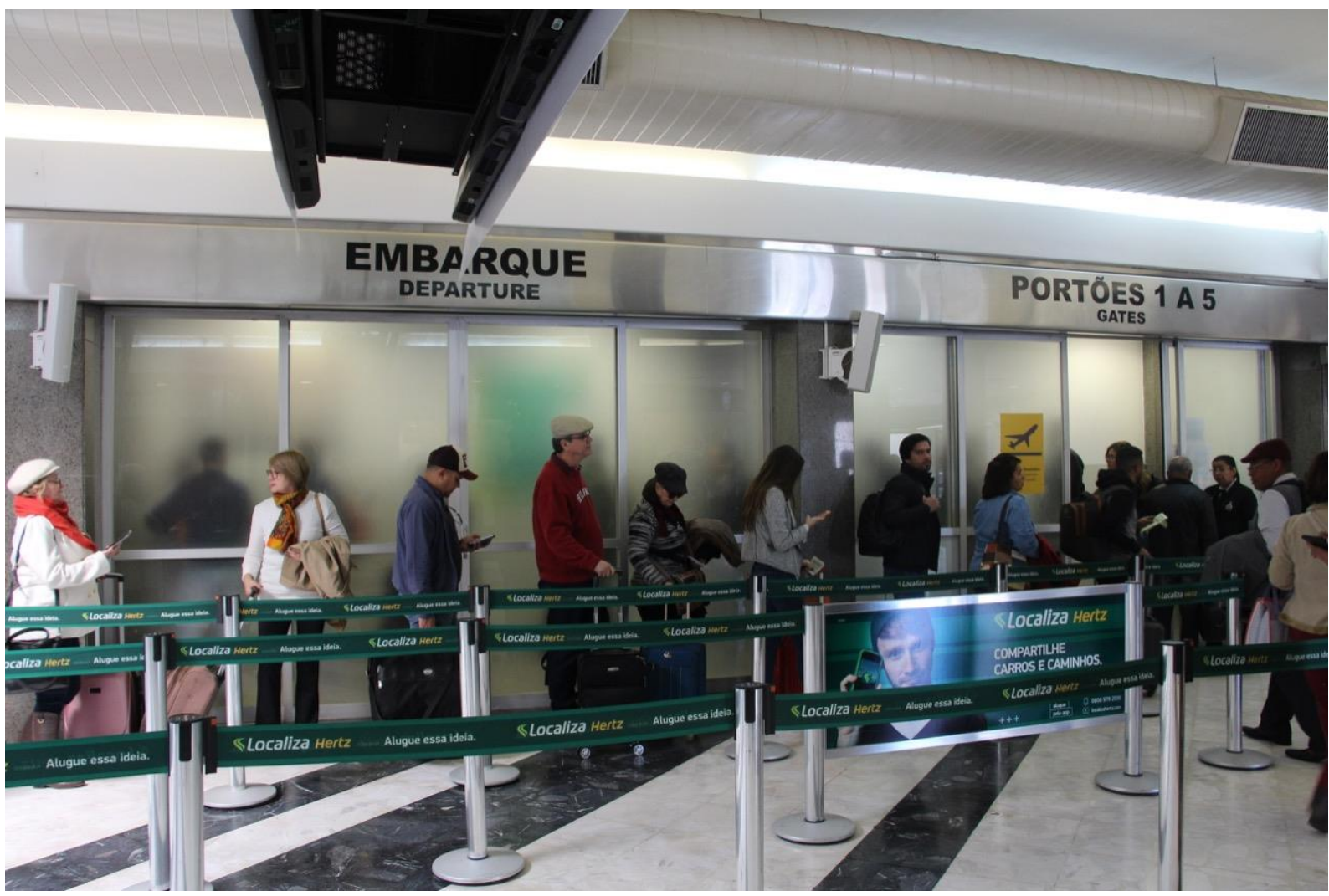

Figura 2.6 Fila com a disciplina Primeiro a chegar, Primeiro a ser atendido, com barreira física para os passageiros, no Aeroporto de Camnpo Grande (MS 


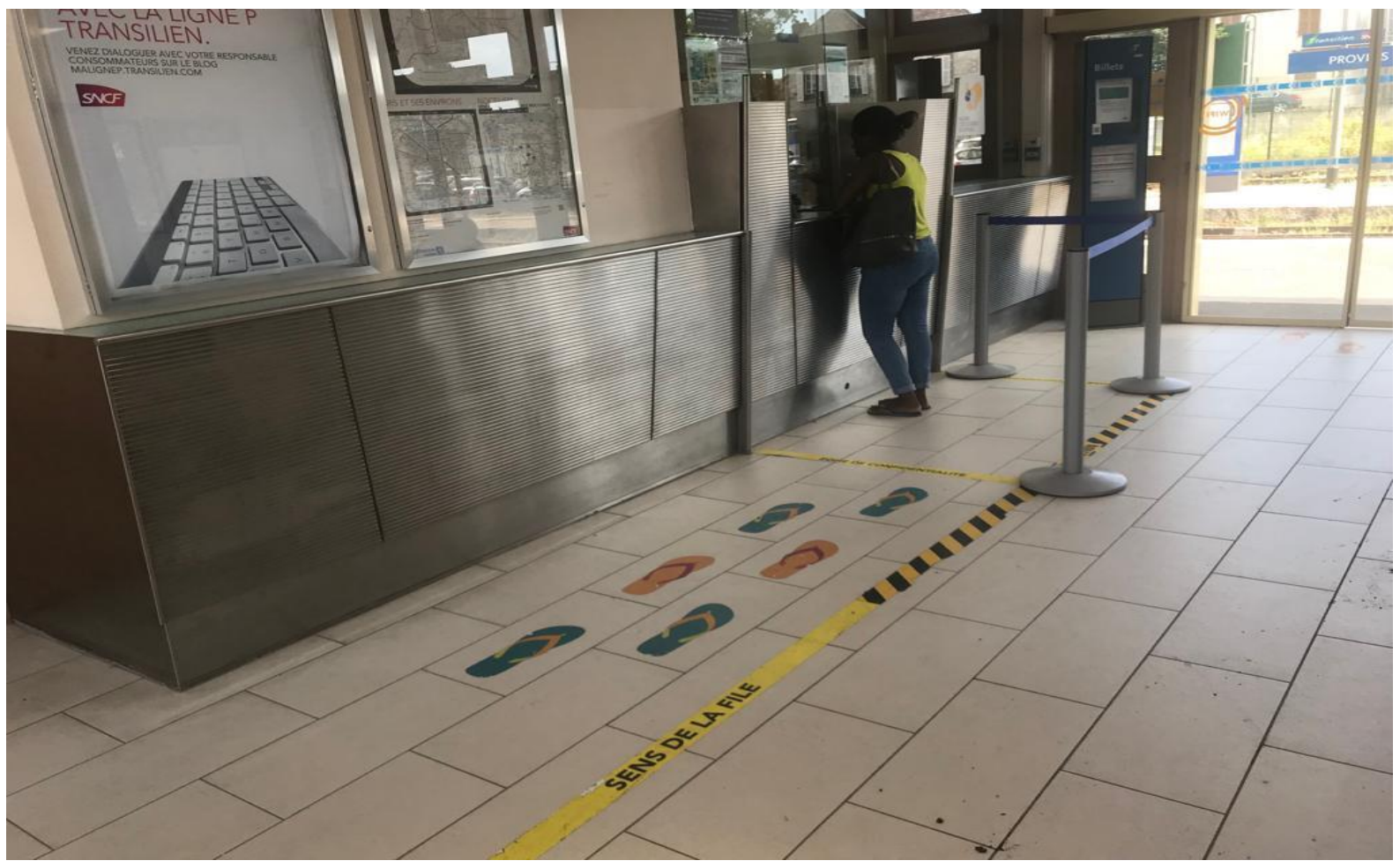

Figura 2.7 Fila com a disciplina Primeiro a chegar, Primeiro a ser atendido, sem barreira física para os passageiros, na estação de trem de Provins, França, cidade onde nasceu Villegaignon, fundador, na costa do Brasil, da França Antártica.

Entretanto, há casos em que não há disciplina de qualquer espécie, o que pode ser considerado sendo de ordem aleatória. como nas plataformas dos metrôs, Figura 2.8.

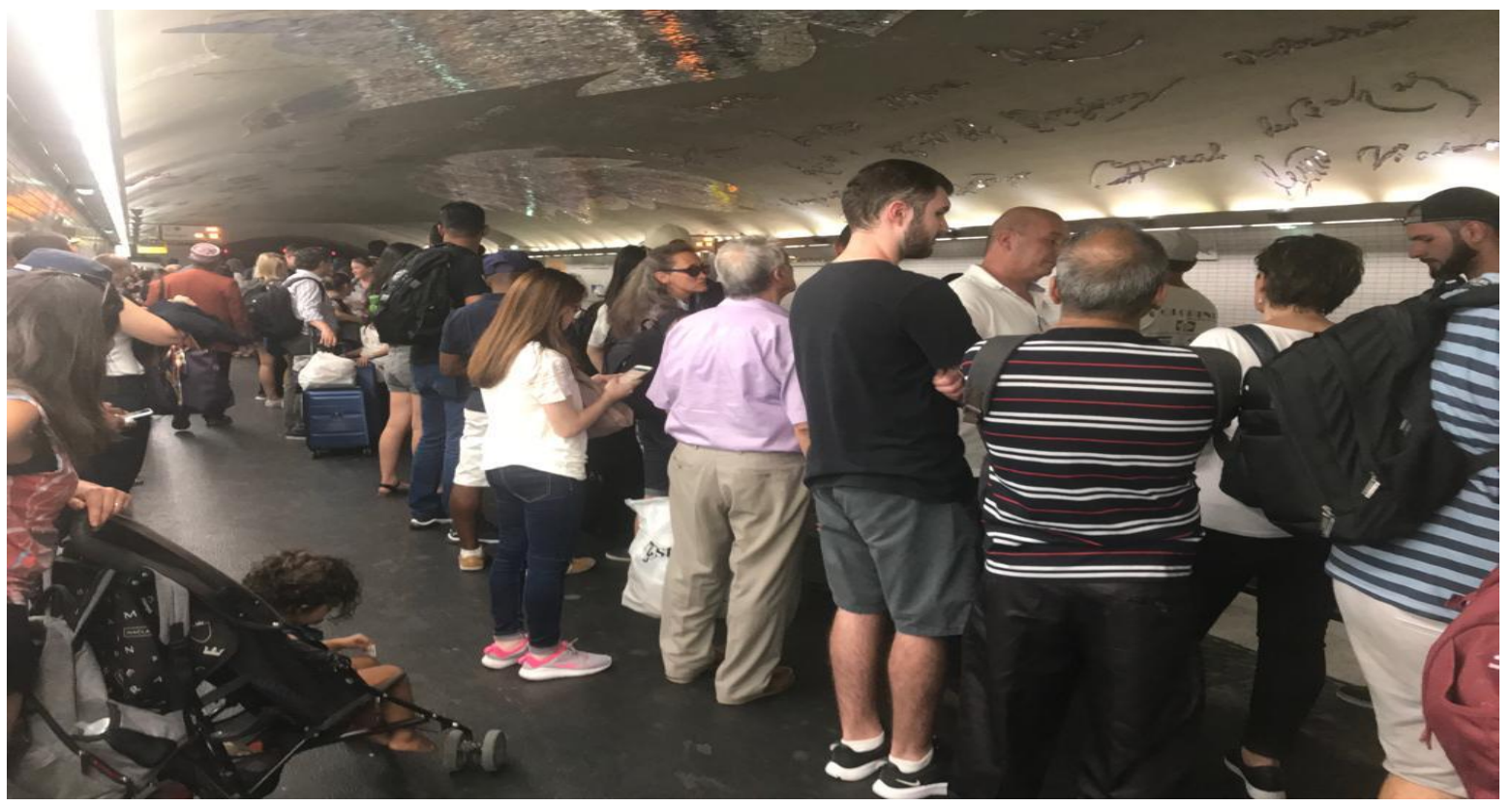

Figura 2.8 Ordem aleatória em uma plataforma de metrô. 
Adicionalmente, para que o embarque e o desembarque no metrô sejam mais ordenados, colocam-se barreiras físicas, com na Figura 2.9.

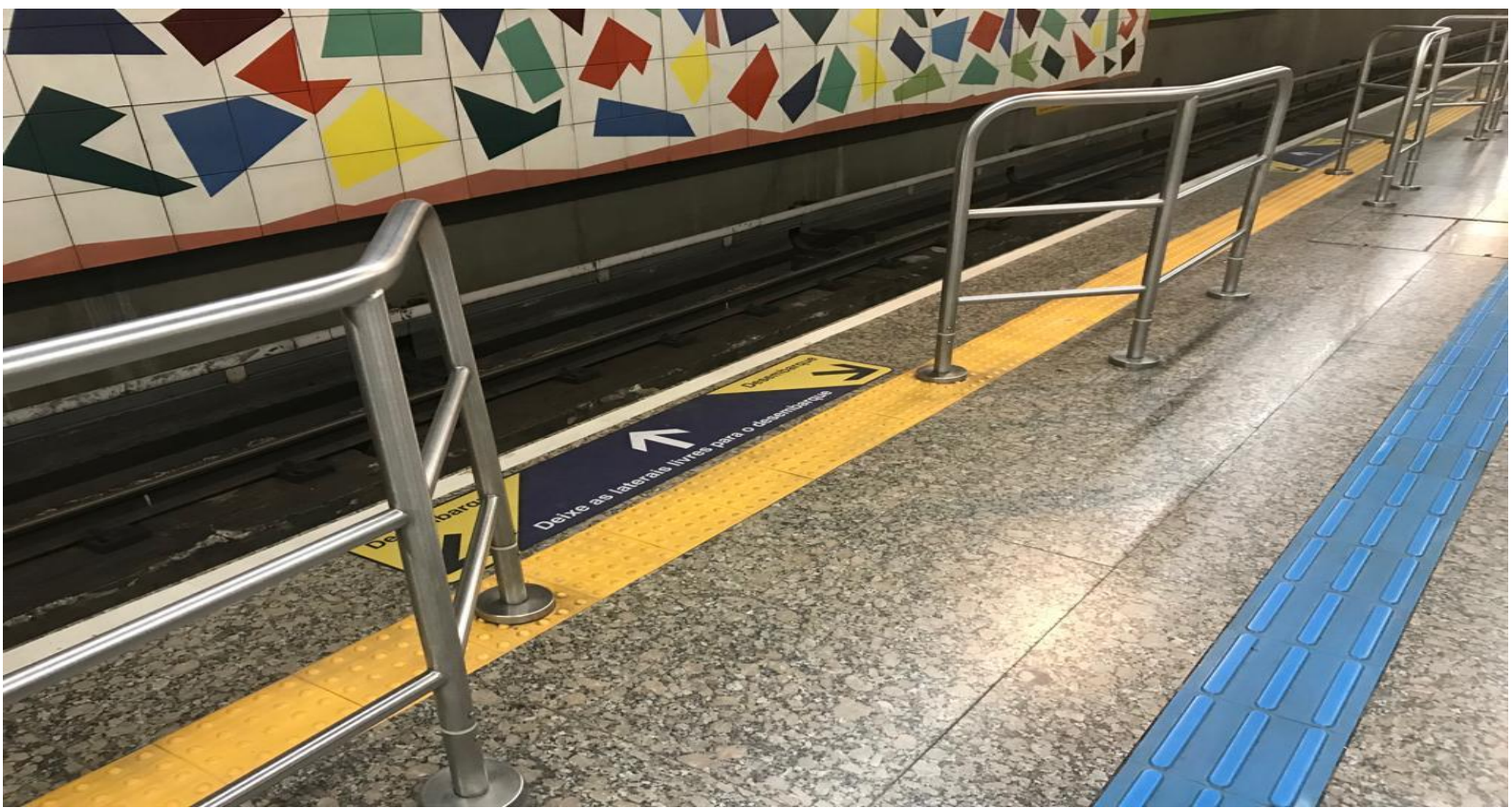

Figura 2.9 Barreira física para embarque e desembarque no metrô de São Paulo, SP.

Para que haja entradas e saídas mais rápidas nas situações de ordem aleatória, notadamente nas estações de metrô, colocam-se orientações nas plataformas para facilitar o embarque e o desembarque.

Todavia, dependendo do país em que se está, essas orientações são conflitantes, Figuras 2.10 e 2.11 .
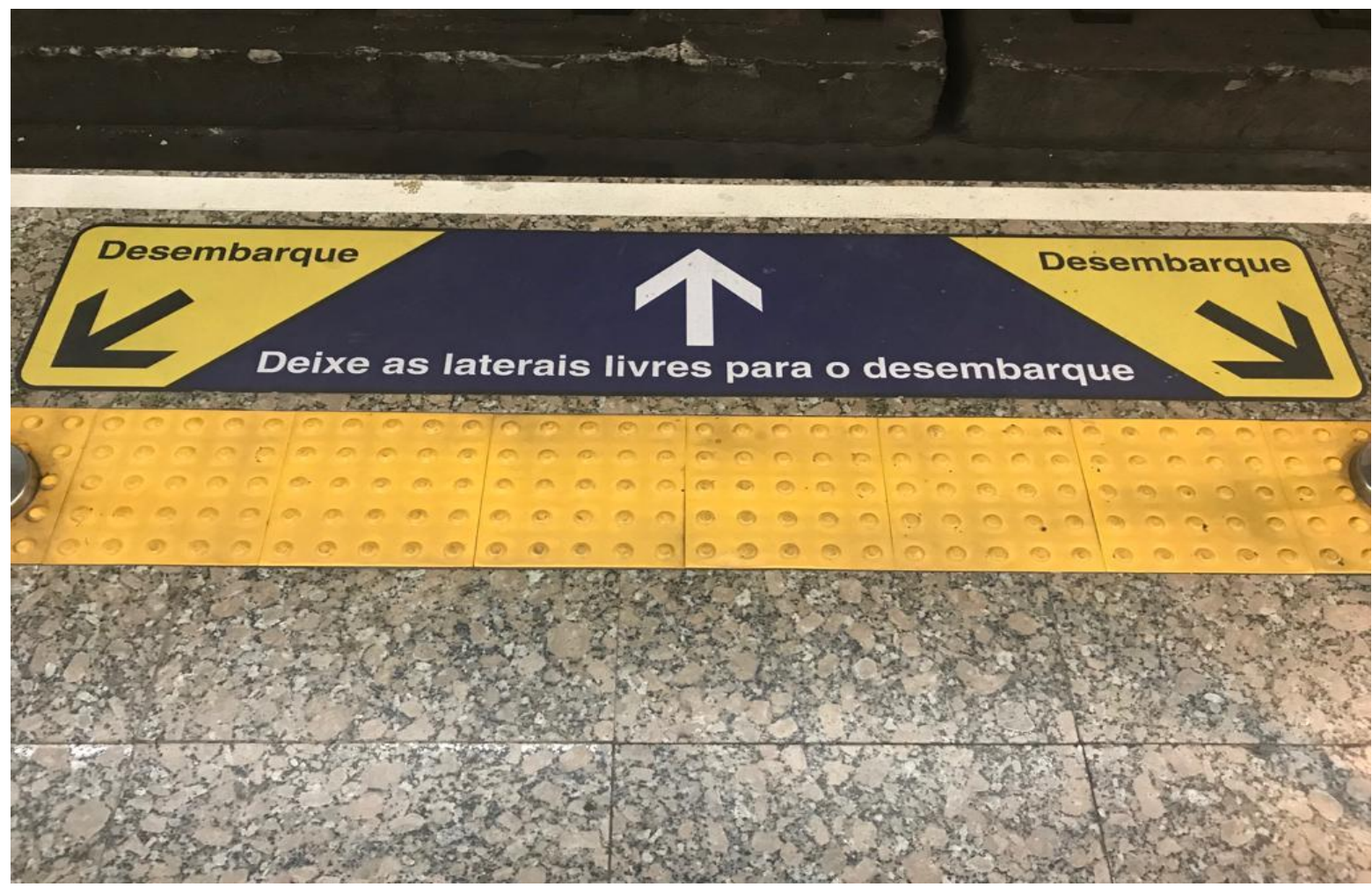

Figura 2.10 Orientação para embarque e desembarque no metrô de São Paulo, SP. 


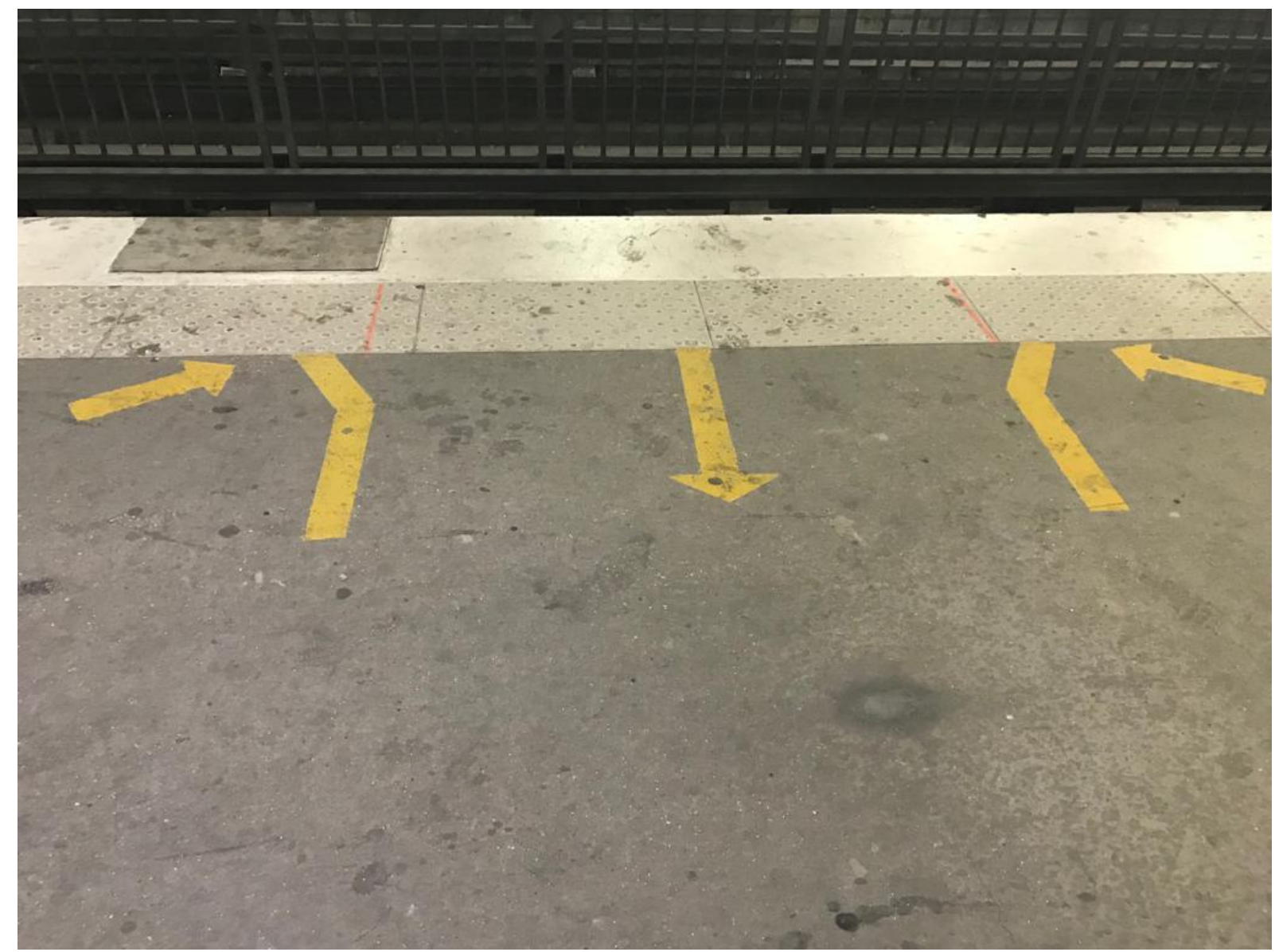

Figura 2.11 Orientação para embarque e desembarque no metrô de Paris, França.

Número de canais de serviço: pode ser um sistema com canal simples ou um sistema com multicanais em paralelo, que podem servir os passageiros simultaneamente.

As Figuras 2.12 e 2.13 esquematizam a definição, e as Figuras 2.14 até 2.17 apresentam fotos de situações reais.

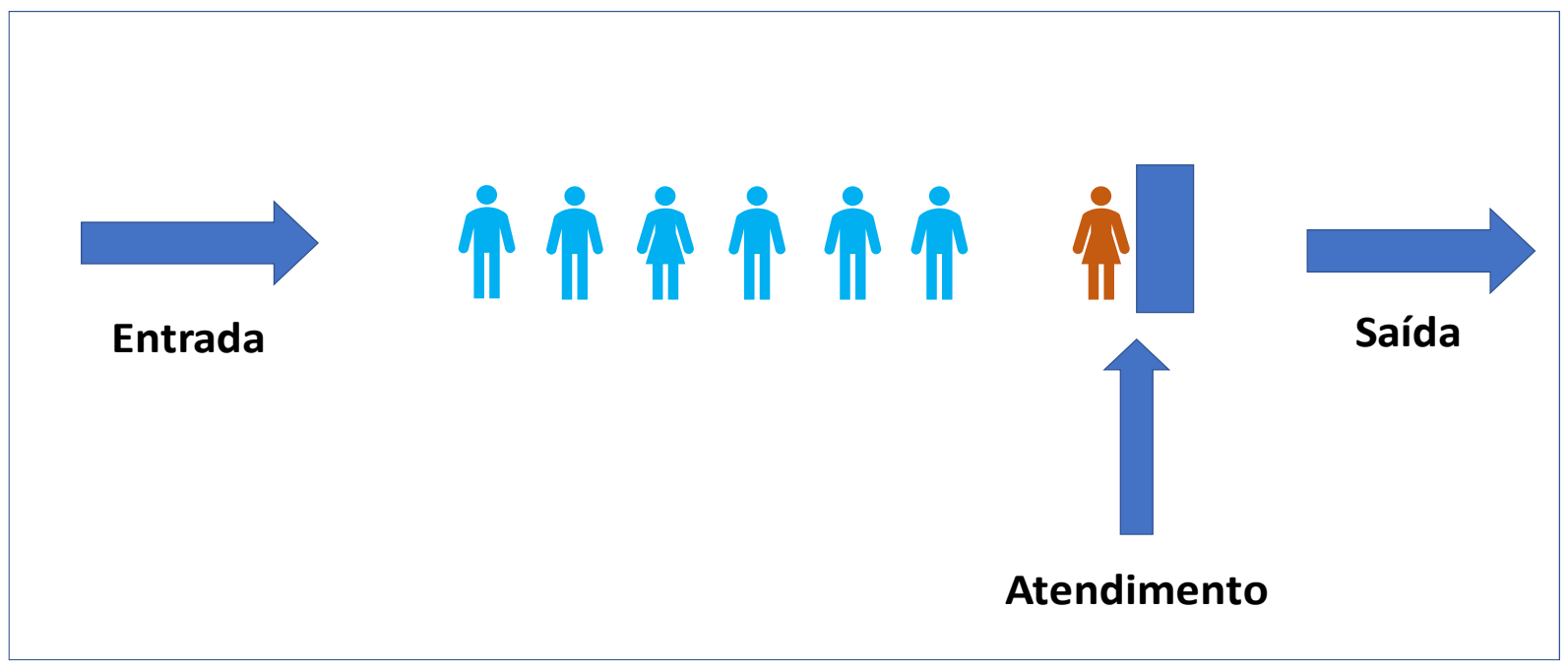

Figura 2.12. Sistema único com canal simples 


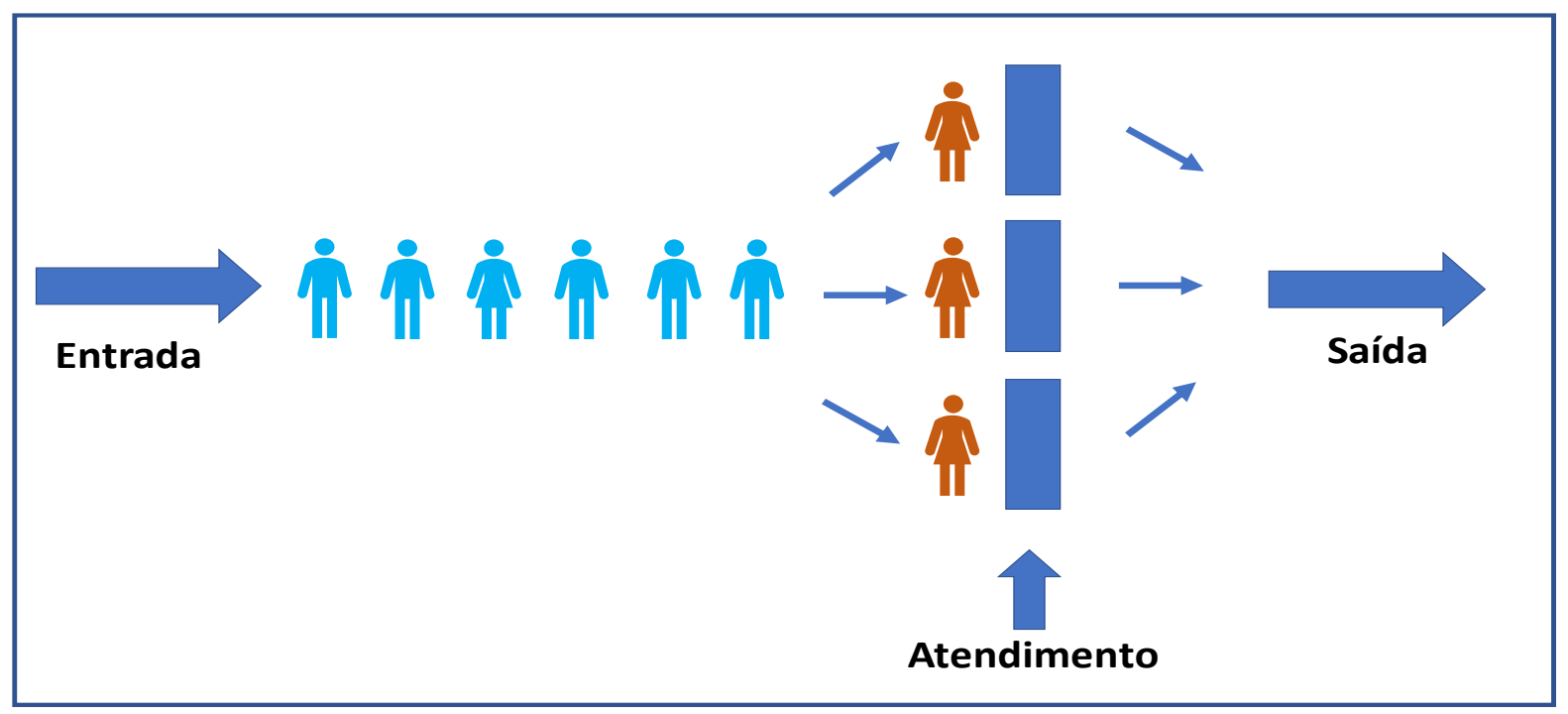

Figura 2.13. Sistema multicanal com fila única

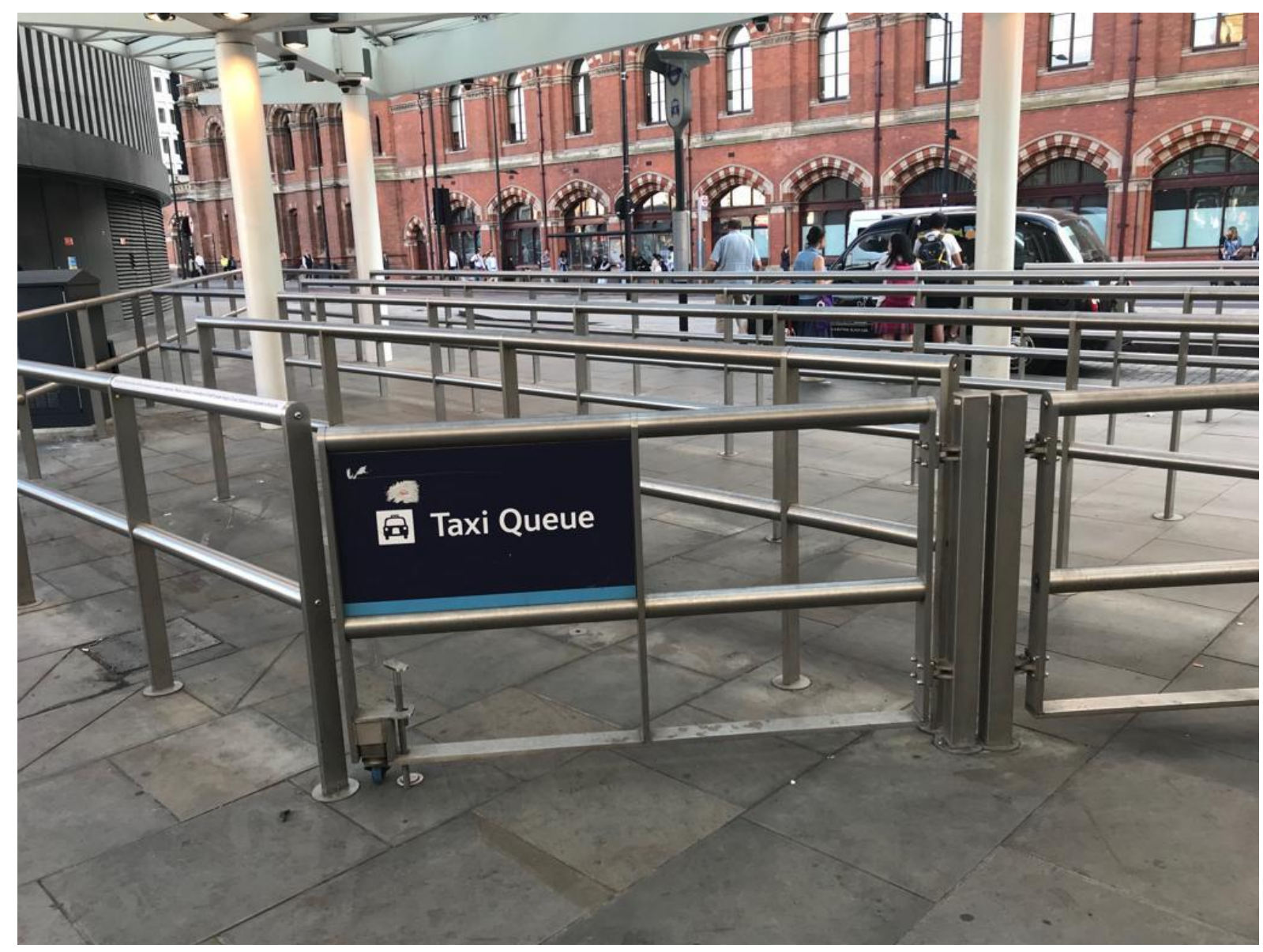

Figura 2.14. Fila única com um canal simples de táxis na estação St. Pancras-King's Cross em Londres, Reino Unido. 


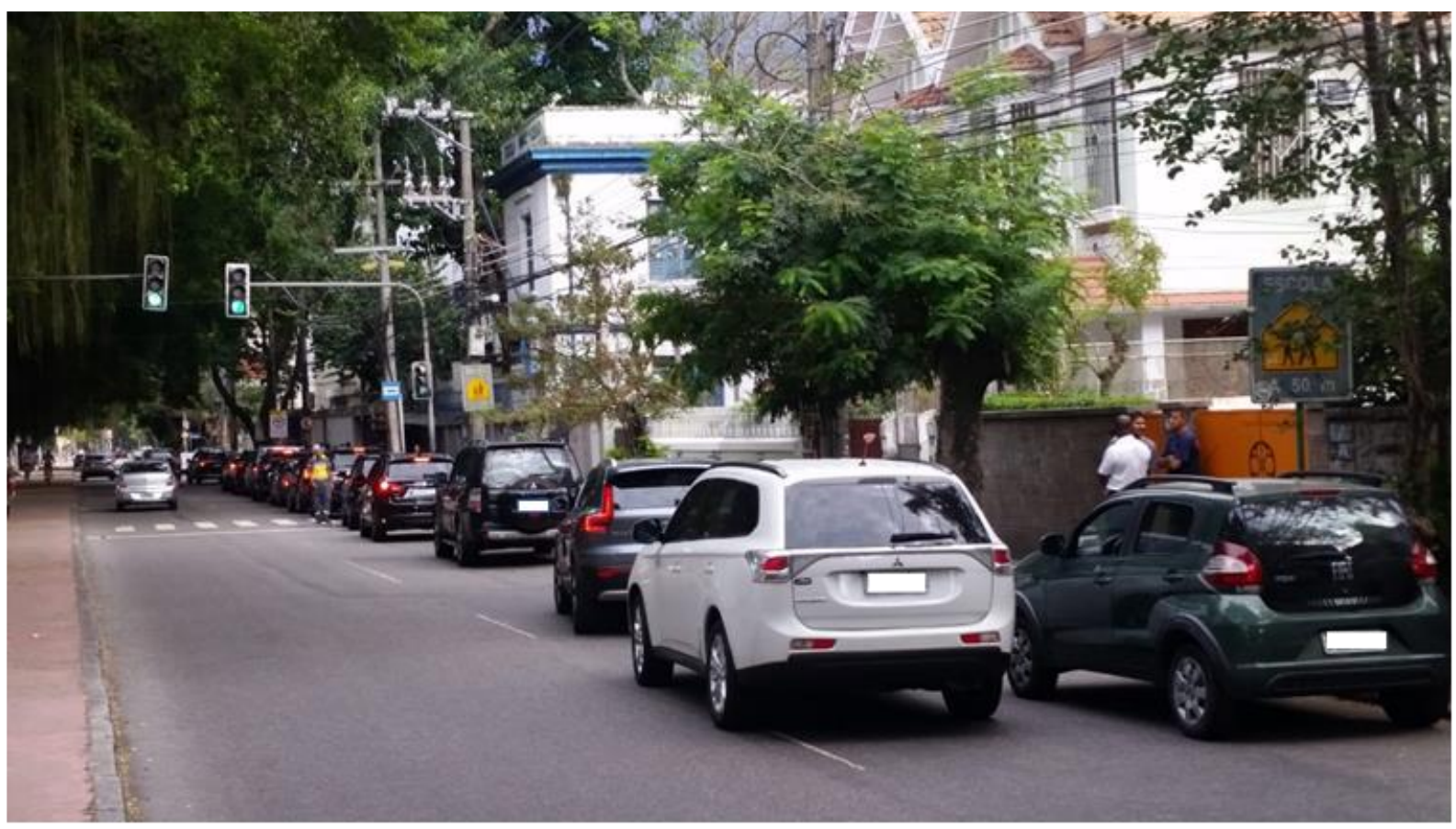

Figura 2.15 Fila de carros para embarque de alunos na frente de um colégio.

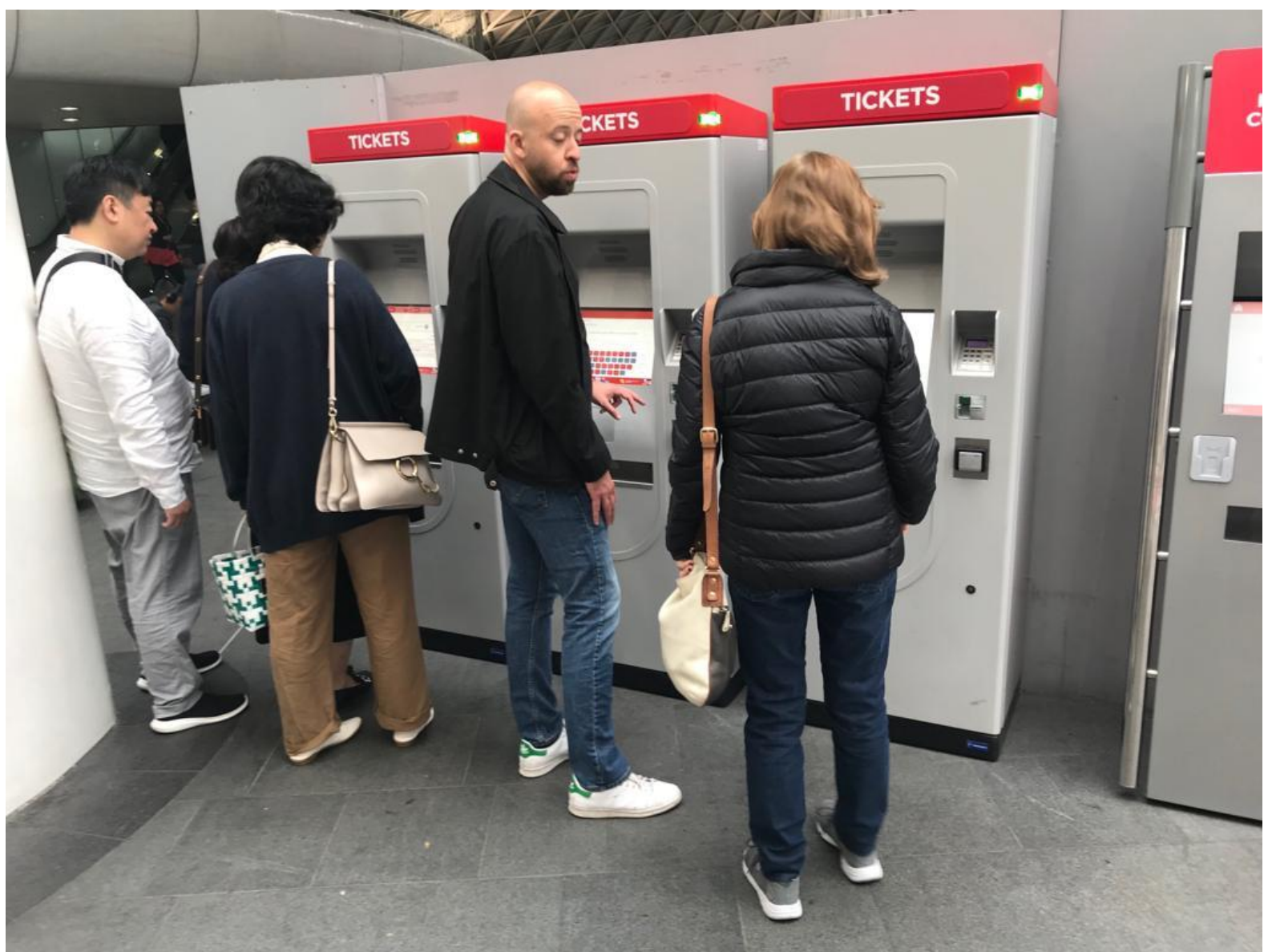

Figura 2.16. Sistema multicanal com fila única em quiosques de venda de bilhetes na estação St. Pancras- King's Cross em Londres 


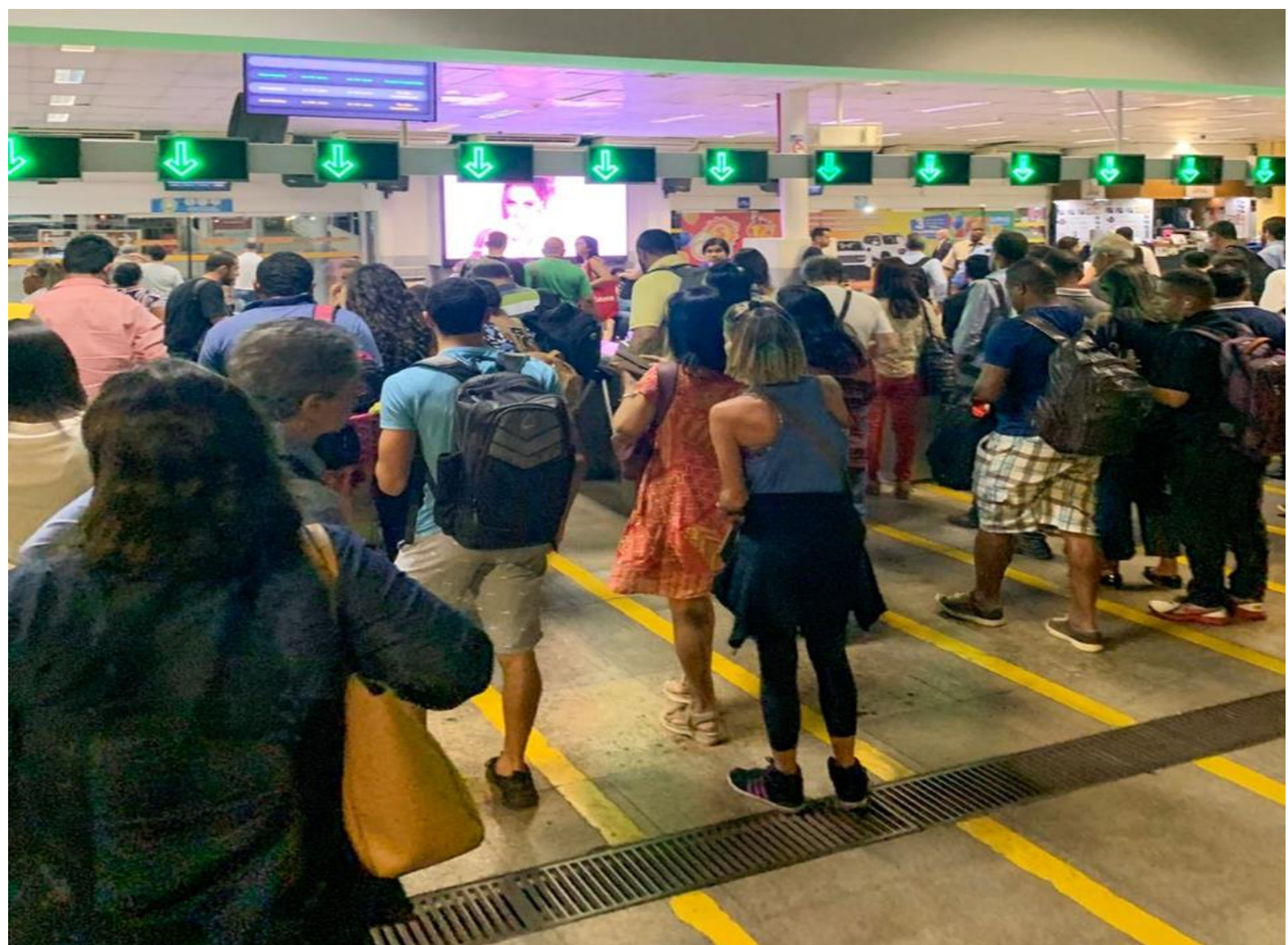

Figura 2.17. Sistema multicanal na estação das barcas Rio-Niterói.

Capacidade do sistema: todo meio de transporte tem uma limitação física no número de passageiros, o que implica no número daqueles que estão na fila. Se o sistema atingir a capacidade total, o passageiro não poderá entrar, e será perdido ou esperar é pelo próximo meio disponível. Essas situações são referidas como sistemas de filas finitos, porque há um tamanho máximo. Figura 2.18.

\section{Para os meios de transportes, sempre existirá uma capacidade máxima.}

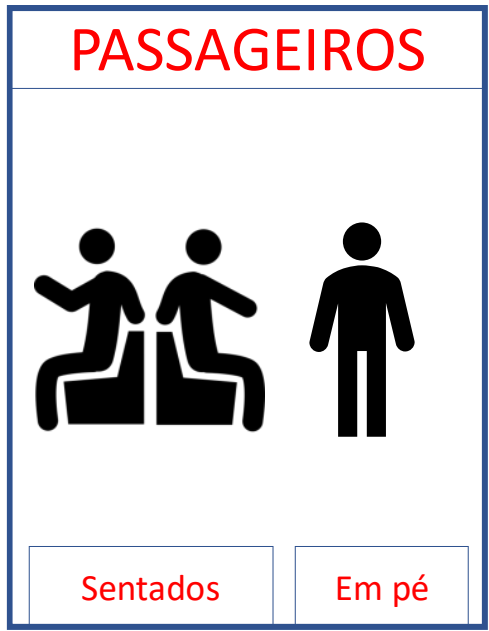

Figura 2.18. Informação sobre a capacidade máxima do meio de transporte 
Uma vez definidas as principais características do sistema e da modelagem de filas, para que sejam tomadas decisões, necessita-se dos chamados parâmetros de desempenho, e os principais são os seguintes:

Número médio de passageiros na fila não vazia: passageiros que aguardam o atendimento e o que determina o tamanho da fila, sendo o parâmetro considerado no momento da escolha da fila a entrar. Supondo que as taxas médias de chegada e de atendimento sejam constantes, o tamanho da fila irá variar em torno desse valor médio.

Número médio de passageiros no sistema: incluem os da fila e aqueles que estão sendo atendidos, limitado à capacidade do sistema.

Tempo médio do passageiro na fila: é aquele em o passageiro fica na fila esperando para ser atendido.

Tempo médio do passageiro no sistema: soma do tempo médio do passageiro na fila com o tempo de atendimento.

No Aeroporto Santos Dumont, Rio de Janeiro, RJ, informa-se o tempo médio de espera no sistema antes da entrada para a fila do Raio-X, Figura 2.19.

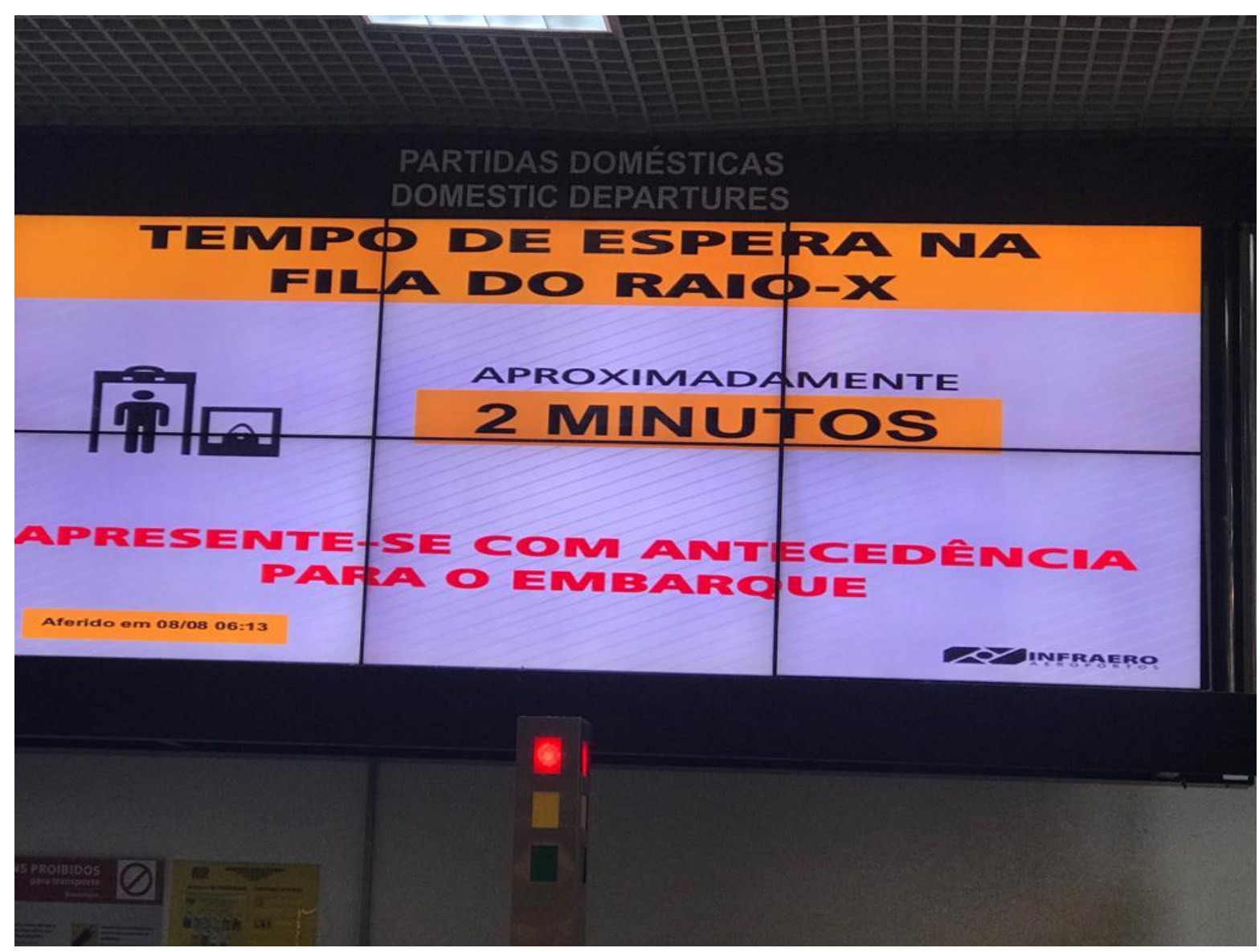

Figura 2.19. Informação sobre o tempo médio de espera no sistema antes da entrada para a fila do Raio-X no Aeroporto Santos Dumont, Rio de Janeiro, R. 
Para evitar filas e liberar rapidamente os passageiros no desembarque, o Aeroporto de Congonhas apresenta uma saída expressa para aqueles que viajam sem bagagem, Figura 2.20

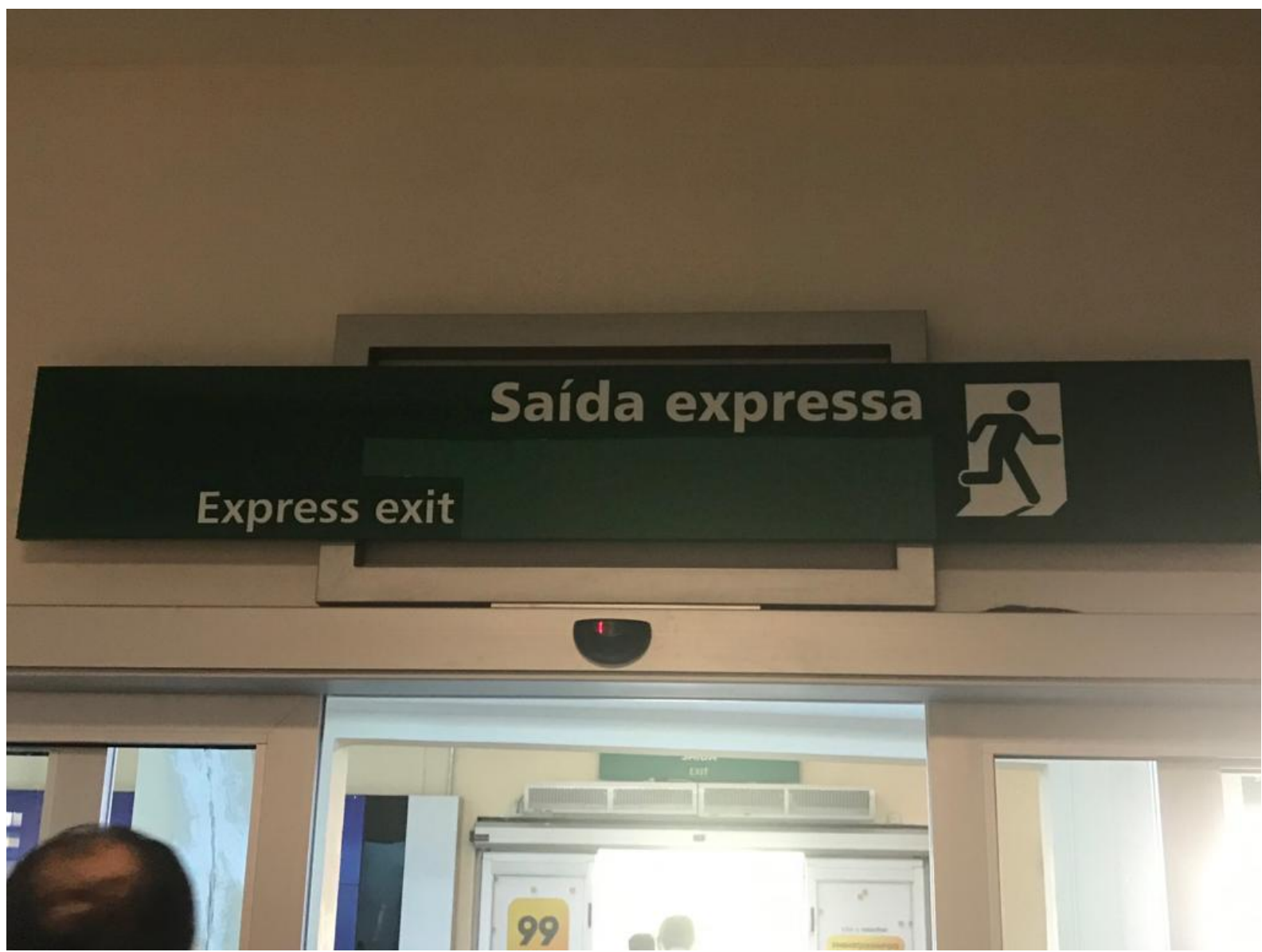

Figura 2.20. Saída expressa no Aeroporto de Congonhas, São Paulo, SP

A notação mais utilizada para descrever o processo de uma fila foi proposta por Kendall, em 1953, e é descrita por uma série de símbolos. A notação consiste na forma $A / B / c / K / m / Z$, onde $A$ descreve a distribuição do tempo entre chegadas, $B$ a distribuição do tempo de serviço, $c$ o número de servidores, $K$ a capacidade do sistema, $m$ o tamanho da população que usa o sistema e $Z$ a disciplina de atendimento. $O$ Quadro 2.3 ilustra alguns símbolos padrão para essas características.

Quadro 2.3 - Notação para descrever uma fila

\begin{tabular}{|l|c|c|}
\hline \multirow{2}{*}{ Características } & Símbolo & Explicação \\
\hline \multirow{2}{*}{$\begin{array}{l}\text { Distribuição dos tempos entre } \\
\text { as chegadas (A) }\end{array}$} & $\mathrm{M}$ & Exponencial \\
\cline { 2 - 3 } & $\mathrm{E}_{\mathrm{k}}$ & Determinístico \\
\cline { 2 - 3 } & $H_{k}$ & Tipo k-Erlang $(\mathrm{k}=1,2, \ldots)$ \\
\cline { 2 - 3 } $\begin{array}{l}\text { Distribuição dos tempos de } \\
\text { serviço (B) }\end{array}$ & $\mathrm{PH}$ & Tipo Fase \\
\cline { 2 - 3 } & $\mathrm{G}$ & Geral \\
\hline $\begin{array}{l}\text { Número de servidores em } \\
\text { paralelo (c) } \\
\begin{array}{l}\text { Capacidade do sistema (K) } \\
\text { Tamanho da população que } \\
\text { fornece passageiros (m) }\end{array}\end{array}$ & & \\
\hline
\end{tabular}


FILAS: conceitos, novos enfoques de abordagem e aplicações em Transportes

\begin{tabular}{|c|c|c|}
\hline \multirow{4}{*}{ Disciplina de atendimento (Z) } & FCFS & First Come First Served \\
\cline { 2 - 3 } & LCFS & Last Come First Served \\
\cline { 2 - 3 } & RSS & Seleção aleatória por serviço \\
\cline { 2 - 3 } & PR & Prioridade \\
\cline { 2 - 3 } & GD & Disciplina geral \\
\hline
\end{tabular}

Quando as letras $K, m$ e $Z$ são omitidas, entende-se que o sistema tem capacidade ilimitada, a população é infinita e o regime da fila é FCFS. Por exemplo M/E1/1 é uma fila com distribuição de chegada seguindo a lei de Poisson, tempo de serviço de acordo com uma distribuição de Erlang de primeiro grau, apenas 1 servidor e, implicitamente, capacidade do sistema ilimitada, população ilimitada e disciplina de atendimento FCFS.

Há diversos tipos de prioridades que são informadas aos passageiros, notadamente nos aeroportos, ou para cumprir-se a lei ou para proporcionar uma nova prioridade ou uma ordem que acelere o embarque, conforme as Figuras 2.21 até 2.25 .

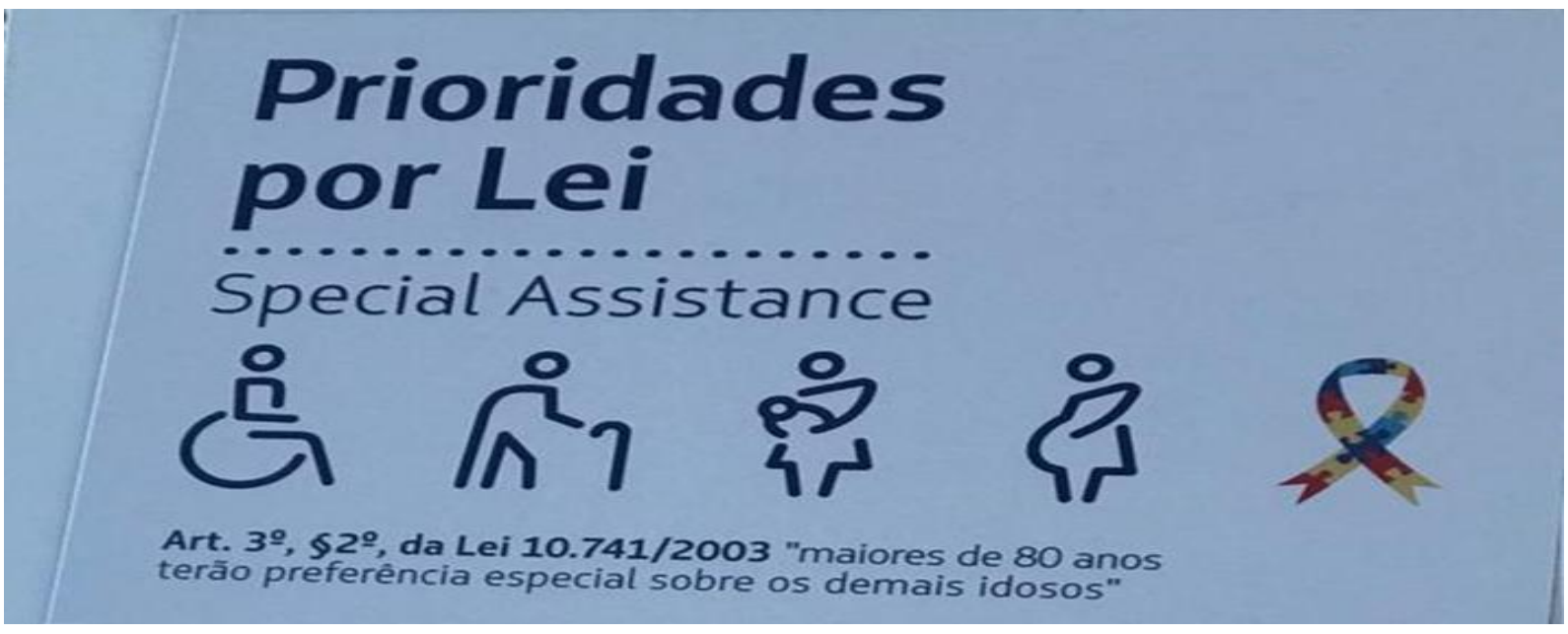

Figura 2.21. Aviso de prioridade por lei.

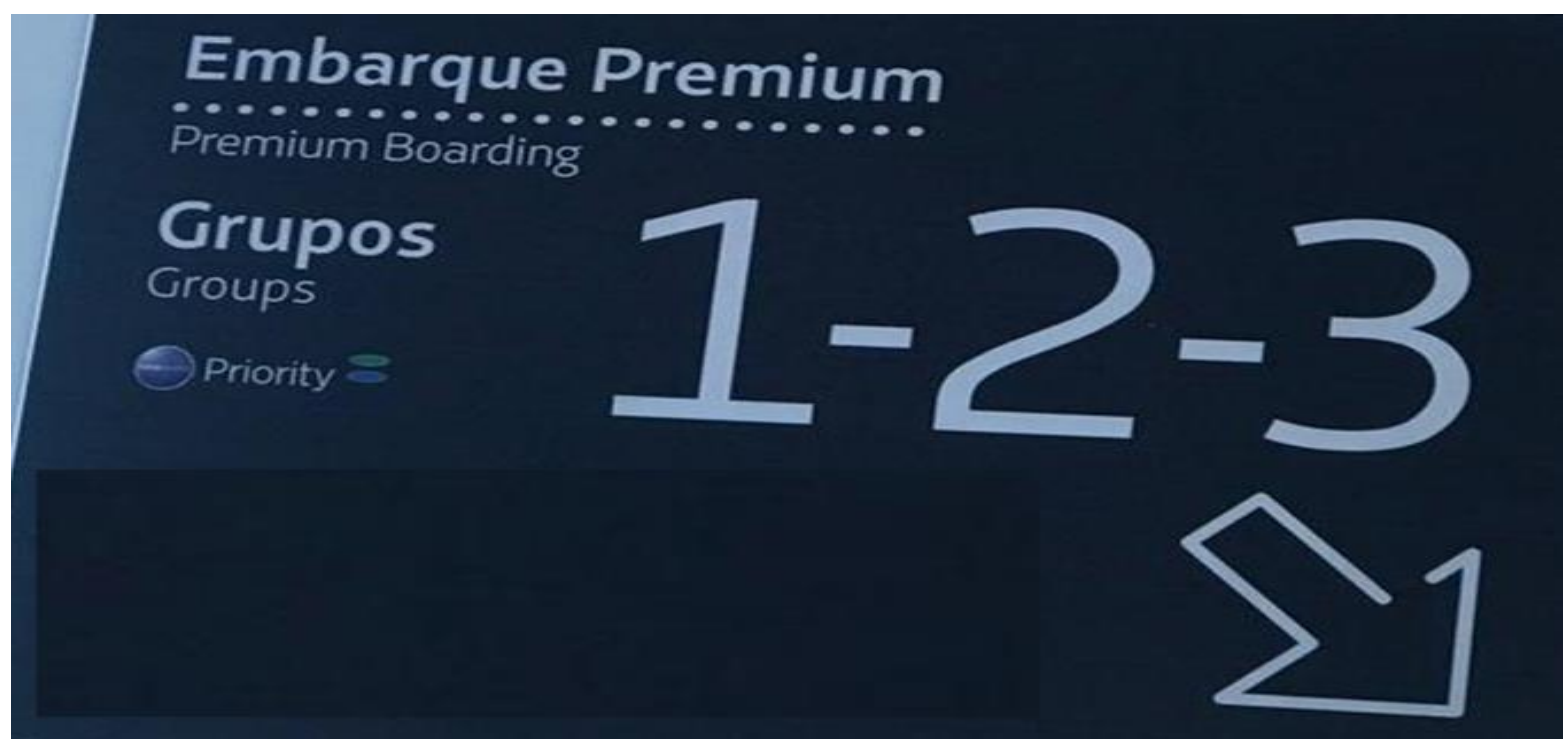

Figura 2.22. Aviso de uma nova prioridade. 


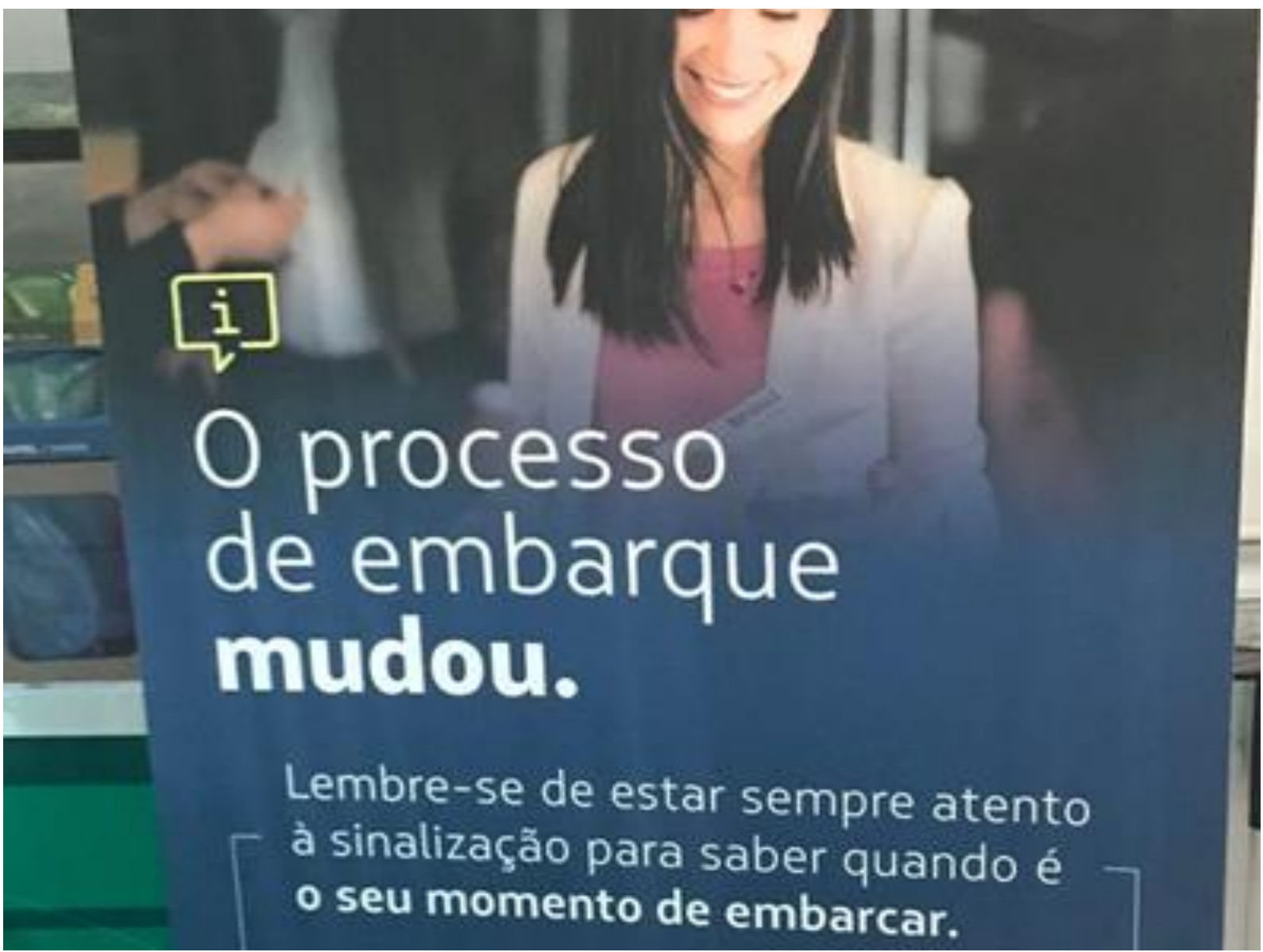

Figura 2.23. Informação de novas prioridades para acelerar o embarque.

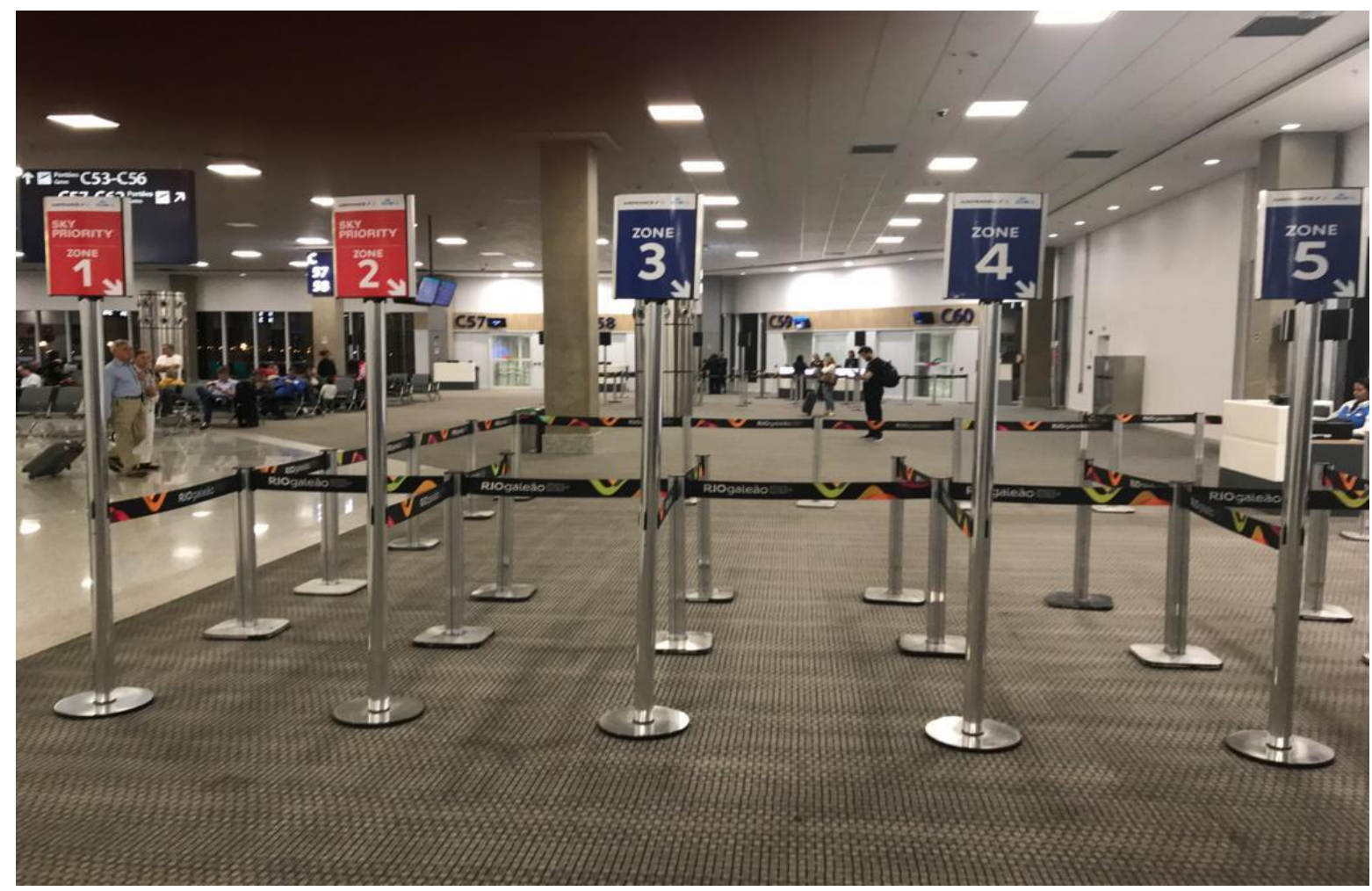

Figura 2.24. Ordenação para acelerar o embarque, 


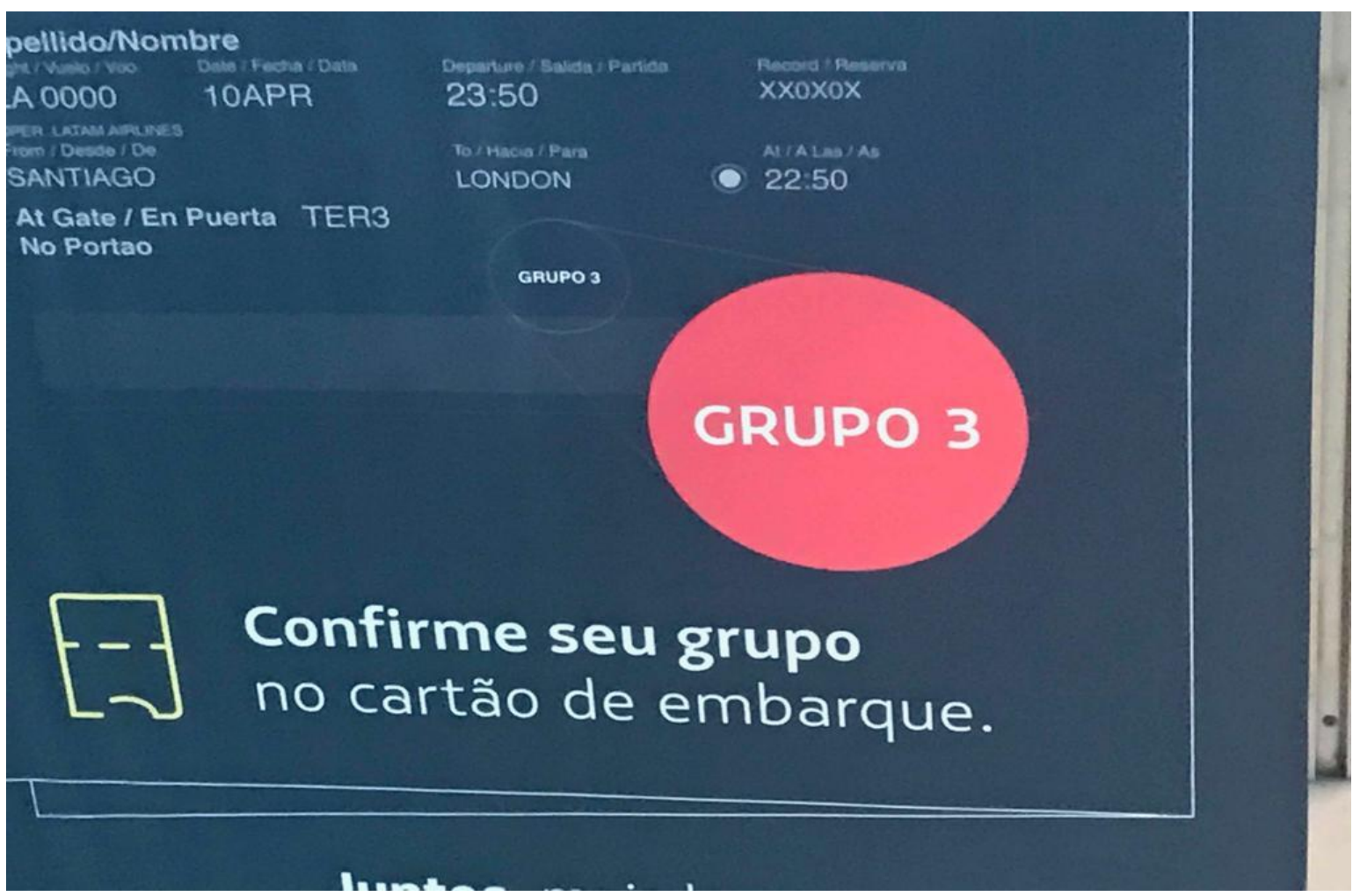

Figura 2.25. Ordenação para acelerar o embarque,

O formato mais comum de uma fila é quando um grupo de pessoas ou objetos, também chamados de passageiros ou carga, chegam a um ponto de atendimento e não podem ser atendidas de imediato, resultando em um tempo de espera. A fila é motivada pela falta de canais de atendimento, porque se fossem em n"umero suficiente, nça haveria filas nem tempos de espera.

A fila, como um processo, tem alguns elementos, tais como:

1. chegada de novos passageiros;

2. serviço demandado;

3. ordenamento para o atendimento, $\mathrm{e}$

4. capacidade da fila.

No primeiro elemento é descrita a frequência temporal que novos passageiros chegam, podendo ser determinístico ou probabilístico.

O serviço demandado pode obedecer a um regime temporal fixo, conforme o passageiro que está sendo atendido, ou ser descrito por uma distribuição probabilística.

A fila obedece a uma ordem de atendimento, que pode ser pelo tempo de chegada, onde o primeiro a chegar é o primeiro a ser atendido, como em filas do pedágio. Porém é possível encontrar filas com outros tipos de regime, tais como os sistemas de armazenamento em banco de dados que controlam a gestão de transportes, comumente organizados em pilha e assim, o último que entra é o primeiro a sair. Por fim, também pode ser visto o atendimento por tempo, onde cada passageiro é atendido por um tempo e quando esgotado esse tempo, mesmo que o atendimento não seja finalizado, um outro passageiro é atendido, fazendo um rodízio com um tempo predeterminado para cada passageiro. 
A capacidade da fila pode ser finita ou infinita, ainda que exista um limite físico para a fila, se for grande o suficiente pode ser considerado infinita, com o intuito de simplificar os cálculos. Caso contrário, quando a fila atingir um limite, não é possível a chegada de novos passageiros.

\subsection{A matemática dos principais tipos de filas}

As expressões matemáticas que descrevem o comportamento das filas podem evoluir de fórmulas básicas a expressões bastante complexas, a depender das características da fila em estudo. Os tipos mais simples e, consequentemente, os primeiros a serem abordados na literatura tradicional são o $\mathrm{M} / \mathrm{M} / 1$ e o $\mathrm{M} / \mathrm{M} / \mathrm{c}$. Esses modelos de fila baseiam-se em uma propriedade de capacidade ilimitada, contudo, considerando a abordagem voltada a transportes deste livro, entende-se que a prioridade deve ser para as fórmulas que abordam capacidade limitada. Decisão essa de simples compreensão, visto os exemplos de uma fila para entrar no ônibus, a fila de aviões esperando para decolar, a fila de caminhões-tanque aguardando para carregar na distribuidora de combustíveis, todos têm capacidade limitada.

Nos Quadros 2.4 a 2.7, apresentam-se as fórmulas dos tipos de filas mais comuns, iniciando-se aquelas mais adequadas aos transportes, ou seja, com capacidade limitada. O conteúdo apresentado foi fundamentado em referências da área, porém se optou por assumir uma abordagem mais objetiva nas formulações necessárias para um entendimento geral, deixando as comprovações como leitura complementar a ser buscada na bibliografia referenciada.

Quadro 2.4 - Fórmulas para uma fila tipo $\mathrm{M} / \mathrm{M} / 1 / \mathrm{K}$

\begin{tabular}{|c|c|c|}
\hline $\begin{array}{l}\text { Tipo de } \\
\text { fila }\end{array}$ & Parâmetros de desempenho & Fórmulas \\
\hline \multirow{7}{*}{$\mathrm{M} / \mathrm{M} / 1 / \mathrm{K}$} & Utilização do servidor & $\rho=\frac{\lambda}{\mu}$ \\
\hline & $\begin{array}{l}\text { Probabilidade de o sistema não } \\
\text { ter passageiros }\end{array}$ & $P_{0}=\left\{\begin{array}{cc}\frac{1}{K+1}, & \rho=1 \\
\frac{1-\rho}{1-\rho^{K+1}}, & \rho \neq 1\end{array}\right.$ \\
\hline & $\begin{array}{l}\text { Probabilidade de haver } n \\
\text { passageiros no sistema (com } n \geq \\
\text { 0) }\end{array}$ & $P(N=n)=\left\{\begin{aligned} \frac{1}{K+1}, & \rho=1 \\
\frac{(1-\rho) \rho^{n}}{1-\rho^{K+1}}, & \rho \neq 1\end{aligned}\right.$ \\
\hline & Comprimento médio do sistema & $L=\left\{\begin{aligned} \frac{K}{2}, & \rho=1 \\
\frac{\rho\left[1+K \rho^{K+1}-\rho^{K}(K+1)\right]}{(1-\rho)\left(1-\rho^{K+1}\right)}, & \rho \neq 1\end{aligned}\right.$ \\
\hline & Comprimento médio da fila & $L_{q}=L-1+P_{0}$ \\
\hline & Tempo médio no sistema & $W=\frac{L}{\lambda\left(1-P_{K}\right)}$ \\
\hline & Tempo médio na fila & $W_{q}=W-\frac{1}{\mu}$ \\
\hline
\end{tabular}


FILAS: conceitos, novos enfoques de abordagem e aplicações em Transportes

\begin{tabular}{|c|c|}
\hline $\begin{array}{l}\text { Probabilidade de existirem no } \\
\text { sistema } k \text { ou mais passageiros }\end{array}$ & $P(N \geq k)=\left\{\begin{array}{r}\frac{K+1-k}{K+1} \\
\frac{\rho^{k}\left(1-\rho^{K-k+1}\right)}{1-\rho^{K+1}}\end{array}\right.$ \\
\hline $\begin{array}{l}\text { Probabilidade de o tempo de } \\
\text { espera na fila exceder } t\end{array}$ & $\begin{array}{c}P\left(T_{q}>t\right)=\sum_{n=0}^{K-2} q_{n+1} \sum_{i=0}^{n} \frac{(\mu t)^{i}}{i !} e^{-\mu t} \\
q_{n}=\frac{P_{n}}{1-P_{K}}\end{array}$ \\
\hline
\end{tabular}

Quadro 2.5 - Fórmulas para uma fila tipo $\mathrm{M} / \mathrm{M} / \mathrm{c} / \mathrm{K}$

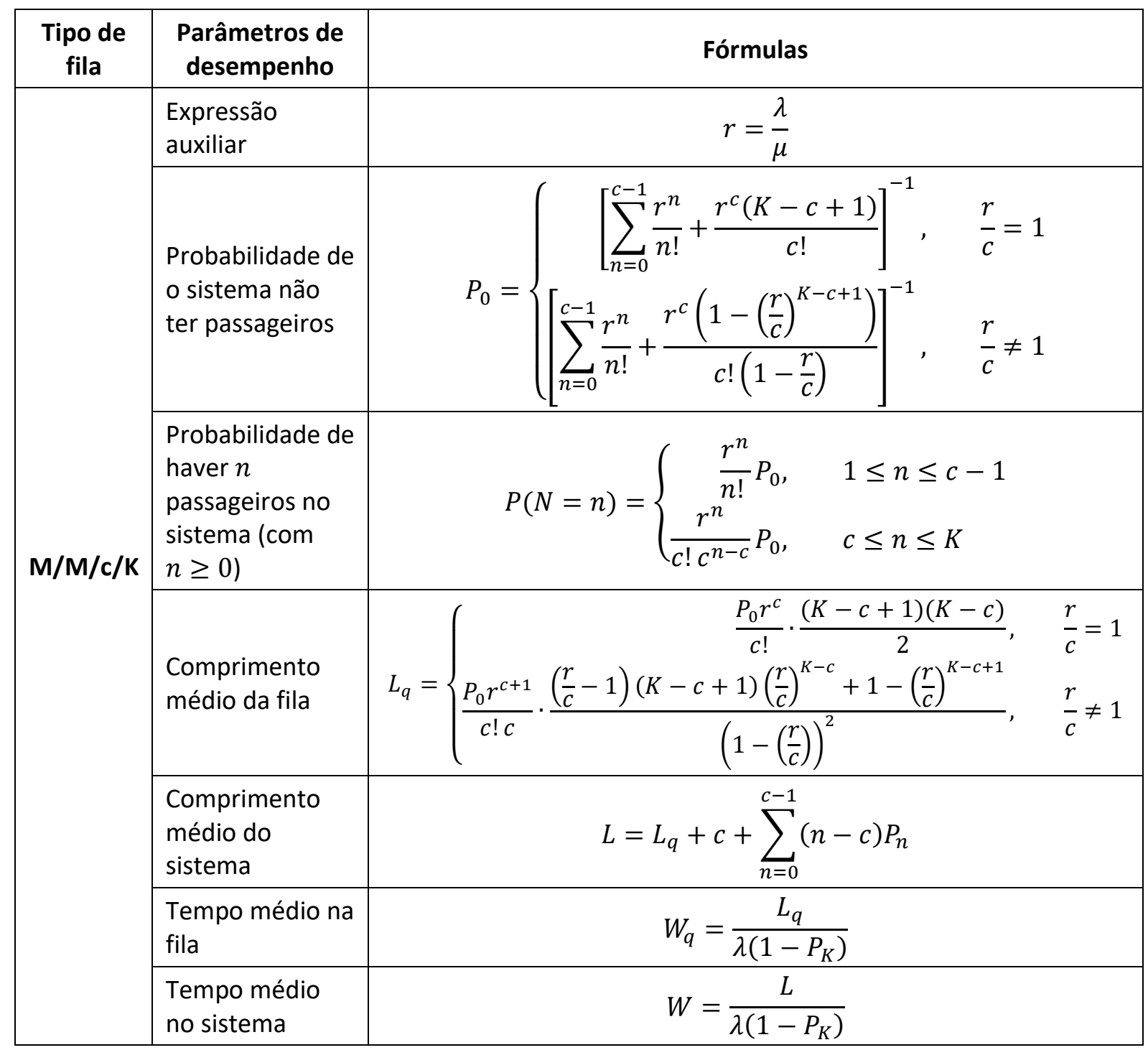


FILAS: conceitos, novos enfoques de abordagem e aplicações em Transportes

Quadro 2.6 - Fórmulas para uma fila tipo M/M/1

\begin{tabular}{|c|c|c|}
\hline $\begin{array}{l}\text { Tipo de } \\
\text { fila }\end{array}$ & Parâmetros de desempenho & Fórmulas \\
\hline \multirow{9}{*}{$M / M / 1$} & Utilização do servidor & $\rho=\frac{\lambda}{\mu}$ \\
\hline & Comprimento médio do sistema & $L=\frac{\rho}{(1-\rho)}$ \\
\hline & Comprimento médio da fila & $L_{q}=\frac{\rho^{2}}{(1-\rho)}$ \\
\hline & Tempo médio no sistema & $W=\frac{1}{\mu-\lambda}$ \\
\hline & Tempo médio na fila & $W_{q}=\frac{\rho}{\mu-\lambda}$ \\
\hline & $\begin{array}{l}\text { Probabilidade de haver } n \text { passageiros no } \\
\text { sistema ( } \operatorname{com} n \geq 0 \text { ) }\end{array}$ & $P(N=n)=\rho^{n}(1-\rho)$ \\
\hline & $\begin{array}{l}\text { Probabilidade de existirem no sistema } k \text { ou } \\
\text { mais passageiros }\end{array}$ & $P(N \geq k)=\rho^{k}$ \\
\hline & $\begin{array}{l}\text { Probabilidade de o tempo gasto no sistema } \\
\text { exceder } t\end{array}$ & $P(T>t)=e^{-(\mu-\lambda) t}$ \\
\hline & $\begin{array}{l}\text { Probabilidade de o tempo de espera na fila } \\
\text { exceder } t\end{array}$ & $P\left(T_{q}>t\right)=\rho e^{-(\mu-\lambda) t}$ \\
\hline
\end{tabular}

Quadro 2.7 - Fórmulas para uma fila tipo $\mathrm{M} / \mathrm{M} / \mathrm{c}$

\begin{tabular}{|c|l|c|}
\hline $\begin{array}{c}\text { Tipo } \\
\text { de fila }\end{array}$ & Parâmetros de desempenho & Fórmulas \\
\hline & Expressão auxiliar & $r=\frac{\lambda}{\mu}$ \\
\cline { 2 - 4 } & Taxa de utilização do sistema & $\rho=\frac{r}{c}$ \\
\cline { 2 - 3 } & $\begin{array}{l}\text { Probabilidade de o sistema não } \\
\text { ter passageiros }\end{array}$ & $P_{0}=\frac{1}{\sum_{n=0}^{c-1} \frac{r^{n}}{n !}+\frac{c r^{c}}{c !(c-r)}}$ \\
\cline { 2 - 3 } $\mathbf{M} / \mathbf{c}$ & Comprimento médio da fila & $L_{q}=\frac{c r^{c+1}}{c !(c-r)^{2}} P_{0}$ \\
\cline { 2 - 3 } & $\begin{array}{l}\text { Comprimento médio do } \\
\text { sistema }\end{array}$ & $L=r+L_{q}$ \\
\cline { 2 - 3 } & Tempo médio na fila & $W_{q}=\frac{r^{c} \mu}{(c-1) !(c \mu-\lambda)^{2}} P_{0}$ \\
\cline { 2 - 3 } & Tempo médio no sistema & $W=\frac{1}{\mu}+W_{q}$ \\
\hline
\end{tabular}


FILAS: conceitos, novos enfoques de abordagem e aplicações em Transportes

\begin{tabular}{|c|c|}
\hline $\begin{array}{l}\text { Probabilidade de haver } n \\
\text { passageiros no sistema (com } \\
n \geq 0 \text { ) }\end{array}$ & $P(N=n)=\left\{\begin{aligned} P_{0} \frac{r^{n}}{n !}, & 1 \leq n<c \\
P_{0} \frac{r^{n}}{c ! c^{n-c}}, & n \geq c\end{aligned}\right.$ \\
\hline $\begin{array}{l}\text { Probabilidade de existirem no } \\
\text { sistema } k \text { ou mais passageiros }\end{array}$ & $P(N \geq k)=1-\sum_{n=0}^{k-1} P(n)$ \\
\hline $\begin{array}{l}\text { Probabilidade de o tempo gasto } \\
\text { no sistema exceder } t\end{array}$ & $\begin{array}{c}P(T>t)=e^{-\mu t}\left[1+\frac{P_{0} r^{c}}{c !(1-\rho)}(h)\right] \\
h=\left\{\begin{array}{cl}\mu t, & \operatorname{se}(c-r-1)=0 \\
\frac{1-e^{-\mu t(c-r-1)}}{(c-r-1)}, & \text { senão }\end{array}\right.\end{array}$ \\
\hline $\begin{array}{l}\text { Probabilidade de o tempo de } \\
\text { espera na fila exceder } t\end{array}$ & $P\left(T_{q}>t\right)=\left(1-\sum_{n=0}^{c-1} P(n)\right) e^{-c \mu(1-\rho) t}$ \\
\hline
\end{tabular}

Adicionalmente, seguem as expressões matemáticas gerais das filas, conhecidas como fórmulas de Little:

$$
\begin{gathered}
L=\lambda W \\
L_{q}=\lambda W_{q} \\
W=W_{q}+\frac{1}{\mu}
\end{gathered}
$$

Onde:

$$
\begin{array}{ll}
\text { - } \lambda=\frac{1}{\mathrm{E}[\text { tempo entre chegadas }]} & \text { Taxa média de chegada } \\
\text { - } \mu=\frac{1}{\mathrm{E}[\text { tempo de serviço }]} & \text { Taxa média de serviço }
\end{array}
$$

- $E[$.$] \quad Valor esperado$

- $P($.$) \quad Probabilidade$

- $\quad$ Número de servidores

- N Número de passageiros no sistema

- T Tempo de um passageiro no sistema

- $T_{q} \quad$ Tempo de um passageiro na fila

- L Comprimento médio do sistema

- $L_{q} \quad$ Comprimento médio da fila

- W Tempo médio de um passageiro no sistema

- $W_{q} \quad$ Tempo médio de um passageiro na fila

- $K \quad$ Capacidade limite do sistema 


\subsection{FCFS ou FIFO, qual a diferença? Há diferença?}

A dúvida que denomina esta seção certamente surgirá na mente do estudante que inicia seus estudos de teoria das filas. Percebe-se que, em geral, os autores utilizam FCFS e FIFO para tratar do mesmo perfil de atendimento, onde há uma fila por ordem de chegada e os servidores atendem respeitando essa sequência.

Contudo, convido o leitor a refletir sobre a semântica de cada termo:

- FCFS - first come, first served - primeiro a chegar, primeiro a ser servido

- FIFO - first in, first out - primeiro a entrar, primeiro a sair

Há diferença, não? Imagine um restaurante onde um grupo de turistas chegou para almoçar e estão aproveitando o dia de forma tranquila e devagar, na sequência, chegou um grupo de trabalhadores que precisam almoçar e voltar ao serviço em até uma hora. Se o restaurante imaginado atende conforme a disciplina FIFO, como o grupo de turistas chegou antes, eles necessariamente terão que sair do restaurante primeiro. Consequentemente os trabalhadores ficarão irritados tendo que esperar os turistas finalizarem seu almoço, não é?

No mesmo sentido, imagine agora que a mesma situação aconteceu em um restaurante que atende conforme a disciplina FCFS. O grupo de turistas por ter chegado primeiro será chamado para a mesa antes do grupo de trabalhadores, contudo, assim que os trabalhadores terminarem de almoçar poderão sair normalmente para cumprir seu limite de horário de almoço.

Entendendo que há diferença de significado entre os termos FCFS e FIFO, por que alguns autores os utilizam ambiguamente? Por hipótese, uma explicação pode estar no caso de uma fila que é atendida somente por um servidor. Em nosso exemplo do restaurante, se houvesse somente uma mesa, não haveria diferença no atendimento, pois por mais que chamássemos a disciplina de FCFS, na prática ela seria FIFO. Portanto, a razão do uso ambíguo dos termos pode estar em uma generalização do caso mais básico, onde há apenas um servidor.

Caro leitor, esteja atento à diferença entre os termos e, principalmente, atento à característica de alguns autores utilizarem as expressões ambiguamente. Compreendida essa particularidade, o estudo de filas é pacífico e não trará novas armadilhas de conhecimento.

\subsection{Regra prática para saber quanto tempo o passageiro vai demorar em uma fila com $X$ canais de atendimento.}

1) Determinar a sua posição na fila.

2) Identificar o número de canais de atendimento.

3) Observar o tempo de chegada t de uma pessoa nessa fila. Usualmente, cada pessoa leva 3 minutos para ser atendida, em média.

4) Dividir o número da sua posição na fila pelo número de canais de atendimento e mltiplicar o resultad por t. Esse será o seu tempo aproximado de espera.

Exemplo: você é a 25a pessoa em uma fila com 4 canais de atendimento. As pessoas que você observou levaram, em média, 5 minutos no atendimento.

O seu tempo estimado de espera será de, aproximadamente, $(25 / 4)$ x $5=30$ minutos. 


\section{$\underline{\text { Referências }}$}

ANDRADE, Eduardo Leopoldino de. Introdução à Pesquisa Operacional. 2. ed. Rio de Janeiro: LTC, 2000.

CAMELO, el al. TEORIA DAS FILAS E DA SIMULAÇÃO APLICADA AO EMBARQUE DE MINÉRIO DE FERRO E MANGANÊS NO TERMINAL MARÍTIMO DE PONTA DA MADEIRA, Rio de Janeiro, v. 29, p. 1-16, $2010 . \quad$ Disponível em: $<$ https://www.epublicacoes.uerj.br/index.php/cadest/article/view/15733/11904>. Acesso em 05 Jun 2019.

FERREIRA FILHO, Virgílio José Martins. PROCESSOS ESTOCÁSTICOS E TEORIA DE FILAS. Rio de Janeiro: UFRJ COPPE.

FOGLIATTI, Maria Cristina; MATTOS, Néli Maria Costa. Teoria das Filas. Rio de Janeiro: Interciência, 2007.

GOSAVI, A. QUEUING FORMULAS. Department of Engineering Management and Systems Engineering, Missouri S \& T.

TORRES, Oswaldo Fadigas. Elementos da teoria das filas. Rev. adm. empres., São Paulo, v. 6, n. 20, p. 111-127, Set. 1966 Disponível em: $<$ http://www.scielo.br/scielo.php?script=sci_arttext\&pid=S003475901966000300005\&lng=en\&nrm=i so>. Acesso em 05 Jun 2019.

ZABINSKY, Zelda. QUEUEING THEORY. University of Washington. Disponível em: < http://courses.washington.edu/inde411/LectureNotes.htm >. Acesso em 12 Jun 2019. 


\section{Capítulo TRÊS \\ Exemplos, exercícios resolvidos e algo mais: aquecendo os neurônios}

FABIRE SOARES REZENDE

Neste capítulo apresentaremos alguns exercícios resolvidos e outros propostos que utilizam conceitos de Teoria das Filas aplicada à área de transportes. O objetivo é exemplificar situações em que os conceitos abordados neste livro se mostram presentes e úteis na resolução de problemas considerados "relativamente simples" sob o ponto de vista de toda a amplitude de complexidade da matéria. Não é objetivo deste autor esgotar o assunto de modo a exemplificar todos os diversos tipos de exercícios possíveis, mesmo porque podem existir infinitas possibilidades de combinações entre as várias distribuições matemáticas para as taxas e peculiaridades de problemas e soluções. Buscaremos desenvolver no leitor à habilidade para diagnosticar o problema, classificar, organizar os dados de entrada, aplicar algumas fórmulas, interpretar os resultados e propor melhorias para o desempenho de alguns serviços. Os softwares e os aplicativos computacionais de teoria das filas possuem limitações, pois não possuem a capacidade humana de interpretação e crítica de resultados. Além disso, restringem os resultados apenas a um determinado leque de opções que pode não ser exatamente a resposta final ou solução final buscada pelo usuário, sendo necessário nesses casos, uma ação humana e "braçal" de junção de resultados parciais ou de complementação no processamento. O mais importante é que o leitor tenha realmente um bom e profundo entendimento dos conceitos para que obtenha sucesso em suas pretensões e aspirações relativas à teoria das filas.

\section{Exemplo 3.1 - Tipo de Fila $\mathrm{M} / \mathrm{M} / 1$ (resolvido):}

Em um destacamento militar do 5을 Batalhão de Engenharia de Construção do Exército Brasileiro (5 BEC), localizado as margens da BR-364 no estado de Rondônia, um primeiro tenente engenheiro de fortificação e construção residente precisa avaliar o comportamento da fila de caminhões que se forma no carregamento de concreto betuminoso usinado a quente (CBUQ) na saída da usina. Para isso, ele possui um levantamento histórico de que o número médio de caminhões que chegam por hora é de 10 caminhões/hora. Em conversa com o experiente segundo sargento do quadro especial usineiro, foi informado que o tempo médio necessário para o carregamento de cada caminhão é de aproximadamente 4 minutos. Assuma que as distribuições de intervalos entre chegadas e tempo de serviço (carregamento) seguem a distribuição de Poisson e exponencial, respectivamente.

Ajude o engenheiro residente a fazer as seguintes avaliações quanto ao comportamento da fila de caminhões:

a) O capitão engenheiro chefe da seção técnica ao qual o primeiro tenente engenheiro residente é subordinado disse que o percentual máximo admitido de ociosidade no carregamento é uma média de $20 \%$. Este percentual médio de ociosidade está sendo atendido? Caso não esteja, qual procedimento poderia ser adotado para reduzir este percentual até o recomendado? 
b) Conforme orientações do capitão comandante do destacamento, o número médio de caminhões que devem esperar na fila é de apenas 1 caminhão. Esta orientação está sendo atendida? Caso não esteja, qual procedimento poderia ser adotado para reduzir o número médio de caminhões na fila?

c) Os cabos e soldados motoristas dos caminhões aproveitam o tempo que estão no sistema para checarem suas redes sociais em seus smartphones e com isso, gostariam de saber o tempo médio que terão disponíveis (tempo na fila mais o tempo de carregamento). Qual seria em média?

d) O comandante do destacamento, para fins de planejamento, precisa saber quantos caminhões serão atendidos em média por hora. Quantos seriam?

\section{Solução:}

Primeiramente, devemos processar e organizar os dados do problema da seguinte forma:

Notação da fila: M/M/1

Disciplina da fila: FCFS ou FIFO

Chegada: $\lambda=10$ caminhões/hora.

Atendimento: em média, 1 caminhão a cada 4 minutos, ou seja, 15 caminhões/hora (60/4). Sendo assim, $\mu=15$ caminhões/hora.

a)

$$
P(L=n)=\rho^{n}(1-\rho)
$$

Calculando $\rho=\frac{\lambda}{\mu}=\frac{10}{15}=0,666$ e com $\mathrm{n}=0$, temos:

$$
\begin{gathered}
P(L=0)=0,666^{\circ}(1-0,666) \\
\mathrm{P}(0)=0,3333=33,33 \%
\end{gathered}
$$

Como 33,33\% > 20\%, concluímos que o percentual médio de ociosidade não está sendo atendido.

Para que seja atendido, devemos reduzir a parcela $(1-\rho)=\left(1-\frac{\lambda}{\mu}\right)$ a um valor menor ou igual a $20 \%$, logo:

$$
\left(1-\frac{\lambda}{\mu}\right) \leq \frac{1}{5}=20 \%
$$

Dessa forma, temos que:

$$
\frac{\lambda}{\mu} \geq \frac{4}{5}
$$

Assim sendo, deveríamos atuar em $\lambda$ ou/e em $\mu$ de modo que a razão $\frac{\lambda}{\mu}$ seja maior ou igual a $4 / 5$.

Para uma média fixa de $\mu=15$ caminhões/hora, deveríamos adotar $\lambda \geq 12$ caminhões/hora. 
b)

$$
\mathrm{L}_{\mathrm{q}}=\frac{\lambda^{2}}{[\mu(\mu-\lambda)]}=\frac{10^{2}}{[15(15-10)]}=1,33 \text { caminhões }
$$

Como 1,33 > 1, concluímos que a orientação do capitão comandante do destacamento não está sendo atendida.

Para que seja atendida, devemos reduzir a parcela $\frac{\lambda^{2}}{[\mu(\mu-\lambda)]}$ a um valor menor ou igual a 1 , logo:

$$
\frac{\lambda^{2}}{[\mu(\mu-\lambda)]} \leq 1
$$

Assim sendo, deveríamos atuar em $\lambda$ ou/e em $\mu$ de modo que $\frac{\lambda^{2}}{[\mu(\mu-\lambda)]}$ seja menor ou igual a 1.

Para uma média fixa de $\mu=15$ caminhões/hora, deveríamos adotar $\lambda \leq 9$ caminhões/hora.

c) Dado que $L=\lambda W$, então:

$$
\mathrm{W}=\frac{L}{\lambda}=\frac{1}{(\mu-\lambda)}=\frac{1}{(15-10)}=\frac{1}{5}=0,2 \text { horas ou } 12 \text { minutos }
$$

d) Se a ocupação média da usina fosse de $100 \%$, então o número médio de caminhões carregados por hora seria de 15 caminhões.

Sendo a ocupação média a $100 \%$ igual a $1-P(0)$, ou seja, igual a $2 / 3$, então o número de caminhões atendidos por hora seria de:

$$
15 * \frac{2}{3}=10 \text { caminhões } / \text { hora }
$$

\section{Exemplo 3.2 - Tipo de fila $\mathrm{M} / \mathrm{M} / 1$ (resolvido):}

Nas chegadas de navios ao berço portuário de atracação do porto do Rio de Janeiro podemos adotar a distribuição de Poisson como referência. Em média, chegam 6 navios por dia. A duração média de atendimentos dos navios é de 3 horas, seguindo-se a distribuição exponencial. Você, na situação de mestre na engenharia de transportes pelo Instituto Militar de Engenharia, foi solicitado pela administração do porto para fins de uma consultoria que tem como objetivo apresentar alguns cálculos e resultados utilizando os conceitos e a fundamentação da teoria das filas. Dessa forma, alguns questionamentos de interesse do porto são relacionados a seguir e devem ser respondidos em sua consultoria.

a) As empresas que administram os navios pressionam o porto do Rio de Janeiro para que a fila de espera seja mínima, sendo o ideal que não houvesse necessidade de fila, pois os custos totais de um navio parado são altíssimos. Sendo assim, qual seria a probabilidade de um navio chegar ao porto do Rio de Janeiro e ser atendido de imediato, isto é, sem precisar esperar para atracar? 
b) De acordo com as médias informadas pela administração do porto, qual seria a quantidade média de navios aguardando em fila até sua vez de atracação?

c) A administração do porto, para fins de planejamento estratégico, precisa saber qual a quantidade média de navios que se encontram neste sistema portuário?

d) A recomendação da administração do porto é de que a quantidade média de navios utilizando o porto não seja superior a 1, pois isso acarretaria em prejuízos ao seu nível de serviço. Esta recomendação está sendo respeitada?

e) Voltando a questão da espera, qual é o tempo médio de um navio na fila?

f) Um tempo considerado razoável de espera na fila seria uma média de 3 horas.

Para tanto, qual deveria ser a taxa de chegada dos navios no porto?

g) Quando um navio chega ao porto, qual é a probabilidade de que encontre o berço portuário em uso?

\section{Solução:}

Primeiramente, devemos processar e organizar os dados do problema da seguinte forma:

Notação da fila: M/M/1

Disciplina da fila: FCFS ou FIFO

Chegada: $\lambda=6$ navios/dia.

Atendimento: em média, 1 navio a cada 3 horas, ou seja, 8 navios/dia (24/3). Sendo assim, $\mu=8$ navios/dia.

a)

$$
P(L=n)=\rho^{n}(1-\rho)
$$

Calculando $\rho=\frac{\lambda}{\mu}=\frac{6}{8}=0,75$ e com $\mathrm{n}=0$, temos:

$$
\mathrm{P}(\mathrm{L}=0)=(0,75)^{0}(1-0,75)=0,25=25 \%
$$

b) $\quad \mathrm{L}_{\mathrm{q}}=\frac{\lambda^{2}}{[\mu(\mu-\lambda)]}=\frac{6^{2}}{[8(8-6)]}=2,25$ navios

c) $\quad \mathrm{L}=\frac{\lambda}{(\mu-\lambda)}=\frac{6}{(8-6)}=3$ navios

d) Total de navios atracados no porto $=\mathrm{L}-\mathrm{L}_{\mathrm{q}}=3-2,25=0,75$ navio

Como $0,75<1$, concluímos que a recomendação está sendo atendida.

e) $\quad \mathrm{W}_{\mathrm{q}}=$ ?, como $\mathrm{L}_{\mathrm{q}}=\lambda \mathrm{W}_{\mathrm{q}}$, então $\mathrm{W}_{\mathrm{q}}=\frac{\mathrm{Lq}}{\lambda}$, ou seja,

$$
\mathrm{W}_{\mathrm{q}}=\frac{2,25}{6}=0,375 \text { dia }=9 \text { horas }
$$

f) $\quad$ Se $\mathrm{W}_{\mathrm{q}}=3$ horas $=0,125$ dias $(3 / 24)$, mantendo-se a mesma taxa de atendimento $(\mu)$, deve-se calcular a nova taxa de chegadas $(\lambda)$. Sendo assim:

Sendo $\mathrm{L}_{\mathrm{q}}=\frac{\lambda^{2}}{[\mu(\mu-\lambda)]}$ e $\mathrm{L}_{\mathrm{q}}=\lambda \mathrm{W}_{\mathrm{q}}$, então $\frac{\lambda^{2}}{[\mu(\mu-\lambda)]}=\lambda \mathrm{W}_{\mathrm{q}}$

Isolando $\lambda$, chegamos a seguinte equação:

$$
\lambda=\frac{W q \mu^{2}}{(W q \mu+1)}
$$


Substituindo-se os valores, já calculados até aqui, na equação de $\lambda$, temos:

$$
\lambda=\frac{W q \mu^{2}}{(W q \mu+1)}=\frac{0,125 * 8^{2}}{(0,125 * 8+1)}=4 \text { navios } / \text { dia }
$$

g) Como calculado na letra "a" de que a probabilidade de que não haja nenhum navio no porto é de $25 \%$, então a probabilidade de que haja pelo menos um navio atracado no berço é de $1-P(L=0)=1-1 / 4=3 / 4=0,75=75 \%$

\section{Exemplo 3.3 - Tipo de fila $M / M / 1$ (resolvido):}

Uma empresa especializada em logística de carga pelo modal rodoviário possui um posto de abastecimento de caminhões em seu pátio com apenas uma bomba. Essa empresa pretende fazer uma análise do custo médio com mão de obra desse processo de abastecimento de seus caminhões. Os ritmos de chegada e de abastecimento dos caminhões podem ser aproximados, com um nível de precisão aceitável, por um modelo Markoviano. Conforme o histórico de registros a taxa de chegadas dos caminhões é de 15 minutos. $O$ frentista do posto consegue atender cada caminhão em uma média de 12 minutos. Os custos diários com o frentista são de $\mathrm{R} \$ 40,00$ e com os motoristas são de $\mathrm{R} \$ 96,00$. Conforme a legislação brasileira, a carga horária diária máxima de trabalho é de 8 horas tanto para frentistas quanto para motoristas. Assim sendo, a empresa solicita que sejam calculados os custos horários do sistema. Para fins de melhor compreensão do sistema e busca por otimizações de custos, a empresa solicita também que seja calculada a probabilidade de ociosidade do frentista.

\section{Solução:}

Primeiramente, devemos processar e organizar os dados do problema da seguinte forma:

Notação da fila: $M / M / 1$

Disciplina da fila: FCFS ou FIFO

Chegada: em média, 1 caminhão a cada 15 minutos, ou seja, 4 caminhões/hora (60/15). Sendo assim, $\lambda=4$ caminhões/hora.

Atendimento: em média, 1 caminhão a cada 12 minutos, ou seja, 5 caminhões/hora (60/12). Sendo assim, $\mu=5$ caminhões/hora.

Custo do frentista: $\mathrm{R} \$ 40,00 / \mathrm{dia}=\mathrm{R} \$ 40,00 / 8$ horas $=\mathrm{R} \$ 5,00 /$ hora.

Custo do motorista: $\mathrm{R} \$ 96,00 / \mathrm{dia}=\mathrm{R} \$ 96,00 / 8$ horas $=\mathrm{R} \$ 12,00 /$ hora

Quantidade de caminhões no sistema:

$$
\mathrm{L}=\frac{\lambda}{(\mu-\lambda)}=\frac{4}{(5-4)}=4 \text { caminhões }
$$

Dessa forma, por hora o frentista abastece 4 caminhões. Logo, podemos calcular o custo horário de mão de obra do sistema como sendo:

$$
(\mathrm{R} \$ 5,00 * 1)+(\mathrm{R} \$ 12,00 * 4)=\mathrm{R} \$ 53,00
$$

A probabilidade do frentista ficar ocioso é de: 


$$
\begin{gathered}
\mathrm{P}(\mathrm{L}=\mathrm{n})=\rho^{n}(1-\rho) \\
\mathrm{P}(\mathrm{L}=0)=\left(\frac{4}{5}\right)^{0}\left(1-\frac{4}{5}\right)=\frac{1}{5}=20 \%
\end{gathered}
$$

\section{EXEMPLO 3.4 - Tipo de fila M/M/S (resolvido):}

Faça uma análise quanto à Teoria das Filas para um porto hipotético, que possui em sua estrutura 3 berços de atracação, com taxas de chegada de usuários e de atendimento nos berços, iguais, sendo de 3 embarcações ao dia.

\section{Solução:}

Primeiramente, devemos processar e organizar os dados do problema da seguinte forma:

Notação da fila: M/M/3

Disciplina da fila: FCFS ou FIFO

Chegada: $\lambda=3$ navios/dia.

Atendimento: $\mu=3$ navios/dia

Calcularemos então a taxa de ocupação do berço, que é dada pela expressão:

$$
\rho=\frac{\lambda}{\mathrm{c} * \mu}
$$

Logo, temos que: $\quad \rho=\frac{3}{3 * 3}$

$$
\rho=0,3333
$$

Após encontrarmos a taxa de ocupação, encontraremos a $\mathrm{P}(0)$, probabilidade do sistema estar vazio, ou seja, não ter embarcações na fila e tampouco em atendimento.

Aplicando-se a fórmula para determinação da probabilidade do sistema estar vazio:

$$
\begin{gathered}
P_{0}=\frac{1}{\sum_{n=0}^{c-1} \frac{(\lambda / \mu)^{n}}{n !}+\frac{(\lambda / \mu)^{c}}{c !(1-\rho)}} \\
P_{0}=\frac{1}{\frac{(3 / 3)^{0}}{0 !}+\frac{(3 / 3)^{1}}{1 !}+\frac{(3 / 3)^{2}}{2 !}+\frac{(3 / 3)^{3}}{3 !(1-0,33)}} \\
P_{0}=\frac{1}{1+1+0,5+0,252} \\
P_{0}=\frac{1}{2,752} \\
\text { Po }=0,3633=36,33 \% .
\end{gathered}
$$

Em posse destes resultados buscaremos então, o número esperado de embarcações no sistema, representados por (L). 


$$
\begin{gathered}
L_{q}=\frac{P_{0}(\lambda / \mu)^{c} \rho}{c !(1-\rho)^{2}} \\
L_{q}=\frac{0,3633(3 / 3)^{3} 0,3333}{3 !(1-0,3333)^{2}} \\
\mathrm{Lq}=0,0454 \text { navios } \\
W q=\frac{L q}{\lambda} \\
W q=\frac{0,0454}{3} \\
W q=0,0151 \mathrm{dia} \\
W=W q+\frac{1}{\mu} \\
W=0,0151+\frac{1}{3} \\
W=0,3484 \text { dia } \\
L=\lambda W \\
L=3 * 0,3484 \\
L=1,0453 \text { navios }
\end{gathered}
$$

O que significa que um porto que tem uma taxa de entrada de 3 navios por dia, uma taxa de atendimento de 3 navios por dia e uma estrutura do porto composta por 3 berços de atracação possui um número médio esperado de 1,0453 navios no sistema.

Por fim calcularemos a probabilidade de que um passageiro fique no sistema mais do que um tempo $t(W(t))$ e a probabilidade de que um passageiro fique na fila mais do que um tempo $t(W q(t))$. Abaixo são listadas as fórmulas para determinação das duas probabilidades:

$$
\begin{gathered}
P(W(t)>1)=e^{\frac{-t}{W}} \\
P(W q(t)>1)=\rho e^{\frac{-t}{W}}
\end{gathered}
$$

Calcularemos as probabilidades para $\mathrm{t}=1$ dia.

$$
\begin{gathered}
P(W(t)>1)=e^{\frac{-1}{0,3484}} \\
\mathrm{P}(\mathrm{W}(\mathrm{t})>1)=0,0567=5,67 \%
\end{gathered}
$$

$\mathrm{e}$

$$
\begin{gathered}
P(W q(t)>1)=0,3333 e^{\frac{-1}{0,3484}} \\
\mathrm{P}(\mathrm{Wq}(\mathrm{t})>1)=0,0189=1,89 \%
\end{gathered}
$$


FILAS: conceitos, novos enfoques de abordagem e aplicações em Transportes

Desta forma um passageiro tem 5,67\% de ficar no sistema mais do que um dia e 1,89\% de ficar na fila, ou seja, aguardando para iniciar seu atendimento, por mais de um dia.

\section{EXEMPLO 3.5 - Tipo de fila M/M/S}

A teoria das filas é uma ferramenta de grande utilidade nos aeroportos e pode ser utilizada para controle das filas nos galpões de check-in. Na literatura e na prática podem-se encontrar exemplos em que a taxa de entrada de passageiros cresce com a proximidade do horário de embarque do voo.

Para exemplificar, escolhemos um voo doméstico em que a aeronave possui capacidade para 475 passageiros. A Figura 3.1 mostra o comportamento dos passageiros na chegada ao check-in no tempo com a proximidade do horário de embarque.

\section{Comportamento do Embarque}

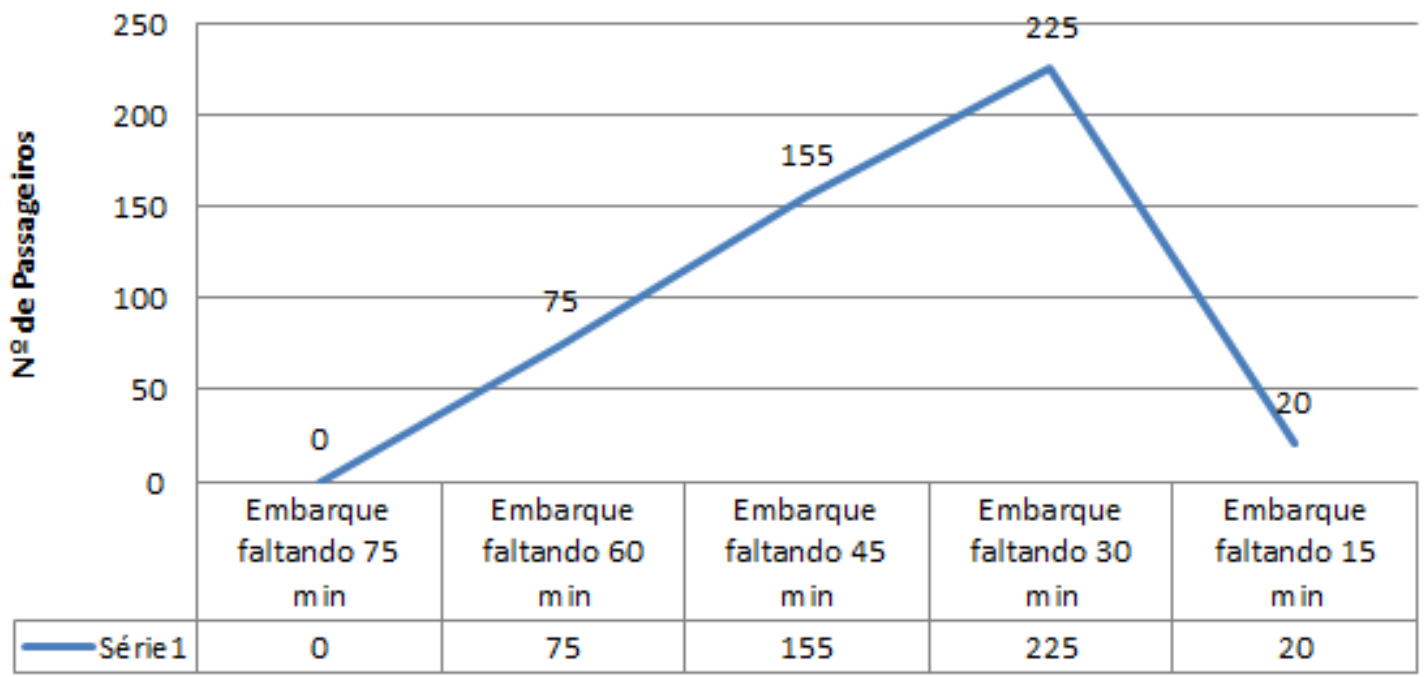

Figura 3.1 Comportamento dos passageiros na chegada ao check-in no tempo com a proximidade do horário de embarque

A companhia aérea coloca 6 posições de atendimento à disposição dos passageiros.

Segundo um levantamento realizado pela empresa, o tempo para cada atendimento teve a distribuição mostrada na Tabela 3.1.

Tabela 3.1 Tempo de atendimento de passageiros

\begin{tabular}{|c|c|}
\hline No de Clientes Atendidos & Tempo de Atendimento (min) \\
\hline 40 & 1,5 \\
\hline 55 & 1,75 \\
\hline 80 & 2 \\
\hline 20 & 2,25 \\
\hline 70 & 2,5 \\
\hline 120 & 2,75 \\
\hline 70 & 3 \\
\hline 55 & 3,25 \\
\hline
\end{tabular}


Considere que o ritmo de chegadas possa ser aproximado satisfatoriamente por um processo de Poisson e que o de atendimento possa ser representado de modo exponencial.

a) A companhia aérea determinou que a probabilidade máxima aceitável de um caixa ficar ocioso é de 10\%. Esta determinação está sendo atendida? Caso contrário, quais seriam os procedimentos que a companhia aérea poderia adotar para resolver a pendência?

b) $\quad 0$ número médio máximo de passageiros na fila, segundo a direção do aeroporto, deve ser de 10 passageiros. Este requisito está sendo atendido? Caso contrário, quais seriam os procedimentos a serem adotados para sanar a pendência?

c) De acordo com uma pesquisa com os passageiros, o tempo máximo que eles aceitariam aguardar em uma fila de check-in de forma paciente seria de $10 \mathrm{~min}$. Este tempo está sendo atendido? Caso contrário, quais seriam os procedimentos que poderiam ser adotados para agradar os passageiros quanto a esse quesito?

d) A meta estabelecida pela companhia aérea foi de um atendimento médio de 450 passageiros por hora. Esta meta está sendo atendida? Caso contrário, quais seriam procedimentos a serem adotado para sanar a pendência?

e) Qual seria a probabilidade de chegando um passageiro para ser atendido, ele encontrar os 4 guichês ocupados? E apenas de 1 guichê desocupado? E de exatamente 2 guichês desocupados? E de exatamente 3 guichês desocupados?

\section{Início da Solução:}

Primeiramente, devemos processar e organizar os dados do problema da seguinte forma: Notação da fila: M/M/6

Disciplina da fila: FCFS ou FIFO

Chegada: $\lambda=$ ? passageiros/hora.

Atendimento: $\mu=$ ? passageiros/hora

Calcularemos inicialmente a taxa média de chegadas $(\lambda)$ a partir da Tabela 3.2.

Tabela 3.2 Tempo faltando para o voo

\begin{tabular}{|c|c|}
\hline $\mathrm{N}^{\mathbf{o}}$ de Passageiros & Tempo faltando para o voo $(\mathrm{h})$ \\
\hline 75 & 1 \\
\hline 155 & 0,75 \\
\hline 225 & 0,5 \\
\hline 20 & 0,25 \\
\hline
\end{tabular}

Logo $\lambda$ será igual à média ponderada da tabela anterior, assim:

$\lambda=(75 * 1+155 * 0,75+225 * 0,5+20 * 0,25) /(1+0,75+0,5+0,25)$

$\lambda=123,5$ passageiros/hora

Em seguida, calcularemos a taxa média de atendimento $(\mu)$ a partir da Tabela 3.3. 
Tabela 3.3 Tempo de atendimento

\begin{tabular}{|c|c|}
\hline № de Clientes Atendidos & Tempo de Atendimento (min) \\
\hline 40 & 1,5 \\
\hline 55 & 1,75 \\
\hline 80 & 2 \\
\hline 20 & 2,25 \\
\hline 70 & 2,5 \\
\hline 120 & 2,75 \\
\hline 70 & 3 \\
\hline 55 & 3,25 \\
\hline
\end{tabular}

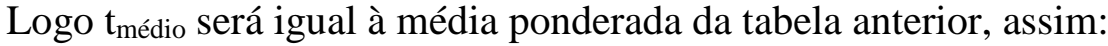

$\mathrm{t}_{\text {médio }}=(40 * 1,5+55 * 1,75+80 * 2+20 * 2,25+70 * 2,5+120 * 2,75+70 * 3+55 * 3,25)$

$/(40+55+80+20+70+120+70+55)$

$\mathrm{t}_{\text {médio }}=2,46 \mathrm{~min} /$ passageiros

Logo $\mu=1 / \mathrm{t}_{\text {médio }}=0,41$ passageiros $/ \mathrm{min} \Rightarrow \mu=0,41$ passageiros $/ \mathrm{min} * 60 \mathrm{~min}=24,38$ passageiros/hora.

Notação da fila: M/M/6

Disciplina da fila: FCFS ou FIFO

Chegada: $\lambda=123,5$ passageiros/hora

Atendimento: $\mu=24,38$ passageiros/hora

a) A probabilidade de haver pelo menos um caixa ocioso poderá ser calculada pelo somatório das probabilidades $\mathrm{P} 0+\mathrm{P} 1+\mathrm{P} 2+\mathrm{P} 3+\mathrm{P} 4+\mathrm{P} 5$ ou pela diferença 1 $\mathrm{P}(\mathrm{N}>=6), \log \mathrm{O}$ :

$\mathrm{P} 0+\mathrm{P} 1+\mathrm{P} 2+\mathrm{P} 3+\mathrm{P} 4+\mathrm{P} 5=?$

$\mathrm{ou}$

$1-\mathrm{P}(\mathrm{N}>=6)=?$

Caro leitor, após alguns exemplos resolvidos e outro iniciado, proponho que continue as resoluções dos exercícios por si só a partir deste ponto.

Continue aquecendo seus neurônios e faça um ótimo trabalho!!!

Confio em você!!!

\section{EXERCÍCIO 3.1 - Tipo de fila $\mathrm{M} / \mathrm{M} / 1 / \mathrm{C}$}

Outro grande uso da teoria das filas no setor aeroportuário é o sistema de liberação das aeronaves para pouso e decolagens. Suponhamos a situação de diagnóstico de uma fila de aguardo para a liberação exclusivamente de pouso em uma pista de um determinado aeroporto. Chegam, em média, 15 aeronaves por hora na fila. Todo o procedimento de pouso leva em torno de $3 \mathrm{~min}$. O modelo pode ser considerado regido pela distribuição de Poisson e exponencial, respectivamente. O número 
total de aeronaves que terão que realizar o procedimento de pouso para fins de diagnóstico são de apenas 12 .

a) O valor esperado máximo aceitável de aeronaves na fila são de 10. Este valor está sendo atingido? Caso contrário, proponha ajustes que poderiam ser feitos para que o limite imposto seja atendido.

b) Por questões relacionadas aos custos operacionais das aeronaves, o recomendado é que o tempo total no sistema seja em média de $30 \mathrm{~min}$. Este limite está sendo atendido? Caso contrário, proponha ajustes para sanar o impasse.

c) A administração do aeroporto possui uma meta de a probabilidade de haver 7 aeronaves no sistema seja inferior a $0,2 \%$. A meta está sendo cumprida? Proponha políticas de ajuste, caso contrário.

\section{EXERCÍCIO 3.2 - Tipo de fila $\mathrm{M} / \mathrm{M} / \mathrm{S} / \mathrm{C}$ :}

Uma praça de pedágio de veículos localizada em uma rodovia federal brasileira concessionada é controlada por 3 guichês que são os responsáveis pelas cobranças manuais das tarifas. Os veículos chegam à praça a cada 35 segundos, conforme uma distribuição de Poisson. Os operadores dos guichês gastam, em média, 1 min e 30 segundos por atendimento segundo uma distribuição exponencial. 0 número total de carros, os quais se pretende analisar o comportamento na fila, é de uma população de 1000. Responda:

a) A meta da concessionária é que a fila não tenha mais do que 10 veículos na fila em média. Esta meta está sendo atingida? Caso contrário, proponha mecanismos para a concessionária atingir sua meta.

b) Qual seria o desvio padrão do número de veículos na fila?

c) Outra meta da concessionária é que o tempo médio gasto para o veículo passar pela praça seja de no máximo 5 min. Esta meta está sendo atingida? Caso contrário, proponha mecanismos para que a meta seja atingida.

d) Qual seria a probabilidade de um veículo chegar na praça e encontrar todos os guichês desocupados? E de encontrar apenas 1 guichê desocupado? E de encontrar menos do que 5 guichês desocupados?

e) Qual seria a probabilidade de um veículo levar mais do que 3 min na fila?

\section{EXERCÍCIO 3.3 - Tipo de fila M/M/1/K:}

Os navios que frequentam um determinado porto apresentam intervalo médio de chegadas de 3,8 horas. A distribuição dos intervalos entre chegadas sucessivas pode ser considerada exponencial. O tempo que um navio permanece atracado no porto é, em média, de 1,8 horas, com distribuição também exponencial. $O$ porto só possui 1 guindaste para realizar a movimentação dos containers e 0 limite de espaço para navios no sistema é de 7 .

a) O número limite de navios no sistema deve ser inferior a 6 e em fila inferior a 5 . Estes números estão sendo atingidos em média? Caso contrário, quais procedimentos devem ser adotados?

b) O tempo médio de espera na fila deve ser inferior a 2 horas. Este tempo está sendo atingido? Caso contrário, proponha procedimentos a serem adotados.

c) A probabilidade para o sistema estar ocupado deve ser inferior a $2 \%$ e a do sistema estar vazio inferior a $1 \%$. Estes percentuais estão sendo atingidos? Caso contrário, quais procedimentos devem ser adotados? 


\section{EXERCÍCIO 3.4 - Tipo de fila M/M/S/K:}

Um edifício comercial possui uma sala de espera para o elevador para no máximo 30 pessoas. 3 elevadores encontram-se em operação. A taxa de chegada de pessoas que pretendem utilizar os elevadores é de 10 pessoas por minuto e segue uma distribuição de Poisson. A taxa de atendimento de cada elevador é de 5 pessoas por minuto. A capacidade do elevador é de 10 pessoas.

a) A probabilidade de se encontrar o sistema ocupado deve ser maior do que $60 \%$. Esta probabilidade está sendo atendida? Caso contrário, o que poderia ser feito para que seja atendida?

b) A probabilidade de se encontrar o sistema vazio deve ser inferior a $12 \%$ Está sendo atendido? Caso contrário, proponha ajustes que poderiam ser realizados de modo a atender a este requisito.

\section{EXERCíCIO 3.5 - Tipo de fila $\mathrm{M} / \mathrm{M} / 1 / \mathrm{K}$ (difícil):}

A sala de espera de uma empresa de ônibus em um terminal rodoviário possui capacidade máxima para 50 pessoas. Os ônibus partem da rodoviária a cada 30 min seguindo uma distribuição exponencial e sua capacidade pode ser considerada suficiente para atender todos os que estiverem na sala de espera aguardando.

a) Determine qual seria a taxa máxima de passageiros que poderiam chegar à sala de espera de modo que sua capacidade máxima não seja superada.

b) Supondo que a capacidade máxima do ônibus seja de no máximo 40 passageiros, qual seria a nova taxa máxima de chegada de passageiros que permitisse que a sala de espera fosse suficiente?

\section{EXERCícIO 3.6 - Tipo de fila $\mathrm{M} / \mathrm{M} / \mathrm{S} / \mathrm{K}$ (difícil):}

Em uma oficina mecânica de uma empresa de ônibus, os veículos devem realizar suas manutenções rotineiras a cada 30 dias segundo uma distribuição de Poisson. A empresa possui uma frota grande. $\mathrm{O}$ espaço para acondicionamento desses ônibus na oficina é limitado a 10 ônibus. 0 tempo médio gasto para realização dos serviços é de 3 dias por mecânico, segundo uma distribuição também exponencial. Trabalham atualmente no local apenas 2 mecânicos. Responda:

a) Qual é a probabilidade da capacidade máxima de acondicionamento da oficina ser atingida?

b) Qual a probabilidade de que existam na fila mais do que 5 ônibus aguardando?

c) A empresa está analisando a necessidade de contratação de mais mecânicos para a oficina. Para tanto, ela possui uma meta de que a probabilidade de que haja mais do que 3 ônibus na fila seja menor do que $5 \%$. Sendo assim, quantos mecânicos ela deveria contratar? Justifique.

\section{EXERCÍCIO 3.7 - Tipo de fila M/M/1/K (difícil):}

A prefeitura de uma determinada cidade está fazendo um redimensionamento da frequência de ônibus necessária para uma certa linha que passa por 5 pontos de ônibus ao todo até reiniciar seu ciclo. A capacidade máxima de cada ônibus é de 60 passageiros. Existem atualmente 4 ônibus fazendo 
esta linha. O tempo total de percurso do ciclo para cada ônibus é, em média, de 1 hora e 30 minutos. Sabe-se que as taxas médias de entrada e saída de passageiros do ônibus em cada um dos pontos baseiam-se na Tabela 3.4:

Tabela 3.4 Dados de entrada e de saída dos passageiros

\begin{tabular}{|c|c|c|c|c|c|}
\hline Ponto & Entrada (passageiros) & Entrada Acumulada & Saída (passageiros) & Saída Acumulada & Total no Ônibus \\
\hline Ponto 1 & 10 & 10 & 0 & 0 & 10 \\
\hline Ponto 2 & 20 & 30 & 10 & 10 & 20 \\
\hline Ponto 3 & 30 & 60 & 15 & 25 & 35 \\
\hline Ponto 4 & 20 & 80 & 30 & 55 & 25 \\
\hline Ponto 5 & 0 & 80 & 25 & 80 & 0 \\
\hline
\end{tabular}

Considere que as taxas de chegada dos passageiros em cada ponto também sejam as de entrada no ônibus segundo uma distribuição exponencial.

a) A meta da prefeitura é que o tempo médio de espera em cada ponto não ultrapasse $30 \mathrm{~min}$. Esta meta está sendo atingida? Caso contrário, proponha mecanismos para reduzir o tempo de espera.

b) Considerando que o limite de pessoas na fila no ponto 3 seja de 30, este limite está sendo atendido? Caso contrário, proponha mecanismos para reduzir o número de pessoas nesse ponto.

\section{$\underline{\text { Referências }}$}

- TEORIA DAS FILAS (Queueing Theory) Baseado em Andrade, Eduardo Leopoldino de, Introdução à pesquisa operacional, LTC - Livros Técnicos e Científicos, Rio de Janeiro, 2000.; Albernaz, Marco Aurélio, Teoria das Filas - Apontamentos da Disciplina Pesquisa Operacional II - Pontifícia Universidade Católica - RJ, 2004 e Costa, Renato Aurélio Castro, Determinação de Estoques, Dissertação de Mestrado, Universidade Federal do Paraná, Curitiba, 2003; Prado, Darci Santos do. Teoria das Filas e da Simulação, ISBN 85-86948-12-8, INDG Tecnologia e Serviços LTDA, Belo Horizonte, 2004.

Disponível em: <http://www.sucena.eng.br/ST/ST5 Mod5TeoriadeFilas.pdf> Acessado em 05/06/2019.

- Exercícios resolvidos sobre Teoria das Filas.

Disponível em: < https://www.ebah.com.br/content/ABAAAgnOOAH/exercicios-resolvidoteoria-das-fila> Acessado em 05/06/2019.

- Pesquisa Operacional e Transportes: Modelos Probabilísticos. Antônio Galvão Novaes. Editora da Universidade de São Paulo - Editora McGraw - Hill do Brasil, LTDA 1975. 


\section{Capítulo \\ Aplicativos computacionais} QUATRO

NEWTON CARLOS DE OLIVEIRA PORTELLA

VITOR NUNES CRUZ

\section{PARTE A: Apps (iOS e Android)}

\subsection{Introdução}

Na pesquisa por aplicativos para dispositivos móveis (celular e tablet), foram elencados abaixo alguns Apps com uma breve explanação sobre suas funcionalidades. Os links correspondentes irão direcionar para a página onde se poderá baixar ou ler sobre cada um deles.

Dentre os Apps citados, é apresentado um passo a passo para a utilização do aplicativo Teoría de Colas com o objetivo de agilizar o entendimento para a inserção dos dados, configurações e obtenção das respostas.

$\mathrm{Na}$ sequência, são resolvidos os quatro primeiros exemplos descritos no capítulo 3 , com as observações sobre a limitação dos cálculos.

Por fim, são apresentadas as considerações finais com as observações sobre utilidades secundárias de dois Apps.

\subsection{Aplicativos e suas serventias}

\section{a. Teoría de Colas (Teoria das Filas) - ANDROID}

https://play.google.com/store/apps/details?id=com.overne.modelocolas

É um App quase completo (só não há opção para escolha da distribuição) de fácil utilização e gratuito para ANDROID 4.0.3 ou superior, com calculadora para sete modelos de fila (M / M / 1; M / M / S; M / M / 1 / C; M / M / S / C; M / M / 1 / K; e M / M / S / K). O número de casas decimais dos resultados pode ser configurado de 0 casas até 5 casas decimais. Ao se tocar nas linhas dos resultados o App mostra a fórmula utilizada. $\mathrm{O}$ app já apresenta automaticamente o cálculo de probabilidades de ocupação do sistema de 0 a 7 elementos.

Avaliações: apesar de terem sido feitos mais de 1000 downloads, há somente nove avaliações com a maioria das notas máximas (5).

\section{b. WhyQ Demo Queue App - ANDROID}

https://play.google.com/store/apps/details?id=com.elixir.urgentcaredemo

É um App tipo DEMO, pago, disponível tanto para sistema ANDROID quanto para IOS. Há a possibilidade de agendar uma DEMO ou utilizar uma versão gratuita, mas reduzida em recursos (versão TRIAL) por tempo ilimitado. $O$ objetivo desse App é organizar filas virtuais por meio de mensagens SMS, na qual o passageiro é cadastrado e recebe informações em seu celular/tablet sobre a proximidade de seu atendimento, organizando a fila e fazendo com que o passageiro aproveite seu tempo de espera. 


\section{c. IBL Line - ANDROID}

https://play.google.com/store/apps/details?id=ibl.line.app

É um App pago, desenvolvido para gerenciamento de filas de restaurantes. Custa R\$ 99,00 por mês, mas neste caso, somente a empresa arca com os custos. Para os passageiros é gratuito, bastando apenas um cadastro do número do celular para ser informado sobre a sua posição na fila. $O$ passageiro pode também fazer observações sobre o local que deseja ocupar, como por exemplo, uma mesa na janela. Este App também pode ser utilizado como Demo, sendo livre de custos por um mês.

\section{d. Aplicativo para Filas - Agecom Telecom https://agecomtelecom.com.br/aplicativo-para-filas - ANDROID e iOS}

É um App pago, desenvolvido pela empresa Agecom, para as plataformas IOS e ANDROID. Não realiza cálculos como o Teoría de Colas acima. Caracteriza-se por ser um organizador de filas com aplicação em logística e carregamento de transportes. O App se comunica aos motoristas por SMS (mensagem de texto) orientando-os quanto ao local onde devem se dirigir e a sua posição na fila de carregamento. A empresa que utiliza desse recurso consegue gerenciar o sistema por meio de computadores ou tablets de modo a evitar erros no fluxo de carregamento, otimizando, assim, o processo.

\section{e. Queue Simulation - ANDROID}

https://play.google.com/store/apps/details?id=brooksturtle.simulation.lewis.simulation\&hl=pt BR É um App para simular a evolução dinâmica da fila durante um tempo ajustado pelo usuário. Utiliza a distribuição de Poisson e tem múltiplos usos, tais como testar se a quantidade de atendentes em um restaurante é suficiente para a quantidade de passageiros. Gratuito. Possui três avaliações e sua nota é 3,7 .

\section{f. Ez Turns - Gerenciamento de filas - ANDROID}

https://play.google.com/store/apps/details?id=ar.com.thinkmobile.ezturnscast

É um aplicativo utilizado para solução de gerenciamento de filas tudo-em-um para lojas de varejo, filas de banco, atendimento de hospitais, caixas para pagamentos, restaurantes etc..

O Ez Turns é um App gratuito que funciona instalado em um celular/tablet que é conectado a um monitor por meio do Chromecast (um aparelho que transmite sinal de vídeo e áudio de um dispositivo móvel - celular/tablet para um monitor, utilizando-se da entrada HDMI).

Os passageiros recebem uma senha impressa na entrada do estabelecimento (loja, banco etc.), gerada pelo Ez Turns e aguarda ser chamado por meio de um ou mais monitores espalhados pelo estabelecimento. Conectados ao celular/tablet com o App, esses monitores mostrarão a senha a ser atendida e também o número do guichê para o qual o passageiro deve se dirigir, organizando assim a fila.

\section{g. Filho sem Fila - saída da escola - ANDROID e iOS}

https://play.google.com/store/apps/details?id=com.intuitiveappz.fsfmaplebearilha

Neste App, os pais de alunos podem avisar com antecedência à escola, que estão a caminho para apanhar seus filhos. A escola libera o aluno bem próximo do horário de chegada dos pais. Com a maior rapidez na saída do aluno, evita-se os típicos engarrafamentos de veículos em filas na porta das escolas, diminuindo também os riscos de assaltos devido ao menor tempo de espera. 
O Filho sem fila funciona da seguinte forma: ao sair de casa os pais entram no App e enviam um aviso à escola informando que iniciaram o deslocamento a partir do local de onde estão. O App, por meio de um navegador de mapas, calcula o tempo de percurso até a chegada à escola. Com essas informações o aluno/professor sabe a hora exata que os pais chegarão e liberam a saída do aluno evitando esperas na porta da escola e congestionamentos no trânsito local.

\section{h. Filho sem Fila - Transporte Escolar - ANDROID e iOS}

https://play.google.com/store/apps/details?id=com.quickpickupappdriver.schoolbusDriver

Este App informa aos pais de alunos a estimativa de tempo para a chegada do transporte escolar, bem como a hora que os alunos saíram ou entraram no transporte. É possível também acompanhar o deslocamento do transporte ao longo do seu itinerário.

A intenção desse App é fazer com que os pais tenham um acompanhamento do deslocamento de ida e de volta de seus filhos até a escola, de forma segura e sem ficar esperando muito para o embarque ou retorno para casa.

\subsection{Utilizando o App Teoría de Colas (Version 1.0) - passo a passo}

Passo 1. Clicar no ícone do aplicativo, Figura 4.1.

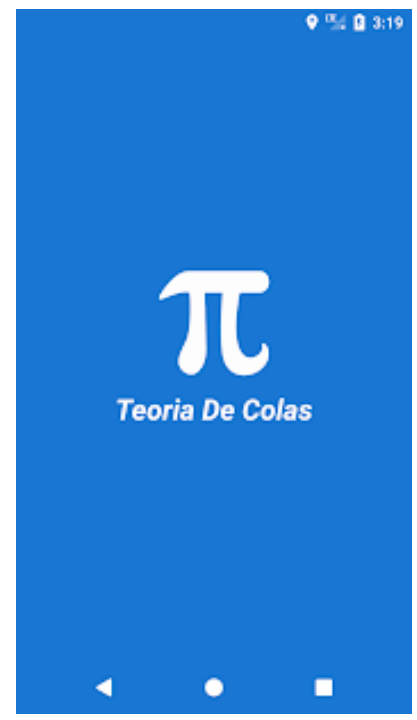

Figura 4.1. Tela inicial do aplicativo

Passo 2. Clicar no ícone do aplicativo, na tela que surge optar pelo modelo de fila. São sete disponíveis, bastando rolar a tela para cima ou para baixo.

* Modelo M / M / 1

* Modelo M / M / S

* Modelo M / M / 1 / C

* Modelo M / M / S / C

* Modelo M / M / 1 / K

* Modelo M / M / S / K 
FILAS: conceitos, novos enfoques de abordagem e aplicações em Transportes

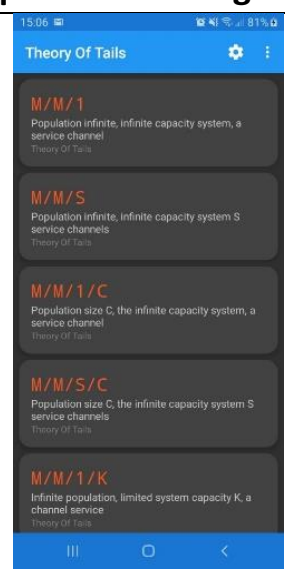

Figura 4.2. Modelos de filas

Passo 3. Clicar no ícone de configuração (roda dentada no canto superior direito), para ser configurado o número de casas decimais que serão exibidas nos resultados.

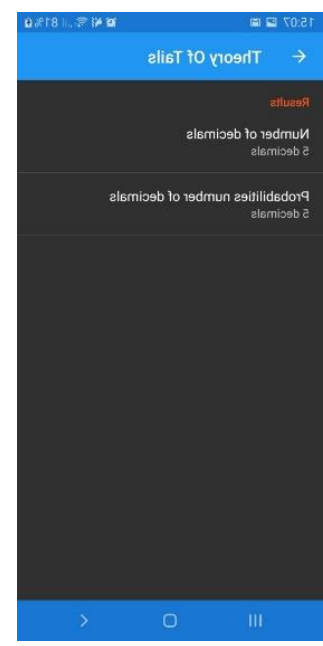

Figura 4.3. Configuração das casas decimais das respostas

Escolha o número de casas decimais entre 0 e 5, bastando clicar na opção desejada. Após escolhida a quantidade de casas decimais, o App retorna ao Passo 3.

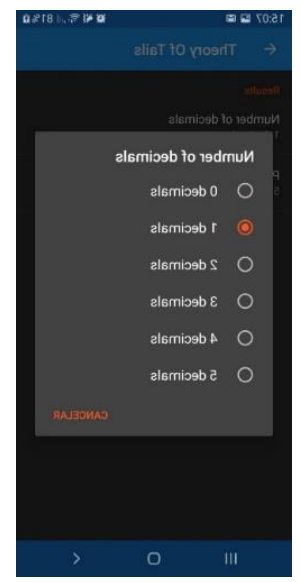

Figura 4.4. Escolha do número de casa decimais 
FILAS: conceitos, novos enfoques de abordagem e aplicações em Transportes

Passo 4. Escolhido o modelo de fila conforme mostrado no passo 1., o usuário pode iniciar o preenchimento dos campos com os dados do problema. Deve-se atentar para o uso das mesmas unidades de medidas, caso contrário serão obtidas respostas erradas, por exemplo, se a taxa de chegada é dada em passageiros por dia, a taxa de serviço também deve ser em passageiros por dia.

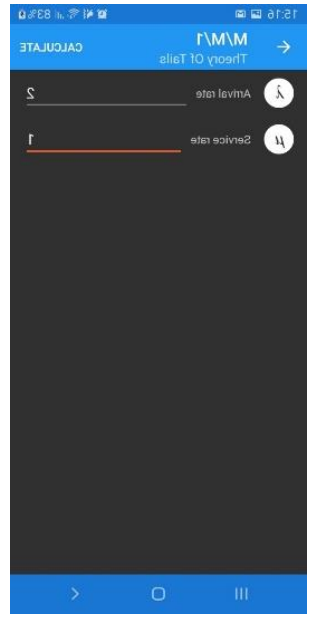

Figura 4.5. Inserção de dados

Passo 5. Clicar no botão CALCULAR, no canto superior direito da tela, para a obtenção dos resultados.

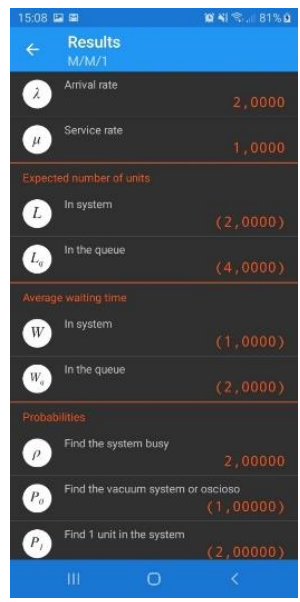

Figura 4.6. Apresentação dos resultados

Passo 6. Clicar na linha correspondente ao resultado para visualizar a fórmula matemática utilizada. Para sair dessa exibição basta clicar no botão ACEPTAR.

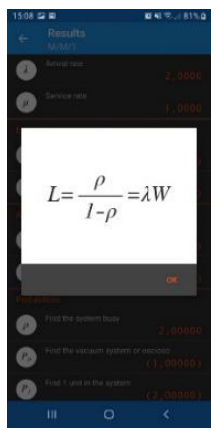

Figura 4.7. Fórmula utilizada para o cálculo 
FILAS: conceitos, novos enfoques de abordagem e aplicações em Transportes

4.4. Resolvendo os exemplos de exercícios do capítulo 3, com uso do App Teoría de Colas.

Exemplo 3.1 - Tipo de Fila $M / M / 1$

Passo 1. Escolha o tipo de fila e insira os dados no App.

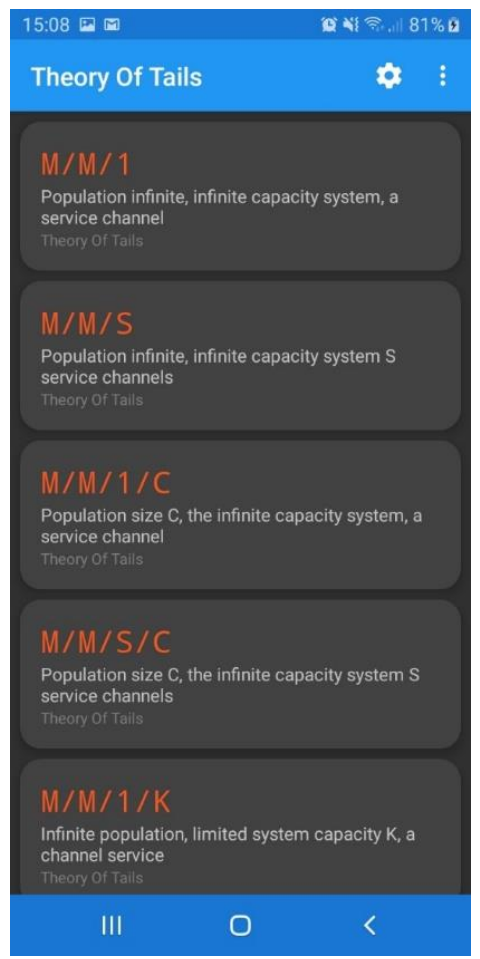

Figura 4.8. Escolha do tipo de fila

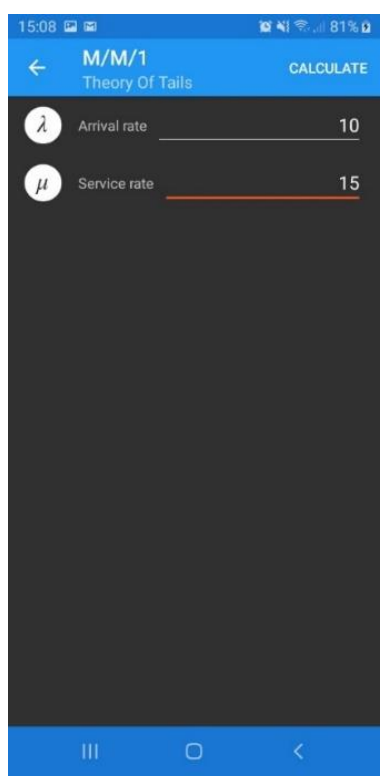

Figura 4.9. Inserção dos dados 
FILAS: conceitos, novos enfoques de abordagem e aplicações em Transportes

Passo 2. Clique em CALCULAR e obtenha as respostas

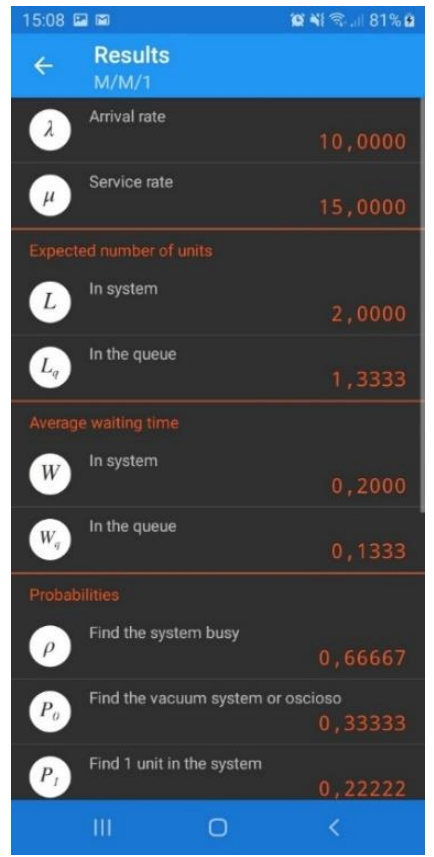

Figura 4.10 Apresentação das respostas - parte 1

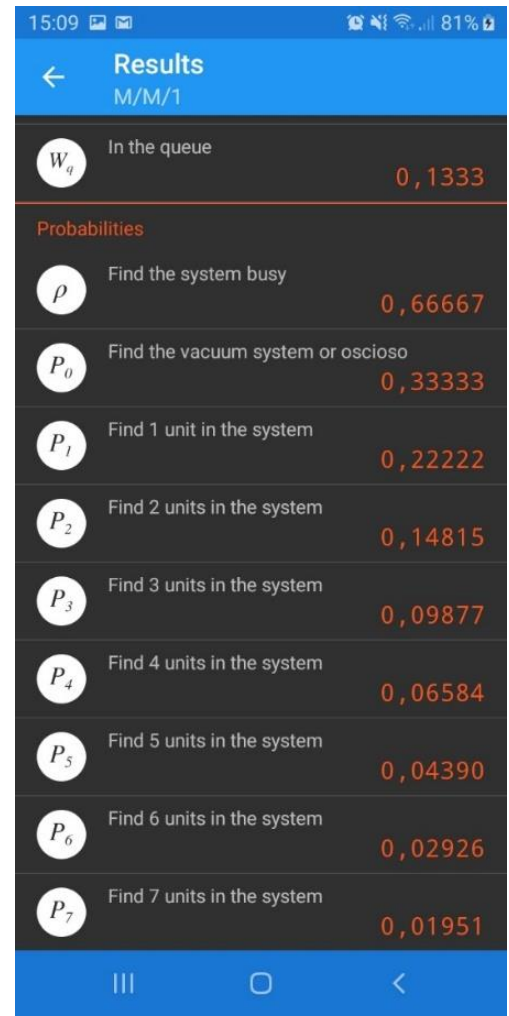

Figura 4.11. Apresentação das respostas - parte 2 
Comparando as respostas da resolução do Exemplo 3.1, capítulo 3, com aquelas no App, tem-se:

a) O App calcula a probabilidade de encontrar o sistema vazio $P_{0}=0,3333(33,33 \%)$. No entanto, esse percentual está acima dos $20 \%$ máximo admitido pelo Capitão. Para esse segundo cálculo nota-se haver uma limitação do App e poderá ser realizado por outro App ou manualmente conforme a resolução manual do exemplo no capítulo 5 .

b) $O$ app calcula o número de caminhões na fila $L_{q}$ em 1,3333. No entanto ultrapassa o número estipulado pelo capitão, que é de 1 caminhão, excedendo em 0,3333 caminhões. Para esse segundo cálculo nota-se haver outra limitação do App. O procedimento para ajuste deverá ser feito manualmente conforme a resolução do exemplo no capítulo 5.

c) O tempo no sistema é calculado pelo App, sem necessidade de ajustes. Confere com a resolução do exercício, sendo $W=0,2$ horas ou 12 minutos.

d) Para esta resposta será necessário cálculo manual ou interpretação de dados. Considerando que a usina tem capacidade de carregar 15 caminhões por hora e que chegam 10 caminhões a cada hora, o limitador para os carregamentos é a chegada de caminhões. Portanto, 10 caminhões por hora.

Observação: as fórmulas utilizadas pelo App podem ser vistas bastando clicar em cima das respostas apresentadas.

\section{Exemplo 3.2 - Tipo de Fila $\mathrm{M} / \mathrm{M} / 1$}

Passo 1. Como os procedimentos são sempre os mesmos para filas $M / M / 1$, a partir de agora iremos apenas mostrar os resultados encontrados. Insira os dados e clique em CALCULAR para obter as respostas.

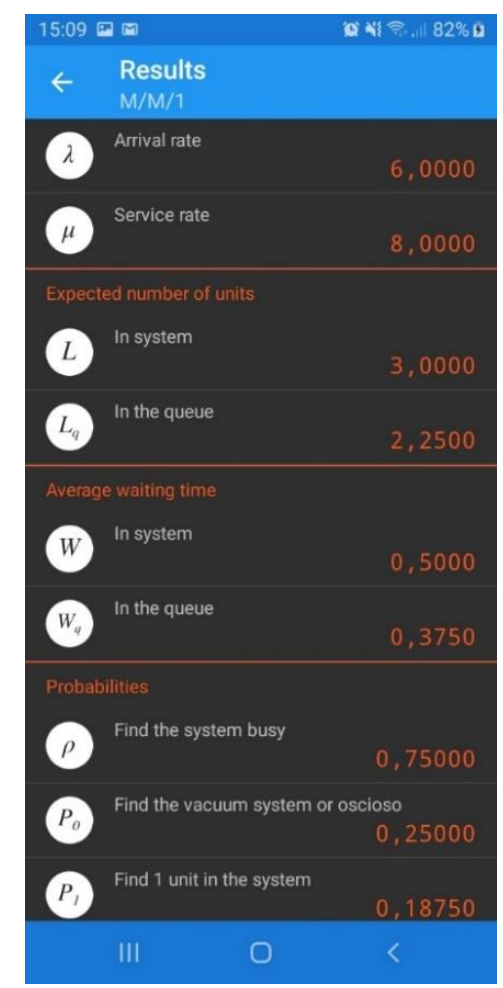

Figura 4.12 Apresentação das respostas - parte 1 


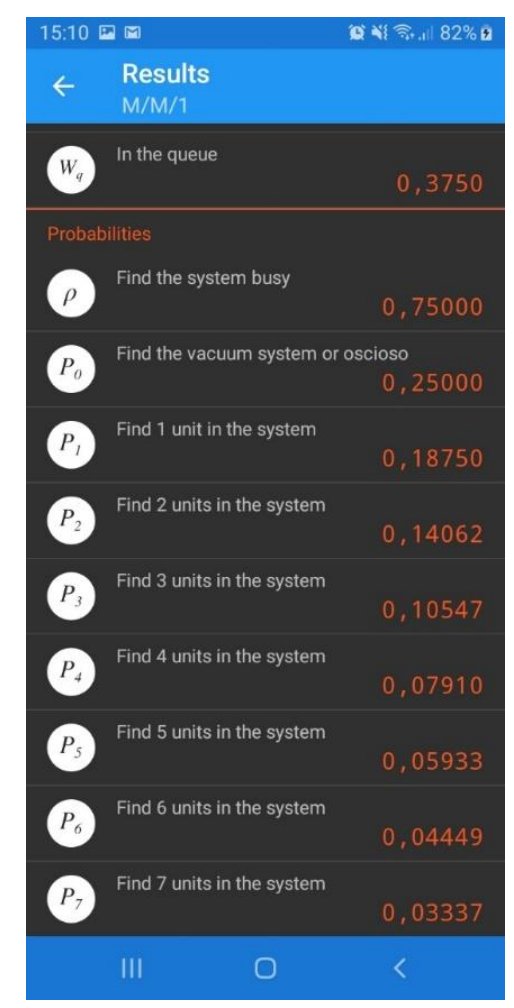

Figura 4.13. Apresentação das respostas - parte 2

Comparando as respostas da resolução do Exemplo 3.2, capítulo 3, e as no App, tem-se:

a) É solicitada a probabilidade de não encontrar filas. Temos que encontrar $\mathrm{P}_{0}$. O App nos mostra $P_{0}$, com o resultado de 0,25 , ou seja $25 \%$. Confere com a resolução manual.

b) Número de navios na fila (cálculo do $L_{q}$ ). Resposta do App é 2,25 navios. Confere com a resolução manual.

c) Número de navios no sistema (cálculo do L). Resposta do App é 3 navios. Confere com a resolução manual.

d) Há limitação do App para cálculo do total de navios atracados no porto. Assim teremos que fazer os cálculos manualmente, bastando fazer a subtração $\left(L-L_{q}\right)$, com os valores fornecidos pelo App. Obtém-se a resposta 0,75 navios atracados.

e) Tempo médio de um navio na fila. (cálculo do $W_{q}$ ). O App nos revela o valor de $W_{q}=0,375$ do dia. Convertendo, teremos 9 dias.

f) Há limitação do App para calcular qual a nova taxa de chegada $(\lambda)$ para que a espera na fila seja de 3 horas. Dessa forma, deve-se utilizar os valores de $L_{q}, W_{q}$ e $\mu$ (disponibilizados no App) para o cálculo manual.

g) O App nos fornece a probabilidade de encontrar o berço portuário em uso (sistema ocupado) que é dado por $\mathrm{p}=0,75$ (75\%). Confere com a resolução manual. 


\section{Exemplo 3.3 - Tipo de Fila $M / M / 1$}

Passo 1. Insira os dados e clique em CALCULAR para obter as respostas.

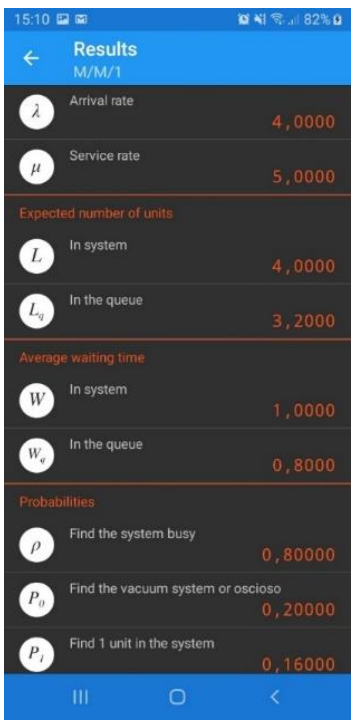

Figura 4.14 Apresentação das respostas - parte 1

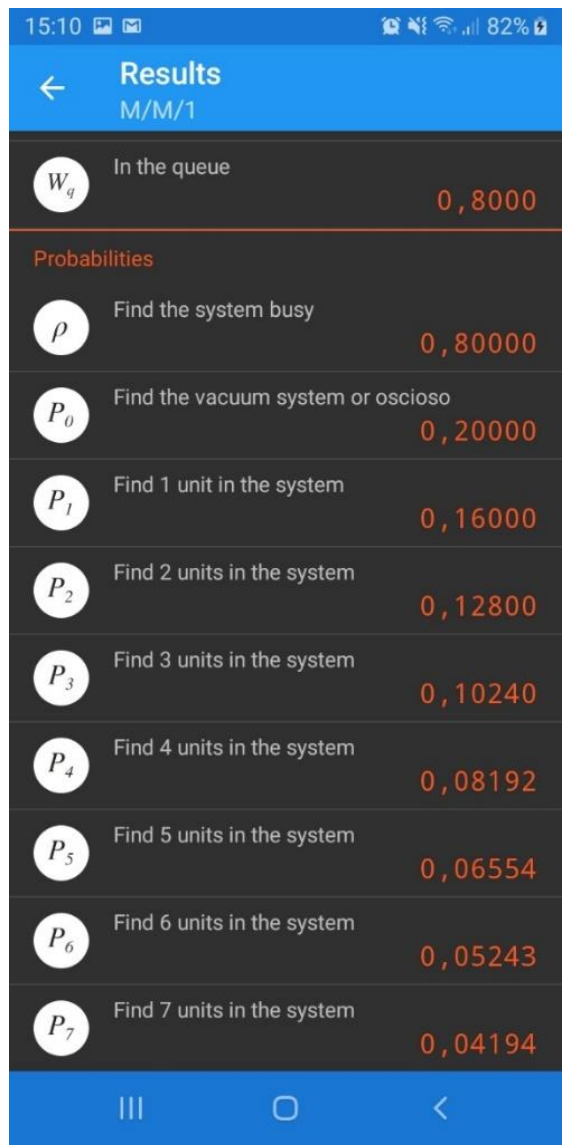

Figura 4.15. Apresentação das respostas - parte 1 
Comparando as respostas da resolução do Exemplo 3.3, capítulo 3, com as respostas no App:

a) É solicitada a quantidade de caminhões no sistema (L). O App nos traz o resultado de 4 caminhões. Confere com a resolução manual.

b) Há limitação do App para cálculo do custo horário de mão de obra no sistema. Devendo ser calculado manualmente com os dados do exemplo 3.

c) O App nos fornece a probabilidade de o frentista ficar ocioso $\left(P_{0}\right)=0,20(20 \%)$. Confere com a resolução manual.

\section{Exemplo 3.4 - Tipo de Fila M/M/S}

Passo 1. Neste exemplo, temos outro tipo de fila. Logo, escolha o tipo de fila M/M/S e insira os dados no App. Agora, além do $\lambda$ e $\mu$, você terá que inserir o número de canais de atendimento (S). Vá em frente!

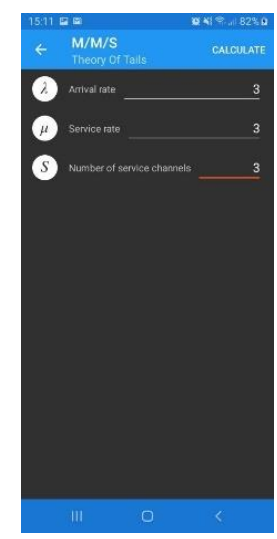

Figura 4.16. Inserção dos dados

Passo 2. Clique em CALCULAR e obtenha as respostas

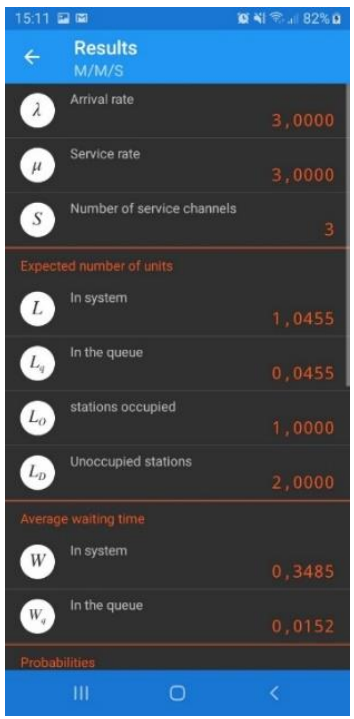

Figura 4.17 Apresentação das respostas - parte 1 


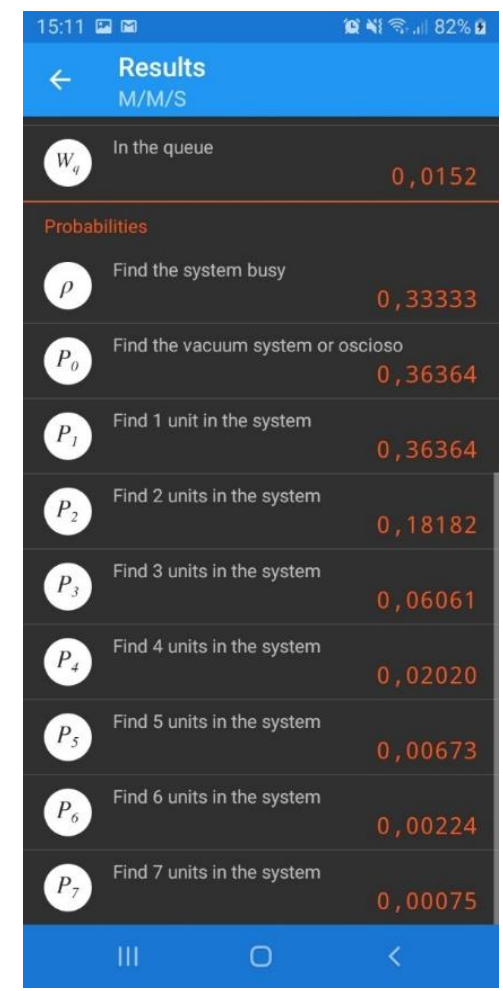

Figura 4.18. Apresentação das respostas - parte 2

Comparando as respostas da resolução do Exemplo 3.4, capítulo 3, com as respostas no App:

a) O App calcula a taxa de ocupação no berço ( $p)$, pedido no exemplo. $p=0,3333(33,33 \%)$. Confere com a resolução manual.

b) $\mathrm{O}$ app calcula a probabilidade de o sistema estar vazio. $\mathrm{P}_{0}=0,36364(36,36 \%)$. Há uma pequena diferença entre o valor calculado manualmente $(36,33 \%)$ e o valor do App $(36,36 \%)$ em $0,03 \%$, provavelmente por motivos de arredondamentos nos cálculos manuais.

c) O App calcula o número esperado de embarcações no sistema que é dado por $L=1,04545$. Há uma pequena diferença entre o valor calculado manualmente $(1,0453)$ e o valor do App $(1,04545)$ em 0,00015 , provavelmente por motivos de arredondamentos nos cálculos manuais.

d) Há limitação do App para calcular a probabilidade de que um passageiro fique no sistema ou na fila mais do que 1 dia.

\subsection{Considerações sobre o uso do App Teoría de Colas, na prática.}

Como se pode observar, o uso do App facilita a obtenção de resultados de maneira a poupar tempo do usuário e de se alcançar resultados mais exatos que nos cálculos manuais. No entanto, há limitações por não se encontrar a flexibilidade de personalizar os cálculos e direcioná-los exatamente àquilo que se deseja obter. Um exemplo é calcular Lâmbda e Mi (o App já pede esses valores definidos e não os calcula). Assim, recomenda-se o uso de softwares que possuem mais flexibilidade para a personalização de cálculos. 


\subsection{Considerações finais}

Os aplicativos para dispositivos móveis, em geral, não apresentam todas as respostas que desejamos. No entanto, nos servem para fornecimento das respostas mais comuns que, tendo conhecimento da teoria, é possível realizar o cálculo dos parâmetros desejados, não apresentados pelos Apps.

Além dos aplicativos que nos auxiliam nos cálculos para as filas, outros Apps se propõem a organizar as filas com emissões de senhas e chamadas aos boxes de atendimento, como o App EZ Turns. Apesar de não serem mostradas as taxas de chegada e os atendimentos realizados na tela principal, alguns Apps desse tipo podem gerar relatórios com as informações de Lambda e Mi colhidas ao longo do dia, bem como indicar o intervalo de pico de atendimentos, as pessoas atendidas e as que desistiram (senhas que foram emitidas, mas não atendidas). Tais dados coletados desde a emissão da senha até a finalização do atendimento servem como indicadores para um possível reajuste do nível de serviço, seja aumentando-o quando dos horários de pico ou reduzindo-o nos horários em que comumente há ociosidade dos funcionários.

Assim, uma serventia secundária para essas informações da dinâmica do atendimento, colhidas pelo App, é a de indicar aos gerentes os dias do mês e faixa de horários que seriam mais propícios para que funcionários se ausentem do trabalho (marquem exames médicos ou odontológicos, por exemplo). Essas horas de ausência podem ser colocadas no banco de horas para compensação nos dias ou horários em que é necessária a presença de mais funcionários no atendimento, colaborando com a elevação do Nível de Serviço pontual, sem incidir no pagamento de horas extras. Em outras palavras seria um rebalanceamento do atendimento nos guichês voltado para viabilizar uma possível flexibilidade de horário de trabalho aos funcionários, dando-lhes maior qualidade de vida, aumentando o nível de serviço pontual no estabelecimento sem comprometer o número de horas de trabalho previstas no contrato (uso do banco de horas).

Os Apps de acompanhamento de filas à distância, como o Filho Sem Fila (Escola e Transporte Escolar), também podem ter uma serventia secundária. É comum observarmos aglomerações de carros de pais parados ao longo da via, aguardando seus filhos saírem da escola gerando congestionamento no trânsito daquela rua.

O Manual de Sinalização de Áreas Escolares, do Departamento Nacional de Trânsito (DNIT), (www.viasseguras.com/content/download/879/.../Sinalização\%20Areas\%20Escolares.pdf), nos traz que é necessário fazer uma avaliação diagnóstica na interferência do desempenho do tráfego por ser a escola um pólo gerador de tráfego. A serventia secundária está no fato que esses Apps proporcionam um efeito mitigador dos impactos no tráfego e a sua adoção poderia colaborar positivamente no processo para a consecução do alvará de instalação da escola que não tenha área de estacionamento interno ou um recuo adequado para estacionamento dos veículos dos pais, comprovando a diminuição das interferências no trânsito local sem necessitar fazer obras. 


\section{PARTE B: Softwares}

Com o advento da tecnologia da informação e a evolução significativa das ferramentas computacionais, os estudos dos problemas de filas evoluíram para outro patamar, em que o principal quesito em um estudo é a capacidade analítica do pesquisador, passando pelas etapas de observar o problema, identificar as oportunidades, compreender a forma de aplicação das variáveis e analisar os resultados de maneira correta no objetivo de propor as soluções para o problema. Sendo assim, as etapas relacionadas ao desenvolvimento matemático ficam a cargo das ferramentas computacionais hoje existentes no mercado.

Em termos práticos, nem todo problema de filas exige a aplicação de ferramentas computacionais ou até mesmo um estudo elaborado por meio de teoria das filas. Grande parte dos problemas que nos deparamos no dia-a-dia apresentam modelagem simples, a qual a aplicação de cálculos estatísticos simples ou métodos empíricos são capazes de proporcionar noção adequada sobre onde atuar para resolver o problema, assim, o grande desafio desses casos está na proposição de soluções para o problema e não em sua identificação.

Um exemplo disso ocorre nas filas em caixas de atendimento ou pagamento de determinados bens e serviços. Ainda que o problema seja declarado e sua solução óbvia por meio da ampliação da capacidade de atendimento $(\mu)$, a viabilidade econômica entra como um fator preponderante na decisão de resolver ou não o problema. Sendo assim, o mercado apresenta ferramentas computacionais por meio de soluções integradas que auxiliam não somente na modelagem do problema, mas também na organização das filas e velocidade do atendimento, atuando em $\lambda$ e $\mu$, respectivamente.

Por outro lado, há problemas que extrapolam o nível de complexidade habitual, tornando impraticável o emprego de métodos empíricos ou até mesmo as ferramentas computacionais mais simples. Nesses casos, é comum observarmos a utilização de softwares de simulação como método de modelagem e estudo do problema. No segmento de transportes, é comum o emprego deste tipo de ferramentas, principalmente, em estudos de capacidade de transporte de um determinado modal, em que há diversas variáveis, externas e internas, que possam afetar a maneira como o sistema se comporta.

Nos tópicos a seguir, serão tratadas algumas ferramentas computacionais capazes de auxiliar os profissionais dedicados ao estudo das filas:

\section{QTSPLUS SOFTWARE}

O Qtsplus é uma ferramenta desenvolvida em plataforma Excel, distribuída gratuitamente pelos autores D. Gross, J. F. Shortle, J. M. Thompson, and C. M. Harris, em seu livro, Fundamentals of Queueing Theory, Fourth Edition - Appendix E.

A ferramenta apresenta sua organização dividida em 8 categorias para escolha do modelo de filas desejado, por exemplo, se o modelo é relacionado a um sistema de canal único ou multicanal. Com base nesta escolha, um novo menu é exibido para opções específica do modelo, descritos conforme a notação de Kendall. 
Ao realizar a seleção do modelo, uma nova tela é exibida com explicações e instruções para aplicação das necessidades de solução, na qual há campos específicos para inserção dos parâmetros pretendidos pelo usuário, com geração automática dos cálculos realizados pela ferramenta.

O link do software para download da ferramenta (em língua inglesa) é o seguinte: https://onlinelibrary.wiley.com/doi/pdf/10.1002/9781118625651.app5.

\section{Queueing Theory Software Plus Toolbox 3.0 (c) 2000-2008. All rights reserved.}

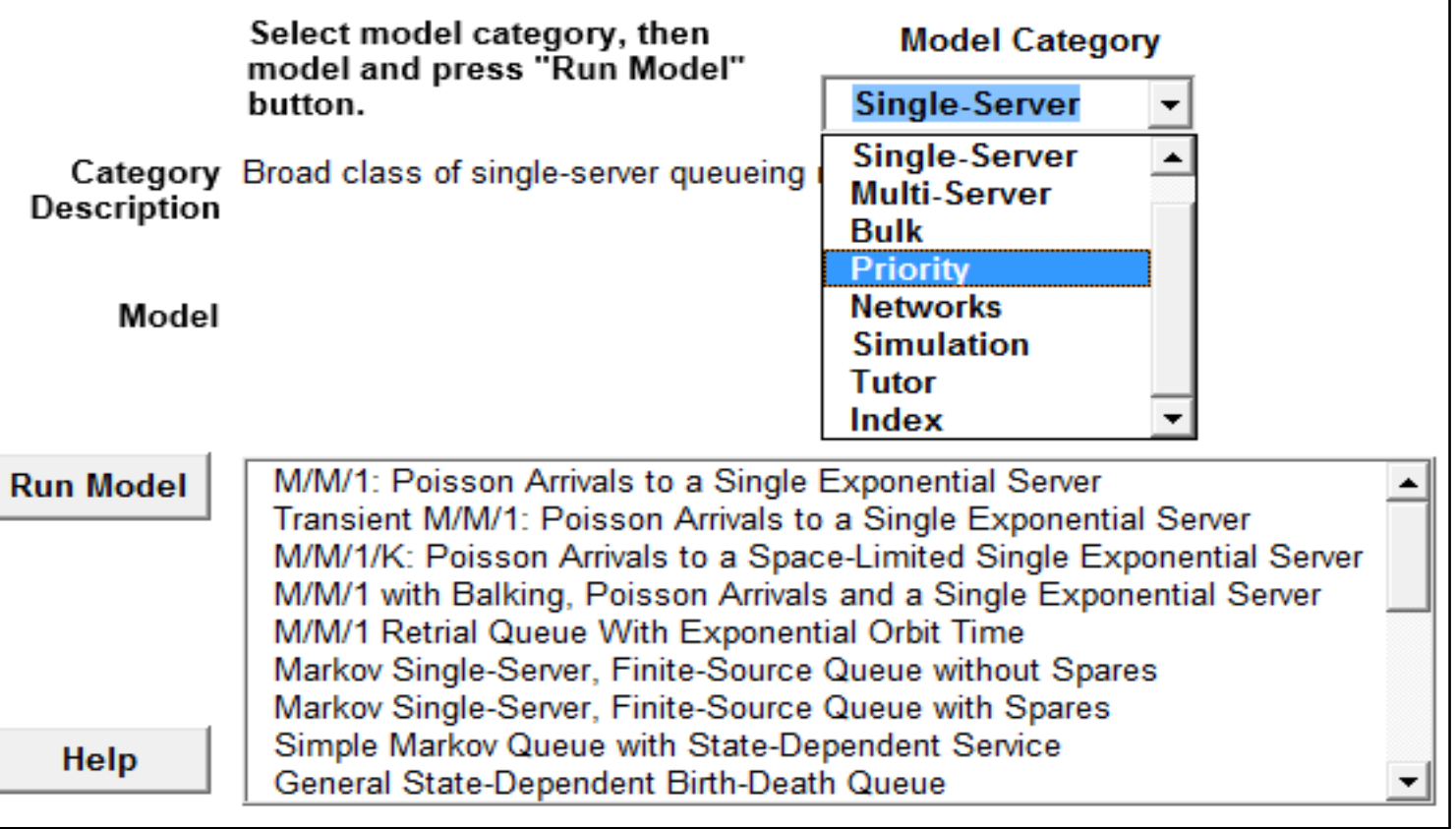

Figura 4.19. Tela inicial do QTSPLUS SOFTWARE.

\section{FIFO - Fila Fácil Online}

Atualmente o mercado também oferece ferramentas com soluções integradas para ordenamento de filas e acompanhamento e controle do desempenho do atendimento, de maneira que auxilie a unidade de serviço a estudar e otimizar suas filas. É o caso da ferramenta Fila Fácil Online ou FIFO, acrônimo referente ao regime de filas Firt In First Out.

Fornecida pela empresa FCA TECNOLOGIA, a ferramenta oferece, por meio de quatro módulos, softwares e hardwares capazes de gerenciar, organizar, acompanhar e analisar as filas e o desempenho dos atendimento. Apesar de apresentar uma versão grátis, mais limitada, há planos com incremental de custos à medida que o cliente solicita mais robustez e funcionalidades ao sistema.

A solução, assim como outras similares no mercado, apresenta-se como opção adequada para os casos em que o estudo do problema não apresenta alta complexidade e, muitas vezes, pode ser identificada de maneira empírica, ao passo que não é necessário conhecimento profundo em teoria das filas ou que exija participação de profissionais especializados para atuação permanente no gerenciamento do problema. Mais informações sobre esta ferramenta podem ser obtidas, em língua portuguesa, em: http://fcatec.com/fifo/. 


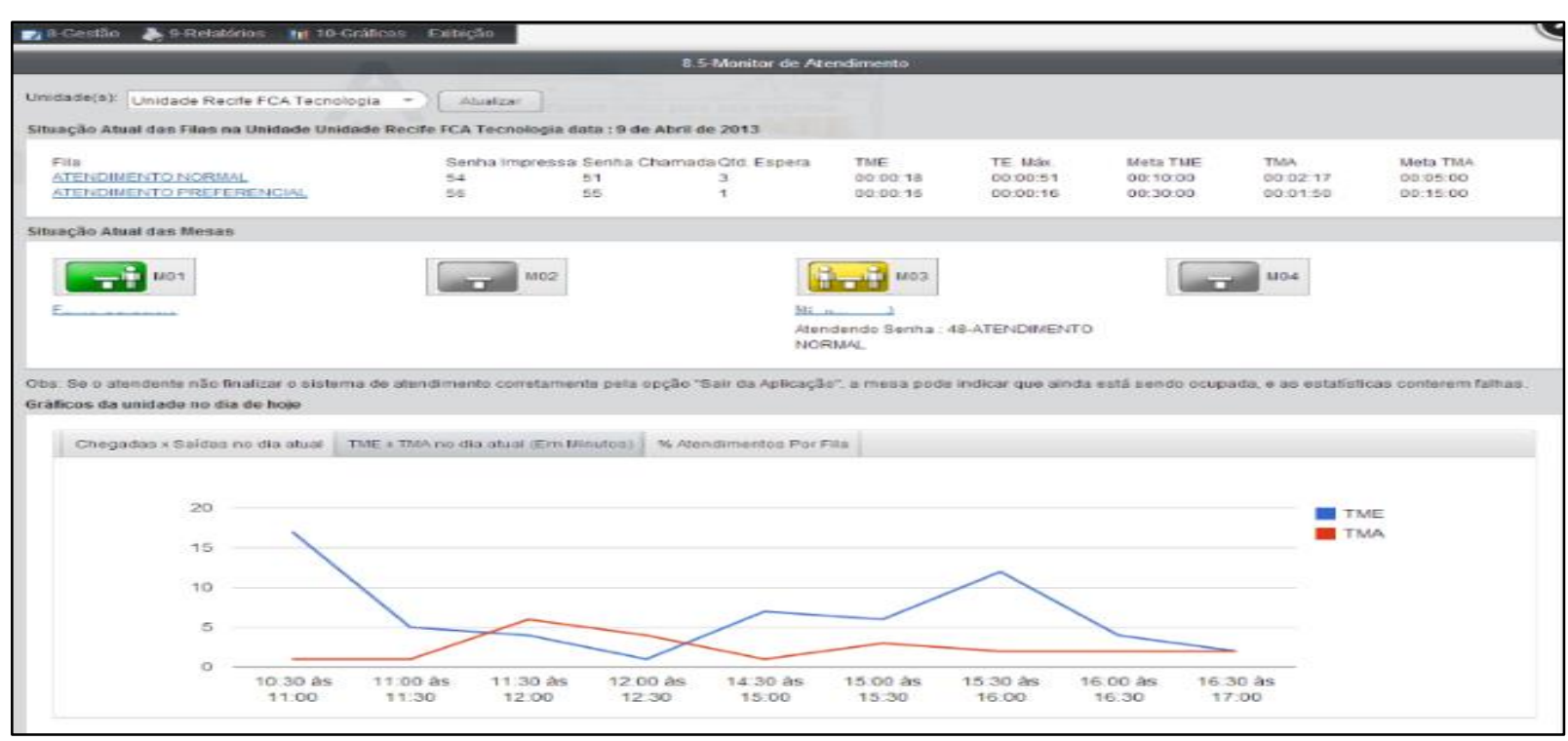

Figura 4.20. Módulo Gerenciamento do software FIFO.

\section{SGA LIVRE - Sistema de Gerenciamento do Atendimento}

Como objetivo similar ao software FIFO, já apresentado, existem outros softwares que permitem gerenciar filas e fluxo de atendimento em quaisquer tipos de empresas, como é o caso do SGA LIVRE. Essa aplicação foi desenvolvida inicialmente para a plataforma Linux, com código fonte aberto, sendo distribuída online gratuitamente pelo governo brasileiro por intermédio do Ministério do Planejamento, Desenvolvimento e Gestão.

A ferramenta exige conhecimento mais aprofundado em computação e, por ser gratuita, não apresenta suporte além dos manuais disponíveis no portal do Software Público Brasileiro, onde também é possível realizar o download da ferramenta em língua portuguesa, disponível em: https://softwarepublico.gov.br/social/sga-livre.

\section{ARENA Simulação}

Em determinados casos, a utilização de softwares baseados apenas teoria das filas podem oferecer limitação no estudo dos problemas;, assim, as ferramentas de simulação apresentam-se como opções indicadas para situações de alta complexidade, ainda que sua utilização apresente necessidade de conhecimentos específicos em modelagem estatística e programação.

Mais comum em grandes empresas de logística e transportes, a simulação computacional é largamente indicada à sistemas complexos, com vários canais e unidades de atendimento, mais de uma distribuição de probabilidade na dinâmica de chegadas e atendimento, variações no regime de fila, interferências de variáveis internas e externas que possam influir diretamente nos resultados modelados matematicamente.

Nesse contexto, o software de simulação ARENA, distribuído pela empresa PARAGON, apresenta-se atualmente como umas das ferramentas mais utilizadas no mundo para modelagem de sistemas complexos. Além da versão paga, existe outra, gratuita, oferecida para fins acadêmicos. Mais informações sobre a ferramenta e suas versões estão disponíveis, em língua portuguesa, no portal da Paragon: https://www.paragon.com.br/lancamento-arena-16/. 


\section{Capítulo CINCO}

e a distribuição de probabilidades modelo dos dados coletados

NEWTON CARLOS DE OLIVEIRA PORTELLA PAULO AFONSO LOPES DA SILVA

Normalmente, os livros de Teoria das Filas apresentam os modelos para diversos tipos de distribuições de probabilidades para os dados de chegada e de atendimento, mas não explicam como identificar tais distribuições. Neste capítulo, serão apresentados os passos necessários para se determinar a taxa de chegada $\lambda$ e a taxa de atendimento $\mu$.

Para tanto, primeiramente, deve-se estudar o ambiente onde otimizar o desempenho das filas para conhecer o horário de funcionamento do meio de transporte, o número de canais de atendimento (manuais ou por máquinas) e período de coleta. Pode ocorrer o caso em que haja tanto o atendimento manual quando o automático, notadamente em aeroportos, quando a atendente das companhias aéreas verifica a identidade do passageiro, o qual, logo após, coloca o seu bilhete na leitora do código de barras para ter acesso à aeronave.

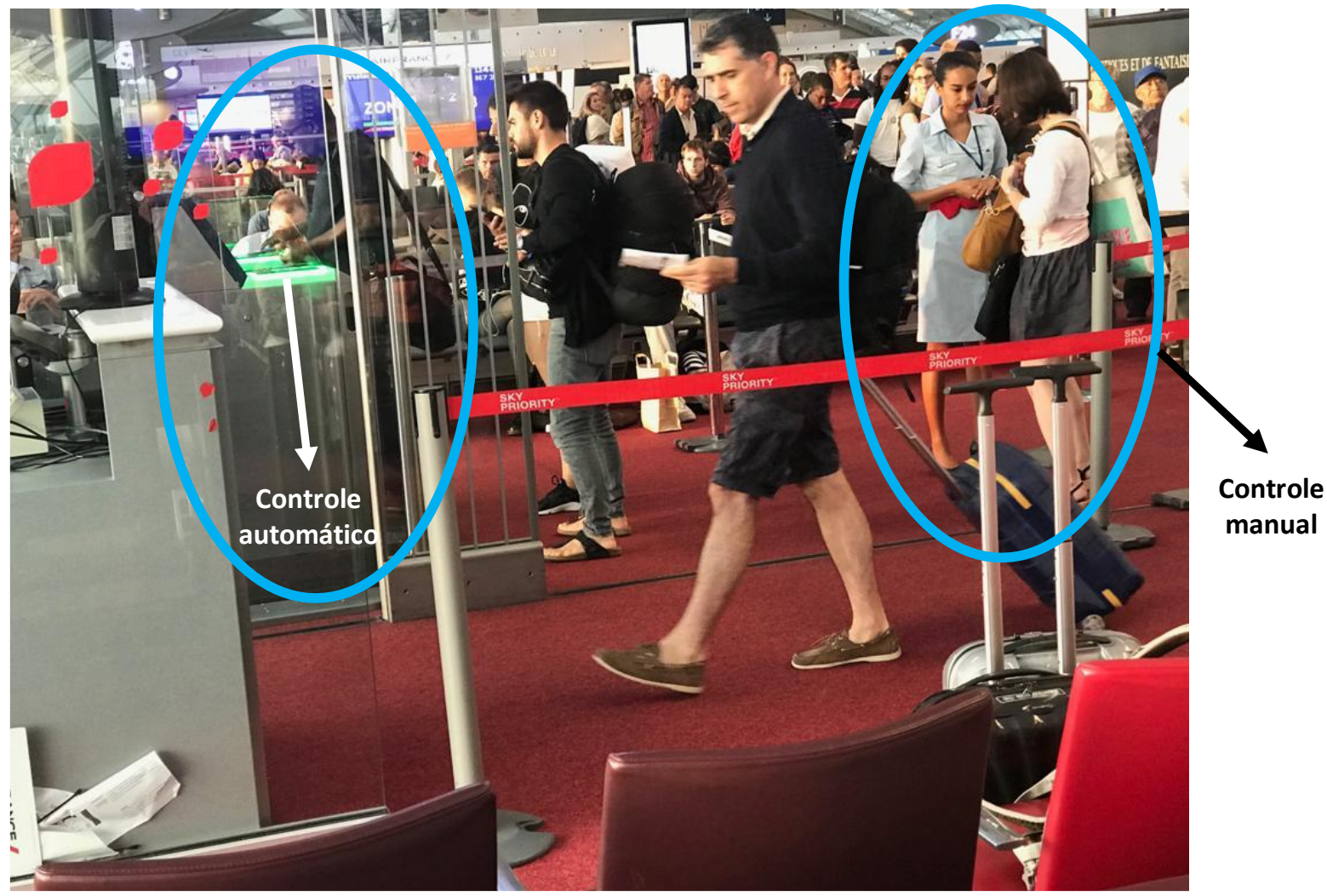

Figura 5.1 Atendimentos manual e automático. 


\subsection{Determinação $\lambda$, a taxa de chegada.}

\section{PASSO 1. Obtenção dos dados de chegada.}

Anotar, em papel ou em um dispositivo móvel, no período de tempo da coleta, o número de ocorrências do que se observa nas chegadas ao sistema (por exemplo, pessoas em um guichê de compra de passagens ou no acesso a um meio de transporte, bem como veículos aproximando-se de um posto de pedágio), transferindo essas informações para uma planilha. Essa é demanda do sistema de filas, ou seja, a chegada de passageiros que, na maioria das vezes ocorre de maneira aleatória e também independentemente uma da outra.

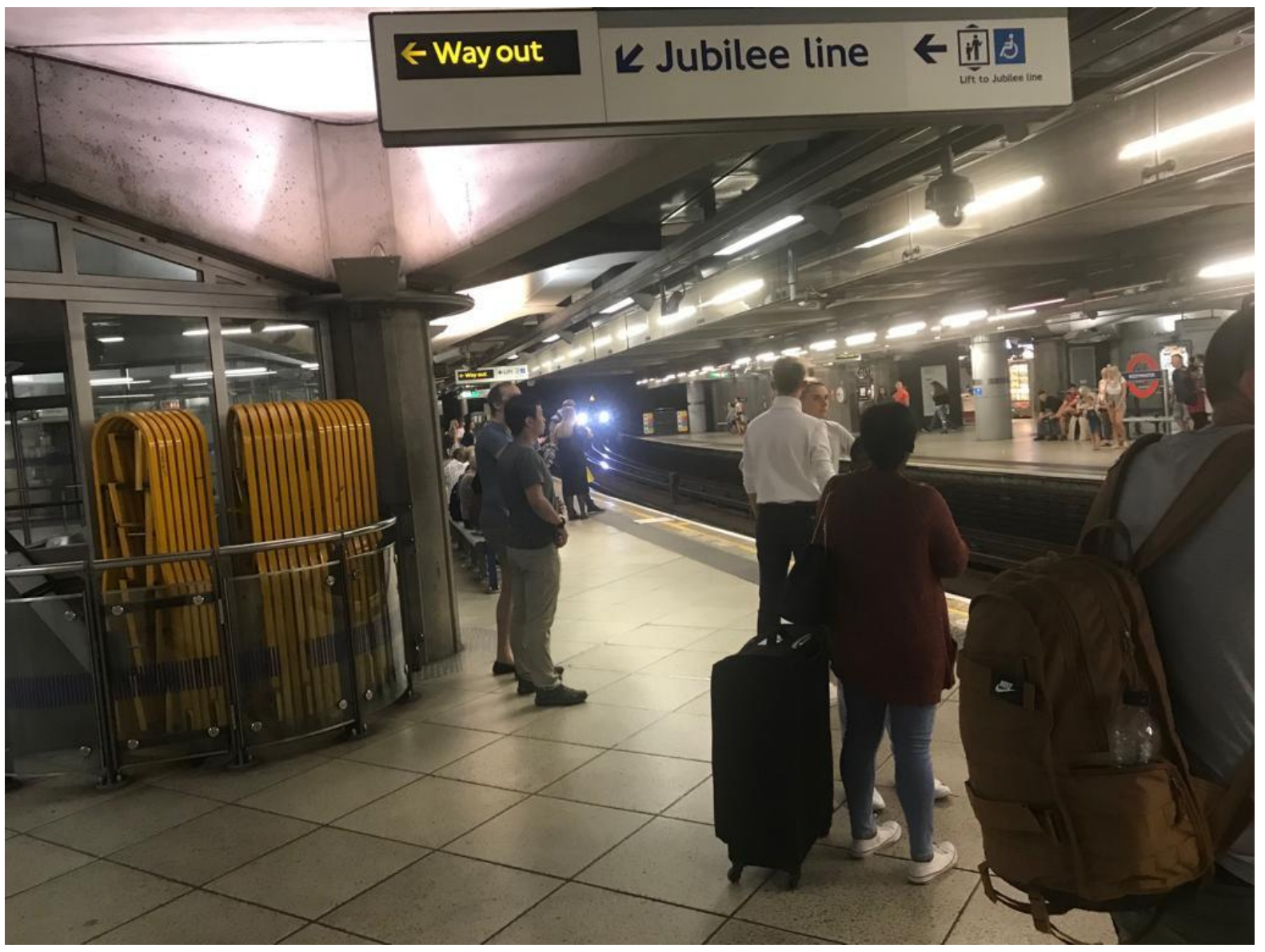

Figura 5.2 Nas estações de metrô, as chegadas são aleatórias e independentes.

Exemplo 5.1: em um meio de transporte de passageiros, considere-se uma coleta realizada no ambiente de embarque, antes da formação da fila, durante 12 horas, das $8 \mathrm{~h}$ às $18 \mathrm{~h}$, em intervalos de $10 \mathrm{~min}$, sendo anotados os números de chegadas de passageiros em um ponto de venda de passagens, resultando em 72 blocos de observações (em uma hora, há 6 blocos de 10 minutos; em $12 \mathrm{~h}$, tem-se $6 \times 12=72$ desses blocos). Parte do resultado dessa coleta está na Tabela 5.1. 
Tabela 5.1. Levantamento inicial dos dados de chegada

\begin{tabular}{|c|c|c|c|}
\hline$\Delta$ & A & B & C \\
\hline 1 & BLOCO & Horário & NÚMERO DE PASSAGEIROS CHEGANDO \\
\hline 2 & 1 & 10hoomin:10h10min & 2 \\
\hline 3 & 2 & 10h10min:10h20min & 1 \\
\hline 4 & 3 & 10h20min:10h30min & 4 \\
\hline 5 & $\ldots$ & $\ldots$ & $\ldots$ \\
\hline 6 & 70 & 17h30min:17h40min & 1 \\
\hline 7 & 71 & 17h40min:17h50min & 3 \\
\hline 8 & 72 & 17h50min:18hoomin & 0 \\
\hline 9 & & Total & 264 passageiros em 12 horas \\
\hline 10 & & & \\
\hline
\end{tabular}

\section{PASSO 2. Determinação da taxa de chegada.}

A partir da Tabela 5.1, constrói-se a tabela com a frequência absoluta de passageiros nos 10 minutos de observação, Tabela 5.2.

Tabela 5.2. frequência absoluta de passageiros

\begin{tabular}{|c|c|}
\hline E & F \\
\hline NÚMERO DE PASSAGEIROS CHEGANDO em 10 min & Frequência absoluta \\
\hline 0 & 125 \\
\hline 1 & 93 \\
\hline 2 & 34 \\
\hline 3 & 10 \\
\hline 4 & 2 \\
\hline Total & 264 \\
\hline &
\end{tabular}

A partir da Tabela 5.2, pode-se calcular a taxa de chegadas a cada 10 min por meio da média aritmética ponderada do número de passageiros:

$0 \times 125+1 \times 93+2 \times 34+3 \times 10+4 \times 2) / 264=0,753788$ passageiros por $10 \mathrm{~min}$.

Pode-se aproximar $\lambda$ para 0,75 passageiro/10min. ou seja, 4,5passageiros/hora.

Esse cálculo da média aritmética ponderada é feito pelos seguintes passos, ilustrados na Figura 5.3com base na Tabela 5.2.

- Passo 1: na célula G2, digitar "=E2*G2" (sem as aspas), selecioná-la e arrastar até a célula G7.

- Passo 2: na célula G7, digitar "=SOMA(G2:G6) e dar "Enter" para obter o numerador da média ponderada.

- Passo 3: na célula G8, digitar "=G7/F7 e dar "Enter" para obter o valor da taxa de chegada. 


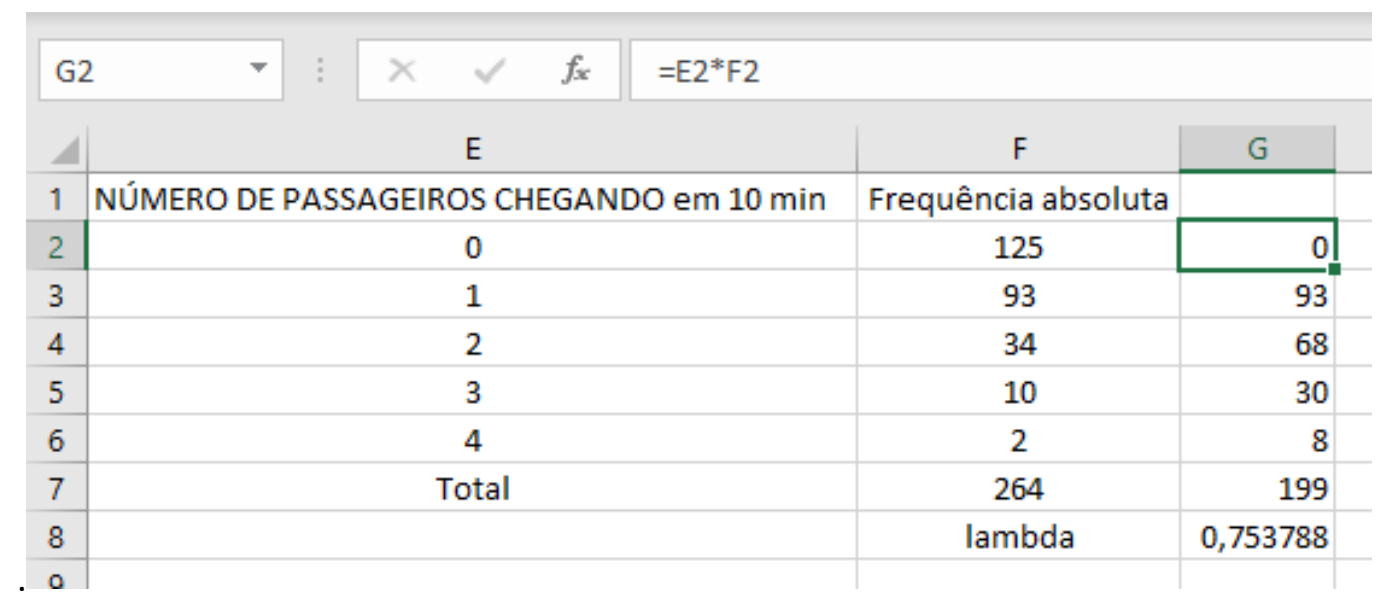

Figura 5.3. Cálculo da média aritmética ponderada

\section{PASSO 3. Identificação da distribuição de probabilidade da taxa de chegada}

Para verificar qual a distribuição de probabilidades é o modelo estatístico dos dados de chegada, utiliza-se o teste de distribuição livre (não paramétrico) do qui-quadrado, que tem a seguinte estatística:

$$
\chi_{\text {calculado }}^{2}=\sum_{i=1}^{n} \frac{\left(O_{i}-E_{i}\right)^{2}}{E_{i}}
$$

na qual $O_{i}$ é o valor observado do número de chegadas i durante o período de coleta, e $E_{i}$ é o valor esperado desse número se o valor observado provir da distribuição que pode ser o modelo estatístico dos dados coletados.

Antigamente, fazia-se manualmente esse teste; hoje, usa-se um aplicativo computacional ${ }^{6}$ que indica a distribuição de probabilidades. Antes do advento dos computadores, identificar o modelo estatístico era por tentativa e erro.

Nos casos comuns da Teoria das Filas, admite-se que a distribuição da taxa de chegada é de Poisson, discreta, para a determinação dos valores esperados de chegada. No Exemplo 5.1, é

apresentado o passo a passo desse procedimento para que se conheça a teoria em que se baseiam os programas computacionais.

Exemplo 5.1 (continuação): se os dados de chegada podem ter como modelo a distribuição discreta de Poisson com média 0,75passageitos/10min, determinam-se os valores esperados para o número de passageiros $0,1,2,3$ e 4, para os quais já se tem os valores observados, conforme a Tabela 5.2 .

Esse valor esperado pode ser determinado manualmente, usando-se a fórmula da distribuição de Poisson,

${ }^{6}$ O Anexo 1 apresenta o aplicativo computacional ARENA. 


$$
\operatorname{Pr}(x \text { chegadas })=\frac{e^{-\lambda} \cdot \lambda^{x}}{x !}
$$

e multiplicando-se a probabilidade de sua ocorrência pelo total de chegadas, ou seja:

$E_{i}=\frac{e^{-\lambda} \cdot \lambda^{x}}{x !} x$ total de chegadas.

Para 0 chegada, tem-se:

$\mathrm{E}_{1}=\frac{e^{-0,75} \cdot 0,75^{x 0}}{0 !} \times 264$, e assim sucessivamente.

Usa-se o Excel para determinar essas probabilidades com o seguinte roteiro:

- Passo 1: escolher uma célula (o que a torna ativa) para colocar o resultado da probabilidade desejada.

- Passo 2: clicar duas vezes no ícone Inserir Função (Figura 5.4), abrindo-se a tela correspondente à da Figura 5.5.

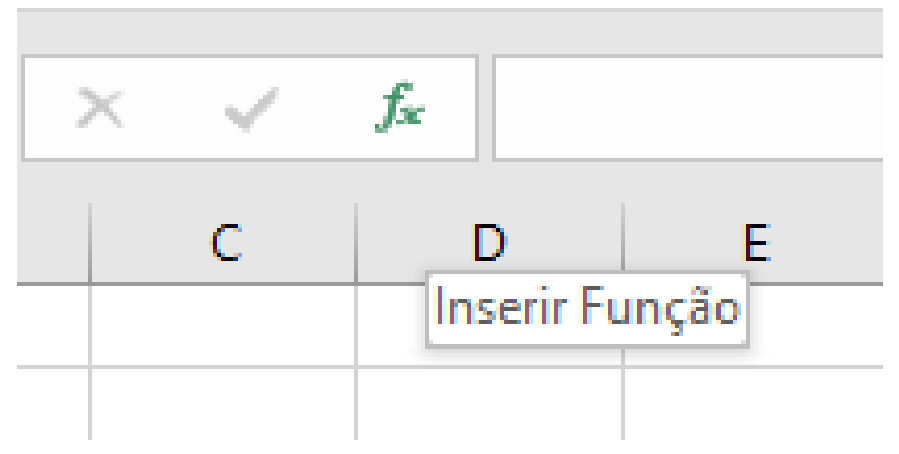

Figura 5.4. Inserir Função

\section{Inserir função \\ Procure por uma função: \\ Digite uma breve descrição do que deseja fazer e clique em 'Ir'}

Ou selecione uma categoria: Estatística

Figura 5.5. Selecionar categoria

- Passo 3: selecionar a categoria Estatística e, depois, DIST.POISSON (a qual deve ser encontrada acionando-se para baixo a barra de rolagem lateral) (Figura 5.6). Na parte inferior, dê um OK; surgindo a tela da Figura 5.7. 


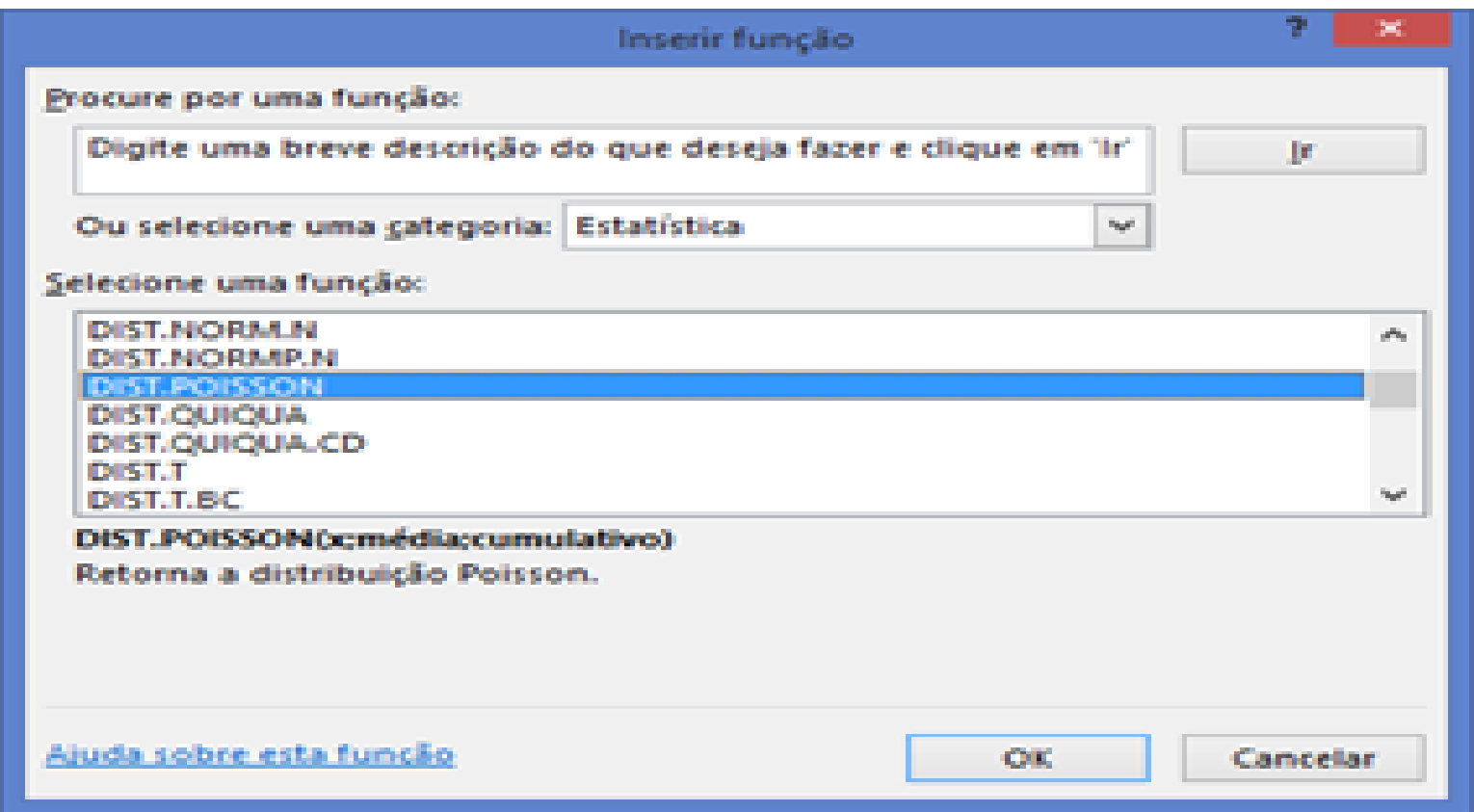

Figura 5.6. Tela inicial do Excel 365 para encontrar a distribuição de Poisson

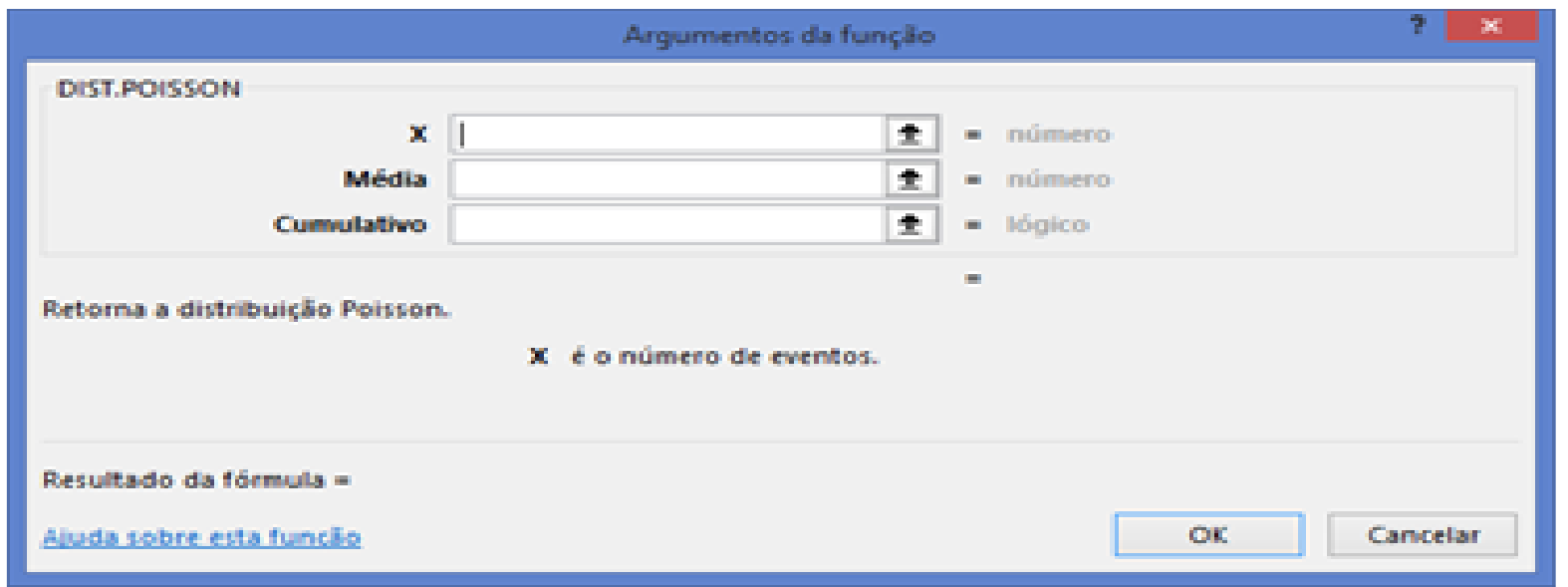

Figura 5.7. Tela inicial do Excel 365 para incluir os dados da distribuição de Poisson

- Passo 4: digitar, no retângulo com o rótulo X (agora com um traço vertical intermitente), o número de chegadas para o qual deseja saber a probabilidade, em Média, o valor de $\lambda$. e em Cumulativo, FALSO.

- Passo 5: clicar em OK; fecha-se a tela e a probabilidade de $X$ chegadas aparece na célula tornada ativa no Passo 1.

Para 0 chegada, a tela preenchida do Excel é a da Figura 5.8. 


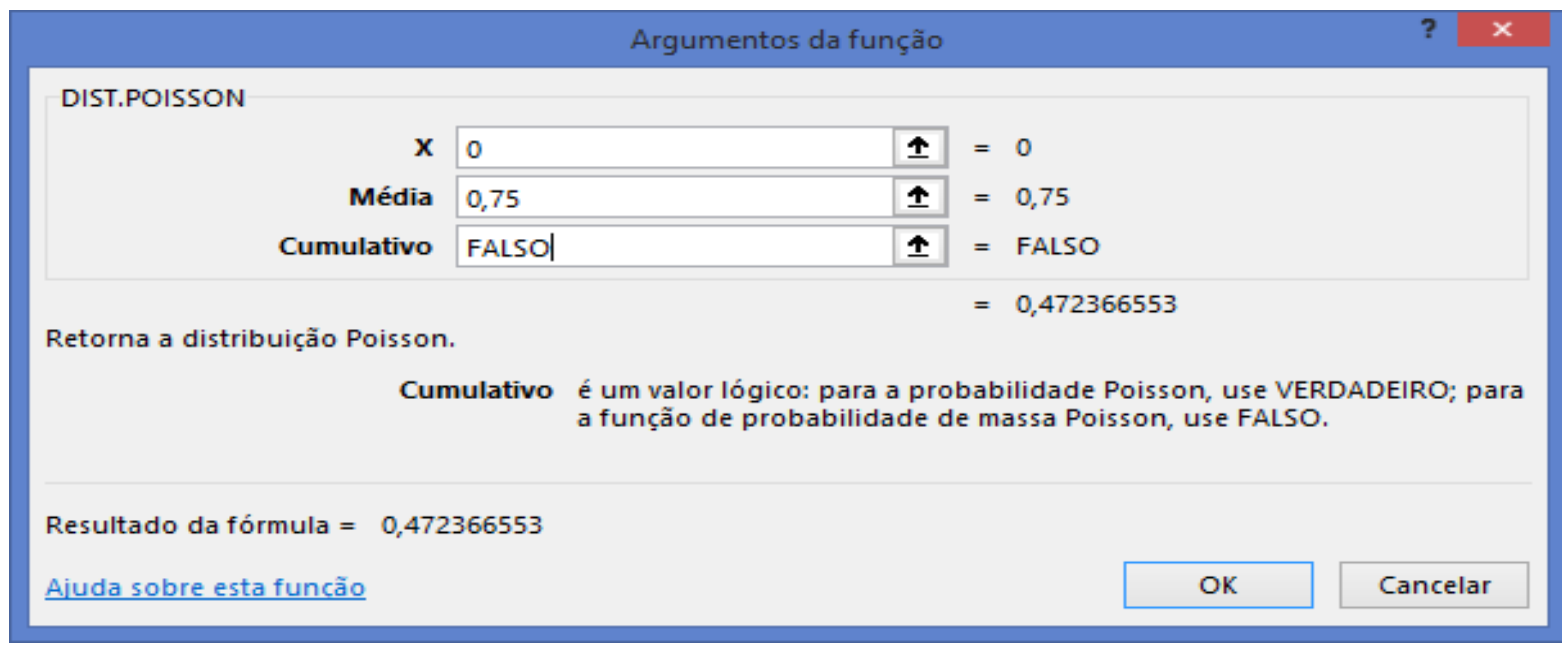

Figura 5.8. Tela do Excel 365 com os dados preenchidos para 0 chegada

O valor esperado de 0 chegada de passageiros é calculado da seguinte maneira;

$\mathrm{E}_{\mathrm{i}}=\operatorname{Pr}(0$ chegadas $) \times$ total de chegadas

$E_{1}=\operatorname{Pr}(0$ chegada $) \times 264=0,472366553 \times 264=124,7$

No Excel, calcula-se a frequência esperada de 0 chegada de passageiros da seguinte maneira: na Figura 5.9 e para o número de chegadas $X=0$, digita-se na célula $C 2$ o seguinte: "B2*264" (sem aspas) e dá-se um "Enter", obtendo-se a frequência esperada para $X=0$. Arrastar essa célula até o último valor de chegada para obter todas as demais frequências esperadas.

\begin{tabular}{|c|c|c|c|c|}
\hline $\mathrm{C} 2$ & $\vec{V}$ & $x$ & $\checkmark$ & $=\mathrm{B} 2 * 264$ \\
\hline$\Delta$ & A & & B & C \\
\hline 1 & Número de c & chegadas $\mathrm{X}$ & $\operatorname{Pr}(X=x)$ & Frequencia esperada de $\mathbf{X}$ \\
\hline 2 & 0 & & 0,472366553 & 124,7 \\
\hline 3 & 1 & & 0,354274915 & 93,5 \\
\hline 4 & 2 & & 0,132853093 & 35,1 \\
\hline 5 & 3 & & 0,033213273 & 8,8 \\
\hline 6 & 4 & & 0,006227489 & 1,6 \\
\hline 7 & & & & \\
\hline
\end{tabular}

Figura 5.9. Tela do Excel 365 para as frequências esperadas no número de chegadas

Finalmente, usando a Equação (5.1), tem-se o valor do qui-quadrado calculado. no EXCEL o resultado está na Tabela 5.3. 
FILAS: conceitos, novos enfoques de abordagem e aplicações em Transportes

\begin{tabular}{|c|c|c|c|}
\hline \multicolumn{4}{|c|}{ Tabela 5.3. Valor da estatística de teste qui-quadrado } \\
\hline \multicolumn{2}{|c|}{ Número de chegadas $X$ ) = Frequencia observadaa de } & $E=$ Frequencia esperada de $X$ & $\left((O-E)^{\wedge} 2 / E\right.$ \\
\hline 0 & 125 & 124,7 & 0,000698937 \\
\hline 1 & 93 & 93,5 & 0,002987259 \\
\hline 2 & 39 & 35,1 & 0,439641124 \\
\hline 3 & 10 & 8,8 & 0,173018029 \\
\hline \multirow[t]{2}{*}{4} & 2 & 1,6 & 0,077062656 \\
\hline & & Qui-quadrado calculado & 0,693408006 \\
\hline
\end{tabular}

Esse teste tem k - 1 graus de liberdade, onde k é o número de células com o número de chegadas na Tabela 3 e o nível de confiança é teórico, usualmente, 95\%. Para determinar o valor da abscissa limite da distribuição qui-quadrado no Excel, a função é a INV.QUIQUA. Nela, em Probabilidade, digita-se o nível de confiança e, em Graus_liberdade, o número de graus de liberdade, Figura 5.10.

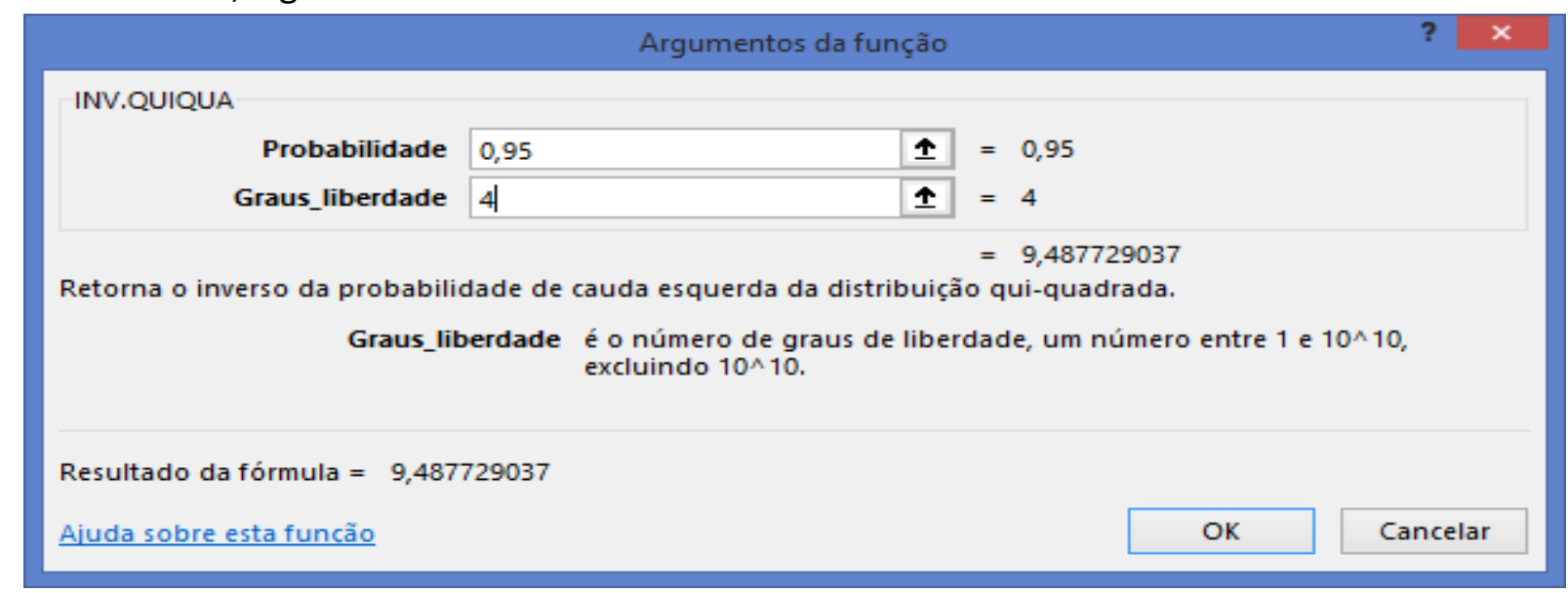

Figura 5.10. Tela do Excel 365 para determinar o valor da abscissa limite da distribuição qui-quadrado

Finalmente, compara-se o valor do qui-quadrado calculado com o valor da abscissa limite da distribuição qui-quadrado. Se o valor do qui-quadrado calculado for menor que o do limite teórico, então a distribuição de Poisson pode ser considerada como o modelo estatístico dos dados da taxa de chegada; se maior, deve-se prosseguir a busca.

Conclusão: como o valor do qui-quadrado calculado é 0,6934 , menor que o valor do qui-quadrado teórico limite, que é 9,4877299037, conclui-se, com 95\% de confiança, que a distribuição de Poisson é o modelo estatístico para a taxa de chegada.

\subsection{Determinação de $\mu$, a taxa de atendimento.}

Em alguns sistemas, os servidores não se apresentam claros, e conhecê-los é um dos desafios a resolver, porque podem ser um ponto de atendimento, como um quiosque de autoatendimento, pessoas que ajudam os passageiros a lidar com essas máquinas ou, em uma intersecção de vias, os semáforos (em que o período de atendimento é a duração dos sinais verde, amarelo e vermelho). 
FILAS: conceitos, novos enfoques de abordagem e aplicações em Transportes

\section{PASSO 1. Obtenção dos dados de atendimento.}

Exemplo 5.1 (continuação): realizado de modo semelhante ao levantamento dos dados de chegada, anotar, podendo ser em papel ou diretamente no dispositivo móvel, no período do tempo de coleta, os tempos em que um passageiro começou a ser atendido e em que esse mesmo deixa o servidor, transferindo essas informações para uma planilha.

A Tabela 5.4 apresenta os resultados das observações dos tempos de atendimento dos 264 passageiros que entraram no sistema, conforme a Tabela 5.1, essa referente à determinação da taxa de chegada. O tempo do atendimento é a diferença entre o tempo em que foi completado e o tempo de seu início. Quando um servidor estiver ocupado (sem ter que esperar a chegada de um passageiro), o tempo inicial do próximo é a cópia do tempo em que foi completada a tarefa do último passageiro; na Tabela 5.4, o servidor está ocupado do passageiro 2 até o passageiro 5 .

Tabela 5.4. Observações dos tempos de atendimento

\begin{tabular}{|c|c|c|c|}
\hline A & B & C & $\mathrm{D}$ \\
\hline $\begin{array}{c}\text { Número de identificação } \\
\text { do passageiro }\end{array}$ & Início do atendimento & Término do atendimento & Tempo do serviço \\
\hline 1 & $08 \mathrm{~h} 01 \mathrm{~min} 32 \mathrm{~s}$ & $08 \mathrm{~h} 02 \mathrm{~min} 45 \mathrm{~s}$ & $1 \min 13 s$ \\
\hline 2 & 08h05min03s & $08 \mathrm{h06min} 42 \mathrm{~s}$ & $1 \mathrm{~min} 39 \mathrm{~s}$ \\
\hline 3 & $08 \mathrm{h06min} 42 \mathrm{~s}$ & $08 \mathrm{~h} 08 \mathrm{~min} 27 \mathrm{~s}$ & $1 \mathrm{~min} 55 \mathrm{~s}$ \\
\hline 4 & $08 \mathrm{~h} 08 \mathrm{~min} 27 \mathrm{~s}$ & 08h9min $10 \mathrm{~s}$ & Omin43s \\
\hline 5 & 08h9min $10 \mathrm{~s}$ & 08h10min45s & $1 \mathrm{~min} 35 \mathrm{~s}$ \\
\hline$\ldots$ & $\ldots$ & $\ldots$ & $\ldots$ \\
\hline 262 & 17h45min $32 \mathrm{~s}$ & 17h46mino3s & Omin31s \\
\hline 263 & 17h46min03s & $08 \mathrm{~h} 48 \mathrm{~min} 12 \mathrm{~s}$ & $2 \min 9 s$ \\
\hline 264 & 17h52min32s & 17h53min59s & $1 \mathrm{~min} 27 \mathrm{~s}$ \\
\hline
\end{tabular}

\section{PASSO 2. Determinação da taxa de atendimento.}

A partir da última coluna da Tabela 5.4, determina-se o tempo médio do atendimento, ou seja, a média aritmética de todos os 264 tempos de atendimento. Nesse exemplo, $\mu=1 \mathrm{~min} 4,8 \mathrm{~s}$, ou seja, 1,08min. vide Tabela 5.5 .

Tabela 5.5. Determinação dos tempos de atendimento

\begin{tabular}{|c|c|c|c|c|}
\hline 4 & A & B & $C$ & D \\
\hline 1 & $\begin{array}{c}\text { Número de identificação } \\
\text { do passageiro }\end{array}$ & $\begin{array}{l}\text { Início do } \\
\text { atendimento }\end{array}$ & $\begin{array}{l}\text { Término do } \\
\text { atendimento }\end{array}$ & $\begin{array}{l}\text { Tempo do } \\
\text { atendimento }\end{array}$ \\
\hline 2 & 1 & $08 \mathrm{~h} 01 \mathrm{~min} 32 \mathrm{~s}$ & $08 \mathrm{h0} 2 \mathrm{~min} 45 \mathrm{~s}$ & $1 \mathrm{~min} 13 \mathrm{~s}$ \\
\hline 3 & 2 & 08h05min03s & $08 \mathrm{h06min} 42 \mathrm{~s}$ & $1 \mathrm{~min} 39 \mathrm{~s}$ \\
\hline 4 & 3 & $08 \mathrm{h06min} 42 \mathrm{~s}$ & $08 \mathrm{h08min} 27 \mathrm{~s}$ & $1 \mathrm{~min} 55 \mathrm{~s}$ \\
\hline 5 & 4 & $08 \mathrm{h08min} 27 \mathrm{~s}$ & 08h9min 10 s & Omin $43 \mathrm{~s}$ \\
\hline 6 & 5 & 08h9min $10 \mathrm{~s}$ & 08h10min45s & $1 \mathrm{~min} 35 \mathrm{~s}$ \\
\hline 7 & $\ldots$ & $\ldots$ & $\ldots$ & \\
\hline 266 & 262 & $17 \mathrm{~h} 45 \mathrm{~min} 32 \mathrm{~s}$ & $17 \mathrm{~h} 46 \mathrm{~min} 03 \mathrm{~s}$ & Omin31s \\
\hline 267 & 263 & 17h46min03s & $08 \mathrm{~h} 48 \mathrm{~min} 12 \mathrm{~s}$ & 2 min9s \\
\hline 268 & 264 & 17h52min $32 \mathrm{~s}$ & 17h53min59s & $1 \mathrm{~min} 27 \mathrm{~s}$ \\
\hline 269 & & & Média & $1 \mathrm{~min} 4,8 \mathrm{~s}$ \\
\hline
\end{tabular}

Esse cálculo da média pode ser feito no Excel, da seguinte maneira: na célula D269, digitar “=MÉDIA(D2:D268)" (sem as aspas) e dar "Enter” para obter o valor da taxa de atendimento. 
PASSO 3. Identificação da distribuição de probabilidade da taxa de atendimento

Para verificar qual a distribuição de probabilidades é o modelo estatístico dos dados de atendimento, utiliza-se o teste de distribuição livre (não paramétrico) do qui-quadrado, que tem a seguinte estatística:

$$
\chi_{\text {calculado }}^{2}=\sum_{i=1}^{n} \frac{\left(O_{i}-E_{i}\right)^{2}}{E_{i}}
$$

na qual $O_{i}$ é o valor observado do número de atendimentos no intervalo i, e $E_{i}$ é o valor esperado desse número se o valor observado provém da distribuição que pode ser o modelo estatístico dos dados coletados.

Antigamente, fazia-se manualmente esse teste; hoje, usa-se um aplicativo computacional que indica a distribuição de probabilidades. Antes do advento dos computadores, identificar o modelo estatístico era por tentativa e erro.

Para a listagem dos valores observados e determinação dos valores esperados dos atendimentos pelos tempos de atendimento, também, a partir da última coluna da Tabela 5.5, gera-se a Tabela 5.6, listando-se os tempos de atendimento de 0,5 em 0,5 min e as suas frequências de ocorrências.

Tabela 5.6. Frequência dos tempos de atendimento de 0,5 em 0,5 min

\begin{tabular}{|c|c|c|}
\hline Tempo de serviço (em min) & Ponto médio do intervalo & Frequencia absoluta de passageiros \\
\hline $0 \mid--0,25$ & 0,0 & 0 \\
\hline $0,25 \mid--0,75$ & 0,5 & 122 \\
\hline $0,75 \mid--1,25$ & 1,0 & 64 \\
\hline $1,25 \mid--1,75$ & 1,5 & 36 \\
\hline $1,75 \mid-2,25$ & 2,0 & 19 \\
\hline $2,25 \mid--2,75$ & 2,5 & 10 \\
\hline $2,75 \mid--3,25$ & 3,0 & 5 \\
\hline $3,25 \mid--3,75$ & 3,5 & 3 \\
\hline $3,75 \mid--4,25$ & 4,0 & 2 \\
\hline $4,25 \mid-4,75$ & 4,5 & 1 \\
\hline $4,75 \mid--5,25$ & 5,0 & 1 \\
\hline $5,25 \mid--5,75$ & 5,5 & 0 \\
\hline $5,75 \mid--6,25$ & 6,0 & 1 \\
\hline & Total & $\mathbf{2 6 4}$ \\
\hline
\end{tabular}

Nos casos comuns da Teoria das Filas, admite-se que a distribuição da taxa de atendimento é a exponencial, contínua, para a determinação dos valores esperados dos atendimentos. No Exemplo 5.1, é apresentado o passo a passo desse procedimento para que se conheça a teoria em que se baseiam os programas computacionais. 
Exemplo 5.1 (continuação): se os dados de atendimento podem ter como modelo a distribuição (contínua) exponencial, cuja média é 1,08min, para se verificar a adequabilidade dele por meio de intervalos, o uso de frequências absolutas acumuladas é mais rápido, ao invés de se determinar diretamente as probabilidades associadas aos intervalos. Por essa razão, vai-se listar as frequências acumuladas observadas (Tabela 5.7) e determinar as esperadas.

Tabela 5.7. Frequências acumuladas observadas

\begin{tabular}{|c|c|c|}
\hline $\begin{array}{c}\text { Ponto médio do intervalo } \\
\text { do tempo de serviço }\end{array}$ & Frequencia absoluta de passageiros & $\begin{array}{c}\text { Frequencia absoluta acumulada } \\
\text { observada de passageiros }\end{array}$ \\
\hline 0,0 & 0 & 0 \\
\hline 0,5 & 122 & 122 \\
\hline 1,0 & 64 & 186 \\
\hline 1,5 & 36 & 222 \\
\hline 2,0 & 19 & 241 \\
\hline 3,5 & 10 & 251 \\
\hline 3,5 & 5 & 256 \\
\hline 4,0 & 3 & 259 \\
\hline 4,5 & 2 & 261 \\
\hline 5,0 & 1 & 262 \\
\hline 5,5 & 1 & 263 \\
\hline 6,0 & 0 & 263 \\
\hline Total & 1 & 264 \\
\hline
\end{tabular}

Para determinar as frequências acumuladas esperadas, deve-se usar o Excel com os seguintes passos:

- Passo 1: escolher uma célula (o que a torna ativa) para colocar o resultado da frequência acumulada esperada.

- Passo 2: clicar duas vezes no ícone Inserir Função e selecionar a categoria Estatística.

- $\quad$ Passo 3: seleciona DISTR.EXPON , Figura 5.11.

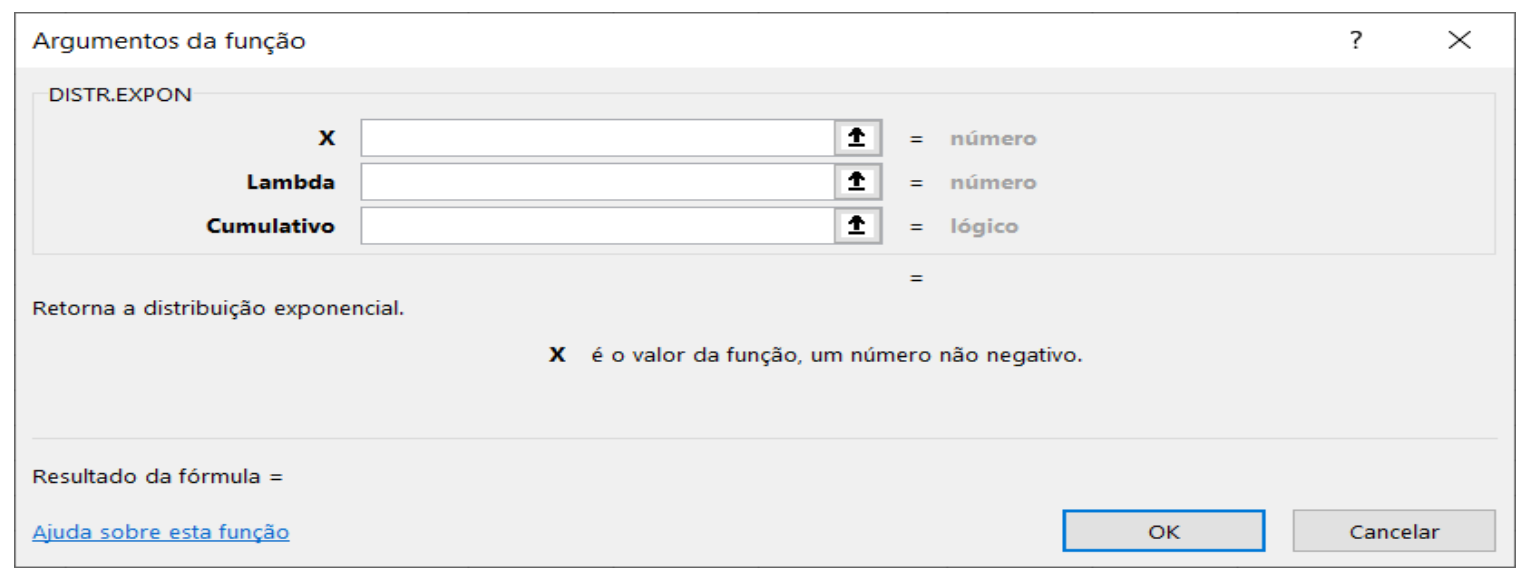

Figura 5.11. Tela inicial do Excel 365 para a distribuição exponencial 
Para o Exemplo 5.1, a tela preenchida para o SEGUNDO intervalo é:

- Passo 4: digite, no retângulo com o rótulo $\mathbf{X}$ (agora com um traço vertical intermitente), o valor do ponto médio do intervalo para o qual deseja saber as frequências acumuladas esperadas, ou seja, 0,5; em Média, o valor de $\mu$, no caso 1,08 e em Cumulativo, VERDADEIRO., Figura 5.12.

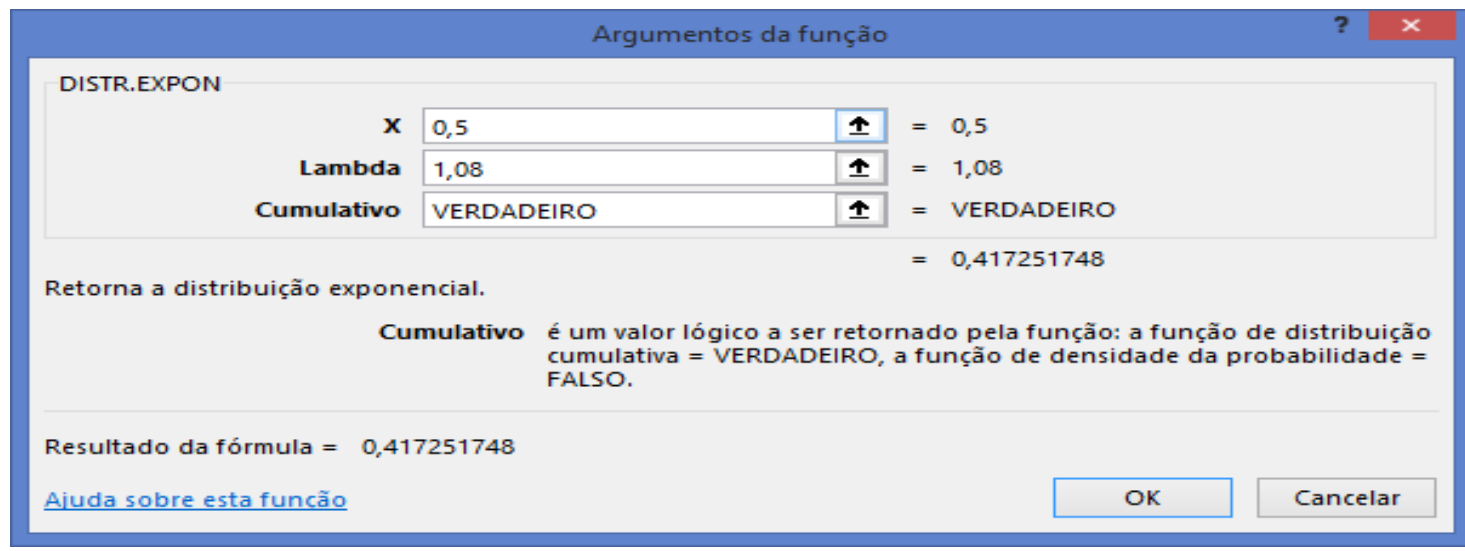

Figura 5.12. Tela inicial do Excel 365 com os dados preenchidos para a distribuição exponencial

- Passo 5: clique em OK; fecha-se a tela e a probabilidade de até $\mathrm{X}$ minutos de atendimento aparece na célula tornada ativa na letra a).

- Passo 6: na coluna seguinte, digite "=", "rótulo da célula do Passo 4)" e multiplique pelo total das frequências absolutas, resultando na Tabela 5.8 .

Tabela 5.8. Frequências acumuladas

\begin{tabular}{|c|c|c|c|c|c|c|c|}
\hline L3 & & - & $\times \vee f_{x}$ & $=$ DISTR.EXPON(G3;1,08;VERDA & DEIRO)*\$H\$15 & & \\
\hline$\Delta$ & E & & $\mathrm{F}$ & G & H & $\mathrm{k}$ & $\mathrm{L}$ \\
\hline 1 & & Tem & o de serviço (em min) & $\begin{array}{l}\text { 1) Ponto médio do intervalo } \\
\text { do tempo de serviço }\end{array}$ & Frequencia absoluta de passageiros & $\begin{array}{l}\text { Frequencia absoluta acumulada } \\
\text { observada de passageiros }\end{array}$ & $\begin{array}{l}\text { Frequencia absoluta acumulada } \\
\text { esperada de passageiros }\end{array}$ \\
\hline 2 & & & $0 \mid-0,25$ & 0,0 & 0 & 0 & 0,00 \\
\hline 3 & & & $0,25 \mid-0,75$ & 0,5 & 122 & 122 & 110,15 \\
\hline 4 & & & $0,75 \mid-1,25$ & 1,0 & 64 & 186 & 174,35 \\
\hline 5 & & & $1,25 \mid-1,75$ & 1,5 & 36 & 222 & 211,75 \\
\hline 6 & & & $1,75 \mid-2,25$ & 2,0 & 19 & 241 & 233,55 \\
\hline 7 & & & $2,25 \mid-2,75$ & 2,5 & 10 & 251 & 246,26 \\
\hline 8 & & & $2,75 \mid--3,25$ & 3,0 & 5 & 256 & 253,66 \\
\hline 9 & & & $3,25 \mid--3,75$ & 3,5 & 3 & 259 & 257,97 \\
\hline 10 & & & $3,75 \mid--4,25$ & 4,0 & 2 & 261 & 260,49 \\
\hline 11 & & & $4,25 \mid--4,75$ & 4,5 & 1 & 262 & 261,95 \\
\hline 12 & & & $4,75 \mid--5,25$ & 5,0 & 1 & 263 & 262,81 \\
\hline 13 & & & $5,25 \mid-5,75$ & 5,5 & 0 & 263 & 263,31 \\
\hline 14 & & & $5,75 \mid--6,25$ & 6,0 & 1 & 264 & 263,60 \\
\hline 15 & & & & Total & 264 & & \\
\hline
\end{tabular}

A frequência absoluta esperada acumulada até o tempo de serviço 0,5 é calculado da seguinte maneira a partir da expressão "=DISTR.EXPON(G3;1,08;VERDADEIRO)*\$H\$15"

$E_{i}=\operatorname{Pr}$ (tempo de atendimento até 0,5$) \times$ total de chegadas

$E_{1}=\operatorname{Pr}($ tempo de atendimento até 0,5) $\times 264=0,41725 \times 264=110,15$

Finalmente, usando a Equação (5.1), tem-se o valor do qui-quadrado calculado, que pode ser feito no Excel, resultando na Tabela 5.9. 
Tabela 5.9. Determinação do valor da estatística de teste.

\begin{tabular}{|c|c|c|c|c|c|}
\hline Tempo de serviço (em min) & $\begin{array}{l}\text { Ponto médio do intervalo } \\
\text { do tempo de serviço }\end{array}$ & $\begin{array}{l}\text { Frequencia de } \\
\text { passageiros }\end{array}$ & $\begin{array}{l}\text { Frequencia acumulada } \\
\text { observada de passageiros }\end{array}$ & $\begin{array}{l}\text { Frequencia acumulada esperada } \\
\text { de passageiros }\end{array}$ & $(O-E)^{\wedge} 2 / E$ \\
\hline $0 \mid-0,25$ & 0,0 & 0 & 0 & 0 & 0 \\
\hline $0,25 \mid--0,75$ & 0,5 & 122 & 122 & 110,1544614 & 1,273818451 \\
\hline $0,75 \mid--1,25$ & 1,0 & 64 & 186 & 174,3467812 & 0,778893116 \\
\hline $1,25 \mid--1,75$ & 1,5 & 36 & 222 & 211,7547434 & 0,495692707 \\
\hline $1,75 \mid--2,25$ & 2,0 & 19 & 241 & 233,554168 & 0,23737711 \\
\hline $2,25 \mid--2,75$ & 2,5 & 10 & 251 & 246,2577446 & 0,091322959 \\
\hline $2,75 \mid--3,25$ & 3,0 & 5 & 256 & 253,6607317 & 0,021572816 \\
\hline $3,25 \mid--3,75$ & 3,5 & 3 & 259 & 257,9748095 & 0,004074102 \\
\hline $3,75 \mid--4,25$ & 4,0 & 2 & 261 & 260,4888307 & 0,001003091 \\
\hline $4,25 \mid--4,75$ & 4,5 & 1 & 262 & 261,9538723 & $8,12269 \mathrm{E}-06$ \\
\hline $4,75 \mid--5,25$ & 5,0 & 1 & 263 & 262,8076226 & 0,000140822 \\
\hline $5,25 \mid--5,75$ & 5,5 & 0 & 263 & 263,3051442 & 0,000353631 \\
\hline \multirow[t]{2}{*}{$5,75 \mid--6,25$} & 6,0 & 1 & 264 & 263,595074 & 0,000622034 \\
\hline & $x_{0}$ & 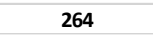 & & qui-quadradocalc & 2,904878961 \\
\hline
\end{tabular}

Esse teste de aderência tem $\mathrm{k}-1$ graus de liberdade, onde $\mathrm{k}$ é o número de células com o número de atendimentos na tabela e o nível de confiança é teórico, usualmente, 95\%.

No Excel, a função é a INV.QUIQUA e, nela, em Probabilidade, digita-se o nível de confiança e em Graus_liberdade, o número de graus de liberdade. Neste Exemplo 5.1, o número de graus de liberdade é 13-1=12 (porque há 13 intervalos de 0,5 minuto), Figura 5.13.

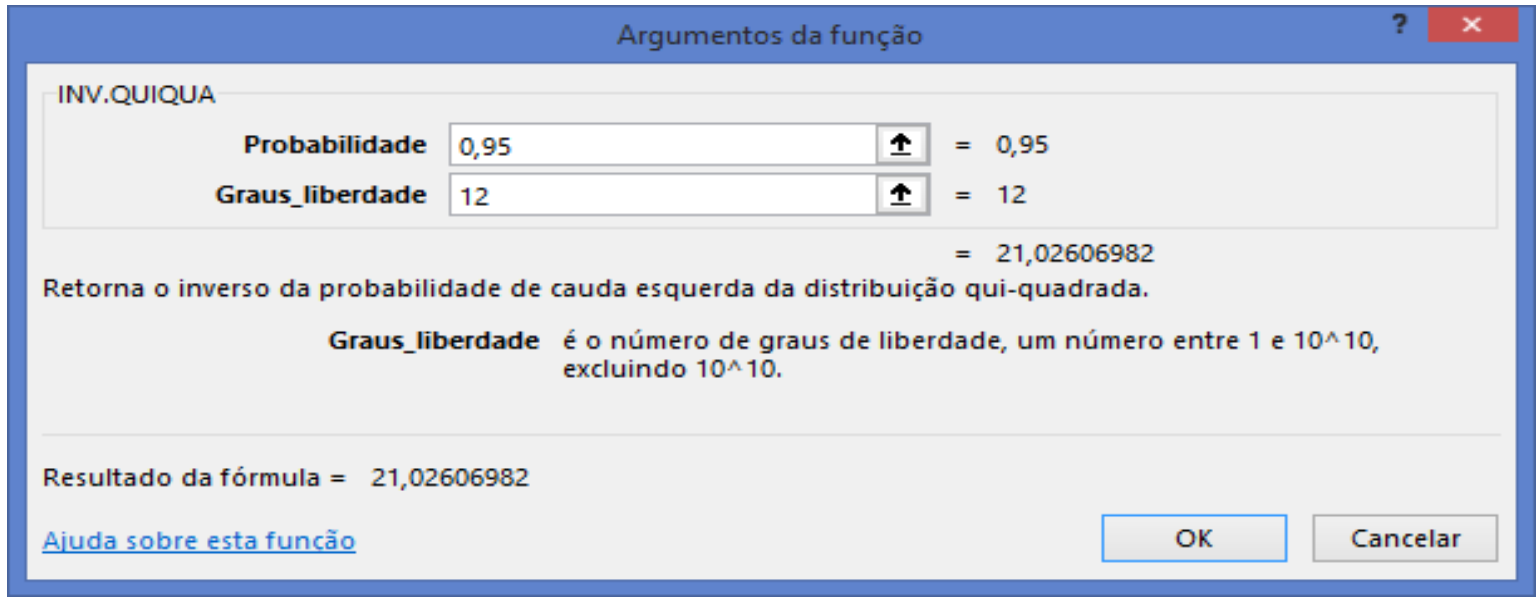

Figura 5.13. Tela do Excel 365 com os dados para determinar o limite teórico

Finalmente, compara-se o valor do qui-quadrado calculado com o valor do qui-quadrado teórico.

Se o valor do qui-quadrado calculado for menor que o do limite teórico, então a distribuição de Poisson pode ser considerada como o modelo estatístico dos dados da taxa de atendimento; se maior, deve-se prosseguir a busca.

Conclusão: como o valor do qui-quadrado calculado é 0,6934 , menor que o valor do quiquadrado teórico limite, que é 9,4877299037, conclui-se, com 95\% de confiança, que a distribuição de Poisson é o modelo estatístico para a taxa de atendimento. 


\subsection{Uso de softwares}

Normalmente, os livros relativos à Teoria das Filas apresentam os modelos para diversos tipos de distribuições de probabilidades para os dados de entrada e de atendimento, mas não indicam como identificar tais distribuições.

Entretanto, isso pode ser feito por intermédio de aplicativos computacionais, que identificam o melhor modelo para os dados coletados. Uma relação de cinco softwares é a seguinte:

1. Pelo ARENA: o tutorial se encontra no Anexo 1.

2. EASYFIT: http://www.mathwave.com/easyfit-distribution-fitting.html, que pode ser testado por 30 dias.

3. XLSTAT: https://www.xlstat.com/en/solutions/features/distribution-fitting, que pode ser testado por 14 dias.

4. ExpertFit: http://www.averill-law.com/distribution-fitting/request-an-expertfit-demo/, que pode ter baixada uma versão Demo, mas que necessita fazer um cadastro no site.

5. MINITAB: pode testar 14 distribuições de probabilidade e duas transformações de uma só vez. O melhor modelo é o que tem o maior $p$-valor.

Os resultados apresentados por dois desses softwares são os seguintes:

a) MINITAB:

Na Figura 5.14, o melhor modelo é a distribuição de Weibull com 3 parâmetros e, em seguida, a lognormal.

\begin{tabular}{|c|c|c|c|}
\hline Distribution & $\mathrm{AD}$ & P & LRT $\mathrm{F}$ \\
\hline Normal & 1.197 & $<0.005$ & \\
\hline Box-Cox Transformation & 0.406 & 0.345 & \\
\hline Lognormal & 0.406 & 0.345 & \\
\hline 3-Parameter Lognormal & 0.331 & * & 0.486 \\
\hline Exponential & 24.618 & $<0.003$ & \\
\hline 2-Parameter Exponential & 6.100 & $<0.010$ & 0.000 \\
\hline Weibull & 1.466 & $<0.010$ & \\
\hline 3-Parameter Weibull & 0.303 & $>0.500$ & 0.000 \\
\hline Smallest Extreme Value & 2.954 & $<0.010$ & \\
\hline Largest Extreme Value & 0.321 & $>0.250$ & \\
\hline Gamma & 0.594 & 0.135 & \\
\hline 3-Parameter Gamma & 0.308 & * & 0.097 \\
\hline Logistic & 1.106 & $<0.005$ & \\
\hline Loglogistic & 0.513 & 0.153 & \\
\hline 3-Parameter Loglogistic & 0.393 & * & 0.303 \\
\hline Johnson Transformation & 0.268 & 0.677 & \\
\hline
\end{tabular}

Figura 5.14. Tela do Minitab com os resultados das distribuições mais apropriadas

Após identificar a distribuição, precisa-se encontrar os valores dos parâmetros, que o Minitab também fornece, ver Figura 5.15. 
FILAS: conceitos, novos enfoques de abordagem e aplicações em Transportes

\begin{tabular}{|c|c|c|c|c|}
\hline Distribution & Location & Shape & Scale & Threshold \\
\hline Normal * & 28.56522 & & 6.98923 & \\
\hline Box-Cox Transformation* & 3.32317 & & 0.24188 & \\
\hline Lognormal* & 3.32317 & & 0.24188 & \\
\hline 3-Parameter Lognormal & 3.04855 & & 0.31575 & 6.41648 \\
\hline Exponential & & & 28.56522 & \\
\hline 2-Parameter Exponential & & & 11.89449 & 16.67071 \\
\hline Weibull & & 4.35553 & 31.31946 & \\
\hline 3-Parameter Weibull & & 1.85718 & 14.07043 & 16.06038 \\
\hline Smallest Extreme Value & 32.19748 & & 7.29878 & \\
\hline Largest Extreme Value & 25.28363 & & 5.72752 & \\
\hline Gamma & & 17.39341 & 1.64230 & \\
\hline 3-Parameter Gamma & & 5.10385 & 3.13720 & 12.55290 \\
\hline Logistic & 28.05381 & & 4.04055 & \\
\hline Loglogistic & 3.31872 & & 0.14150 & \\
\hline 3-Parameter Loglogistic & 2.86738 & & 0.22260 & 9.80521 \\
\hline Johnson Transformation* & 0.04555 & & 0.97553 & \\
\hline
\end{tabular}

Figura 5.15. Tela do Minitab com os parâmetros das distribuições mais apropriadas

b) EASYFIT:

Seja a distribuição da chegadas de navios no Porto de Santos no ano de 1968, Tabela 5.10, retirada do livro Pesquisa Operacional e Transportes, de Antônio Galvão Novaes, editora McGraw-Hill, página 13.

Tabela 5.10 Chegadas de navios no Porto de Santos no ano de 1968

\begin{tabular}{cc}
\hline Navios por dia & Frequência \\
\hline 0 & 11 \\
1 & 37 \\
2 & 69 \\
3 & 78 \\
4 & 68 \\
5 & 56 \\
6 & 21 \\
7 & 15 \\
8 & 3 \\
9 & 3 \\
10 & 2 \\
11 & 1 \\
12 & 1 \\
mais de 12 & 0 \\
\hline Soma & 365 \\
\hline
\end{tabular}

Após a entrada de dados, o software Easyfit nos informa o melhor tipo de distribuição que se ajusta aos dados coletados. Neste caso, a distribuição é a de Johnson SB (Figura 5.16), uma família de distribuições de probabilidade de quatro parâmetros, deduzida por N. L. Johnson in 19497 .

\footnotetext{
7 Johnson, N. L. (1949). Systems of Frequency Curves Generated by Methods of Translation. Biometrika. 36 (1/2): 149-176. doi:10.2307/2332539. JSTOR 2332539.
} 


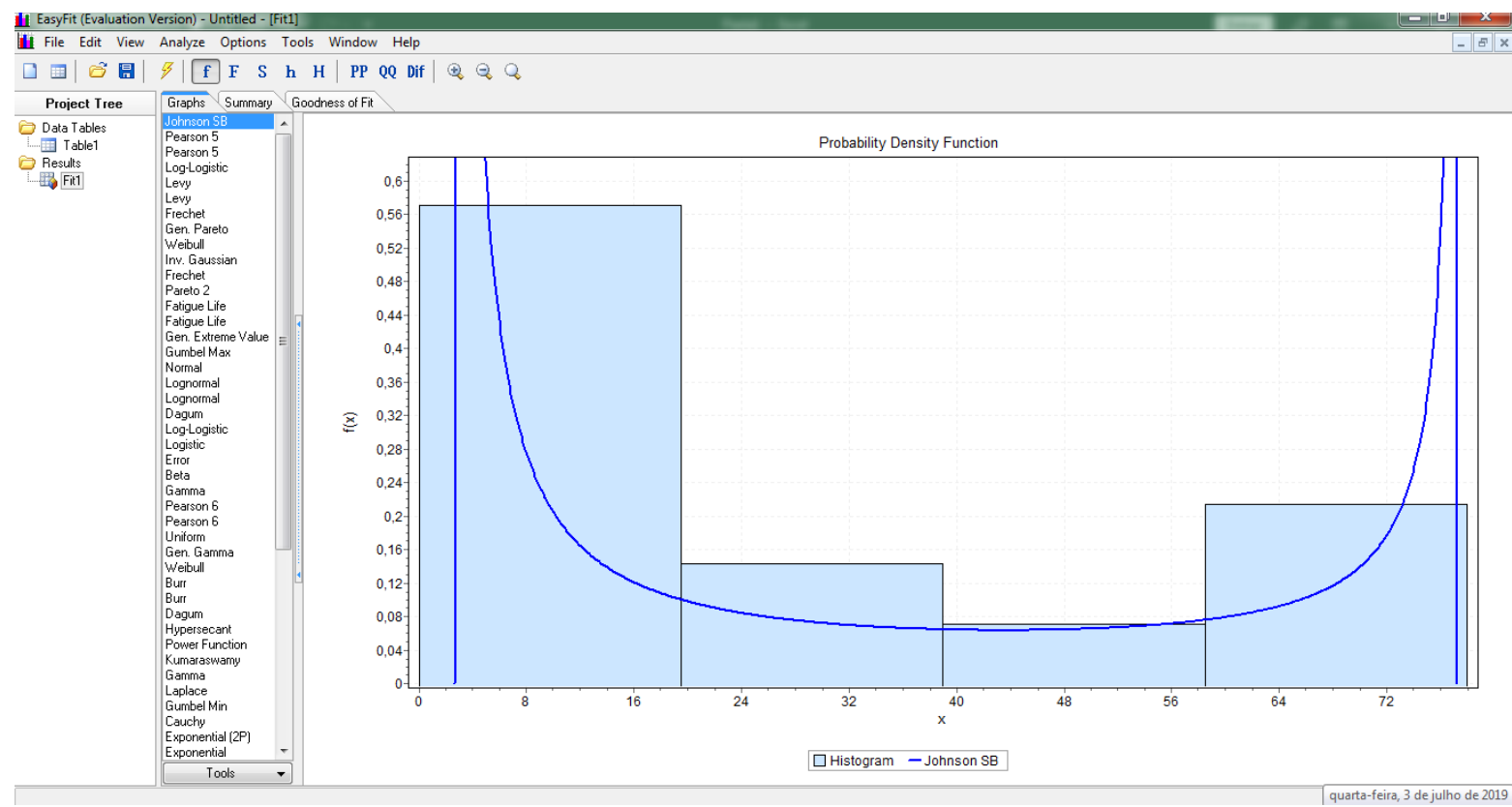

Figura 5.16. Distribuições identificadas pelo Easyfit.

Os seguintes testes de aderência são feitos e ordenados pelo Easyfit: Kolmogorov-Smirnov, Anderson Darling e Qui-quadrado, Figura 5.17.

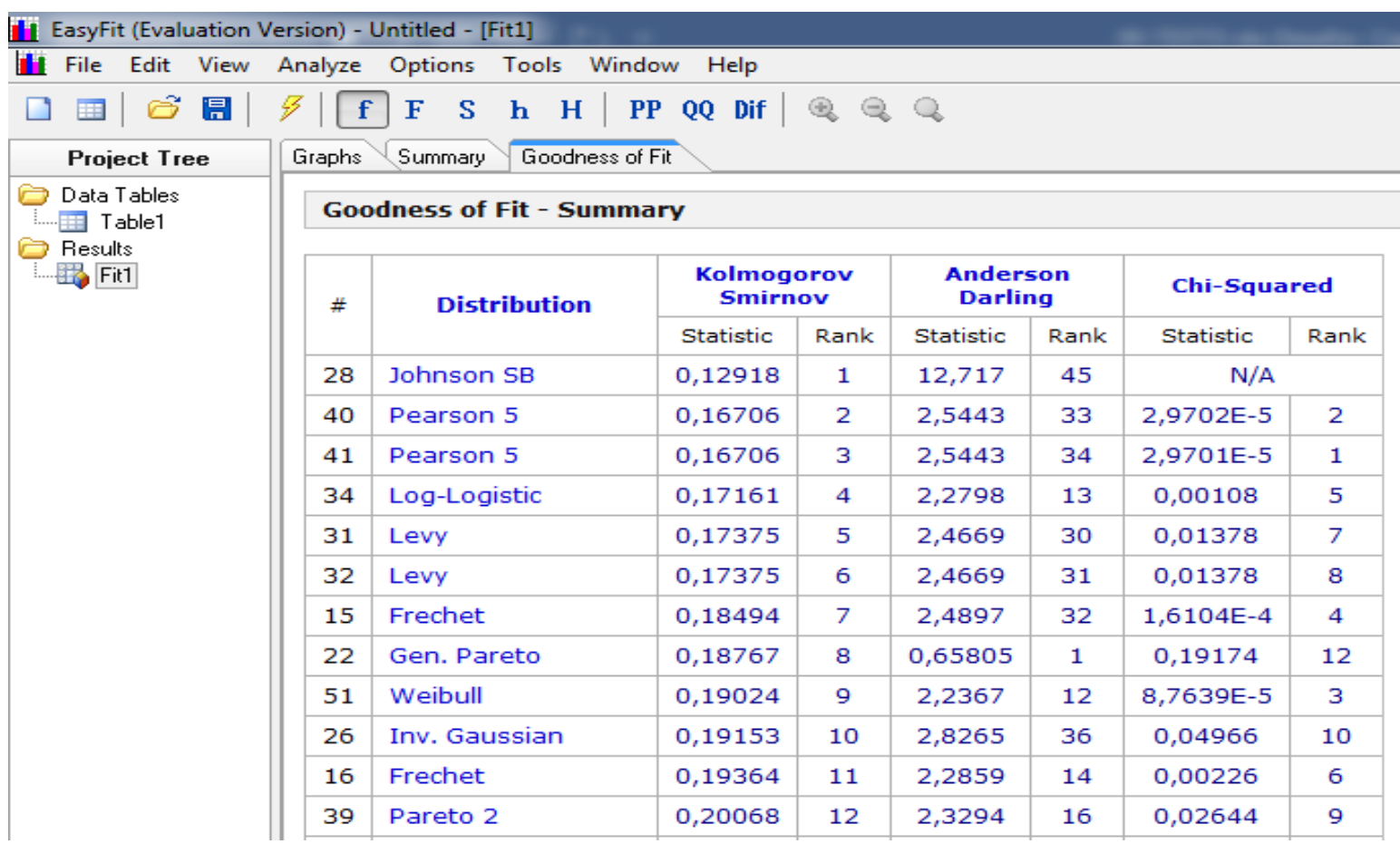

Figura 5.17. Distribuições ordenadas pelo Easyfit.

O software Easyfit também informa os parâmetros para cada tipo de distribuição, conforme a Figura 5.18 , onde os da distribuição Jonhson SB estão destacados. 


\begin{tabular}{|c|c|c|c|}
\hline Hille Edit View & Analyze & Tools Windo & Help \\
\hline$\square$ 四|四 & 3 & $\mathbf{H} \mid \mathbf{P P}$ & QQ Dif $\Leftrightarrow \Leftrightarrow$ \\
\hline Project Tree & Graphs & Goodness of $F$ & \\
\hline \multirow{14}{*}{ 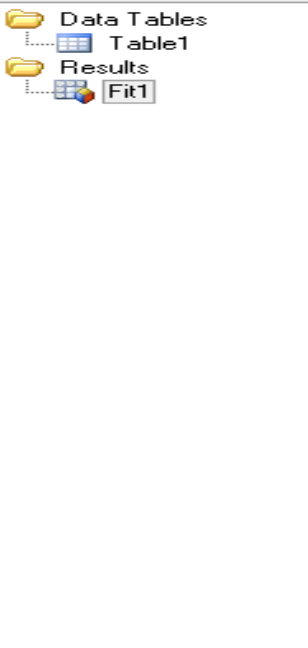 } & 16 & Frechet & $\alpha=0,52734 \quad \beta=2,6754$ \\
\hline & 17 & Gamma & $\alpha=0,66662 \quad \beta=42,118$ \\
\hline & 18 & Gamma & $\alpha=0,78413 \quad \beta=33,249$ \\
\hline & 19 & Gen. Extreme Value & $k=0,22055 \quad \sigma=18,345 \quad \mu=10,423$ \\
\hline & 20 & Gen. Gamma & $k=216,55 \quad \alpha=0,00582 \quad \beta=79,119$ \\
\hline & 21 & Gen. Gamma & $k=0,89224 \quad \alpha=0,79986 \quad \beta=33,249$ \\
\hline & 22 & Gen. Pareto & $k=-0,03086 \quad \sigma=34,175 \quad \mu=-7,0807$ \\
\hline & 23 & Gumbel Max & $\sigma=22,956 \mu=12,821$ \\
\hline & 24 & Gumbel Min & $\sigma=22,956 \mu=39,322$ \\
\hline & 25 & Hypersecant & $\sigma=29,442 \mu=26,071$ \\
\hline & 26 & Inv. Gaussian & $\lambda=4,3395 \mu=28,077$ \\
\hline & 27 & Inv. Gaussian & $\lambda=20,443 \quad \mu=26,071$ \\
\hline & 28 & Johnson SB & $\begin{array}{l}\gamma=0,50846 \quad \delta=0,17501 \\
\lambda=74,517 \quad \xi=2,6892\end{array}$ \\
\hline & 29 & Kumaraswamy & $\begin{array}{l}\alpha_{1}=0,09166 \quad \alpha_{2}=0,36647 \\
a=-2,1769 E-14 \quad b=78,0\end{array}$ \\
\hline
\end{tabular}

Figura 5.18 Parâmetros das distribuições

A análise e escolha do melhor tipo de distribuição permitirá a formação de modelos estatísticos mais adequados para aplicação, em simulação de filas.

Se o usuário desejar se aprofundar mais, há um vídeo no Youtube que resumidamente ensina a usar o EasyFit: https://www.youtube.com/watch?v=jcQPeDjbFGM.

\subsection{Resolver pelas fórmulas ou por simulação? Qual o momento ideal de cada uma dessas alternativas?}

A Teoria das Filas é uma ferramenta matemática que produz resultados analíticos, que são ótimos e não há dúvida disso.

Entretanto, a simulação não garante o encontro de uma solução ótima. O máximo que se pode afirmar é que o resultado da otimização nos provê resultados subótimos, mesmo que ele seja ótimo. Isso é fácil de entender quando se verifica que a simulação pode trazer consigo uma infinidade de variáveis para inserção no modelo, o que não seria possível fazer com as fórmulas da teoria das filas.

Com a Teoria das filas, basta fazer os cálculos uma única vez, porém a simulação, quando feita somente uma rodada, apresenta uma solução determinística, o que pode resultar em conclusões erradas; por esse motivo, deve-se, então, repetir inúmeras vezes a fim de gerar estimativas razoáveis. 


\section{Capítulo SEIS \\ Aplicação da teoria das filas no transporte rodoviário}

RAFAEL FERREIRA ALMEIDA ${ }^{8}$

\subsection{INTRODUÇÃO AO TRANSPORTE RODOVIÁRIO}

As características dos serviços inerentes ao modal rodoviário são os principais motivos do crescimento e difusão de sua utilização. Quase todos os tipos de produtos podem ser carregados por um caminhão, mas geralmente não é assim que é feito. Para caminhões, não há restrições como trilhos, localização de aeroportos ou vias navegáveis. Para que uma entrega seja feita, precisa-se apenas de uma rua, pavimentada ou não. A figura 6.1 apresenta o mapa rodoviário brasileiro.

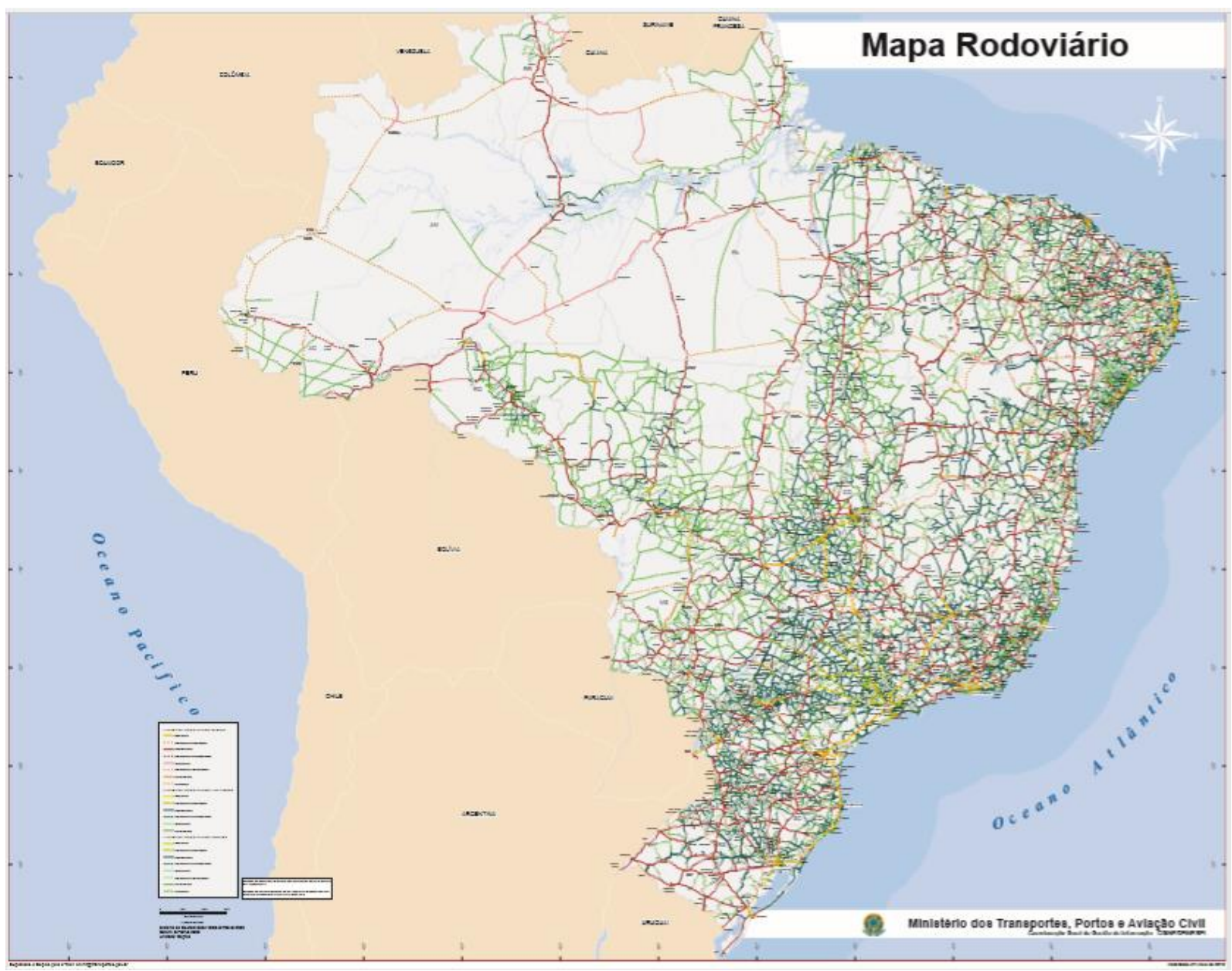

Figura 6.1. Mapa rodoviário brasileiro

Fonte: http://infraestrutura.gov.br/component/content/article/63-bit/5124-bitmodosmapas.html

\footnotetext{
${ }^{8}$ Com a participação de Adonis Carneiro da Silva, Felipe Pereira Rosa Pierrotti, Lucas de Castro Valente e Yuri
} Marinho de Carvalho. 
O mapa mostra a grande capilaridade do modal rodoviário, principalmente nas regiões próximas à costa marítima, sendo utilizado por quase todos os demais modais para integrar o fluxo do transporte e permitir a transferência de bens e passageiros, da origem até o destino.

Durante a coleta e entrega de mercadorias em áreas urbanas, fica evidenciada a vantagem da acessibilidade dos caminhões. Sua flexibilidade de entrega garante a capacidade de prover um serviço porta a porta, o que representa a maior vantagem do modal rodoviário sobre os demais modais. Daí sua importância para os sistemas de alimentação dos outros modais, podendo transferir os produtos entre eles, mesmo que não estejam interligados diretamente.

Os caminhões fazem a ponte entre os pontos de coleta e de entrega e as instalações de outros modais, dando-Ihe a denominação de "coordenador universal". Mas suas limitações de tamanho e de velocidade são enxergadas como desvantagens, já que outros usuários também compartilham a rodovia. Isto faz com que sejam mais indicados para transportes de curtas e médias distâncias, não sendo competitivos em longas distâncias, devido a inconstância de sua velocidade e que as ferrovias conseguem prever com maior precisão os tempos de entrega.

O transporte rodoviário de carga no Brasil apresenta as seguintes características, apresentadas no Quadro 6.1:

Quadro 6.1. Características do transporte rodoviário

\begin{tabular}{|c|c|}
\hline Vantagens & Desvantagens \\
\hline $\begin{array}{l}\text { Possui a maior representatividade entre os } \\
\text { modais existentes }\end{array}$ & Alto custo de manutenção \\
\hline Adequado para curtas e médias distâncias & Muito poluente com forte impacto ambiental \\
\hline Baixo custo inicial de implantação & $\begin{array}{l}\text { Segurança no transporte comprometida } \\
\text { devido à existência de roubos de cargas }\end{array}$ \\
\hline Serviço de entrega porta a porta & Transporte com velocidade moderada \\
\hline Maior flexibilidade com grande extensão da & Os custos se tornam altos para grandes \\
\hline $\begin{array}{l}\text { malha } \\
\text { Tempo de entrega confiável }\end{array}$ & $\begin{array}{l}\text { distancıas } \\
\text { Baixa capacidade de carga com limitações de } \\
\text { volume e peso }\end{array}$ \\
\hline & \\
\hline
\end{tabular}

Fonte: Adaptado de Pereira (2003)

Após alinhamento dos conceitos iniciais sobre o modal rodoviário, serão ilustradas algumas oportunidades de utilização da teoria das filas neste transporte.

\subsection{VISÃO DE QUATRO PROFESSORES E DE UM PROFISSIONAL DA ÁREA DE TRANSPORTES}

a) Visão dos professores

1. A visão acadêmica é fundamental para consolidação dos conceitos no setor rodoviário. Assim, o professor do Instituto Militar de Engenharia, Orivalde Soares da Silva Junior, explicita algumas características, a partir do questionário a seguir:

1) Utiliza ou já utilizou Teoria das Filas na solução de problemas envolvendo transportes? 
Sim.

2) Se sim, como? (Problema abordado, coleta de dados, metodologia, indicadores analisados, software utilizado...)

Problema: Recolhimento de jornais não vendidos nas bancas de jornal.

Coleta de dados: Foram realizados nos postos de coleta de jornais durante 10 dias, registrando os seguintes valores: Horário de Chegada; Horário de início de atendimento; Horário de término de atendimento.

Metodologia: Simulação.

Indicadores analisados: Número médio de clientes na fila; Tempo médio de espera na fila; Número médio de clientes no sistema; Tempo médio gasto no sistema.

Software utilizado: ARENA

2. O professor Glaydston Mattos Ribeiro (Programa de Engenharia de Transportes da Universidade Federal do Rio de Janeiro - PET/COPPE/UFRJ) acredita que a teoria das filas tem aplicação em diversos problemas de transportes associados a todos os modais, cabendo ao tomador de decisão avaliara se é possível empregar a esta técnica para obtenção de medidas de desempenho que deseja. Também informou já ter utilizado a teoria das filas para avaliar problemas relacionados à transportes, sendo que em todos casos aplicou codificação em linguagem C ou Pascal, conforme descrito a seguir.

1 - Teoria das Filas aplicada a Praça de Pedágio. Realizei um levantamento de dados que incluiu a chegada dos veículos e o atendimento. A chegada dos veículos foi verificada por meio de câmaras de monitoramento e o atendimento foi avaliado por meio de pesquisadores posicionados nas cabines. $O$ objetivo deste trabalho foi avaliar o impacto das motocicletas no atendimento e, com isso, definir novos processos de atendimento que permitissem minimizar as longas filas.

2 - Teoria das Filas para avaliar a chegada de veículos e o atendimento (entrada desses veículos) em uma refinaria da Petrobras. Neste caso, havia necessidade de avaliar se as áreas de espera dos veículos estavam dimensionadas adequadamente para não interromper o fluxo de passagem dos demais veículos da rodovia. Os dados utilizados foram os de chegada e de atendimento de outra refinaria, semelhante a que foi estudada. Cenários foram elaborados para auxiliar o processo de decisão.

3 - Simulação de atendimento de veículos enguiçados na Avenida Brasil. Neste trabalho, foi proposto um modelo matemático de programação linear inteira com teoria das filas para melhor posicionar veículos de atendimento (ou de regaste) que realizam a remoção de veículos enguiçados. A ideia foi minimizar o número de veículos de resgate e maximizar o atendimento. Dados da CET-Rio foram coletados sobre geração de enguiços e de atendimentos como, por exemplo, tempo médio e distribuições de probabilidade. Cenários foram avaliados com diferentes veículos de resgate.

3. A professora Andréa Souza Santos (PET/COPPE/UFRJ) atua na área de cidades sustentáveis e identifica oportunidades de utilização de teoria das filas sempre que a demanda for superior à capacidade de fornecimento do serviço, porque as filas irão ocorrer e deve-se atentar à variabilidade, tanto no intervalo entre chegadas como no tempo de atendimento, porque influenciam no processo. 
A metodologia poderia oferecer dados para auxiliar na modelagem do serviço para encontrar um balanceamento ideal entre os custos de realizar um determinado serviço e os custos que os atrasos ocasionados pelas filas podem gerar, entre outros.

4. O professor Márcio de Almeida D'Agosto (PET/COPPE/UFRJ) já utilizou teoria das filas na solução de problemas envolvendo transporte rodoviário, com auxílio de planilhas em excel, na recepção de veículos que acessam um edifício garagem (formação de fila de acesso e tempos de processamento por um elevador) e recepção de veículos que vão abastecer em posto que dispões de gás natural combustível. Neste último caso a ideia era dimensionar o número de pontos de abastecimento. Sendo que há oportunidades de utilização desta técnica em toda a aplicação que está associada a um sistema de recepção e processamento de unidades, com por exemplo em armazéns e centros de distribuição.

b) Visão de profissionais da área

O entendimento dos problemas enfrentados com a teoria das filas no transporte ferroviário pode ser explicitado com a experiência do profissional deste Autor que atua na área de operação e logística de uma das maiores distribuidoras de combustíveis do Brasil.

1 - Cite ao menos um problema de filas encontrado em sua organização:

Filas de caminhões tanque para carregar combustíveis claros em bases de distribuição.

2 - Quais são os métodos utilizados para solução do problema?

Análises estatísticas e análises empíricas por meio de experiência prática.

3 - A organização dispõe de alguma ferramenta computacional para estudo do problema? Caso positivo, cite-a.

Sim. Software com algoritmo próprio (desenvolvido internamente na empresa) para dimensionar grades de carregamento e gerenciar o agendamento dos caminhões.

4 - O campo a seguir é destinado a qualquer comentário adicional para complementar a pesquisa. Sinta-se à vontade.

Atualmente está em andamento um projeto de utilização de teoria das filas através de simulação computacional para melhor dimensionamento da capacidade operacional.

\subsection{APLICAÇÕES PUBLICADAS EM REVISTAS CIENTÍFICAS E DA ÁREA DE TRANSPORTES}

a) "Models of Bus Queueing at Curbside Stops", publicado na revista Transportation, Qualis B2. Neste artigo as paradas de ônibus foram analisadas com a fila de veículos que esperam para encostar para embarque e desembarque de passageiros. Este modelo permite que, através da demanda de ônibus se dimensione o tamanho do berço para parada dos veículos.

b) "Uso de la Teoría de Colas para la organización del complejo cosecha-transporte del arroz en el Complejo Agroindustrial Arrocero Los Palacios", publicado na revista Ciências Técnicas Agropecuárias. O presente artigo utiliza a teoria das filas para otimizar a logística de distribuição da produção de arroz.

c) "Terminal appointment system design by non-stationary $M(t) / E k / c(t)$ queueing model and genetic algorithm", publicado no International Journal of production economics. Este artigo trata das filas de caminhões nos portos, à espera da chegada e descarregamento dos navios. 
FILAS: conceitos, novos enfoques de abordagem e aplicações em Transportes

d) "Finding of the expected income of the closed queueing structure and its application in transport logistics", publicado no Journal of Computational and Applied Mathematics,.

e) Aplicação da Teoria das Filas na Análise do Tráfego

www.producao.ufrgs.br/arquivos/disciplinas/412 teoria de filas.pdf

f) ANTT alerta quanto ao limite máximo das filas nas rodovias federais concedidas https://www.cnt.org.br/agencia-cnt/antt-alerta-quanto-limite-maximo-filas-rodoviasfederais-concedidas

g) HISTÓRIA: Massari, a base do Papa-Fila - Diário do Transporte https://diariodotransporte.com.br/2018/03/04/historia-massari-a-base-do-papa-fila/

h) Governo Federal lança projeto-piloto do Documento Eletrônico de Transporte (DT-e) http://www.brasil.gov.br/noticias/infraestrutura/2019/05-2/governo-federal-lanca-projetopiloto-do-documento-eletronico-de-transporte-dt-e

i) Departamento de Transportes Engenharia de Tráfego - TT056 http://www.tecnologia.ufpr.br/portal/dtt/wpcontent/uploads/sites/12/2018/10/trabalholl 2018 2sem.pdf

j) Tensões e conflitos no transporte coletivo de Campos dos Goytacazes: uma sociologia das filas de espera

http://www.cchla.ufpb.br/rbse/Freire\&JuniorArtDossie.pdf

k) Governo lança projeto para simplificar operação de transporte de carga http://agenciabrasil.ebc.com.br/geral/noticia/2019-05/governo-lanca-projeto-parasimplificar-operacao-de-transporte-de-carga

I) Aplicação da Teoria das Filas à Operação de Transportes https://docplayer.com.br/14253461-Aplicacao-da-teoria-das-filas-a-operacao-detransportes.html

m) CPI dos Transportes: diligência constata filas longas e falta de informação em loja da RioCard http://www.eliomar.com.br/24014/

n) Comissão aprova isenção de pedágio se fila ultrapassar 100 metros ou 5 minutos https://www2.camara.leg.br/camaranoticias/noticias/TRANSPORTE-E-TRANSITO/455587COMISSAO-APROVA-ISENCAO-DE-PEDAGIO-SE-FILA-ULTRAPASSAR-100-METROS-OU-5MINUTOS.html

o) Como se resolvem as insuportáveis filas de trânsito https://shifter.sapo.pt/2018/03/mobilidade-lisboa/

p) Avaliação da qualidade do transporte rodoviário intermunicipal de passageiros: uma abordagem exploratória https://www.revistatransportes.org.br/anpet/article/viewFile/376/408 
q) DEFICIÊNCIAS DE RODOVIAS, FILAS E RESTRIÇÕES URBANAS ELEVAM CUSTOS http://www.ntctec.org.br/media/files/artigos/rodovias-restricoes-estadia.pdf

r) Congestionamentos de trânsito: Los Angeles o pesadelo dos condutores https://pt.euronews.com/2017/02/23/congestionamentos-de-transito-los-angeles-opesadelo-dos-condutores

s) Mais tempo no ônibus que no trabalho https://brasil.elpais.com/brasil/2015/03/23/politica/1427126376 249449.html

t) MOBILIDADE URBANA: O QUE TEM DE ERRADO COM O NOSSO TRÂNSITO? https://www.politize.com.br/mobilidade-urbana-transito-problemas/

u) Agendamento online reduz filas para garantir passe escolar https://www.folhadelondrina.com.br/cidades/agendamento-online-reduz-filas-paragarantir-passe-escolar-1025960.html

v) Planejamento integrado dentro do Governo do Estado busca amenizar filas nas rodovias durante a temporada

http://sc.gov.br/index.php/noticias/temas/transportes-e-estradas/planejamento-integradodentro-do-governo-do-estado-busca-amenizar-filas-nas-rodovias-durante-a-temporada

w) Fila de caminhões no Pará está sendo zerada

http://www.agricultura.gov.br/noticias/fila-de-caminhoes-no-para-deve-ser-zerada-ate-estasexta-feira

x) Fila no Pedágio: conheça seus direitos http://www.opensat.com.br/blog/dicas/fila-no-pedagioconheca-seus-direitos.html

y) Pânico com falta de combustíveis. Bombas fechadas, postos lotados e transportes em risco https://www.cmiornal.pt/portugal/detalhe/bombas-de-combustiveis-comecam-a-encerrarem-dia-de-greve

z) Filas na CPTrans para compra de passe popular http://www.jornaldepetropolis.jex.com.br/cidade/filas+na+cptrans+para+compra+de+passe + popular

aa) Logística lean aplicada a uma transportadora https://www.lean.org.br/artigos/506/logistica-lean-aplicada-a-uma-transportadora.aspx

bb) Logística Sustentável - Vencendo o Desafio Contemporâneo da Cadeia de Suprimento https://books.google.com.br/books?id=nm16DwAAQBAJ\&pg=PT169\&lpg=PT169\&dq=filas $+n$ os+transportes\&source=b|\&ots=vcEhmUZ9Lw\&sig=ACfU3U1GRXHPDghFO6B ifRykiU8LXB3| $\underline{\mathrm{Q} \& \mathrm{hl}=\mathrm{pt}-}$ BR\&sa=X\&ved=2ahUKEwiP8pP4koXjAhVDIbkGHZbECOY4qgEQ6AEwBXoECAkQAQ\#v=onepag e\&q=filas\%20nos\%20transportes\&f=false 
cc) Transporte público | Grupo Transporte Humano

https://transportehumano.wordpress.com/category/transporte/transporte-publico/

\subsection{APLICAÇÕES APRESENTADAS EM CONGRESSOS}

\section{Simpósio Brasileiro de Pesquisa Operacional}

Planejamento de operações de logística outbound com apoio de simulação estocástica

Este trabalho analisa em um estudo de caso os custos de operação de docas de um centro de distribuição de alimentos. Atualmente, este centro de distribuição trabalha com 3 pessoas para realizar o carregamento por doca. Além disso, utiliza um sistema de disciplina da fila, onde cada uma das docas possui um atendimento exclusivo, ou seja, cada doca só atende um tipo de cliente, que são divididos em clientes de carga unitizada e clientes com carga não unitizada. $O$ trabalho verifica os custos totais envolvidos e analisa se a empresa alimentícia deve disponibilizar mais um servidor (doca), diminuir para uma doca ou se deve manter a quantidade atual. Além disso, verificar os custos da atual disciplina da fila, estudando a viabilidade de alterá-la de dedicada para com prioridade ou sem.

Desta maneira, utilizou-se a simulação e a Teoria das filas como ferramenta para a tomada de decisão quanto ao dimensionamento das operações logísticas do Centro de Distribuição.

O resultado: a forma como as operações estão ocorrendo, com dois servidores e cada qual dedicado a apenas um tipo de carga, só não se mostrou mais custosa do que a operação com uma doca, conforme observa-se na Tabela 6.1.

Tabela 6.1. Análise de cenários.

\begin{tabular}{|c|c|c|c|c|c|c|c|}
\hline \multirow{2}{*}{ Cenários } & \multirow{2}{*}{$\begin{array}{l}\text { Custo } \\
\text { total } / \mathrm{h}\end{array}$} & \multirow{2}{*}{$\begin{array}{l}\text { Tempo } \\
\text { médio na } \\
\text { fila (h) }\end{array}$} & \multirow{2}{*}{$\begin{array}{c}\text { Tempo } \\
\text { médio no } \\
\text { sistema (h) }\end{array}$} & \multirow{2}{*}{$\begin{array}{l}\text { Veículos não } \\
\text { atendidos/h }\end{array}$} & \multicolumn{3}{|c|}{ Utilização dos Servidores } \\
\hline & & & & & Doca 1 & Doca 2 & Doca 3 \\
\hline 1S sem regra & $\mathrm{R} \$ 363,22$ & 3,5 & 4,67 & 0,1414 & $89,70 \%$ & - & - \\
\hline $\begin{array}{l}\text { 1S com } \\
\text { prioridade }\end{array}$ & $\mathrm{R} \$ 348,68$ & 3,4 & 4,54 & 0,1342 & $87,70 \%$ & - & - \\
\hline $\begin{array}{l}\text { 2S dedicados } \\
\text { Situação Atual }\end{array}$ & $\mathrm{R} \$ 324,01$ & 2,9 & 4,13 & 0,1124 & $83,40 \%$ & $9,50 \%$ & - \\
\hline $2 \mathrm{~S}$ sem regra & $\mathrm{R} \$ 112,52$ & 0,4 & 1,77 & 0,0068 & $60,70 \%$ & $44,90 \%$ & - \\
\hline $\begin{array}{l}2 \mathrm{~S} \text { com } \\
\text { prioridade }\end{array}$ & $\mathrm{R} \$ 105,10$ & 0,4 & 1,75 & 0,0032 & $59,20 \%$ & $44,50 \%$ & - \\
\hline $3 \mathrm{~S}$ sem regra & $\mathrm{R} \$ 148,18$ & 0,1 & 1,49 & 0,0002 & $53,80 \%$ & $35,10 \%$ & $18,30 \%$ \\
\hline $\begin{array}{l}3 \mathrm{~S} \text { com } \\
\text { prioridade }\end{array}$ & $\mathrm{R} \$ 147,83$ & 0,1 & 1,50 & 0 & $54,00 \%$ & $34,70 \%$ & $18,80 \%$ \\
\hline
\end{tabular}

Fonte: Risso et al. (2013)

Constata-se dos experimentos realizados que a disciplina da fila utilizada é prejudicial para a empresa, tendo em vista que uma doca é utilizada em $83,4 \%$ das vezes e a segunda $9,5 \%$. Desta maneira, a segunda doca permanece ociosa por um tempo superior, aumento custos com mão de obra contratada, diminuindo a eficiência e o nível de serviço apresentado.

Tendo em vista os resultados apresentados no artigo, é possível afirmar que a abordagem da teoria de filas com o uso de simulação estocástica mostrou-se eficiente quanto a análise de cenários e dimensionamento das operações da empresa estudada. Faz-se notável perceber que a tomada de 
decisão poderá ser baseada ou na questão dos custos logísticos observados ou no nível de serviço apresentado. Contudo, é interessante perceber que o aumento de números de vagas não traz benefícios diretos imediatos, como se deduziria, pois, em determinados momentos, os servidores poderiam estar ocupados por cargas com maior tempo de processamento e em outros, ficariam ociosos, aumentando a relação entre os custos fixos e os benefícios causados. Os resultados revelaram que o cenário atual é três vezes mais custoso em comparação com a melhor alternativa proposta.

\section{Exemplos do Encontro Nacional de Engenharia de Produção}

1) Análise das durações dos sinais de semáforo visando melhorar o fluxo de veículos em um cruzamento de via da cidade de Ponta Grossa-PR.

Resumo: O objetivo deste estudo é melhorar o tráfego de um cruzamento de vias da cidade de Ponta Grossa-PR visando reduzir o tamanho de fila. Para isso, fez-se uso da análise do cenário atual como base para propor uma melhoria na programação temporal e, a partir de conceitos de Teoria das Filas, simular a eficiência da alteração. As sugestões indicam que aumentar (ou diminuir) o tempo do semáforo permite reduzir os tempos de espera bem como o tamanho da fila em aproximadamente $30 \%$.

2) Proposta de aplicação de teoria das filas na linha de transporte coletivo de Macapá/SantanaAP simulado no software Arena.

Resumo: O presente artigo aborda o transporte público coletivo entre as cidades de Macapá e Santana do Estado do Amapá. Os municípios articulam-se entre si por vias rodoviárias e há um grande deslocamento de pessoas que utilizam deste tipo de transporte, havendo assim uma grande procura diária pelo serviço. O conhecimento das características do sistema de transporte urbano entre Macapá e Santana caracteriza-se de fundamental importância, com o intuito de diagnosticar as suas necessidades, propondo medidas através da utilização de teorias das filas aplicada e simulada ao software ARENA para melhoria da qualidade de vida dos cidadãos dos municípios que são objeto de estudo desse trabalho.

3) Impactos da tecnologia na redução de filas em uma praça de pedágio da BR-116

Resumo: O transporte rodoviário é o grande responsável pelo transporte de cargas no Brasil. Com isso, tem-se um grande fluxo de veículos nas estradas, principalmente, na região do Sul do estado do Rio de Janeiro, na Rodovia Presidente Dutra, também chamada de BR-116, que liga as duas maiores regiões metropolitanas do país, Rio de Janeiro - São Paulo, e ao longo da qual se concentram grandes polos industriais. Neste artigo foi estudado, por meio do software de simulação Arena, o impacto do sistema de identificação e cobrança automática na fila de veículos de uma praça de pedágio existente nesta rodovia, que resultou na redução de $60 \%$ do tempo de médio de fila do pedágio, permitindo assim a saída de um maior número de veículos do mesmo, sendo este valor correspondente a um aumento $150 \%$. O método científico foi o experimental, com o tipo de pesquisa quantitativa, por meio da realização de coleta de dados em campo, com a finalidade de propor soluções para a Praça de Pedágio Itatiaia.

4) Aplicação de teoria das filas em transporte público urbano: caso de terminal de ônibus da cidade de Ponta Grossa. 
Resumo: O objetivo deste estudo é apresentar alternativas operacionais de modo a melhorar o rendimento do transporte coletivo em um ponto de ônibus da cidade de Ponta Grossa -Paraná. A linha estudada apresenta longas filas de usuários, reclamações e esperas consideradas desconfortáveis. Baseado nos dados obtidos pode-se realizar um estudo de como o serviço prestado porta-se havendo diferentes demandas e diferentes tempos de espera. Com os resultados alcançados no estudo foi possível mostrar que a fila média e espera média em fila podem ser reduzidas. 0 serviço prestado comporta-se normalmente até o momento em que a demanda aumenta para $60 \%$ da atual, conclui-se que para uma melhor distribuição de atendimento, assim como para diminuir tempos de espera e a quantidade de passageiros em fila, recomenda-se uma redução do tempo de passagem entre dois veículos consecutivos de 10 para 9 minutos ou inferior. Para os períodos de baixa demanda propõe-se que o ônibus aguarde no ponto por 5 minutos, fazendo com que os usuários esperem em média 4,09 minutos a menos e existem em média seis pessoas a menos aguardando em fila se comparadas ao atual funcionamento.

\subsection{NOTÍCIAS DE JORNAIS SOBRE TEORIA DAS FILAS}

Notícias veiculadas em portais de grande circulação sobre filas em transportes no modal rodoviário:

Free public transport is an attractive idea. But would it solve our traffic woes?

The promise of free public transport is an enticing one: fewer cars, less congestion, less pollution.

https://www.abc.net.au/news/2019-03-18/free-public-transport-do-promises-stack$\underline{\text { up } / 10893288}$

\section{Ônibus cheios de visitantes fazem fila para entrar no Jardim Botânico}

Parque ficou lotado durante o feriado de Corpus Christi em 2019.

\section{https://globoplay.globo.com/v/7709166/}

1 a cada 4 idosos diz que prioridade em filas e ônibus nunca é respeitada

https://www1.folha.uol.com.br/cotidiano/2018/06/1-a-cada-4-idosos-diz-que-prioridade-emfilas-e-onibus-nunca-e-respeitada.shtml

Sobram filas nos pontos de ônibus do Rio:

O déficit no serviço de ônibus gera reclamações de usuários, crescem o número de filas nos pontos e os carros andam sempre lotados.

https://odia.ig.com.br/rio-de-janeiro/2019/06/5653228-sobram-filas-nos-pontos-de-onibus-dorio.html

Passageiros do transporte público encaram longas filas e ônibus lotadas em Porto Alegre

https://www.correiodopovo.com.br/not\%C3\%ADcias/geral/passageiros-do-transportep\%C3\%BAblico-encaram-longas-filas-e-\%C3\%B4nibus-lotados-em-porto-alegre-1.264709

\section{Restrições de horários gera filas na espera por ônibus em Porto Alegre}


FILAS: conceitos, novos enfoques de abordagem e aplicações em Transportes https://www.jornaldocomercio.com/ conteudo/2018/05/geral/629198-restricao-de-horariosgera-filas-na-espera-por-onibus-em-porto-alegre.html

Ônibus fazem fila para abastecer em posto de combustível de Campo Grande, no Rio http://g1.globo.com/rio-de-janeiro/videos/v/onibus-fazem-fila-para-abastecer-em-posto-decombustivel-de-campo-grande-no-rio/6755666/

Passageiros reclamam de filas em ponto de ônibus

https://globoplay.globo.com/v/7215102/

Com proibição do uso de dinheiro, terminais registram filas para compra de passagens https://www.portalcbncampinas.com.br/2019/03/com-proibicao-do-uso-de-dinheiro-nosonibus-de-campinas-terminais-registram-filas-para-a-compra-de-passagens/

Greve de ônibus causa filas, caos e tumultos no Rio

https://www.otempo.com.br/brasil/greve-de-\%C3\%B4nibus-causa-filas-caos-e-tumultos-no-rio$\underline{1.390435}$

Catracas visam a reduzir filas nos pontos de ônibus

http://www.cuiaba.mt.gov.br/transito-e-transporte-urbano/catracas-visam-a-reduzir-filas-nospontos-de-onibus/3333

Medo de desabastecimento causa filas de carros em postos de combustíveis em Manaus

http://www.cuiaba.mt.gov.br/transito-e-transporte-urbano/catracas-visam-a-reduzir-filas-nospontos-de-onibus $/ 3333$

Toda sexta, terminais têm fila de interessados em ficar com bicicletas no fim de semana https://tribunadoceara.com.br/noticias/mobilidadeurbana/toda-sexta-terminais-tem-fila-deinteressados-em-ficar-com-bicicletas-no-fim-de-semana/

Falta de vagas para estacionamento de motos provoca filas e irregularidades

https://tribunadepetropolis.com.br/falta-de-vagas-para-estacionamento-de-motos-provoca-filase-irregularidades

Mudança no Aeroporto Santos Dumont diminuem filas para embarque em táxis

https://oglobo.globo.com/rio/mudancas-no-aeroporto-santos-dumont-diminuem-filas-paraembarque-em-taxis-11122034

Passageiros fazem fila para comprar passagens a $\mathrm{R} \$ \mathbf{3 , 2 5} \mathrm{em}$ Porto Alegre

https://correiodopovo.com.br/Noticias/Geral/Transporte\%20P\%C3\%BAblico/2016/2/580378/Pa ssageiros-fazem-fila-para-comprar-passagens-a-R-3,25-em-Porto-Alegre

Proposta libera carro de pedágio se fila superar 200 metros ou 10 minutos

https://www2.camara.leg.br/camaranoticias/noticias/TRANSPORTE-E-TRANSITO/573062PROPOSTA-LIBERA-CARRO-DE-PEDAGIO-SE-FILA-SUPERAR-200-METROS-OU-10-MINUTOS.htmI 
FILAS: conceitos, novos enfoques de abordagem e aplicações em Transportes

Pessoas com deficiência enfrentam fila grande para ter passe livre

https://www.metropoles.com/distrito-federal/transporte-df/pessoas-com-deficienciaenfrentam-fila-grande-para-ter-passe-livre

\section{Referências}

COYLE, J. J.; BARDI, E. J.; NOVACK, R. A. Transportation. St. Paul: West Publishing Company, 1994.

FARIA, C. C. O.; CARVALHO, M. O.; GUIMARÃES, E.; LEMOS, W. M. Impactos da tecnologia na redução de filas em uma praça de pedágio da BR-116. In: XXXVIII ENCONTRO NACIONAL DE ENGENHARIA DE PRODUCAO. Maceió, Alagoas, Brasil, 16 a 19 de outubro de 2018. Disponível em: <http://www.abepro.org.br/biblioteca/TN STO 263512 35348.pdf>. Acesso em: 03/07/2019.

GUIMARÃES, C. A. B.; FRANÇOSO, M. T.; TRABANCO, J. L. A.; LOPES, J. M. Um modelo determinístico de filas para análise do dimensionamento de plataformas de embarque e desembarque em terminais rodoviários de passageiros. Revista dos Transportes Públicos - ANTP - Ano 40 - 2018 - 2o quadrimestre, pág. 61 a 78. Disponível em: <http://files.antp.org.br/2018/7/31/rtp149-e.pdf>.

PEREIRA, Ana Cristina da Silva. Transporte Intermodal: Um estudo do modelo Estadunidense Europeu vs. Situação Brasileira. Dissertação de Mestrado Coppead. UFRJ, 2003, 174P.

PEREIRA, M. B.; SILVA, V. H. R.; SILVA, D. A. S.; CARNEIRO, L. R. Proposta de aplicação de teoria das filas na linha de transporte coletivo de Macapá/Santana-AP simulado no software Arena. In: XXXVII ENCONTRO NACIONAL DE ENGENHARIA DE PRODUCAO. Joinville, SC, Brasil, 10a 13 de outubro de 2017. Disponível em: < http://www.abepro.org.br/biblioteca/TN STO 243410 33830.pdf>. Acesso em: 03/07/2019.

REIS, L. O. F.; LAND, R. O.; OSATCHUK, T.; CHIN, S. Y. Aplicação de teoria das filas em transporte público urbano: caso de terminal de ônibus da cidade de Ponta Grossa. In: XXXVIII ENCONTRO NACIONAL DE ENGENHARIA DE PRODUCAO. Maceió, Alagoas, Brasil, 16 a 19 de outubro de 2018. Disponível em: <http://www.abepro.org.br/biblioteca/TN WIC 263511 35358.pdf>. Acesso em: 03/07/2019.

RISSO, L. A.; PICANÇO, A. R. S.; SILVA, A. L.; IGNÁCIO, P. S. A. Planejamento de operações de logística outbound com apoio de simulação estocástica. In: XLIX Simpósio Brasileiro de Pesquisa Operacional, pág. 3200 a 3211. Blumenau-SC, 27 a 30 de agosto de 2017. Disponível em: <http://www.sbpo2017.iltc.br/pdf/169315.pdf>. Acesso em: 03/07/2019.

SOUZA, M. V. J.; FILHO, A. C. P. Automação semafórica: aplicando tecnologia para maximizar a capacidade viária existente. Revista dos Transportes Públicos - ANTP - Ano 40 - 2017 - 3ㅇ quadrimestre, pág. 27 a 44. Disponível em: <http://files.antp.org.br/2017/12/21/rtp147e.pdf>. Acesso em: 03/07/2019.

YOSHIMA, C. H.; KOVALESKI, F.; FARIA, L.; CHIN, S. Y. Análise das durações dos sinais de semáforo visando melhorar o fluxo de veículos em um cruzamento de via da cidade de Ponta GrossaPR. In: XXXIV ENCONTRO NACIONAL DE ENGENHARIA DE PRODUCAO. Curitiba, PR, Brasil, 07 a 10 de outubro de 2014.2 Disponível em: $<$ http://www.abepro.org.br/biblioteca/enegep2014 TN WIC 200134 26038.pdf>. Acesso em: 03/07/2019. 


\section{Capítulo SETE \\ Aplicação da teoria das filas no transporte ferroviário}

LUCAS DE CASTRO VALENTE ${ }^{9}$

\subsection{INTRODUÇÃO AO TRANSPORTE FERROVIÁRIO}

Embora uma ferrovia possibilite maiores ganhos por meio de economia de escala, oriunda da redução do custo unitário proporcional ao aumento do volume de utilização, esse tipo de transporte demanda altos investimentos devido a necessidade constante de manutenção em toda a sua infraestrutura operacional, como estações, sistemas de telecomunicações, sinalização, segurança, trilhos, dormentes, material rodante, passagens de nível e aparelhos de mudança de vias (máquinas de chave).

Algumas características do transporte ferroviário podem ser evidenciadas no quadro 7.1:

Quadro 7.1 - Características do transporte ferroviário

\begin{tabular}{|l|l|}
\hline \multicolumn{1}{|c|}{ Vantagens } & \multicolumn{1}{|c|}{ Desvantagens } \\
\hline $\begin{array}{l}\text { Grande capacidade de carga } \\
\text { Adequado para grandes distâncias }\end{array}$ & $\begin{array}{l}\text { Alto custo de implantação } \\
\text { Transporte lento devido às suas operações } \\
\text { de carga e descarga } \\
\text { Baixa flexibilidade com pequena extensão da } \\
\text { malha } \\
\text { Elevada eficiência energética }\end{array}$ \\
$\begin{array}{l}\text { Baixa integração entre os estados } \\
\text { Baixo custo de transporte manutenção } \\
\begin{array}{l}\text { Possui maior segurança em relação ao modal } \\
\text { rodoviário, visto que ocorrem poucos } \\
\text { acidentes, furtos e roubos } \\
\text { Pouco poluente }\end{array}\end{array}$ \\
\hline
\end{tabular}

Fonte: Elaborado pelo autor

A vantagem sobre o transporte dutoviário é que permite o fluxo de produtos nos dois sentidos, tanto na ida quanto na volta, embora, por questões técnicas, o duto apenas permita o fluxo em um sentido.

Porém, deve-se atentar para o tamanho da bitola, que é a distância entre os trilhos em uma ferrovia, porque no Brasil há 3 tipos diferentes, e os vagões são adaptados para cada uma dessas bitolas especificamente.

A partir da Figura 7.1, pode-se observar que a malha ferroviária brasileira está concentrada no Sul e Sudeste, devido à proximidade dos portos e à capacidade de escoamento da produção, ligando os

\footnotetext{
${ }^{9}$ Com a participação de Adonis Carneiro da Silva, Felipe Pereira Rosa Pierrotti, Rafael Ferreira Almeida e Yuri Marinho de Carvalho.
} 
FILAS: conceitos, novos enfoques de abordagem e aplicações em Transportes

centros mais desenvolvidos às principais portas de entrada e de saída do país. Entretanto, falta interconectividade entre os atuais e futuros polos de desenvolvimento com as outras regiões do país.

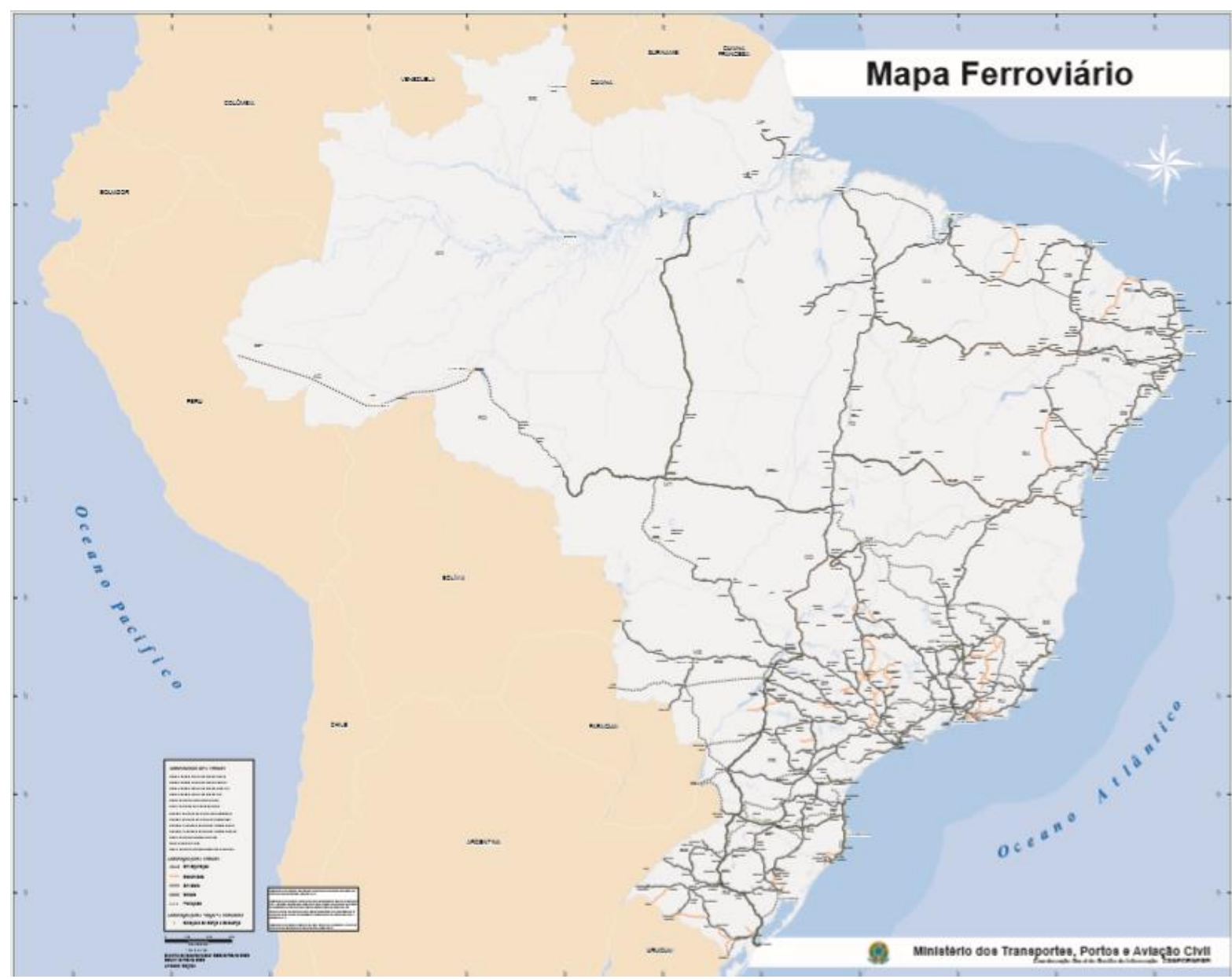

Figura 7.1. Mapa ferroviário do Brasil

Fonte: http://infraestrutura.gov.br/component/content/article/63-bit/5124-bitmodosmapas.html

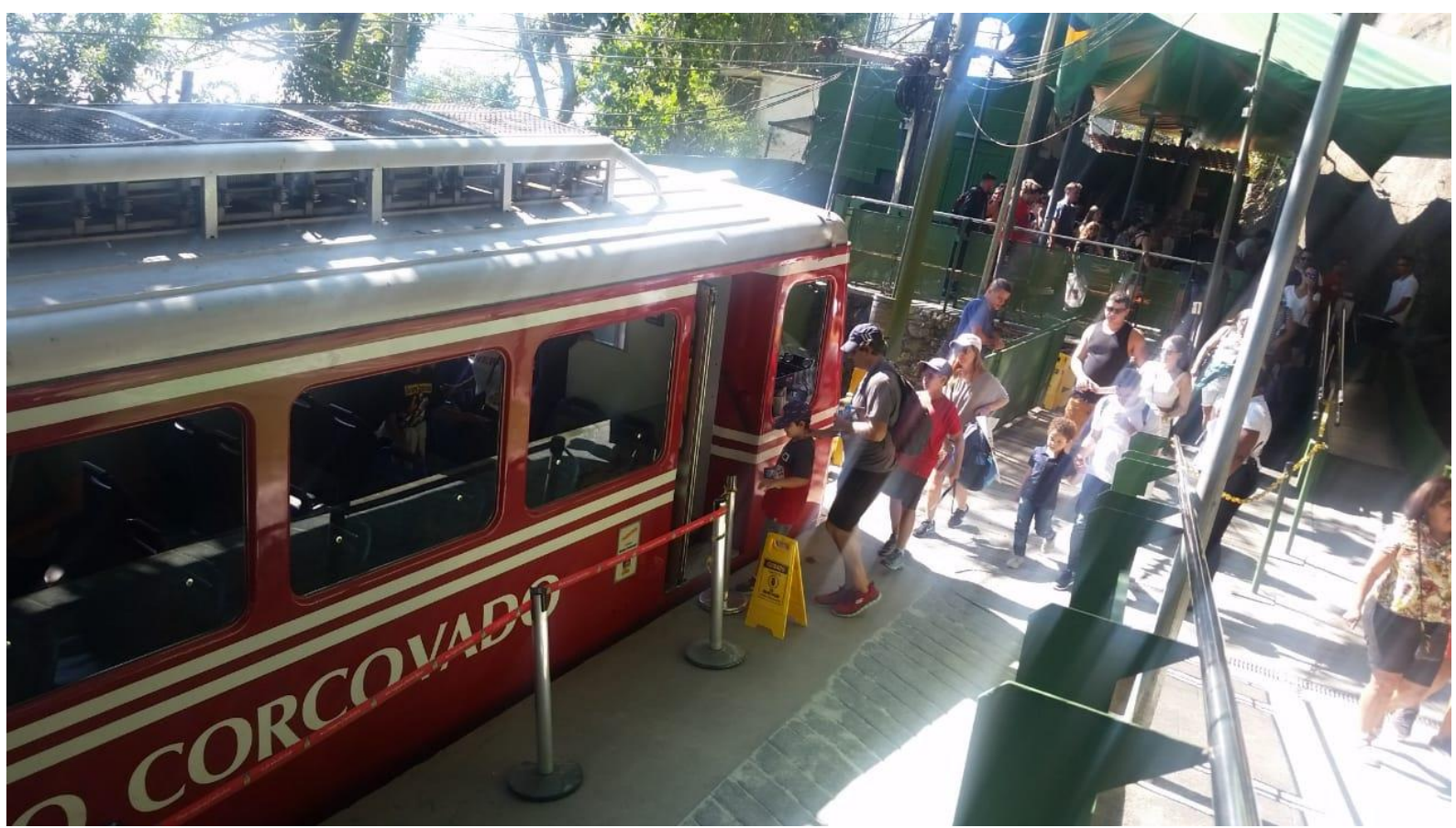

Figura 7.2. Fila para o trem de acesso à estátua do Cristo Redentor, Rio de Janeiro, RJ. 


\subsection{VISÃO DE UM PROFESSOR E DE DOIS PROFISSIONAIS DE TRANSPORTES}

a) Visão de um professor da área

Os fundamentos de teoria das filas e suas aplicações no modal ferroviário, principalmente em ferrovias de carga conhecidas como heavy haul vem sendo um tema de estudo pelo professor Luiz Antonio Silveira Lopes do Instituto Militar de Engenharia. Assim, sua vasta experiência é compartilhada para assimilação dessa teoria por meio de uma entrevista.

1 - Conte-nos sua experiência em estudos práticos utilizando teoria das filas?

$\mathrm{Na}$ ocasião precisávamos estudar a chegada de trens, formando filas, em um pátio ferroviário de formação de trens. Os dados puderam ser coletados por meio do sistema de logística do CCO (Centro de Controle Operacional) da ferrovia concessionária e também por meio de filmagens cedidas. $O$ amplo trabalho utilizou os conceitos de teorias de filas, mas foram modelados e os resultados obtidos por meio de simulação em softwares específicos.

2 - Quais foram as oportunidades identificadas no estudo?

A modelagem e utilização de teoria de filas tanto no modal ferroviário quanto em outros modais permitem identificar os gargalos e estudá-los de forma a reduzi-los. Assim, nesse estudo foram identificadas as oportunidades de melhoria que reduziriam os impactos operacionais causados devido ao gargalo no pátio ferroviário em questão.

b) Visão de dois profissionais da área

Para compreensão da forma como profissionais da área de operação realizam estudos envolvendo a aplicação dos conceitos de Teoria das Filas, faz-se necessário entrevistá-los para melhor entendimento. Nesse contexto o especialista ferroviário da Engenharia de Operação da MRS Logística, concessionária da Rede Ferroviária Federal S.A para atuação na malha ferroviária da região Sudeste, Thales Augusto dos Santos, descreve como são os desafios operacionais nos trens de carga, para o que utiliza o software ARENA para simulação.

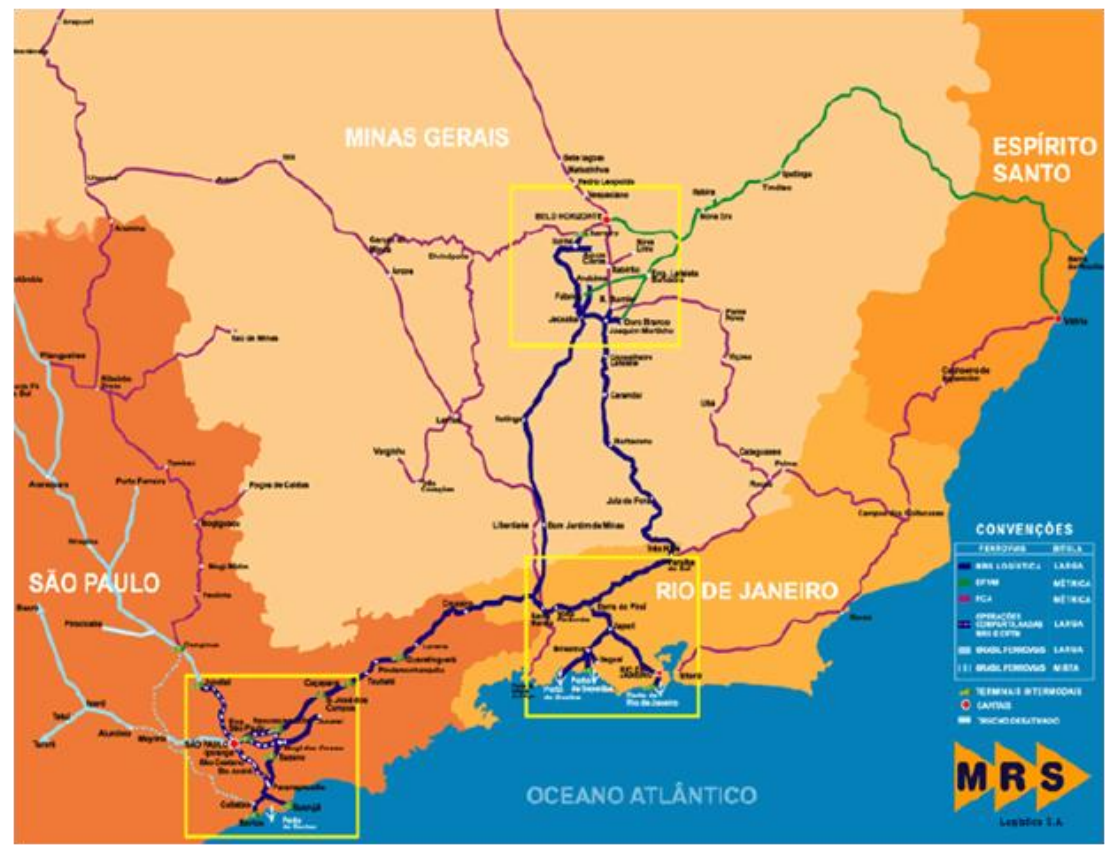

Figura 7.3. Área de atuação da MRS Logística

Fonte: MRS Logística 
1 - Quais são as etapas para as análises desde a identificação da formação de filas de trens até as conclusões para melhoria da capacidade do sistema ferroviário?

Todo modelo deve começar do entendimento do problema e do método que vai ser usado para avaliá-lo e resolvê-lo. Assim, não fugindo à regra e de algumas referências, a modelagem pode ser descrita como:

A- Entendimento do problema;

A.1 - Coleta de dados e informações;

A.2 - Entrevistas com especialistas e gestores para definir o escopo da modelagem e indicadores a serem coletados, obter informações críticas e sanar dúvidas. É importante tomar o cuidado em mapear o que não pode ser modelado devido a diversos motivos e os possíveis impactos nos resultados;

B - Construção do modelo - a partir do "zero" ou de modelagens anteriores que tenham similaridades com o problema atual;

C - Validação parcial: Verificação da conformidade dos processos simulados com o mundo real. Ex.: No pátio Valente, os trens carregados passam pela $L 1$ e os vazios na $L 2$, a animação do modelo mostra isso? Se não, são necessárias correções nas lógicas de simulação;

D - Validação final: Comparação dos resultados (indicadores) do modelo com os dados reais. Ex.: transit time, fila em pátio, tempo de permanência. Na etapa $A$, é importante definir qual o percentual aceitável de variação do simulado $x$ real. Normalmente, usamos $+-10 \%$, porque os estudos são estratégicos, sem a precisão de dados de entrada e saída de ferramentas operacionais.

E - Se validado, o modelo pode ser usado para estudos de cenários. Ex.: Se a frequência de trens na Linha do Centro aumentar em $20 \%$, qual será o transit time esperado? O pátio de M. Castilho, que é usado para fila de vazios, terá capacidade para processamento? Qual o aumento do tempo de permanência naquele pátio? É aceitável em termos do que é praticado hoje?

2 - Quais são as situações em que são aplicadas a modelagem e simulação estocástica para entendimento das redes ferroviárias?

Atualmente os modelos são usados em estudos tático-estratégicos, ou seja, para operações que vão acontecer daqui a alguns meses ou até 30 anos. Há modelos para os corredores ferroviários (L. Centro, F. Aço, Vale do Paraíba, etc), para pátios e terminais e modelos integrados de malha. Estes últimos são mais simplificados em termos das lógicas de sinalização e cruzamento de trens e se concentram mais na avaliação de capacidade dos terminais de carga e descarga. Os momentos que requerem modelos de simulação vão desde o Plano Diretor da MRS, Orçamento, solicitações de outras ferrovias, governos e agências reguladoras, projetos e demandas do Comercial e Planejamento Estratégico.

3 - Se em um certo problema ferroviário, o software de simulação identificar que o atendimento para uma determinada fila seja do tipo exponencial, é possível que haja convergência entre o modelo analítico da teoria das filas e o computacional?

Sim. Desde que os mesmos parâmetros que descrevem o atendimento exponencial sejam usados para descrever a taxa de chegada e o tempo de atendimento dos trens no modelo analítico. 
FILAS: conceitos, novos enfoques de abordagem e aplicações em Transportes

4 - Qual estudo de caso você considera que houve um grande retorno por meio de metodologia que vem sendo utilizada na MRS?

Houve vários, mas o mais marcante e recente foi o plano de negócios para prorrogação da concessão MRS. Neste trabalho, os projetos de expansão da empresa foram avaliados e defendidos por meio das ferramentas de simulação desenvolvidas aqui, sendo que a metodologia, o detalhamento e os resultados dos modelos foram reconhecidos pelo corpo técnico da agência reguladora.

O setor ferroviário apresenta diferentes desafios de acordo com a finalidade da operação quanto ao problema de filas. Assim, uma entrevista com o gerente de Material Rodante do Metrô do Rio de Janeiro, Fábio Rezende, contextualiza as particularidades do modal para o transporte de passageiros.

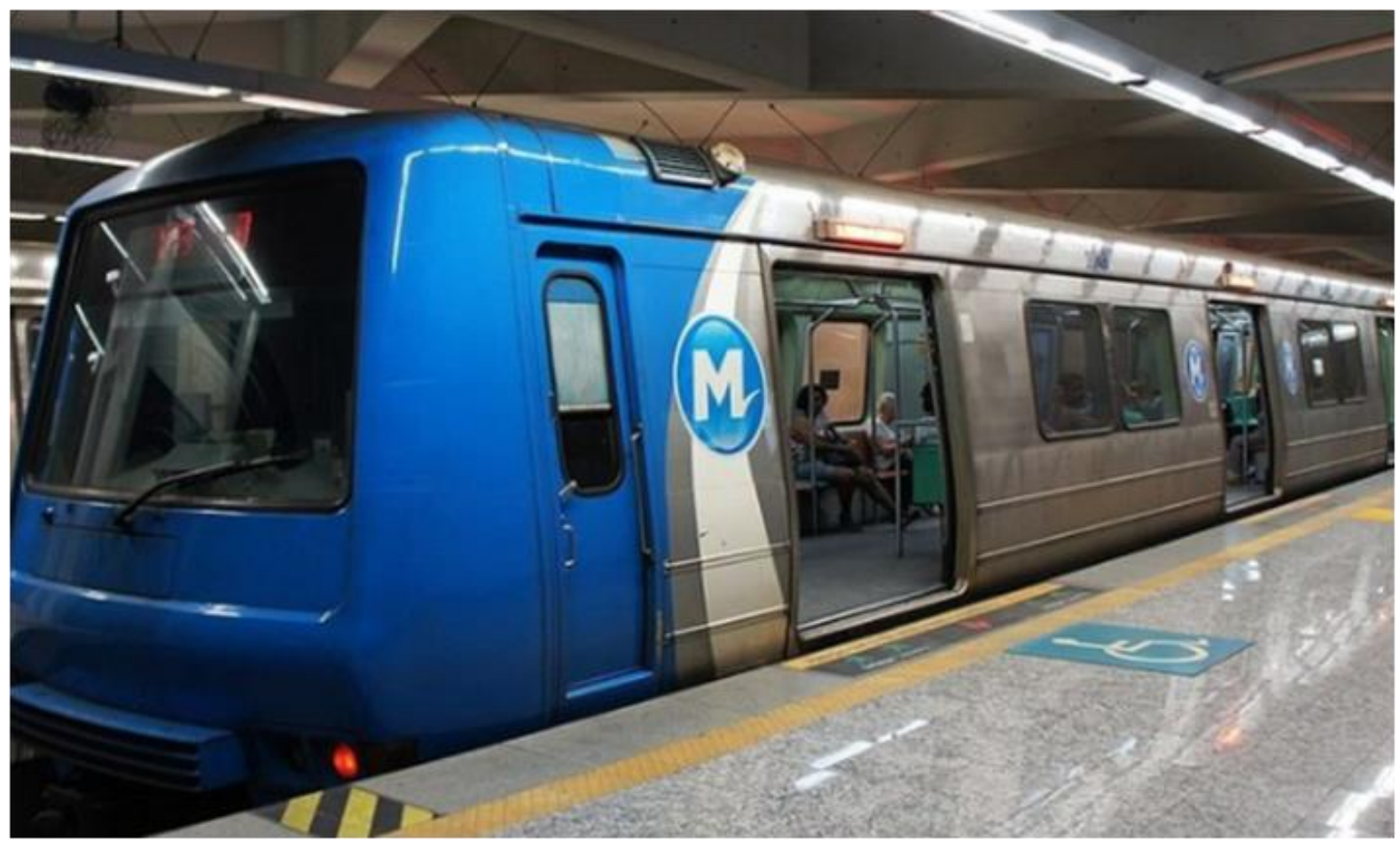

Figura 7.4 Metrô do Rio de Janeiro

1 - Atualmente como o MetrôRio realiza análises para evitar filas na circulação dos trens visando atender com previsibilidade os passageiros?

Existem diversos indicadores operacionais que são monitorados constantemente para avaliar o desempenho operacional. Dois destes indicadores, por exemplo, são o indicador de passageiros impactados por atrasos na viagem e o indicador de regularidade de intervalos.

$\mathrm{O}$ indicador de regularidade dos intervalos mede a aderência dos intervalos realizados ao programa de operação padrão. São realizadas medições de intervalos nos terminais de partida e em pontos estratégicos da linha para verificar se o processo está sob controle. Para tanto é definido um limite de controle inferior e superior e todos os intervalos praticados que não estiverem compreendidos entre estas faixas, são considerados não conformidades e necessitam de investigação e tratamento.

No caso do indicador de passageiros impactados por atrasos, são verificados quantos atrasos de viagem ocorreram durante a operação comercial e qual é a estimativa do número de 
passageiros totais que estavam em cada uma das viagens em atraso. $\mathrm{O}$ acompanhamento deste indicador visa identificar os momentos, locais e causas dos atrasos. Com base neste diagnóstico são propostos planos de ação para alterar o estado atual para minimizar o número de viagens em atraso e o número de passageiros impactados. Desta forma, estas análises suportam as estratégias para prover um serviço mais previsível e de maior qualidade ao passageiro.

2 - Quais são as aplicações em que são utilizadas as técnicas de modelagem envolvendo teoria das filas?

Os trens operam num modelo de carrossel onde os primeiros trens a chegarem em um terminal $\mathrm{X}$ são aqueles que realizaram a as primeiras viagens (sequenciamento FIFO). Esta programação é modificada pelas operações de injeção e/ou retirada, que são os momentos onde novos veículos são inseridos ou retirados do carrossel de trens. A variabilidade do processo é controlada por meio do uso de técnicas de planejamento que possibilitem as ações de regulação dos operadores de tráfego. Uma destas técnicas é a utilização de trens reservas alocados em pontos específicos das linhas e/ou o uso do tempo de regulação nos terminais, onde os eventuais atrasos e/ou adiantamentos nas viagens são absorvidos.

Adicionalmente o monitoramento estatístico dos dados das viagens realizadas por viagem e por trecho, retroalimentam o processo de planejamento operacional. Utilizando estas informações as marchar tipos são revalidadas ou revisadas e o plano operacional é readequado.

3 - Há diferenças na modelagem para representar a fila dos trens durante os período de pico no dia?

Sim. Há diferenças entre o planejamento dos intervalos nos diferentes períodos do dia. A realização de viagens tem como objetivo a criação de oferta de lugares para atender uma dada demanda. Desta forma, a programação dos intervalos é realizada tomando em consideração a demanda para o serviço.

Em nosso caso, são extraídos os dados de entrada de passageiros nas várias estações do sistema e aplicando os dados da matriz origem $x$ destino. Estes estudos são realizados para monitoramento contínuo da adequação da oferta de lugares ofertada (taxa de ocupação dos veículos, fator de renovação da oferta nível de conforto dos usuários nos trens e plataformas). Existem ainda estudos de projeção de demanda futura (horizontes futuros, ou início de novos serviços) pela área de inteligência de mercado mediante o acompanhamento de variáveis macroeconômicas, uso de solo e monitoramento do setor de transportes e concorrência.

4 - Para melhor aderência das análises operacionais, faz-se necessário conhecer a confiabilidade do material rodante. Assim, quais são as técnicas de engenharia de confiabilidade utilizadas na manutenção?

As equipes de engenharia de manutenção suportam as equipes de manutenção com técnicas de RAMS. São criados os masterplan de manutenção preventiva, inspeção regular da frota, análises de falha e acompanhamentos estatísticos. A engenharia de manutenção também tem investido em projetos de monitoramento preditivo. A ferramenta FMEA também é utilizada para construção das árvores de falhas dos sistemas e subsistemas de Material Rodante, Infraestrutura e Sistemas, que auxiliarão na identificação de causas e efeitos para definição de ações que serão utilizadas para inibir as falhas. 


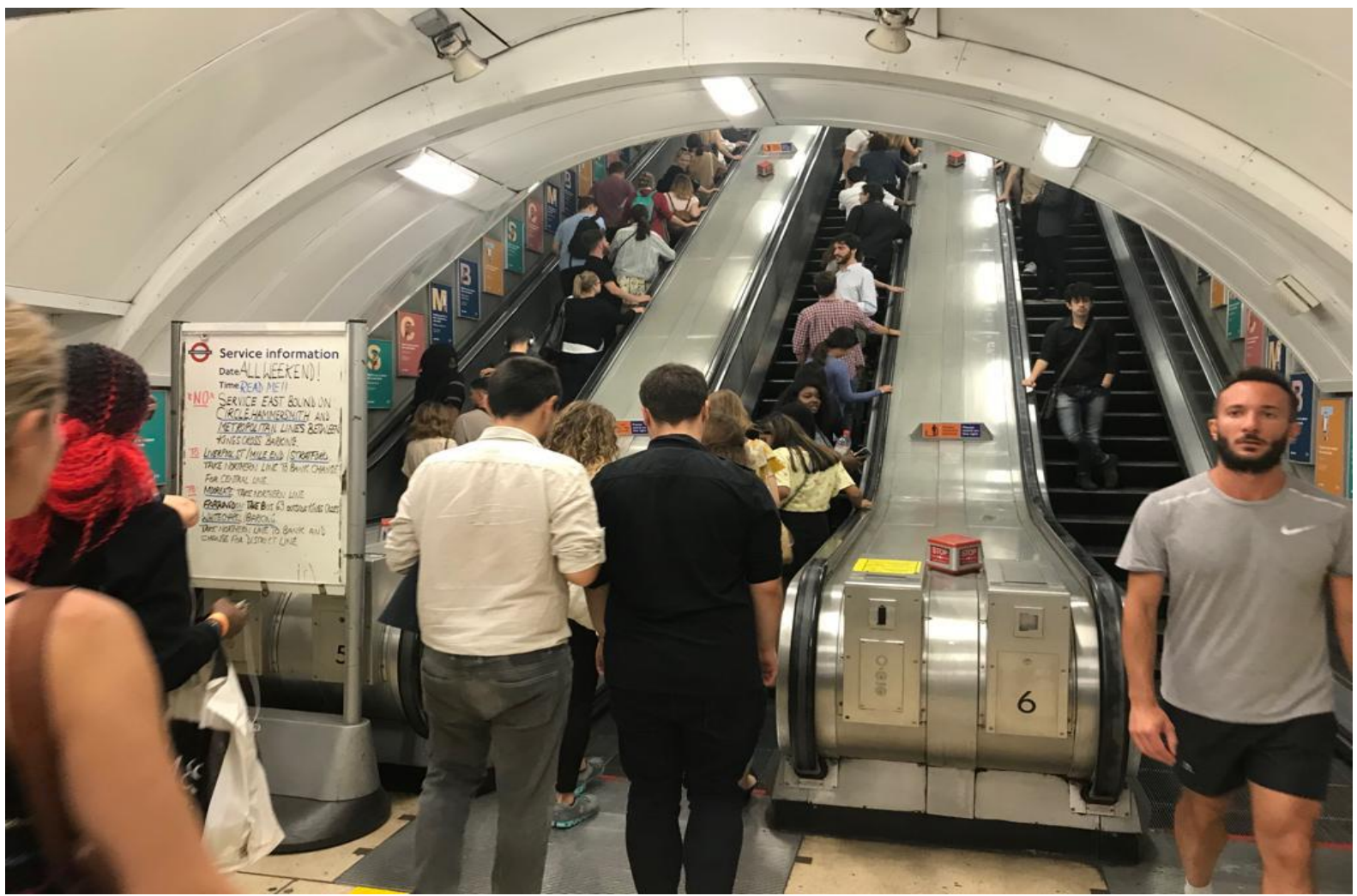

Figura 7.5 Nas estações de metrô, as filas se iniciam nos acessos às plataformas.

\subsection{APLICAÇÃO PUBLICADA EM REVISTA CIENTÍFICA E OUTROS LOCAIS}

a) "Investigation into the bimodal transportation process by modelling rail module states" publicado em 2017 no períodico Transports Problems: an international scientific journal, artigo que analisa a probabilidade do modo estável num sistema ferroviário de filas com prioridades, com ou sem mudança de marchas em operação.

b) Análise do desempenho de Terminais Ferroviários utilizando Teoria das Filas e simulação de eventos discretos - Um estudo www.ufjf.br/engenhariadeproducao/files/2014/09/2005 3 Guilherme.pdf

c) PLANEJAMENTO OPERACIONAL BASEADO EM TEORIA DE FILAS E SIMULAÇÃO DE EVENTOS DISCRETOS

http://transportes.ime.eb.br/etfc/monografias/MON014.pdf

d) Os trens urbanos e a teoria das filas

https://institutoparacleto.org/2013/04/25/os-trens-urbanos-e-a-teoria-das-filas/ 


\title{
7.4 APLICAÇÕES APRESENTADAS EM CONGRESSOS
}

\author{
Encontro Nacional de Engenharia de Produção
}

1) JUNIOR, J. U. P.; NASCIMENTO, A. N. Modelagem para otimização do transporte de cargas no complexo logístico intermodal Porto Sul. In: XXXIV ENCONTRO NACIONAL DE ENGENHARIA DE PRODUCAO. Curitiba, PR, Brasil, 07 a 10 de outubro de 2014. Disponível em:

<http://www.abepro.org.br/biblioteca/enegep2014 TN STO 200134 25049.pdf>. Acesso em: 03/07/2019.

Resumo: O presente trabalho consiste em uma proposta de metodologia para representar o transporte ferroviário de cargas de minério de ferro a partir de minas localizadas no interior da Bahia para o complexo logístico, incluindo porto, que vem sendo estruturado na cidade de llhéus. A metodologia está concebida em base de estudo analítico-descritivo por decomposição hierárquica do complexo, envolvendo simulação de eventos discretos e otimização dos custos. Como recurso informatizado da simulação propõe-se o emprego do software Arena, o qual deverá facilitar a modelagem da fila das composições ferroviárias e seus recursos e, posteriormente, contribuir na modelagem do sistema portuário. Os dados para simulação estão sendo levantados no próprio Projeto do empreendimento, divulgado pelo Governo do Estado da Bahia, bem como em operações ferroviárias equivalentes existentes no Brasil. Como resultado a metodologia aqui proposta deverá ser bastante útil na tomada de decisão gerencial, sobretudo no fluxo otimizado da extração do minério e dos recursos materiais necessários.

2) DIAS, L. C.; DZEMBATY, R.; RODRIGUES, V. O.; CHIN, S. Y. Aplicação de teoria das filas para analisar o nível de serviço prestado pelo metrô da estação do Jabaquara na cidade de São Paulo-SP. In: XXXVIII ENCONTRO NACIONAL DE ENGENHARIA DE PRODUCAO. Maceió, Alagoas, Brasil, 16 a 19 de outubro de 2018. Disponível em: <

http://www.abepro.org.br/biblioteca/TN WIC 263511 36158.pdf>. Acesso em: 03/07/2019.

Resumo: objetivo deste trabalho é aplicar os conceitos de teoria das filas na definição do melhor nível operacional oferecido ao usuário, estabelecendo os valores adequados de headway e do número de vagões. $O$ transporte público tem grande importância para a cidade de São Paulo. Para o estudo, serão considerados os níveis de demandas alto, médio e baixo. Os resultados mostram que para o nível de demanda baixa, o headway e o número de vagões atuais são suficientes para suprir as necessidades, enquanto para a demanda média e alta mostra que a mudança no headway e no número de vagões respectivamente se faz necessária para que possa ser usada a capacidade do sistema e atender as demandas.

\subsection{NOTÍCIAS DE JORNAIS SOBRE TEORIA DAS FILAS}

Menos filas no carnaval: estação Cinelândia do VLT terá mais duas máquinas de venda de bilhetes

https://oglobo.globo.com/rio/menos-filas-no-carnaval-estacao-cinelandia-do-vlt-tera-mais-duasmaquinas-de-venda-de-bilhetes-20819579 
FILAS: conceitos, novos enfoques de abordagem e aplicações em Transportes

Fila para entrar no metrô chega a $\mathbf{3 0}$ minutos em estações da zona leste

https://sao-paulo.estadao.com.br/noticias/geral,fila-para-entrar-no-metro-chega-a-30-minutosem-estacoes-da-zona-leste, 1018342

Estações de metrô têm longas filas em São Paulo

https://jornaldebrasilia.com.br/politica-e-poder/estacoes-de-metro-tem-longas-filas-em-saopaulo/

Pequim reforça segurança no metrô e forma filas enormes

https://www.terra.com.br/noticias/mundo/asia/pequim-reforca-seguranca-no-metro-e-formafilas-enormes,793406ebd4146410VgnVCM3000009af154d0RCRD.html

Linha 5 do metrô de SP tem atraso e fila na estreia de gestão privada

https://www1.folha.uol.com.br/cotidiano/2018/08/linha-5-do-metro-de-sp-tem-atraso-e-fila-naestreia-de-gestao-privada.shtml

Volta dos bondes de Santa Teresa registra longas filas e espera de mais de uma hora para embarque

https://oglobo.globo.com/rio/volta-dos-bondes-de-santa-teresa-registra-longas-filas-espera-demais-de-uma-hora-para-embarque-16975617 


\section{Capítulo OITO \\ Aplicação da teoria das filas no transporte aquático ${ }^{10}$}

YURI MARINHO DE CARVALHO ${ }^{11}$

\subsection{INTRODUÇÃO AO TRANSPORTE AQUÁTICO}

Regulamentado pelo Ministério da Infraestrutura, por meio da Agência Nacional de Transportes Aquaviários (ANTAQ), é o modal que trafega por rios, lagos, canais, mares e oceanos. É utilizado para o transporte de mercadorias e pessoas. Com relação aos custos desse modal, destacam-se: custo fixo médio (navios e equipamentos), custos portuários, administrativos e custo do combustível (principalmente na navegação de cabotagem, onde há incidência de ICMS (17\%), PIS (1,65\%). CONFINS $(7,6 \%)$ e CIDE $(5,5 \%)$.

Analisando as nossas exportações, nota-se que pelos nossos portos passam a maior parte das mercadorias comercializadas no exterior, o que demonstra a importância de ações públicas institucionais que visem aumentar o nível de eficiência do setor e, ao mesmo tempo, diminuir os custos logísticos agregados. O Brasil é um país abundante em hidrovias navegáveis que, muitas vezes, não são exploradas de forma adequada.

Embora a maior parte do comércio exterior brasileiro passe pelos portos, o nível de eficiência do setor se tornou inadequado nas últimas décadas, o que demonstra a importância de ações que visem aumentar a estrutura logística capaz de atender à crescente demanda. Como podemos observar na figura $\mathrm{X}$, apesar do Brasil ser farto em vias aquaviárias navegáveis e o custo de transporte por esse modal ser compensador (devido a nossa extensão territorial), a movimentação por vias aquaviárias ainda representa menos de $15 \%$ da participação total dos modais.

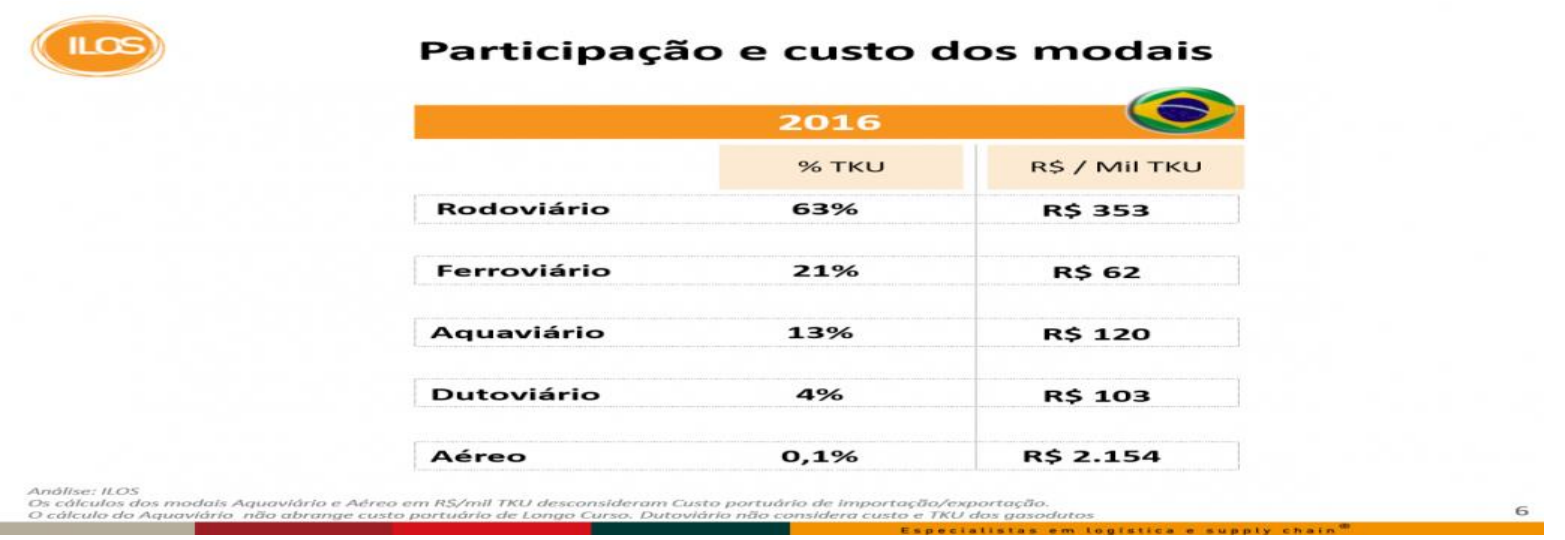

Figura 8.1 - Participação e custo dos modais.

Fonte: Instituto ILOS (2016).

\footnotetext{
${ }^{10} \mathrm{O}$ nome inicial era aquaviário. Entretanto, atendeu-se à sugestão do professor Márcio de Almeida D'Agosto (PET/COPPE/UFRJ), que sugeriu ser mais adequado utilizar transporte aquático ao invés de aquaviário, porque nem toda a atividade pelo modo aquático (por água) considera a existência de uma via.

${ }^{11}$ Com a participação de Adonis Carneiro da Silva, Felipe Pereira Rosa Pierrotti, Lucas de Castro Valente e Rafael Ferreira Almeida.
} 
Esse tipo de transporte depende de terminais portuários para carga, descarga, movimentação e manuseio das cargas, mesmo que existam barcaças e navios que permitem o transbordo diretamente para outras sem a necessidade do suporte em terra. Para realizar as operações de carregamento e descarregamento são utilizados empilhadeiras, guindastes, correias transportadoras, entre outros.

Na maioria das vezes, esses terminais são construídos por agências locais, que operam seus próprios armazéns devido às necessidades especiais da operação, ou então são construídos por órgãos governamentais.

A navegação marítima é responsável pelo maior volume de tráfego devido a possibilidade de transportar grande quantidade de carga entre os países de outros continentes, ou até mesmo pela costa, ainda que não seja o transporte mais rápido. As principais subdivisões do transporte aquático são em hidroviário e marítimo.

O transporte marítimo utiliza o mar aberto e pode ser subdividido em dois:

1) Cabotagem, quando se navega entre um ponto costeiro e um fluvial ou entre costas, também conhecido como navegação costeira. Por exemplo, Porto de Suape (Pernambuco) e Porto de Santos (São Paulo); ou

2) Navegação de longo curso ou internacional, quando se navega entre um porto brasileiro e um estrangeiro.

A Agência Nacional de Transportes Aquaviários (ANTAQ) define algumas características para o transporte marítimo de carga no Brasil, que constam no Quadro 8.1.

Quadro 8.1- Características do transporte marítimo

Grande capacidade de carga

Pode transportar cargas de grandes tamanhos

Baixo custo de transporte para grandes

distâncias

Transporta diversos tipos de cargas

Flexibilidade superior ao transporte

hidroviário

Fonte: Elaborado pelo autor.

As Figuras 8.2 e 8.3 indicam a localização geográfica e quantitativa dos principais portos brasileiros, com a maior concentração no Sul e no Sudeste.
Transporte lento

Necessidade de portos e alfândegas maior concentração no Sul 


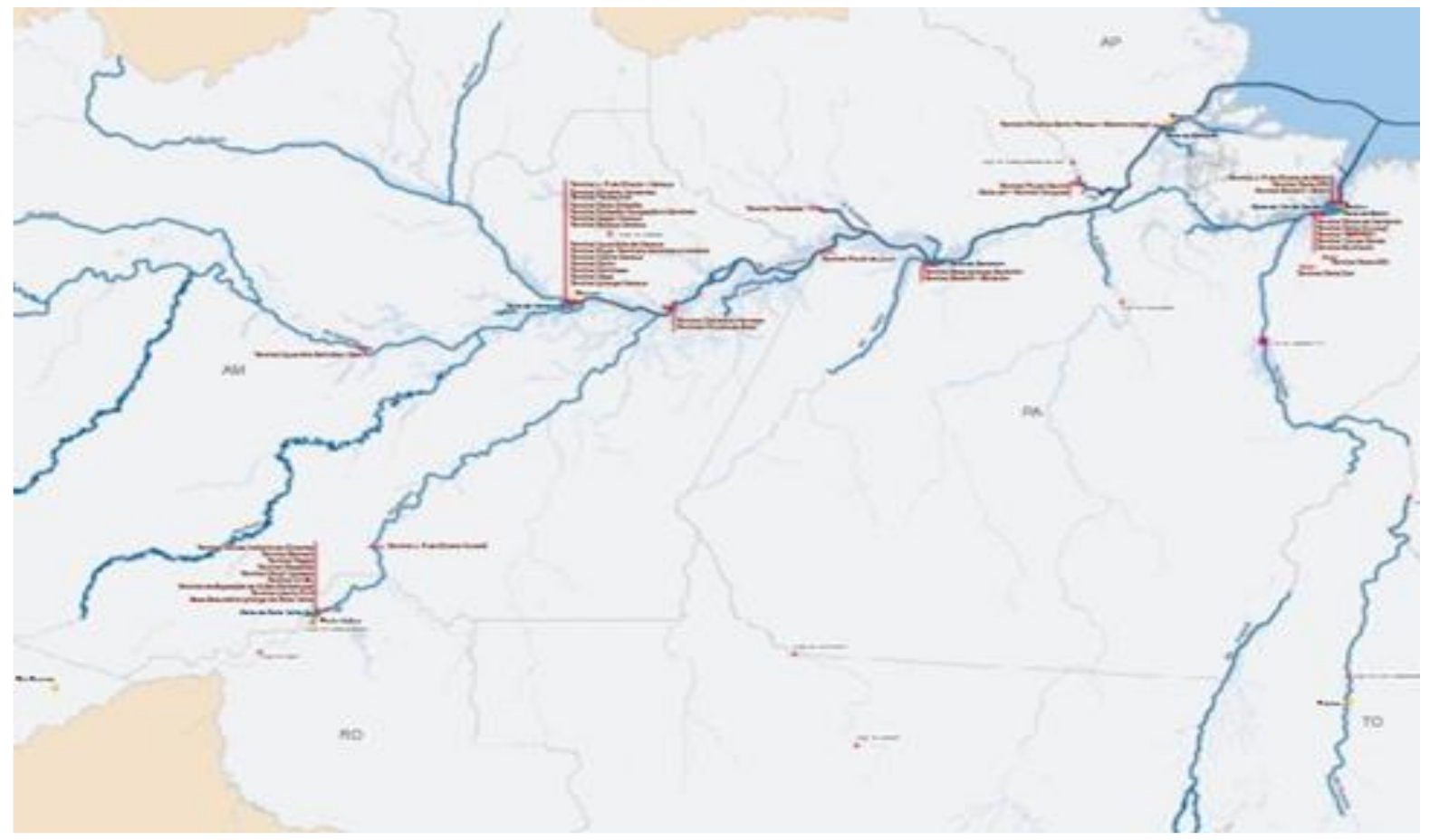

Figura 8.2. Região Norte

Fonte: http://infraestrutura.gov.br/component/content/article/63-bit/5124-bitmodosmapas.html

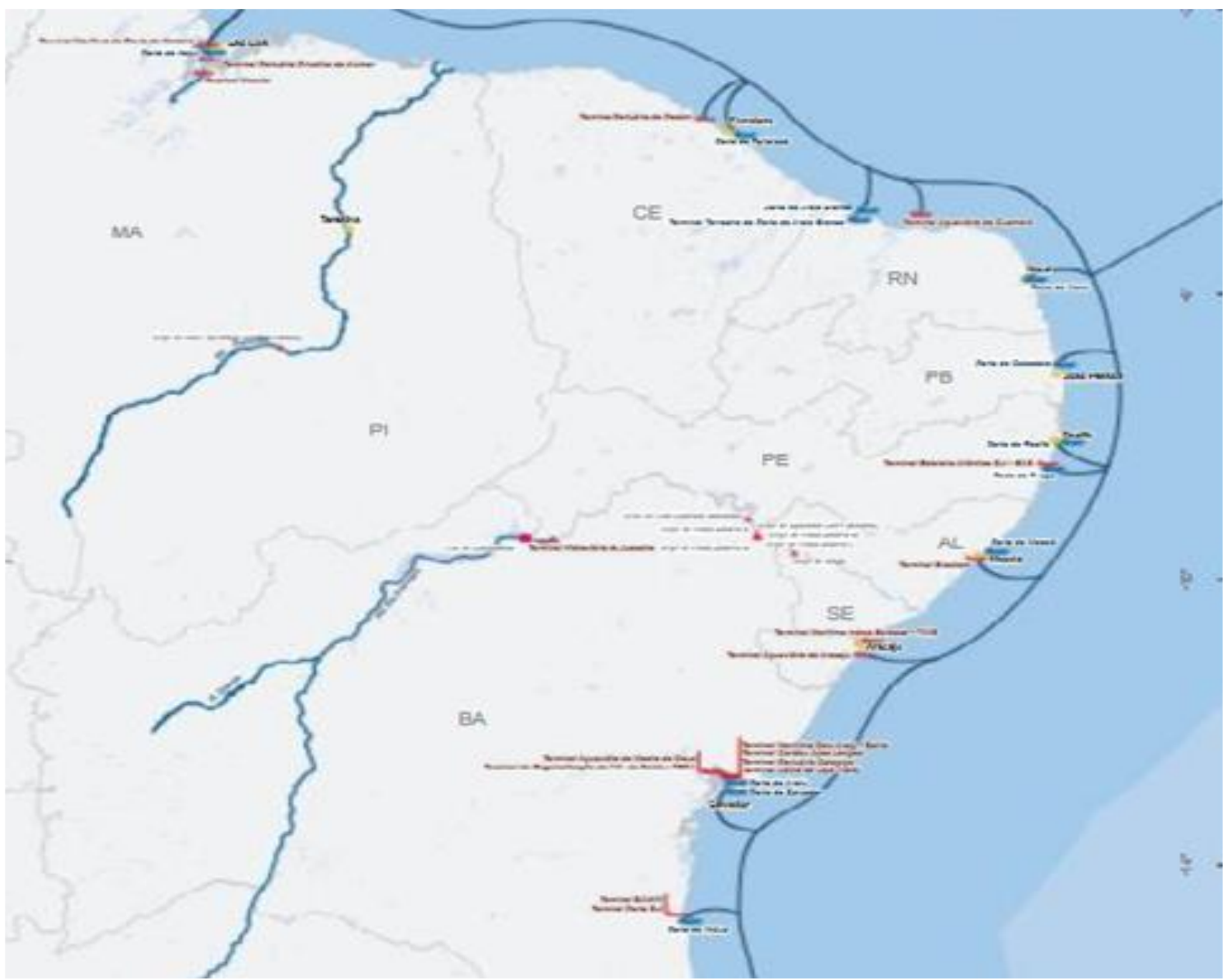

Figura 8.3. Região Nordeste

Fonte: http://infraestrutura.gov.br/component/content/article/63-bit/5124-bitmodosmapas.html 


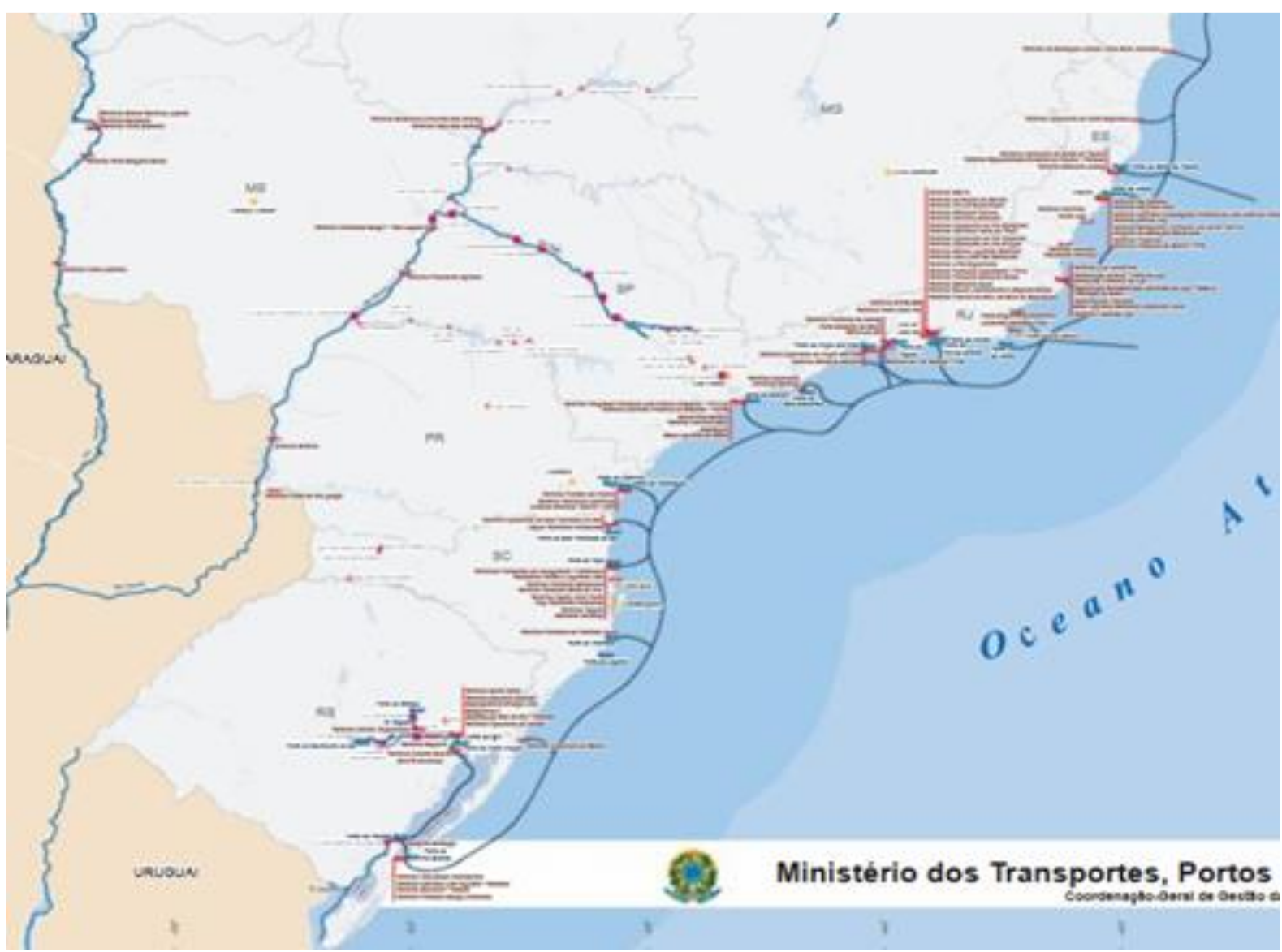

Figura 8.4. Regiões Sul, Sudeste e Centro-Oeste

Fonte: http://infraestrutura.gov.br/component/content/article/63-bit/5124-bitmodosmapas.html

O transporte hidroviário é realizado em hidrovias, percursos pré-determinados para o tráfego aquático. Os rios, lagos e lagoas navegáveis passam por um processo de adequação às normas de segurança, recebendo melhorias como sinalização, dragagem, derrocagem e balizamento para permitir um fluxo seguro de embarcações pelas vias marítimas. As principais hidrovias brasileiras estão dispostas no Quadro 8.2 e ilustradas na Figura 8.5.

\begin{tabular}{|c|c|}
\hline Regiões hidrográficas & Hidrovias \\
\hline Amazônica & $\begin{array}{c}\text { Do Amazonas, do Solimões, do } \\
\text { Madeira, do Tapajós, do Pará, do } \\
\text { Negro, do Juruá, do Trombetas e do } \\
\text { Xingu }\end{array}$ \\
\hline Do Paraná & Do Paraná-Tietê e do Paranaíba \\
\hline Do Paraguai & Do Paraguai \\
\hline Do Tocantins-Araguaia & Do Tocantins e do Araguaia \\
\hline Do São Francisco & Do São Francisco \\
\hline Do Atlântico Sul & Do Sul \\
\hline
\end{tabular}




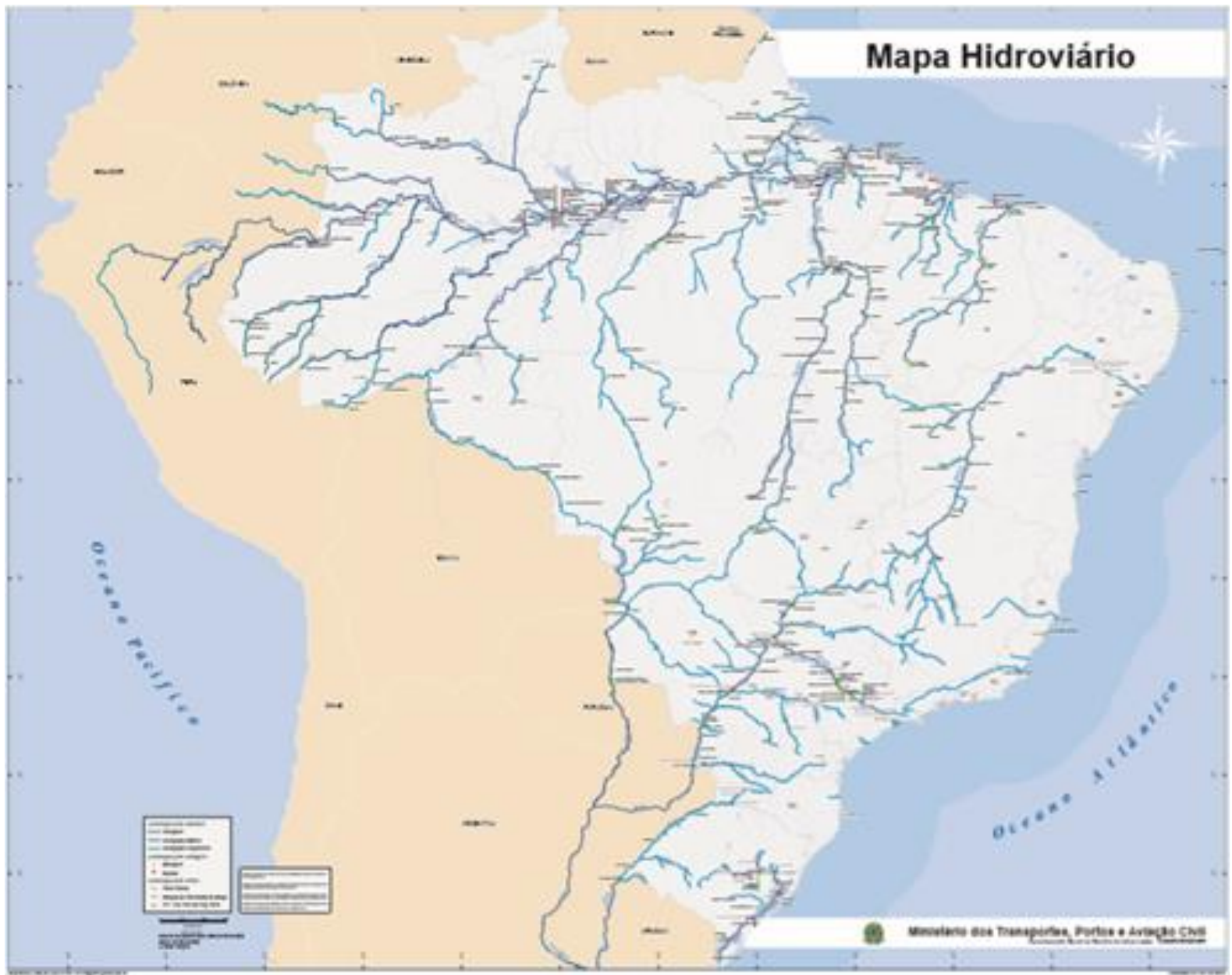

Figura 8.5 - Mapa Hidroviário

Fonte: http://infraestrutura.gov.br/component/content/article/63-bit/5124-bitmodosmapas.html

É através das hidrovias que são transportados elevados volumes de mercadorias a longas distâncias, com o principal objetivo de redução de emissão de $\mathrm{CO} 2$ e do custo do frete. Algumas das principais características desse modal estão dispostas conforme o quadro 8.3.

Quadro 8.3- Características do transporte hidroviário

\begin{tabular}{|c|c|}
\hline Vantagens & Desvantagens \\
\hline $\begin{array}{l}\text { Grande capacidade de carga } \\
\text { Baixo custo de transporte } \\
\text { Baixo custo de manutenção } \\
\text { Baixo custo de implantação quando se analisa } \\
\text { uma via natural, mas pode ser elevado se } \\
\text { existir necessidade de construção de } \\
\text { infraestruturas especiais como eclusas, } \\
\text { barragens e canais. }\end{array}$ & $\begin{array}{l}\text { Baixa flexibilidade } \\
\text { Transporte lento } \\
\text { Influenciado pelas condições climáticas }\end{array}$ \\
\hline
\end{tabular}

Fonte: Elaborado pelo autor 


\subsection{VISÃO DE UM PROFESSOR E DE UM PROFISSIONAL DA ÁREA}

a) Visão de um professor da área:

O professor Márcio de Almeida D'Agosto da COPPE/UFRJ possui ampla experiência em aplicação de teoria das filas nos transportes aquáticos e rodoviários. Para essa etapa exploraremos os conhecimentos do professor em nossa entrevista para o modal aquático.

1 - Quais são os desafios envolvendo filas no modal aquático?

Nesse modal temos o problema clássico de receber navios em um porto. As chegadas geralmente seguem uma distribuição de Poisson e os tempo de atendimento seguem uma FDP exponencial negativa. Analisadas as chegadas por dia e os tempos de atendimento nos berços. Verificar a utilização dos berços e se havia algum ponto com excesso de ocupação. Nos estudos em que já realizei utilizei apenas a modelagem analítica por meio do Excel, não envolvi softwares de simulação.

2 - Quais os melhoramentos você pode decifrar nos estudos envolvendo teoria de filas?

Idealmente, toda a aplicação que está associada a um sistema de recepção e processamento de unidades pode usar a teoria das filas. Por exemplo: aeroportos, pátios ferroviários, armazéns, centros de distribuição etc.

b) Visão de um profissional da área:

O modal aquático apresenta suas particularidades que serão elucidadas por Tiago Terra do setor Engenharia e Operação da organização CCR Barcas:

1 - Quais são os problemas encontrados com filas em sua organização?

Temos como questão central em nossa organização o desafio de equalizar a taxa de chegada muito concentrada em um curto espaço de tempo.

2 - Indique o método mais aplicado na busca por soluções.

Realizamos análises práticas e estatísticas. Dessa forma, confrontamos os modelos analítico com o observado no dia a dia.

3 - A organização dispõe de alguma ferramenta computacional para estudo do problema? Caso positivo, cite-a.

Não dispõe de ferramenta de simulação internalizada na empresa. Nos casos específicos para desenvolvimento de projetos de simulação, que envolvem filas ou demais metodologia de simulação, realizamos a contratação de empresas terceirizadas especializadas em cada tipo de solução.

\subsection{APLICAÇÕES REAIS APRESENTADAS EM CONGRESSOS E ARTIGOS}

A falta de investimento em infraestrutura aquaviária concatenada com o alto valor transportado pelo modal aquático, torna este transporte um dos objetos de estudo mais recorrentes em congressos e revistas de transporte. Podemos verificar a aplicabilidade da teoria das filas em alguns casos, como os a seguir expostos: 
1. Análise da implementação do sistema de agendamento de carga no porto de Santos

Neste trabalho, verificou-se que o porto de Santos, apesar de escoar mais de $70 \%$ da produção brasileira, possui problemas com relação a chegada de caminhões de carga. Desta maneira, a CODESP (autoridade portuária santista) decidiu implantar um sistema de pré-agendamento para melhorar a gestão do porto. Com vista a evitar filas nas rodovias, este trabalhou buscou avaliar os métodos utilizados em agendamentos de carga e descarga.

2. Carregamento e descarregamento de navios na zona portuária de Vitória -ES: simulação com modelo desenvolvido no software arena.

Apesar de ter sido utilizado um software de simulação, neste artigo podemos ver o conceito de fila sendo empregado em uma empresa atuante na área portuária, na cidade de Vitória, Espírito Santo. Nestes casos, o maior problema geralmente ocorre na troca de modalidade de transporte e, este trabalho identificou gargalos e ociosidade de carretas e em carregamento ou descarregamento de navios. A partir de então, buscou-se otimizar o tempo de espera das carretas nas filas, para melhorar o processo da empresa.

3. Aplicação da teoria das filas na movimentação de navios no complexo portuário de Itajaí.

A aplicação da teoria das filas pode ser observada neste trabalho, que a utilizou para tornar mais eficiente a movimentação de navios nos terminais Portonave S/A e APM Terminals Itajaí, pertencentes ao Complexo portuário de Itajaí. O modelo originado foi o $M / M / n$ com " $n$ " canais de atendimento no terminal de destino, sendo possível a partir desse modelo, sugerir melhorias na infraestrutura dos terminais. Constatou-se que o complexo atua com demanda reprimida e não está preparado para um aumento no curto prazo, principalmente o APM Terminals Itajaí, que necessita aumentar seu nível de serviço vigente.

\subsection{REPORTAGENS QUE ABORDAM FILAS NO TRANSPORTE AQUÁTICO.}

O transporte aquático é dependente da intermodalidade para viabilizá-lo. Desta maneira, devido a diversos fatores, como a diferença de capacidade de carga, infraestrutura de manuseio de mercadorias, dentre outros, podem gerar filas quando a capacidade e a demanda não estão otimizadas. Desta maneira, podemos observar algumas reportagens de alguns periódicos que abordam o problema das filas neste modal.

1. Privatização das balsas não garante fim das filas nas margens, diz secretário de Transportes.

Em São Paulo, o secretário de Logística e Transportes não garante que as filas das oito travessias que funcionam diariamente transportando passageiros e veículos irão acabar após a privatização das travessias litorâneas. Os passageiros reclamam semanalmente sobre o tempo de espera nas filas e sobre as condições das balsas.

https://g1.globo.com/sp/santos-regiao/noticia/2019/05/27/privatizacao-das-balsas-naogarante-fim-das-filas-nas-margens-diz-secretario-de-transportes.ghtml 
2. País não tem como escoar safra sem fila, admite ministro.

Em 2014, o então ministro da Secretaria Especial dos Portos (SEP), admitiu ser impossível garantir que não haverá fila nos portos para escoamento das safras de grãos. A Agência Nacional de Transportes Aquaviários aplicou multas pesadas para evitar o problema. Embora este problema seja complexo, o agendamento de caminhões diminuiu o gargalo portuário que havia na época.

\section{https://economia.estadao.com.br/noticias/geral,pais-nao-tem-como-escoar-safra-sem-fila- admite-ministro-imp-,1134207}

3. Porto da Capital tem fila de espera para navios atracarem.

Infelizmente, devido à burocracia e à falta de infraestrutura, grande parte dos portos brasileiros apresentam filas para atracação. É o que observamos ter ocorrido nesta reportagem no Cais Navegantes (Porto de Porto Alegre). A falta de berço de atracação acarreta um congestionamento de navios, que aguardam para descarregar produtos para a fabricação de fertilizantes.

https://transportes.rs.gov.br/porto-da-capital-tem-fila-de-espera-para-navios-atracarem

4. Porto de Paranaguá diminui fila de caminhões e melhora eficiência.

https://canalrural.uol.com.br/conteudo-patrocinado-campanha/porto-de-paranaguadiminui-fila-de-caminhoes-e-melhora-eficiencia/

A aplicação de sistemas que otimização através de simulação ou teoria das filas acarreta melhoria da eficiência em alguns portos brasileiros. É o que constatamos nesta reportagem. O Porto de Paranaguá, principal complexo exportador de grãos e derivados do Brasil, é considerado um modelo no segmento devido ao sistema de tecnologia da informação que otimiza/ simula o fluxo de carga desde o carregamento até o embarque. Assim sendo, aumenta-se a produtividade do porto e diminui os custos envolvidos.

5. Fila de navios para embarcar soja no Brasil cresce $60 \%$ com protestos e tabela de frete:

No ano de 2018, o protesto de caminhoneiros nas rodovias ocasionou enormes filas nos portos brasileiros. O total de navios em portos brasileiros aguardando para embarcar produtos do complexo de soja ficou quase $60 \%$ superior ante igual período do ano de 2017 , enquanto a quantidade de embarcações efetivamente recebendo cargas apresenta queda de $42 \%$ na base de comparação.

https://g1.globo.com/economia/agronegocios/noticia/fila-de-navios-para-embarcar-soja-nobrasil-cresce-60-com-protestos-e-tabela-de-fretes.ghtml

6. Codesp quer reduzir o tempo de espera de navios no porto de Santos:

A Companhia Docas do Estado de São Paulo (Codesp) realizou estudo para reduzir o tempo de espera dos navios para atracar no Porto de Santos. Para que a espera diminuísse de nove para seis dias, a autoridade portuária aumentou a sincronização entre trens e navios, além de promover a implantação de hidrovia para o transporte de contêineres. 
https://g1.globo.com/sp/santos-regiao/porto-mar/noticia/codesp-quer-reduzir-o-tempo-deespera-de-navios-no-porto-de-santos.ghtml

7. Prejuízo no porto de Santos chegou a $\mathrm{R} \$ 1,5$ bilhões, estima sindicato:

Alteração na disciplina da fila/ fluxo de caminhões durante a greve dos caminhoneiros e transtorno logístico no porto acarretou enormes filas de espera de navios para atracação. Prejuízo estimado é de $\mathrm{R} \$ 1,5$ bilhões.

https://www1.folha.uol.com.br/mercado/2018/06/prejuizo-no-porto-de-santos-chegou-a-r15-bi-estima-sindicato.shtml

8. Fila de caminhões com soja causa congestionamento de $4 \mathrm{~km}$ na BR 324 :

Superlotação no galpão do Terminal Portuário de Cotegipe, na Baía de Aratu, ocasionou congestionamento de cerca de 400 caminhões da multinacional holandesa, Band Alimentos, por aproximadamente $4 \mathrm{~km}$ de acostamento na BR-324.

https://www.correio24horas.com.br/noticia/nid/fila-de-caminhoes-com-soja-causacongestionamento-de-4km-na-br-324/

9. Brexit: Could leaving with no deal cause traffic jams?

Nesta reportagem da $B B C$ News, observamos um dos possíveis impactos da saída da Inglaterra do BREXIT, que será o engarrafamento em torno dos portos. Especialistas estudam planos de contingenciamento para gerenciar o fluxo de tráfego em caso de não acordo no BREXIT.

\section{https://www.bbc.com/news/uk-46794226}

\subsection{USO NO TURISMO.}

As hidrovias podem ser utilizadas pelo turismo, por meio de navegação simples pelos rios da região. Dois exemplos estão nas Figuras 8.6 e 8.7.

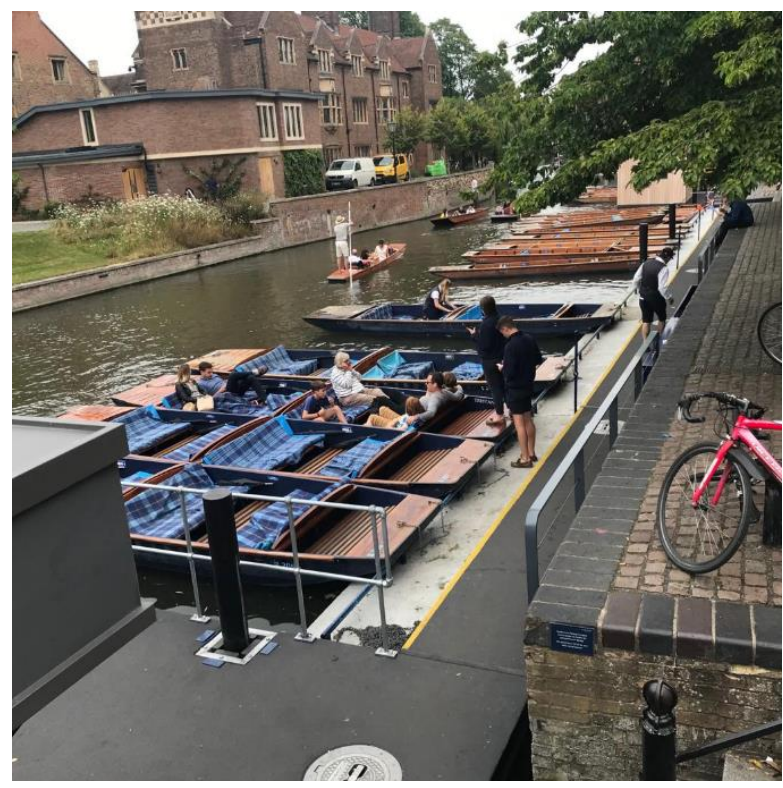

Figura 8.6. Passeio no rio Cam, na cidade de Cambridge, Reino Unido. 


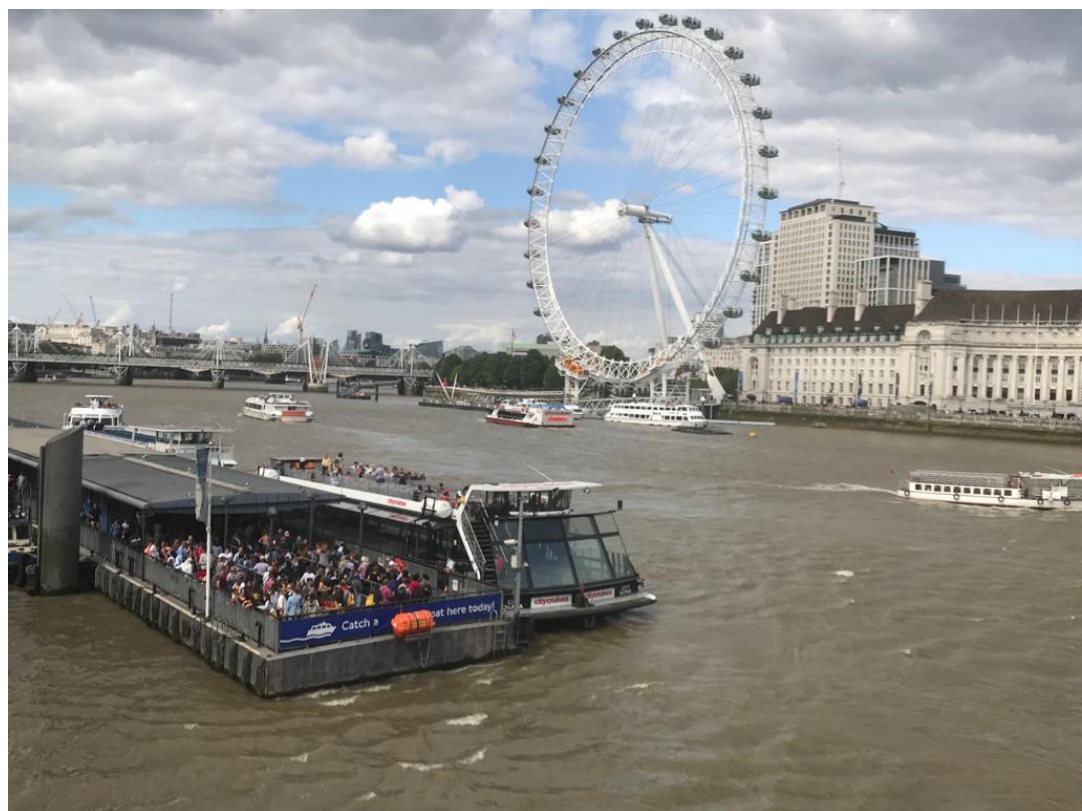

Figura 8.7. Passeio no rio Tâmisa, na cidade de Londres, Reino Unido.

\section{REFERÊNCIAS BIBLIOGRÁFICAS}

BRASIL. Agência Nacional De Transportes Aquaviários (ANTAQ). Anuário estatístico (2019b). Brasília, 2010. Disponível em: <web.antaq.gov.br/Anuario/>. Acesso em: 10/07/2019

BRASIL. Ministério da Infraestrutura. Mapas Hidroviários. 2019a. Disponível em:<http://infraestrutura.gov.br/component/content/article/63-bit/5124-bitmodosmapas.html>. Acesso em 24/07/2019

GROSSL, B.; BECKERT, D.; FERNANDES, C. W. N.; LIMA, E. C. S. Aplicação da teoria das filas na movimentação de navios no complexo portuário de Itajaí. In: XXXVII ENCONTRO NACIONAL DE ENGENHARIA DE PRODUCAO. Joinville, SC, Brasil, 10 a 13 de outubro de 2017. Disponível em: < http://www.abepro.org.br/biblioteca/TN_STO_243_410_31427.pdf>. Acesso em: 03/07/2019.

Instituto llos. Participação e custo dos modais. <https://www.ilos.com.br/web/wpcontent/uploads/custos-log\%C3\%ADsticos_modais-ILOS-1030x773.png>. Acesso em 18/07/2019.

JUBINI, S. V.; VITOR, S. S.; AVELAR, M. P. M.; LEOPOLDO, B. P.; HENRIQUES, M. R. Carregamento e descarregamento de navios na zona portuária de Vitória -ES: simulação com modelo desenvolvido no software arena. In: XXXVI ENCONTRO NACIONAL DE ENGENHARIA DE PRODUCÃO. João Pessoa/PB, Brasil, de 03 a 06 de outubro de 2016. Disponível em: < http://www.abepro.org.br/biblioteca/TN_STO_231_350_29003.pdf>. Acesso em: 03/07/2019.

PEREIRA, Ana Cristina da Silva. Transporte Intermodal: Um estudo do modelo Estadunidense Europeu vs. Situação Brasileira. Dissertação de Mestrado Coppead. UFRJ, 2003, 174P.

SOLIANI, R. D.; JÚNIOR, J. B. C. Análise da implementação do sistema de agendamento de carga no porto de Santos. Revista dos Transportes Públicos - ANTP - Ano 37 - 2015 - 2 quadrimestre, pág. 111 a 124. Disponível em: <http://files.antp.org.br/2016/4/8/rtp140-e.pdf>. Acesso em: 03/07/2019. 


\section{Capítulo NOVE \\ Aplicação da teoria das filas no transporte aéreo}

FELIPE PEREIRA ROSA PIERROTTI ${ }^{12}$

\subsection{INTRODUÇÃO AO TRANSPORTE AÉREO}

A principal característica do transporte aéreo é a capacidade de mover rapidamente cargas de pequeno volume e alto valor agregado em grandes distâncias. Sua alta velocidade é devido ao fato deste modal não enfrentar as barreiras físicas que os modais terrestres enfrentam. Permite o controle da falta de produtos devido a rapidez da prestação do serviço, levando em consideração o trade-off entre custo e nível de serviço, pois é o transporte que possui o frete mais caro, devendo ser utilizado em momentos de emergência, para produtos com alto valor agregado e alto grau de perecibilidade.

Com relação ao nível de serviço, este modal é o mais veloz, porém o menos consistente, devido a sua sensibilidade às condições climáticas e a importância prestada à segurança. Já a sua capacitação, que é a possibilidade de trabalhar com produtos de diferentes volumes e variedades, só ultrapassa o dutoviário, assim como a frequência só está acima do aquático, possuindo mais disponibilidade mediana comparada aos outros meios de transporte. Embora apresente custos fixos altos (aeronave e sistemas de manuseio), seus custos variáveis também são os mais elevados (combustível, mão-de-obra e manutenção). Consequentemente este modal possui o maior preço relativo do frete praticado no Brasil e a menor participação na matriz de transportes, mesmo possuindo velocidade muito superior aos outros modais, níveis de avarias e extravios mais baixos e maior segurança e confiabilidade, pois sua capacidade de carga é bem menor que os modais marítimo e ferroviário, ganhando apenas do rodoviário.Algumas de suas principais características podem ser identificadas no Quadro 9.1:

Quadro 9.1- Características do transporte aéreo

\begin{tabular}{|l|l|}
\hline \multicolumn{2}{|c|}{ Vantagens } \\
$\begin{array}{l}\text { Embarques em pequenas quantidades e sem } \\
\text { necessidade de embalagens tão } \\
\text { especializadas e custosas quanto aos demais } \\
\text { modais }\end{array}$ & $\begin{array}{l}\text { Requer terminais elaborados e caros, que } \\
\text { geralmente não são de propriedade dos } \\
\text { operadores }\end{array}$ \\
$\begin{array}{l}\text { Sistemas de carga e descarga contribuem para } \\
\text { o baixo nível de danos aos produtos }\end{array}$ & $\begin{array}{l}\text { Necessita utilizar ajuda de sistemas de } \\
\text { navegação } \\
\text { Opera em rotas nacionais e internacionais } \\
\text { Alto custo do frete } \\
\text { Muito tempo consumido nas formalidades } \\
\text { exigidas no terminal }\end{array}$ \\
$\begin{array}{l}\text { Utiliza via natural, não necessitando de } \\
\text { investimento de capital na via } \\
\text { Redução do nível de estoque devido ao } \\
\text { menor tempo em trânsito }\end{array}$ & \\
\hline
\end{tabular}

Fonte: Elaborado pelo autor

\footnotetext{
${ }^{12}$ Com a participação de Adonis Carneiro da Silva, Lucas de Castro Valente, Rafael Ferreira Almeida, e Yuri
} Marinho de Carvalho. 
A partir do mapa aeroviário brasileiro na figura $X$, pode-se perceber que os terminais aeroportuários, além de consumirem uma vasta área para suas operações, na maioria das vezes, não são localizados nos grandes centros urbanos, gerando longos percursos por terra e somando mais tempo ao seu deslocamento total de produtos até os passageiros.

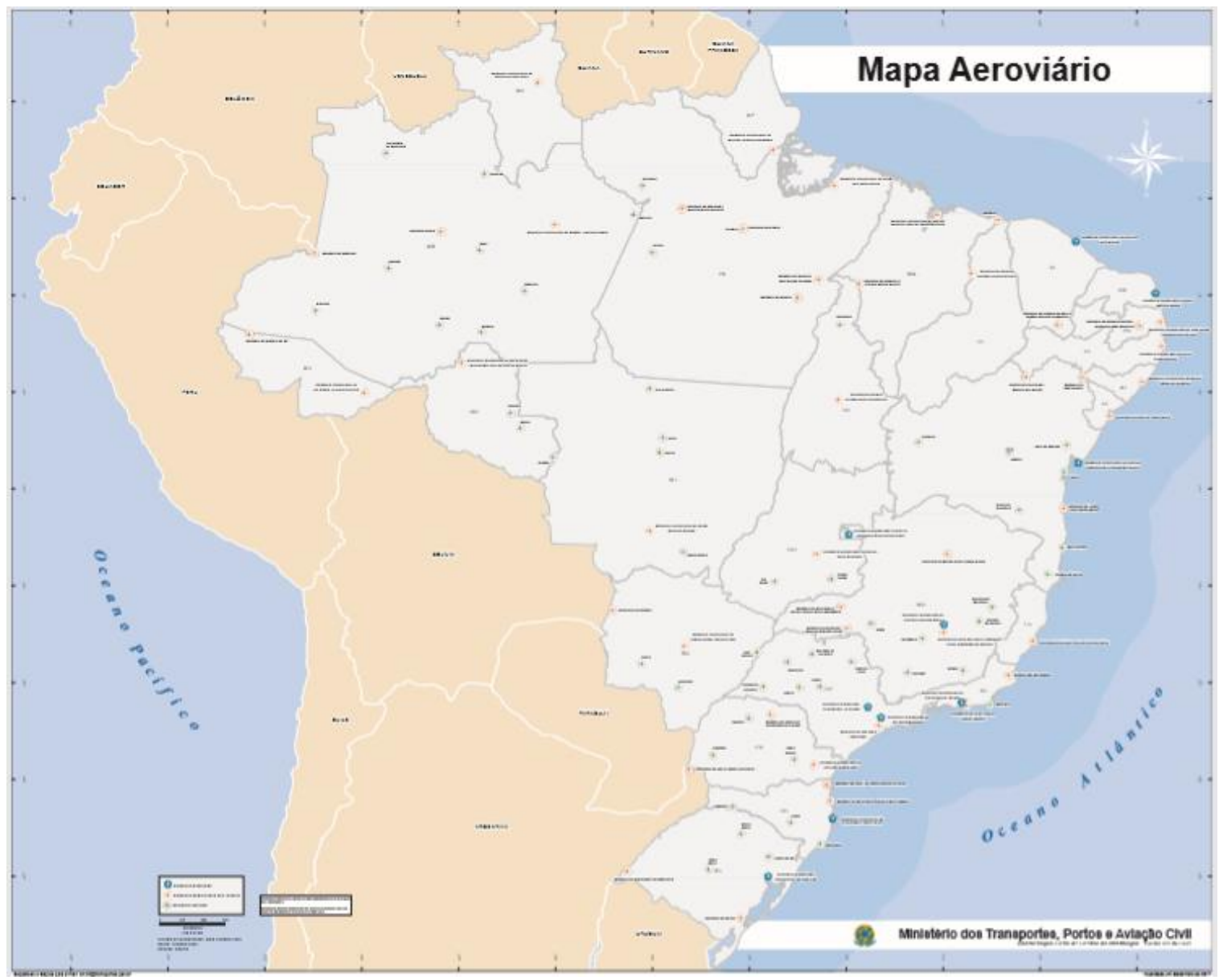

Figura 9.1. Mapa aeroviário do Brasil.

Fonte: http://infraestrutura.gov.br/component/content/article/63-bit/5124-bitmodosmapas.html

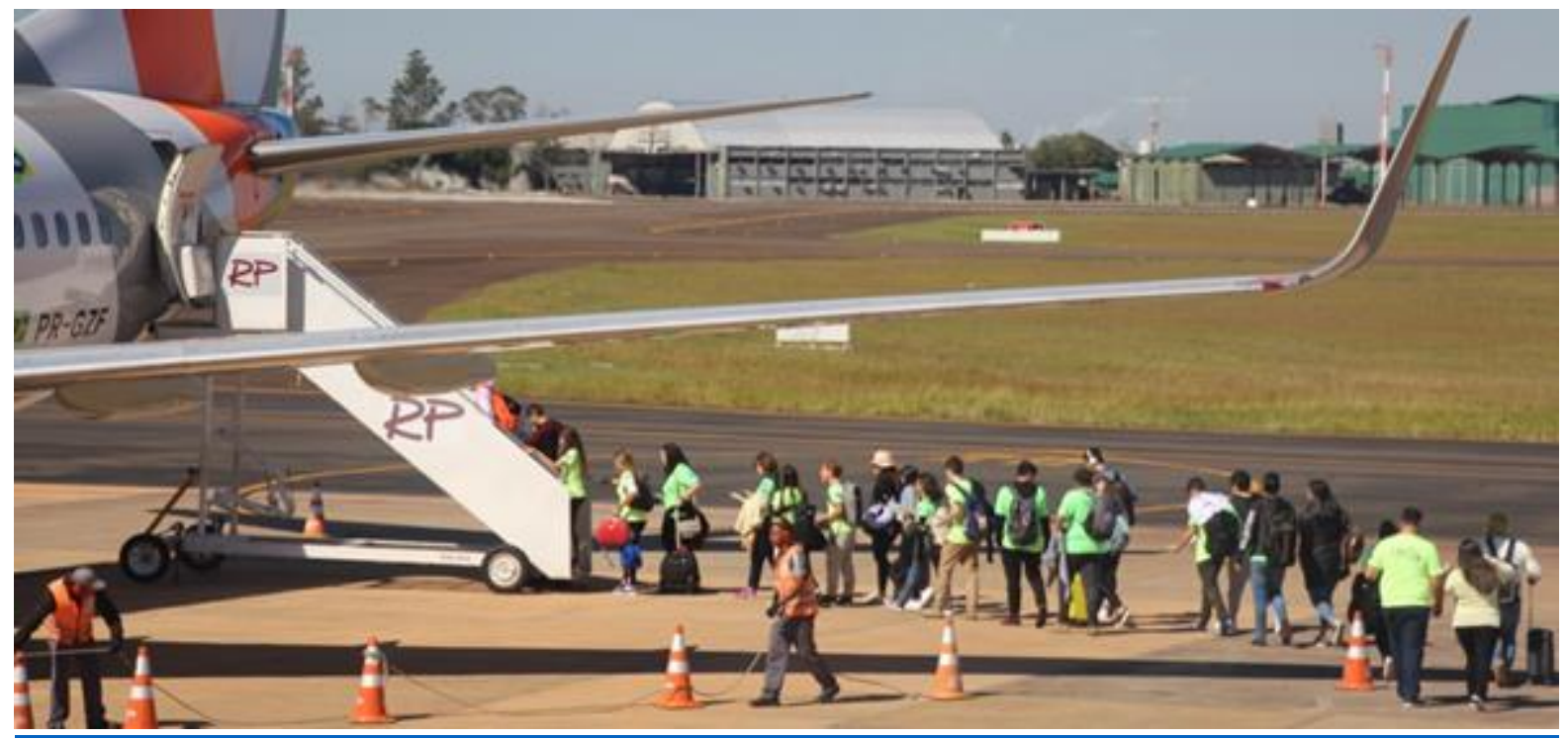

Figura 9.2. Embarque de passageiros em uma aeronave. 
FILAS: conceitos, novos enfoques de abordagem e aplicações em Transportes

\section{$9.2 \quad$ NOTÍCIAS DE JORNAIS SOBRE TEORIA DAS FILAS}

Aeroporto de Cumbica tem fila de aviões até fora do pico em São Paulo

https://sao-paulo.estadao.com.br/noticias/geral,aeroporto-de-cumbica-tem-fila-de-avioes-ate-

fora-do-pico-em-sao-paulo, 823863

Congonhas já teve 15 aviões em fila de espera no ar

https://www2.camara.leg.br/camaranoticias/noticias/107683.html

Fila no avião logo após o pouso é o que mais irrita viajantes brasileiros

http://g1.globo.com/turismo-e-viagem/noticia/2015/05/fila-no-aviao-logo-apos-o-pouso-e-oque-mais-irrita-viajantes-brasileiros.html

Heathrow Airport passport queues reach 2.5 hours

https://www.bbc.com/news/uk-45165222

Travel chaos at Gatwick Airport as passengers queue two hours for a bus in the heat

https://metro.co.uk/2018/05/06/travel-chaos-at-gatwick-airport-as-passengers-queue-two-

hours-for-a-bus-in-the-heat-7525470/

Gatwick Airport: Queues as drones halt flights

https://www.bbc.com/news/av/uk-england-sussex-46633502/gatwick-airport-queues-as-droneshalt-flights

Airport queues highlight UK's border problems ahead of Brexit

https://www.ft.com/content/c5b05bb6-93db-11e8-b747-fb1e803ee64e 


\section{Capítulo DEZ \\ Aplicação da teoria das filas no transporte dutoviário}

ADONIS CARNEIRO DA SILVA ${ }^{13}$

\subsection{INTRODUÇÃO AO TRANSPORTE DUTOVIÁRIO}

Neste modal a via acaba se confundindo com a unidade de carregamento, pois os produtos seguem em um fluxo contínuo pelo duto, da origem até o destino e sem a possibilidade do fluxo reverso pela mesma via, já que ao invés do meio de transporte se deslocar, são os produtos que se deslocam. A Figura 10.1 mostra o mapa dutoviário brasileiro.

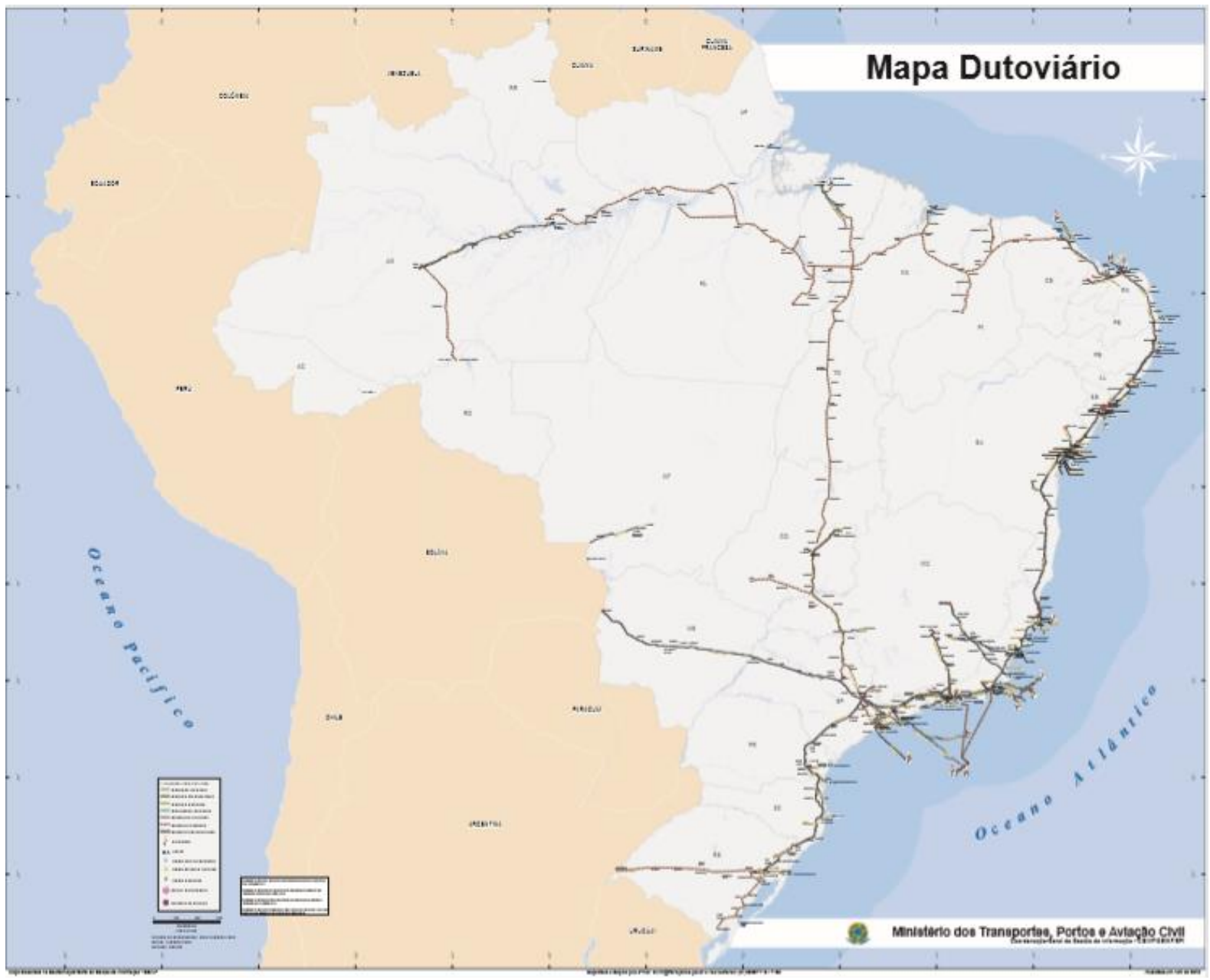

Figura 10.1. Mapa dutoviário brasileiro.

Fonte: http://infraestrutura.gov.br/component/content/article/63-bit/5124-bitmodosmapas.html

${ }^{13}$ Com a participação de Felipe Pereira Rosa Pierrotti, Lucas de Castro Valente, Rafael Ferreira Almeida, e Yuri Marinho de Carvalho. 
O transporte dutoviário engloba principalmente os minerodutos, gasodutos, e oleodutos, sendo as cargas típicas para esse tipo de transporte o petróleo e seus derivados, porque o duto possui a capacidade de mover cargas líquidas e gasosas com regularidade e a baixo custo, porém com restrições de velocidade e disponibilidade.

Existem também outros meios de transportes através de dutos, como os polidutos e carbodutos, por exemplo, que não serão abordados neste estudo.

A partir de sua instalação, o transporte dutoviário acaba tornando-se um modal competitivo, pois não depende das condições climáticas, possui baixo custo operacional e serve como armazenagem temporária do produto que está sendo transportado, devido sua extensão e lentidão do fluxo. Outras características são evidenciadas no quadro 10.1.

\section{Quadro 10.1- Características do transporte dutoviário}

\section{Vantagens}

Não há necessidade de usar embalagens de transporte, pois a dutovia é a própria unidade de carregamento Apenas a mercadoria transportada se move Não sofre influência de congestionamentos ou dificuldades físicas

Não existe viagem de retorno para equacionar

Consome pouca mão-de-obra

Segurança superior aos demais modais

\section{Desvantagens}

Inflexível quanto à rota de distribuição, pois sua posição não é fácil de alterar após a fixação dos dutos Requer grande investimento de capital Não é adequado para produtos sujeitos a mudanças de padrão de carregamento Demanda restrita a pontos fixos

Não é aconselhável utilizar o mesmo duto para o transporte de produtos de grupos distintos

Fonte: Elaborado pelo autor

\subsection{MINERODUTO}

Os principais produtos transportados são o minério de ferro, concentrado fosfático e sal-gema. Geralmente no início da obra de construção de um mineroduto há a necessidade de realização de obras de terraplanagem ao longo da via, sendo que a estrutura deve contar com estações de bombeamento, válvulas e de monitoramento de pressão, além de leitos de anodo para o sistema de proteção catódica contra corrosões.

Como exemplo, pode-se citar o mineroduto Minas-Rio, que foi desenvolvido pela Anglo American, o qual passa por 32 municípios e é considerado atualmente o maior do mundo em volume de toneladas de minério de ferro transportado. $O$ transporte começa por meio do impulsionamento da polpa de minério por bombas de pistão de alta pressão, com apoio de 2 estações de bomba para percorrer um trajeto de 7 dias de duração a uma velocidade média de $6 \mathrm{~km} / \mathrm{h}$, controlada pelas estações de válvulas que corrigem a pressão do sistema de bombeamento, Figura 10.2. 


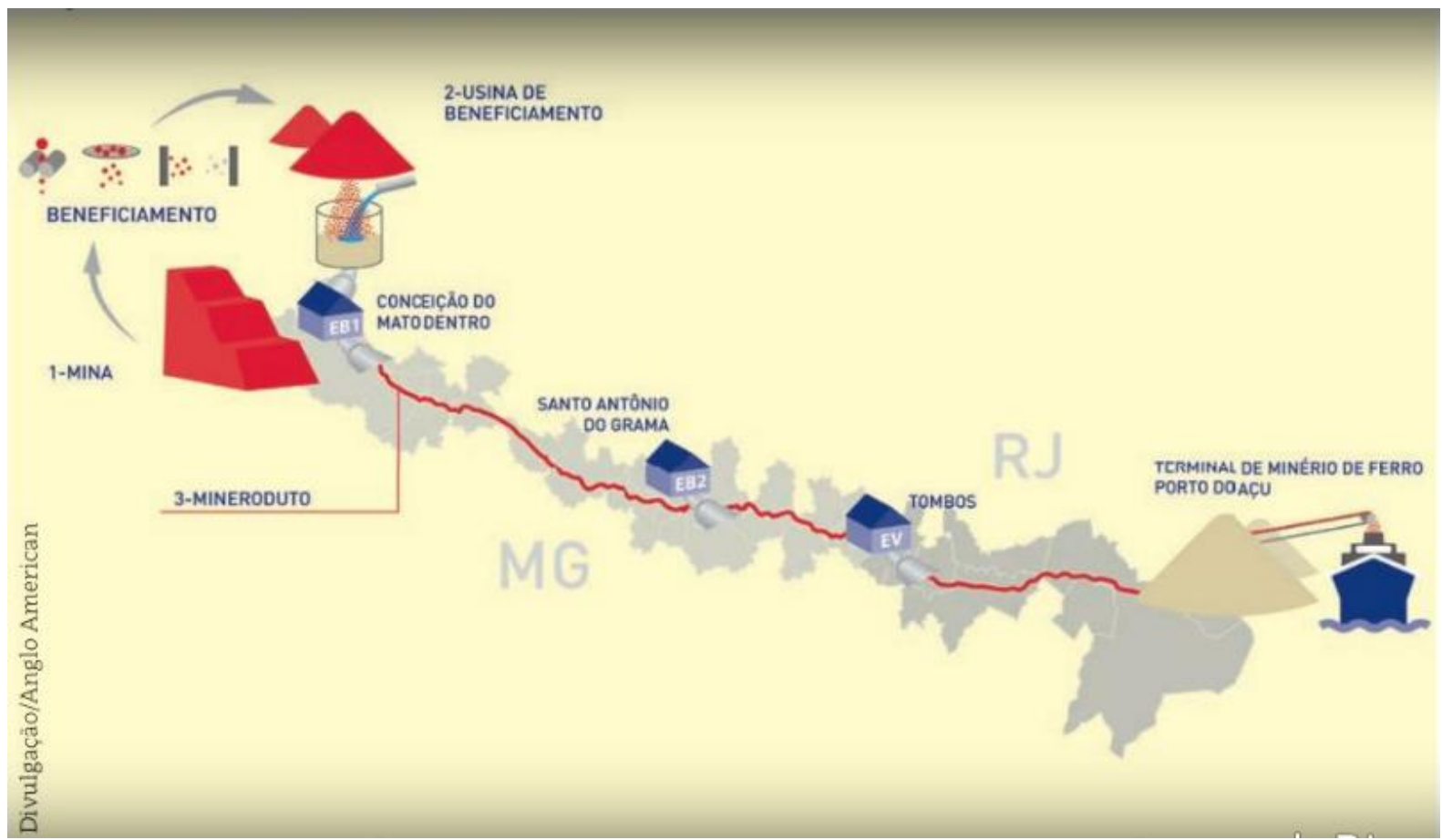

Figura 10.2. Mineroduto Minas-Rio.

Fonte: https://issuu.com/revista logistica/docs/revista-logistica-fev292?e=9516189/11399738

\subsection{GASODUTO}

Um Gasoduto é responsável pelo transporte de grandes volumes de gás natural à alta pressão. No sistema integrado de transporte de gás, quando o gasoduto se aproxima da cidade, sua pressão é diminuída para possibilitar a transferência do gás nos pontos de entrega das companhias distribuidoras locais. Como exemplo, pode-se citar os dutos da Transportadora Brasileira Gasoduto Bolívia-Brasil (TBG), Figura 10.3, compostos por tubos de aço soldados e enterrados no solo com 1 metro de profundidade e 20 metros de largura (devidamente demarcada e sinalizada) transportando gás natural oriundo da Bolívia para o Brasil, percorrendo os estados de Mato Grosso do Sul, São Paulo, Paraná, Santa Catarina e Rio Grande do Sul.

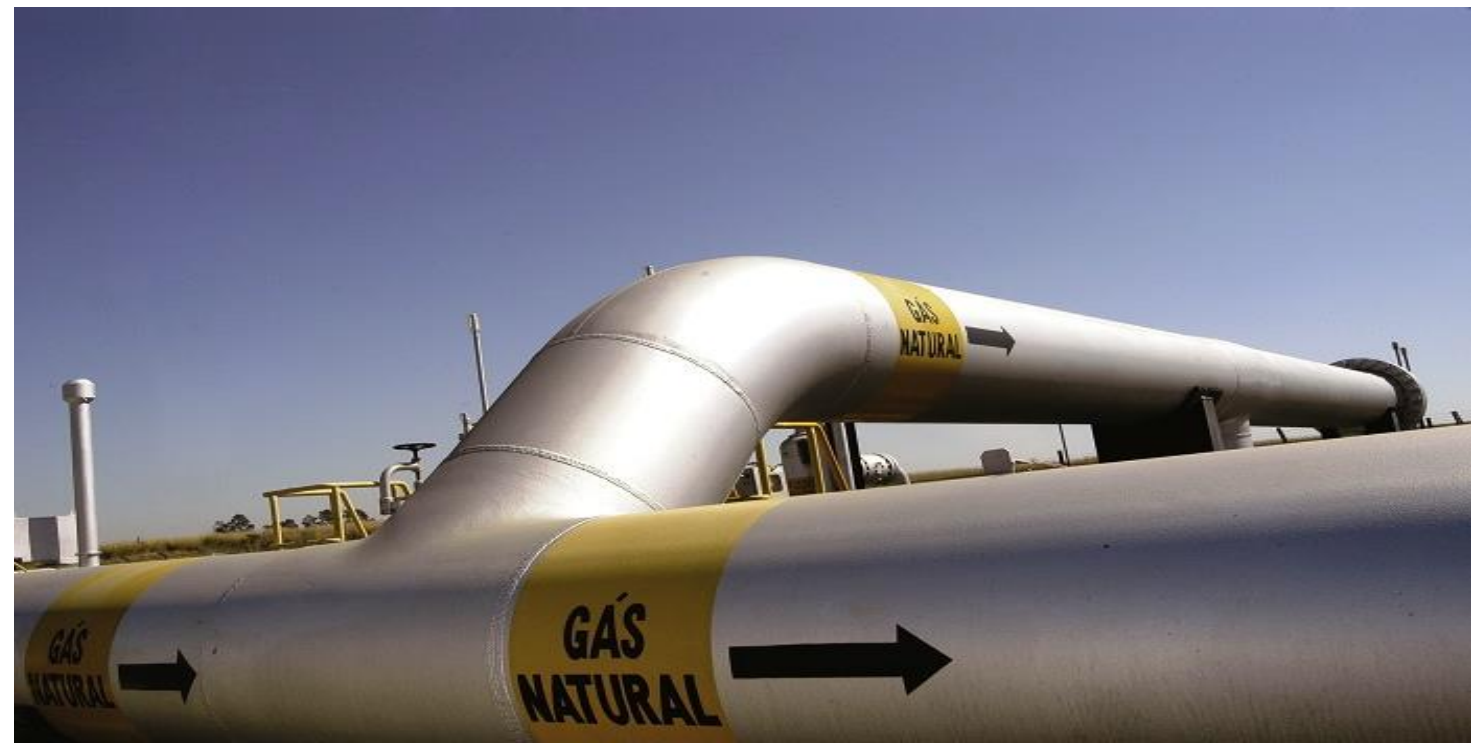

Figura 10.3. Gasoduto Bolívia-Brasil.

Fonte: http://www.tbg.com.br/pt br/o-gasoduto/o-que-e.htm 


\subsection{OLEODUTO}

Tem como principais produtos transportados o petróleo e seus derivados, como GLP, nafta, querosene, álcool, gasolina, diesel, óleo combustível entre outros, Figura 10.4.

A gestão das operações de transporte de carga através dos oleodutos são um importante elo na cadeia de abastecimento das empresas de energia, como as do setor de Petróleo. Como exemplo, pode-se citar a Transpetro que utiliza a malha dutoviária desde os campos de produção, onde o petróleo é transportado pelos oleodutos para os terminais e posteriormente às refinarias, sendo que, logo após o refino, os derivados são escoados novamente pelos oleodutos aos terminais para distribuição ou diretamente para as companhias distribuidoras para abastecimento ao mercados internos e externos.

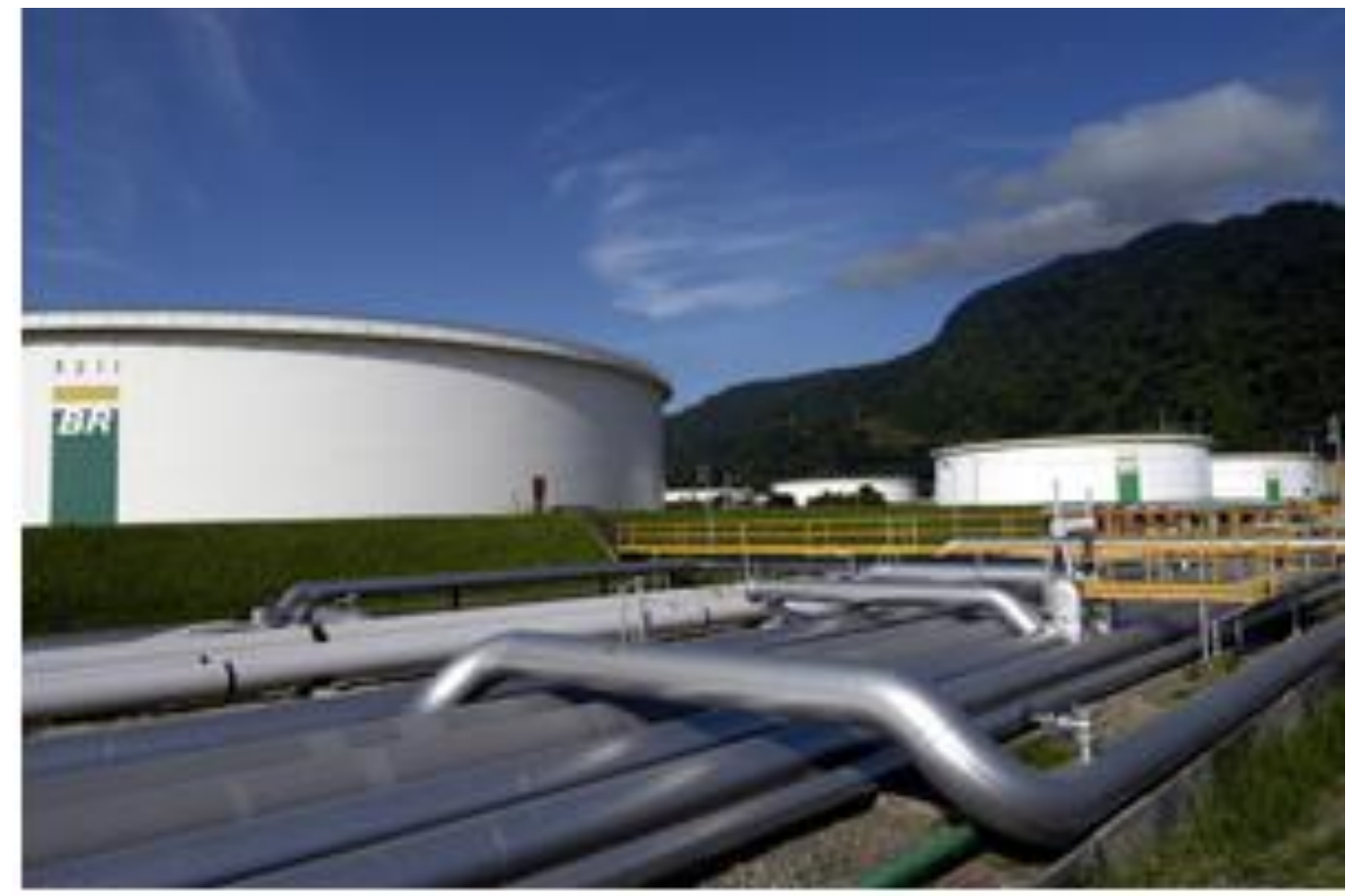

Figura 10.4. Oleoduto.

Fonte: http://www.transpetro.com.br/pt br/areas-de-negocios/terminais-e-oleodutos.html

\subsection{UTILIZAÇÃO DA TEORIA DAS FILAS NO TRANSPORTE DUTOVIÁRIO}

Caso 1: Como o transporte de cargas através dos dutos utiliza sistema de cilindros arranjados para mover produtos de um ponto de origem a um ponto de destino, a fila se dá no interior desses tubos, sem possibilidade de ultrapassagem (first in first out), pois a circulação acontece por pressão ou arraste por componentes condutores. Porém há a possibilidade de mistura de componentes líquidos através de tubulação secundária acoplada à principal, com acionamento manual ou automático para gerar compostos químicos para atendimento às legislações específicas, como o percentual de biocombustíveis na gasolina e diesel para composição final do combustível a ser distribuídos nos portos para abastecimento da frota nacional.

Caso 2: Medição e análise da taxa de ocupação dos dutos baseado na capacidade de vazão instalada (por produtos) e da demanda transportada, com o objetivo de medir a eficiência do sistema, porque, segundo Ballou (2006), o modal dutoviário possui capacidade limitada. 


\section{Referências}

PEREIRA, Ana Cristina da Silva. Transporte Intermodal: Um estudo do modelo Estadunidense Europeu vs. Situação Brasileira. Dissertação de Mestrado Coppead. UFRJ, 2003, 174P.

BALLOU, R.H. Gerenciamento da cadeia de suprimentos/ Logística empresarial, 5ạ edição. Porto Alegre: Bookman, 2006.

COYLE, J. J.; BARDI, E. J.; NOVACK, R. A. Transportation. St. Paul: West Publishing Company, 1994.

MARTINS, D. W. P.; DANTAS, M. J. P. Suplemento do EXCEL desenvolvido em linguagem VBA para simulação discreta de sistemas de filas $\mathrm{m} / \mathrm{m} / 1$. In: XLIX Simpósio Brasileiro de Pesquisa Operacional, pág. 810 a 822. Blumenau-SC, 27 a 30 de agosto de 2017. Disponível em:

<http://www.sbpo2017.iltc.br/pdf/169412.pdf>. Acesso em: 03/07/2019 
FILAS: conceitos, novos enfoques de abordagem e aplicações em Transportes

\section{Capítulo ONZE

\author{
Breve introdução ao transporte \\ por bicicletas de aluguel
}

MARION GOMES DE MORAES FERNANDES

PAULO AFONSO LOPES DA SILVA

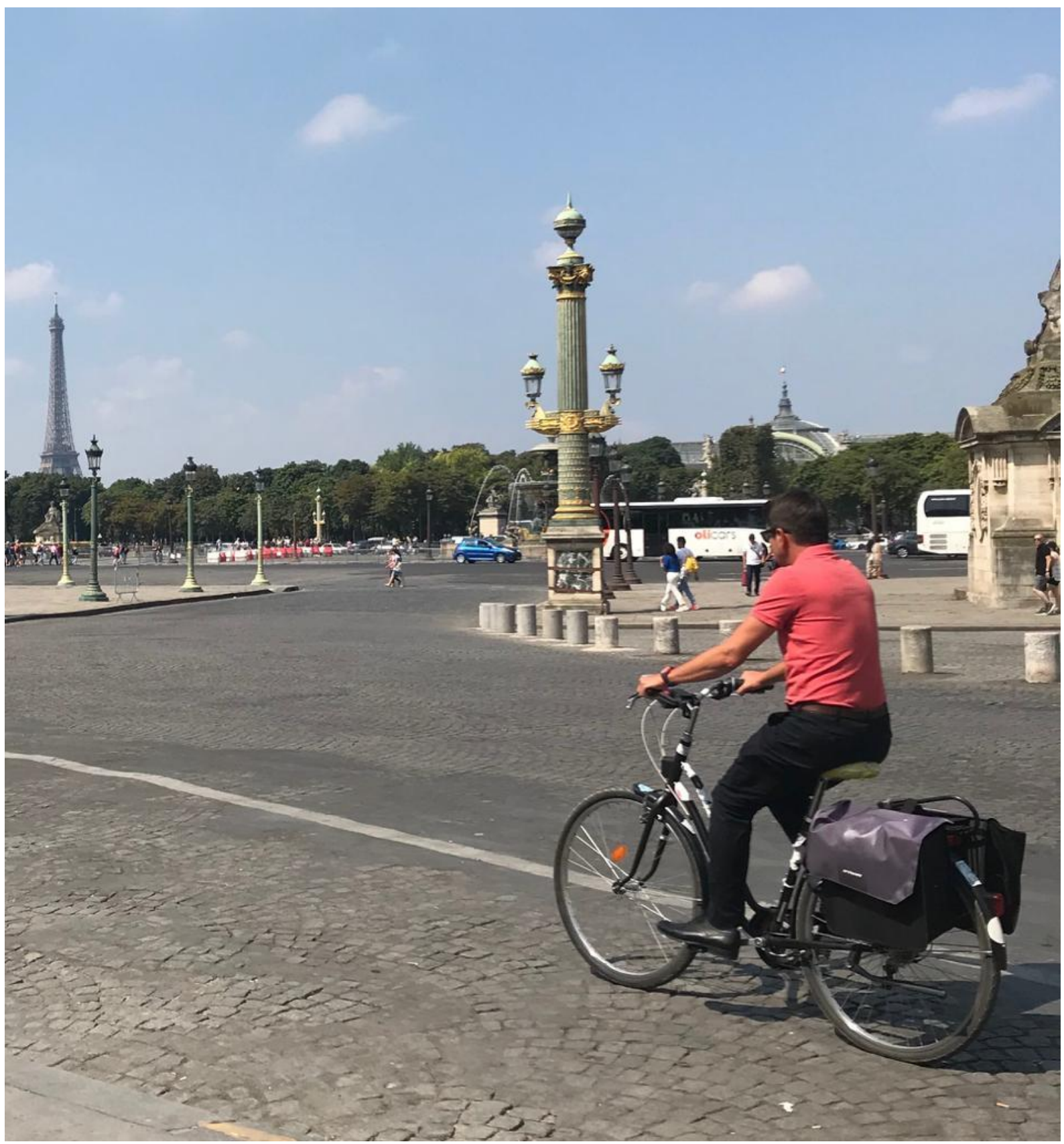

Figura 11.1. A bicicleta como um meio popular de transporte 
Uma das aplicações do uso dos conceitos de otimização de filas refere-se ao no Sistema de Compartilhamento de Bicicletas, uma solução sustentável de transporte público urbano implementada, primeiramente, em 1965, na cidade de Amsterdam, nos Países Baixos, Figura 11.2.

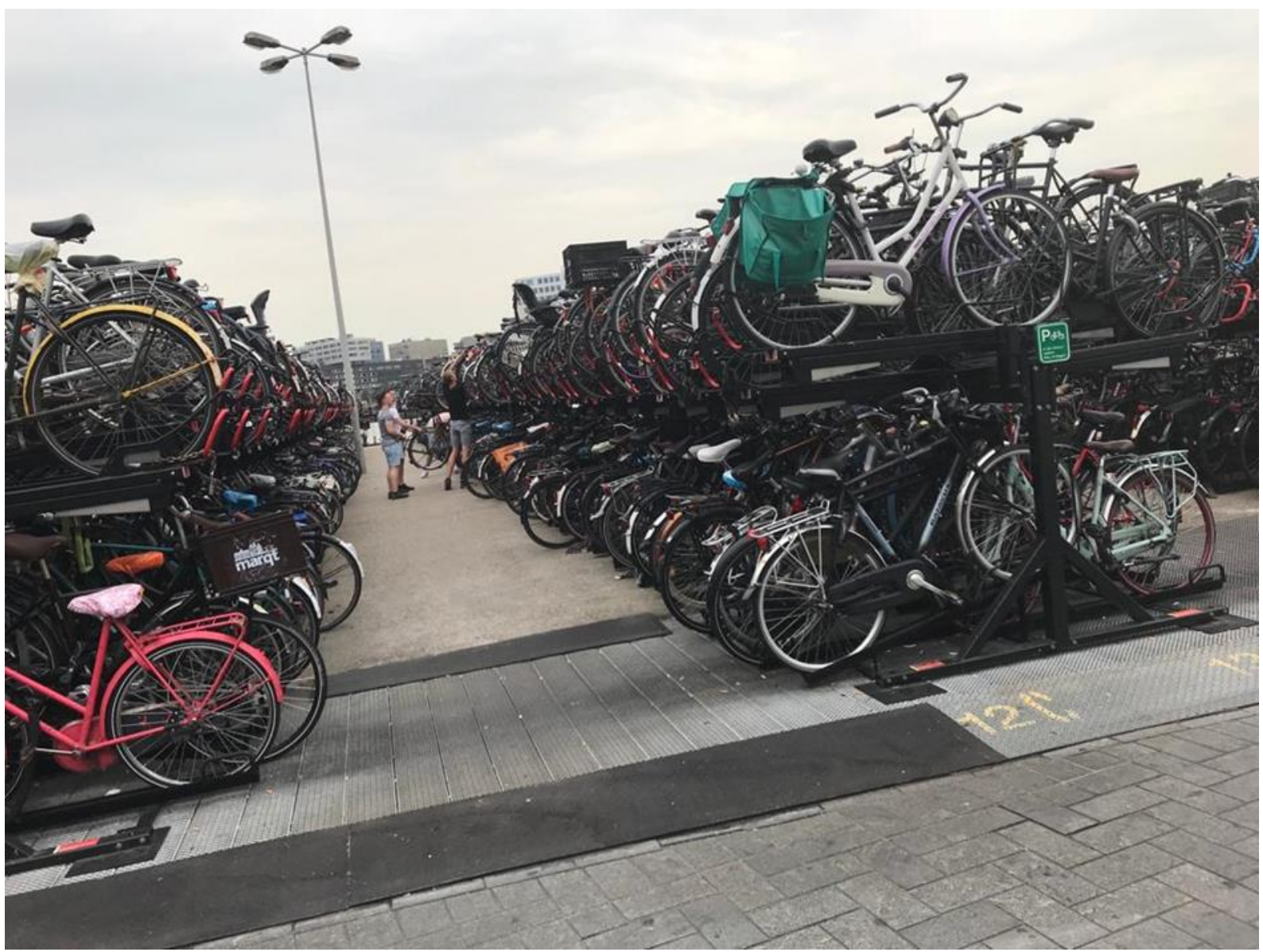

Figura 11.2. Estacionamento para 10 mil bicicletas, perto da estação central de trem, na cidade de Amsterdam, nos Países Baixos.

Nos Países Baixos, de 10 pessoas, 9 utilizam a bicicleta como meio de transporte, seja para o trabalho ou para o lazer, sendo conhecido como o país dos ciclistas.

Em Amsterdam, a população de bicicletas é, aproximadamente, $5 \%$ maior que a de pessoas, e quatro vezes maior do que o de carros. Diferentemente de outras cidades, Amsterdam não tem um sistema de autosserviço para aluguel de bicicletas como em Paris (Vélib Metropole), São Paulo ou Rio de Janeiro, porém se encontra, com facilidade, lojas para alugá-las.

No Brasil, desde 2015, essa opção pelo aluguel de bicicletas tem aumentado em algumas cidades e, para algumas pessoas, já é o principal meio de transporte diário na rota casa-trabalho-casa, além do lazer. A primeira a ter o chamado bike sharing foi Recife, no estado de Pernambuco, na qual dados deste ano de 2019 indicam que o projeto desenvolvido desde 2014 pelo governo aumentou, em 2018, cinco vezes o número de viagens.

A capital do estado de São Paulo foi a segunda cidade do país a implantar esse sistema de aluguel de bicicletas. 
Em determinadas cidades brasileiras, existem diversas estações espalhadas pelos bairros, onde as prefeituras autorizam a construção de docas para a fixação de bicicletas, a serem alugadas por meio de um aplicativo de celular.

O usuário cadastra-se, paga uma taxa e recebe uma senha que destrava a bicicleta da doca. Após a sua viagem, o usuário pode devolver a bicicleta em qualquer outra estação e finalizar o serviço, Figura 11.3.

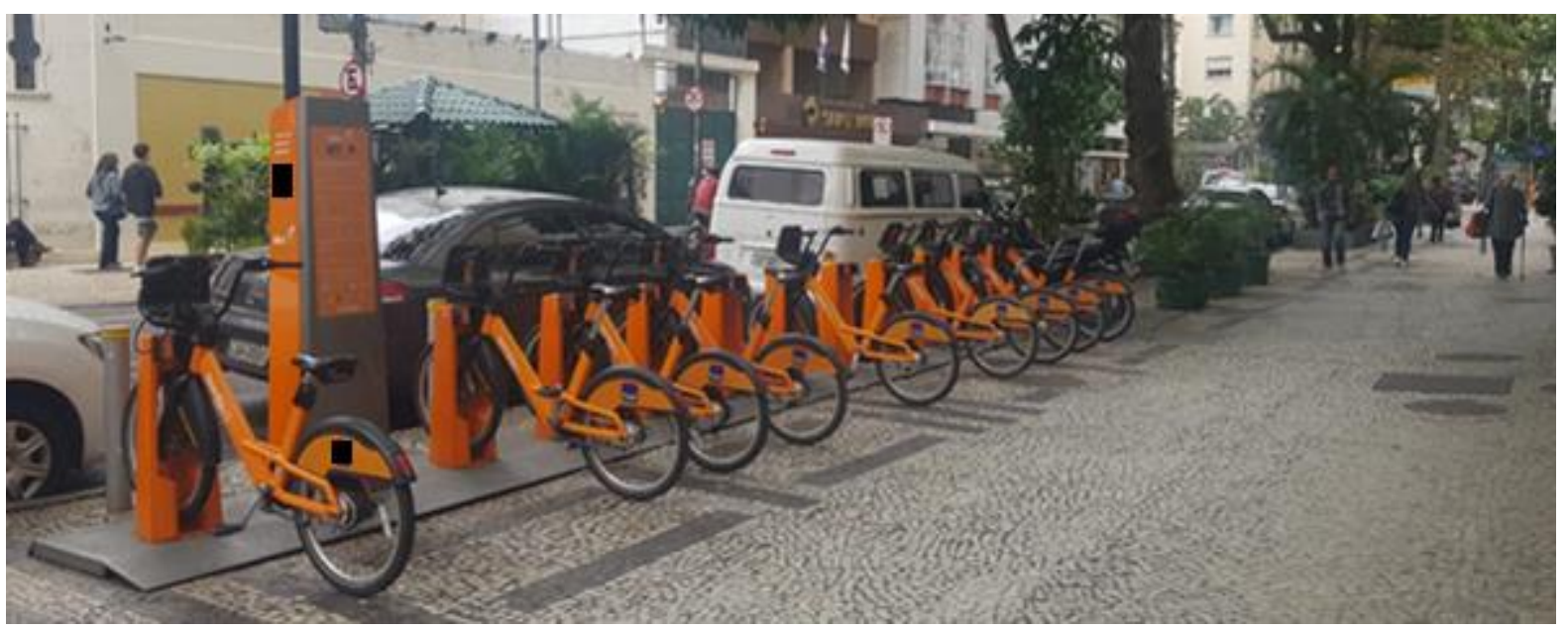

Figura 11.3. Docas para a fixação de bicicletas no Rio de Janeiro

Estes são exemplos de como a teoria das filas pode ser aplicada para melhorar o cotidiano das pessoas. O usuário não sabe a resposta sobre qual a melhor fila, esperar na estação ou ir para outra, mas aquele que gerencia o sistema de compartilhamento e aplica a teoria das filas em seus softwares de controle sabe! A partir desse estudo. define a sua estratégia de redistribuição de bicicletas e instalação de estações.

Conhecendo as características da demanda, como os horários de retirada e de devolução, e as estações mais demandadas, o gerente do sistema estabelece a sua estratégia. Uma delas se encontra artigo "Performance Analysis and Improvement of the BikeSharing System Using Closed Queuing Networks with Blocking Mechanism"14:

1. Acompanhar: em tempo real, as estações lotadas e as estações vazias, de modo que se possa transportar bicicletas de uma estação para a outra e equilibrar o sistema.

2. Controlar: adaptar e alterar o número de docas nas estações, e de bicicletas no sistema.

3. (Re)-projetar: refazer a rede de estações acrescentando ou subtraindo estações do sistema.

Ainda sobre o tema do compartilhamento de bicicletas, acrescenta-se a informação de que na cidade de Fortaleza - Ceará, as bicicletas podem ser retiradas às sextas-feiras e devolvidas na segunda-feira seguinte. Além da função de transporte funcional, as bicicletas têm um papel importante no lazer e saúde da população. Esta medida funcionou tão bem, que gerou mais uma fila! A fila das sextas-feiras! A notícia completa pode ser lida em https://tribunadoceara.com.br/noticias/mobilidadeurbana/todasexta-terminais-tem-fila-de-interessados-em-ficar-com-bicicletas-no-fim-de-semana/ .

${ }^{14}$ Samet, Bacem \& Couffin, Florent \& Zolghadri, Marc \& Barkallah, Maher \& Haddar, Mohamed. (2018). Performance Analysis and Improvement of the Bike Sharing System Using Closed Queuing Networks with Blocking Mechanism. Sustainability. 10. 4663. 10.3390/su10124663. 
Nesses projetos de compartilhamento de bicicletas promovidos parcerias público-privadas, as retiradas são feitas por meio de aplicativos de celulares, pelos quais se pode conhecer as estações oferecidas e quais têm unidades disponíveis para locação. Essas últimas informações são úteis porque, assim como ocorre no tráfego de veículos de passageiros, os horários de pico e determinadas regiões aumentam a demanda pela disponibilidade de bicicletas e também de docas livres para a retirada e para a devolução.

Quando o usuário vai até a estação mais próxima e não há bicicletas disponíveis, cria-se uma demanda não atendida e, portanto, uma fila. Neste momento fica a dúvida: aguardar na estação até que um outro usuário chegue e libere uma bicicleta, ou ir até outra estação próxima? E se ao chegar lá, também não houver bicicleta? Essa é a dúvida clássica que todo usuário tem: "Troco ou não de fila?"

O mesmo se aplica para quando o usuário quer devolver a bicicleta e não há doca vazia. Neste caso, a situação é um pouco mais complicada pois não se pode simplesmente desistir da bicicleta e ir embora... há que se deixar a bicicleta em alguma doca! O usuário tornou-se refém do veículo que alugara!

Se essa programação é falha, gera-se uma fila nas estações de bicicletas, sendo importante o levantamento desses dados para um completo planejamento. O aplicativo somente oferece a informação, porém não aumenta o número de bicicletas disponíveis para locação nem o número de. docas para devolução, Figura 11.4.

Conclusão: um sistema que, teoricamente, traria total flexibilidade e mobilidade às grandes cidades, nem sempre tem sido bem-sucedido por falta de um estudo sobre filas com capacidade limitada, assunto tratado neste livro.

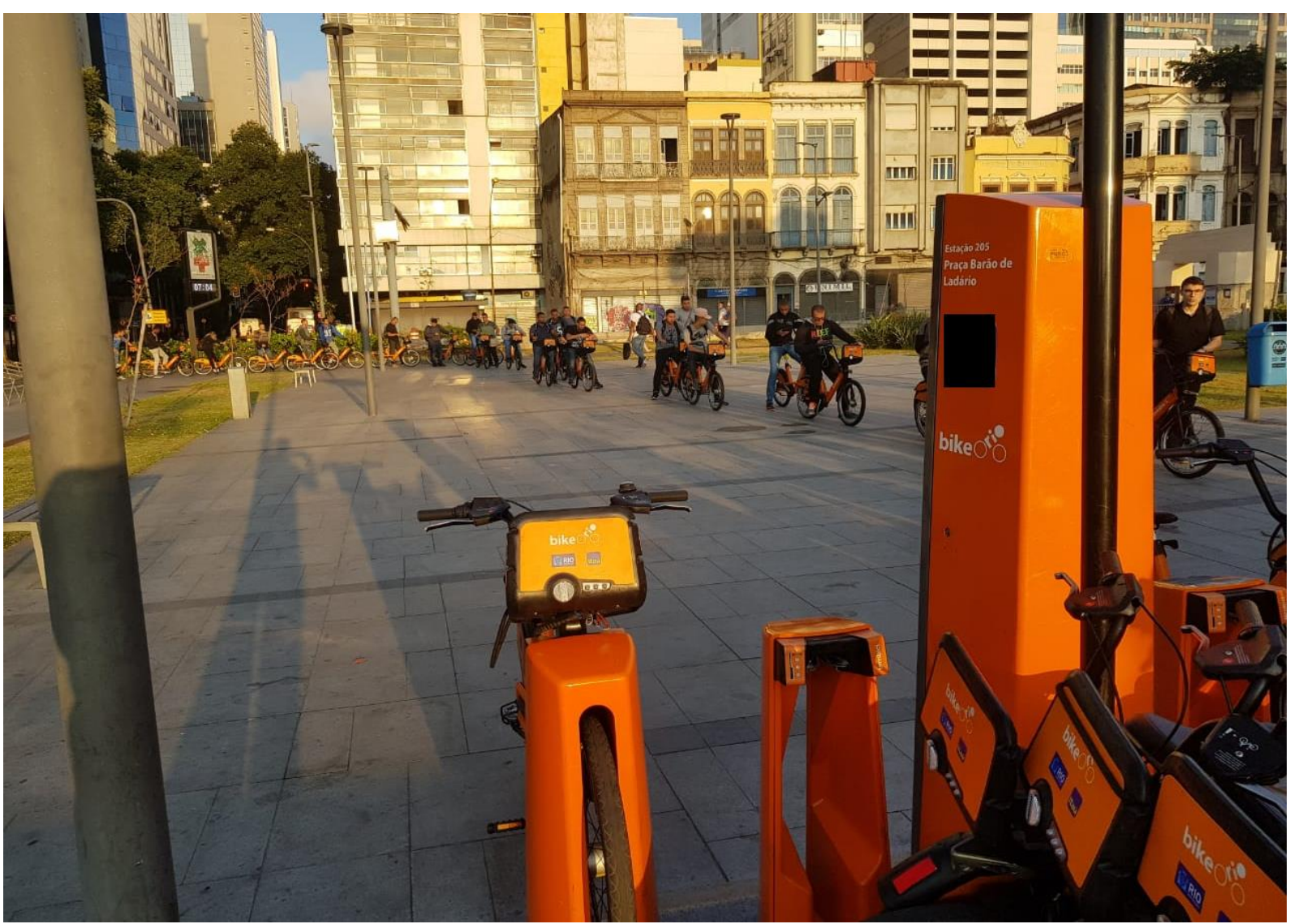

Figura 11.4. Elevada demanda para devolução e menor número de docas disponíveis. 


\section{Capítulo DOZE \\ DESFECHO}

ERNESTO RADEMAKER MARTINS

\section{Estamos todos na fila}

\section{A} cada minuto alguém deixa esse mundo pra trás. Não sabemos quantas pessoas estão na nossa frente. Não dá pra voltar pro "fim da fila". Não dá pra sair da fila. Nem evitar essa fila. Então, enquanto esperamos a nossa vez: Faça valer a pena cada momento vivido aqui na Terra. Tenha um propósito. Motive pessoas! Elogie mais, critique menos. Faça um "ninguém" se sentir um alguém do seu lado. Faça alguém sorrir. Faça a diferença. Faça amor. Faça as pazes. Faça com que as pessoas se sintam amadas. Tenha tempo pra você. Faça p e q u e n o s

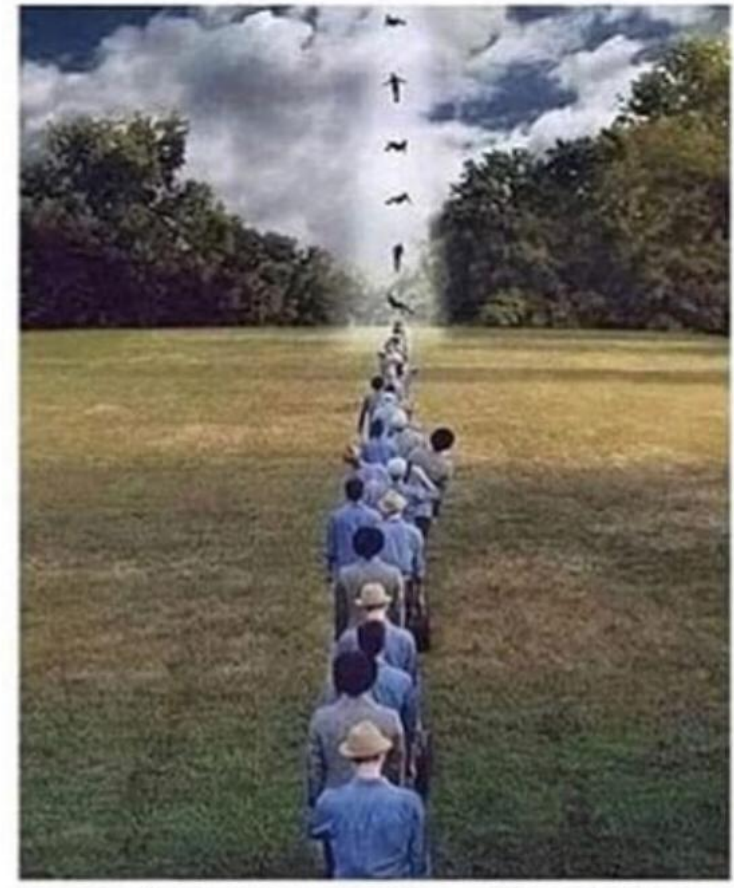

momentos serem grandes. Faça tudo que tiver que fazer e vá além. Viva novas experiências. Prove novos sabores. Não tenha arrependimentos por ter tentado além do que devia, por ter valorizado alguém mais do que deveria, por ter feito mais ou menos do que podia. Tudo está no lugar certo. As coisas só acontecem quando têm quem acontecer. Releve. Não guarde mágoas. Guarde apenas os aprendizados. Liberte o rancor. Transborde o amor. Doe amor. Ame, mesmo quem não merece.

Ame, sem querer receber nada em troca. Ame, pelo simples fato de vc vibrar amor e ser amor.

Mas sempre, ame a si mesmo antes de qualquer coisa." Esteja preparado para partir a qualquer momento. Vc não sabe seu lugar na Fila, então se prepare pra deixar aqui apenas boas lembranças. Suas mãos vão embora vazias. Não dá pra levar malas, nem bens..

S e p r e p r e DIARIAMENTE pra levar consigo, somente aquilo que tens guardado no coração.

Desconheço a autoria)

No dia a dia, na faculdade, escola, trabalho, trânsito, bancos, supermercados, em qualquer lugar do mundo estamos sujeitos a enfrentar filas. Há quem diga que elas são uma forma de organização de pessoas à espera de um determinado serviço. Outros sugerem que as filas surgem devido a ineficiência do serviço ofertado. Já para alguns, a fila é o lugar certo para refletir e pensar sobre diversos assuntos da vida. E para os mais impacientes, as filas não passam de um tempo de vida perdido. Mas, você já parou para imaginar como seria um mundo sem filas? Qual a importância delas? Pra que servem, como funcionam e por que se formam? Será mesmo que as filas são essenciais para a sociedade? 
Vejamos as várias definições atribuídas às filas segundo o ponto de vista de diferentes pessoas:

- "Ordem de chegada de pessoas, bens, coisas com o mesmo objetivo";

- "Sequência de elementos ordenados de um determinado tamanho";

- "Sequência de pessoas, objetos, elementos aguardando atendimento";

- "Uma linha de coisas, pessoas, objetos";

- "Um elemento de organização";

- "Uma aglomeração de elementos que aguardam uma prioridade";

- "Um conjunto de itens ou pessoas em espera por um atendimento";

- "Ordenação de elementos que aguardam a um atendimento associado a um tempo de espera";

- "Alocação de elementos aguardando atendimento";

- "Uma angústia controlada de uma percepção alterada aguardando atendimento";

- "Condição momentânea de nível de atendimento de serviço";

- "Tempo perdido de produtividade";

- "Teste de paciência";

- "A medida da diferença de capacidade de atendimento em relação a quantidade de passageiros";

- "Demanda momentânea não atendida coordenada";

- "Jeito civilizado de organizar pessoas em um determinado lugar";

- "Oportunidade de fazer amizade";

- "Forma de aplicação de prioridade de atendimento ou passagem";

- "Algo que irrita muita gente";

- "Lugar onde se pode organizar outras ideias";

- "Cadenciamento do fluxo para uma determinada ação";

- "Medida de capacidade de tempo de atendimento, maior o tempo, maior será a fila";

- "Fluxo de material em ordem";

- "Representação de uma ordem, sendo que o sentido de ordem varia";

- "Expectativa";

- "Uma sequência de pessoas, coisas, atividades aguardando um serviço"

- "Representação física do tempo";

- "Uma sucessão de indivíduos que alimentam a esperança de ser atendido";

Como podemos perceber, as filas são comuns no cotidiano das pessoas, e, em algumas situações, é inevitável não passar por uma. Basicamente, as filas são formadas quando a procura por um determinado serviço é maior que a capacidade de oferta do mesmo, sendo assim difícil definir o tempo de espera na fila assim como a possibilidade de formação de fila ou não. Para entendermos um pouco melhor sobre o assunto vamos voltar no tempo e entender quando esse problema surgiu.

\section{0 que são filas?}

Esta pergunta nos faz refletir, normalmente, como um ser humano, em um experimento ordenado. Mas filas não são apenas próprias de um sistema humano. Há filas de vários tipos, que se formam naturalmente, como por exemplo, a queda de uma cachoeira, em um determinado momento, há uma fila de partículas de água, que caem sobre uma outra plataforma. 


\section{Então, como classificar as filas? 0 que elas seriam?}

Em princípio, fila seria uma forma disciplinada de organização de indivíduos ou objetos que estão à espera de um serviço. Ela se forma quando esse serviço, em um determinado momento ou período, não tem disponibilidade para atender toda a demanda.

As filas podem ser de diversas formas e independem da vontade humana. Animais muito hierarquizados sempre organizam filas. Processos mecanizados de fabricação podem formar fila caso um dos serviços, em paralelo ou sequencial, não esteja disponível para a demanda esperada, ou quando há falha em um dos canais.

Quando falamos de logística, o ser humano está sempre presente, quer seja participante do processo ou apenas um observador. Portanto, a fila seria sempre um evento social-humano, principalmente quando se trata de logística.

Mas como observador, isso também influi? Sim, mesmo quando observamos uma fila, ela se altera.

A física quântica, no experimento da dupla fenda, mostra que, quando observado, o comportamento dos átomos muda. Quando se coloca alguém para tomar o tempo das filas, esse observador faz com que o comportamento do indivíduo, tanto ele seja o provedor de serviço, quanto do indivíduo na fila, também mude.

Considerando que nenhuma interação física é possível sem a interação humana, vamos considerar todo e qualquer experimento observado, e as fórmulas e a teoria são desenvolvidas a partir desse contexto, ou seja, como observador e não passageiro.

Tem-se questões psicossociais em um estudo mais sofisticado de filas. Uma ansiedade generalizada atinge, como uma doença, quem está nela, entendida, normalmente, como uma perda desnecessária de tempo e a sensação de "estar sendo lesado".

Sendo inevitável estar-se em uma fila, as pessoas devem ser educadas no sentido de obedecerem à disciplina dela, e nunca passarem à frente das outras pessoas para serem atendidas primeiro, Figura Desfecho-1.
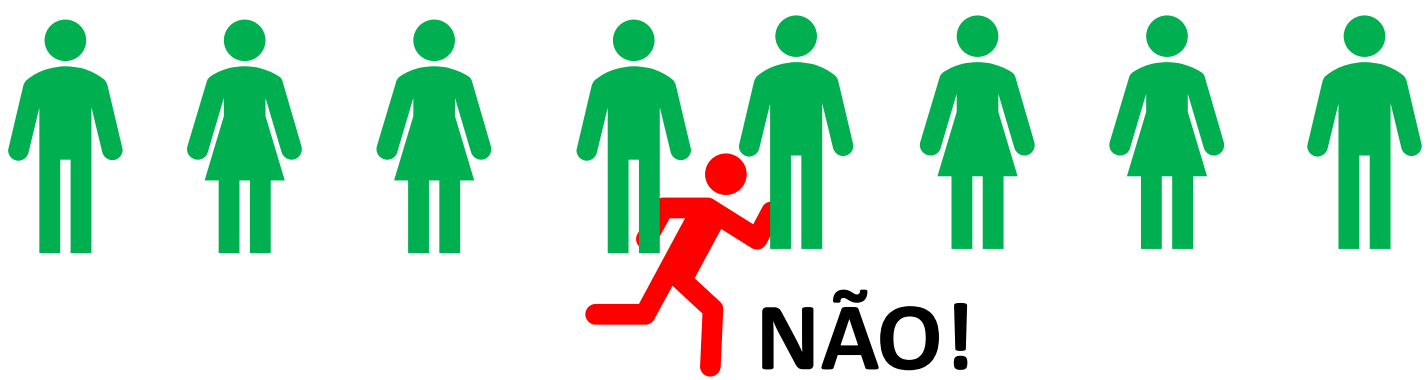

Figura Desfecho-1. Em uma fila, nunca passar à frente das outras pessoas

Agora que você acabou de ler o livro, responda:

No seu entender, $\mathrm{O}$ que vem a ser uma fila? 


\section{ANEXO \\ 1 \\ Tutorial para o uso do ARENA, incluindo exemplo de filas}

MELQUISEDEQUE DAMASCENO DO NASCIMENTO

1. Como baixar e instalar o software Arena ${ }^{\circledR}$.

O programa ARENA, é um dos softwares mais utilizados na simulação de eventos discretos no mundo, sendo aplicado como o instrumento para tomada de decisão em diversas áreas de atuação, como Manufatura, Ferrovias, Mineração, Call Center, Farmacêutico, Alimentos e Bebidas, Portos, Siderurgia e Logística.

Este software possui um ambiente gráfico integrado de simulação com um amplo leque de recursos para a modelagem de processos, desenho e animação, análise estatística e análise de resultados. A implementação de um sistema nessa plataforma é através de uma abordagem simples da modelagem por fluxogramas. Não sendo necessário ser um programador para tirar vantagem dos atributos e capacidades do Arena.

O primeiro passo para baixar o Arena ${ }^{\circledR}$ é entrar no endereço eletrônico <https://www.arenasimulation.com/>, ir na aba "Academic" e clicar no subitem "Student". Como pode ser observado na Figura A1.1:

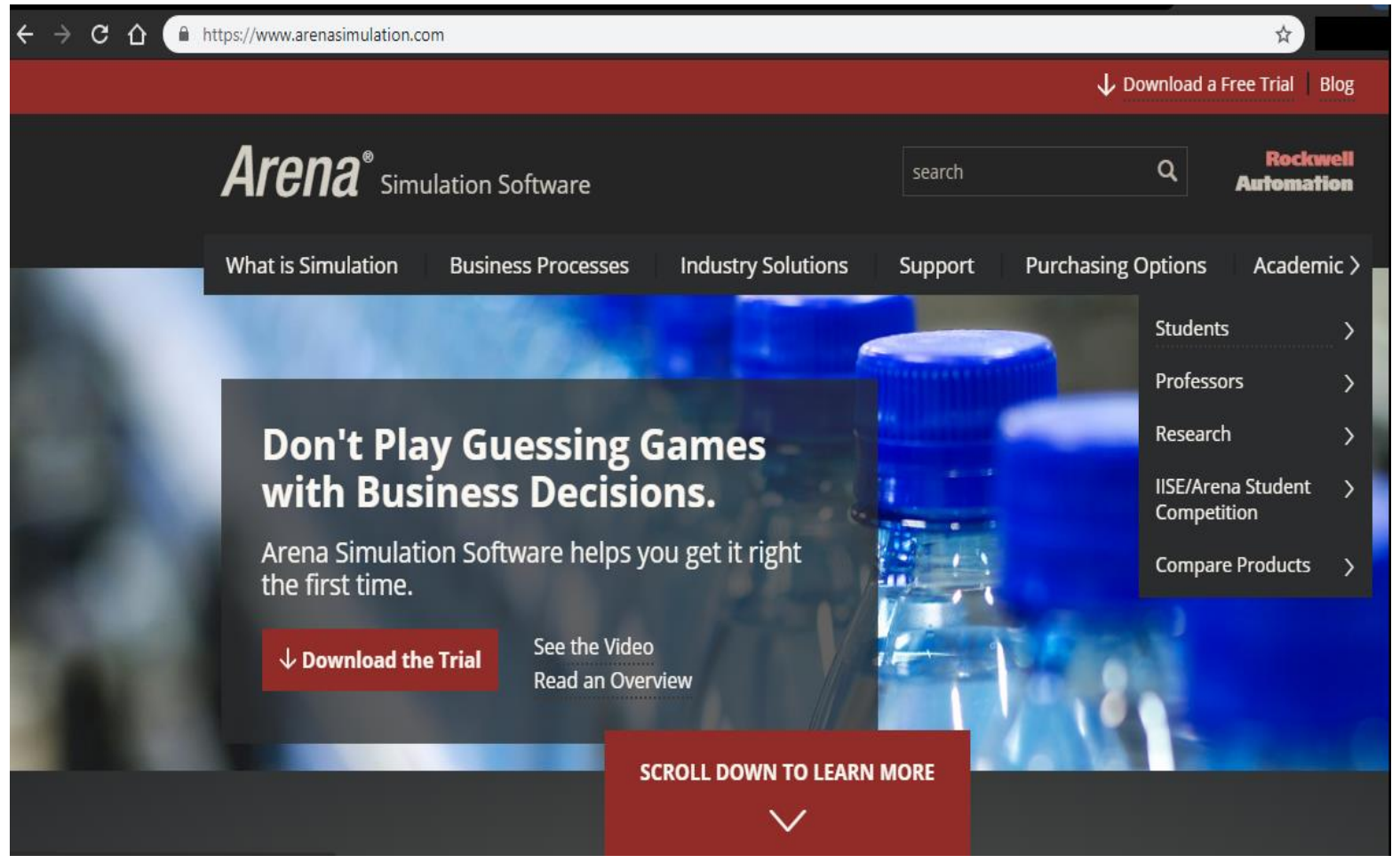

Figura A1.1. Tela inicial para baixar o Arena. 
Em seguida o site será redirecionado para uma página contendo algumas informações sobre este software, como pode ser visto na Figura A1.2. Deve-se clicar na opção "Download Arena For Students".

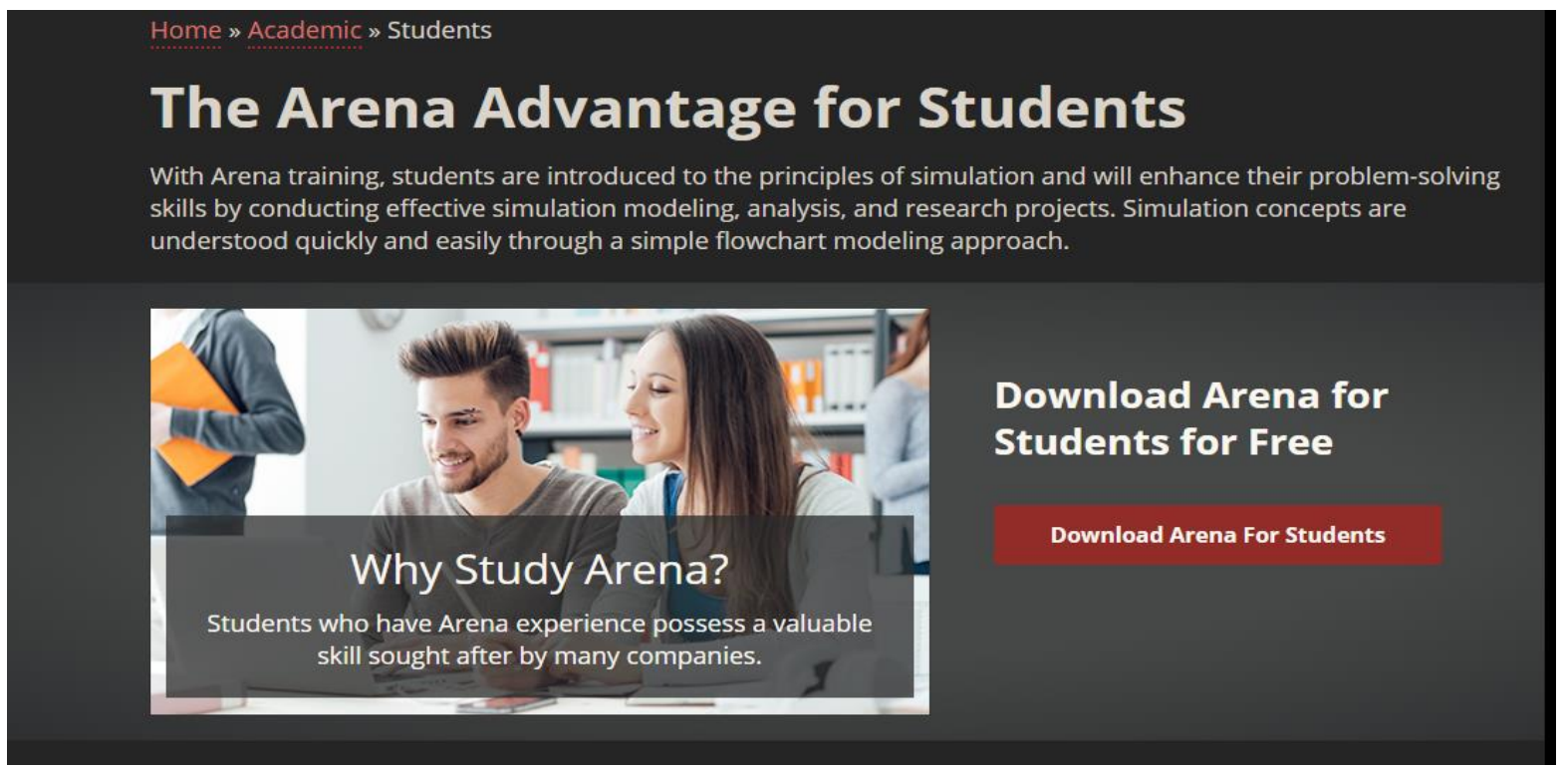

Figura A1.2. Tela inicial para baixar o Arena.

Feito isso, será pedido o preenchimento de um formulário contendo algumas informações pessoais, entre elas o e-mail.

Todos os dados devem ser preenchidos e depois deve-se clicar na opção Submit no fim do formulário, Figura A1.3

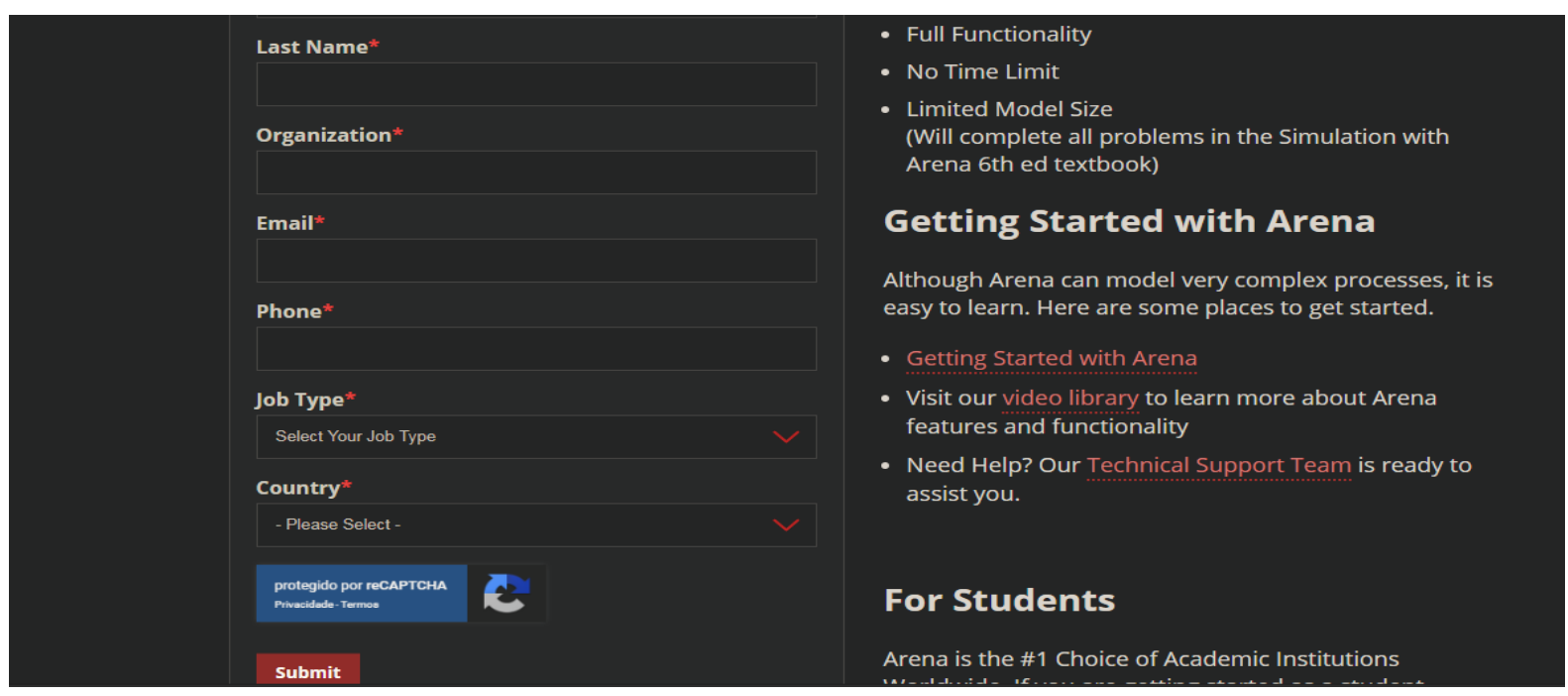

Figura A1.3. Opção Submit no fim do formulário.

Após essa submissão do formulário, deve-se verificar na caixa de entrada do e-mail, a mensagem contendo os links para baixar o programa, assim como é mostrado na Figura A1.4. 
FILAS: conceitos, novos enfoques de abordagem e aplicações em Transportes

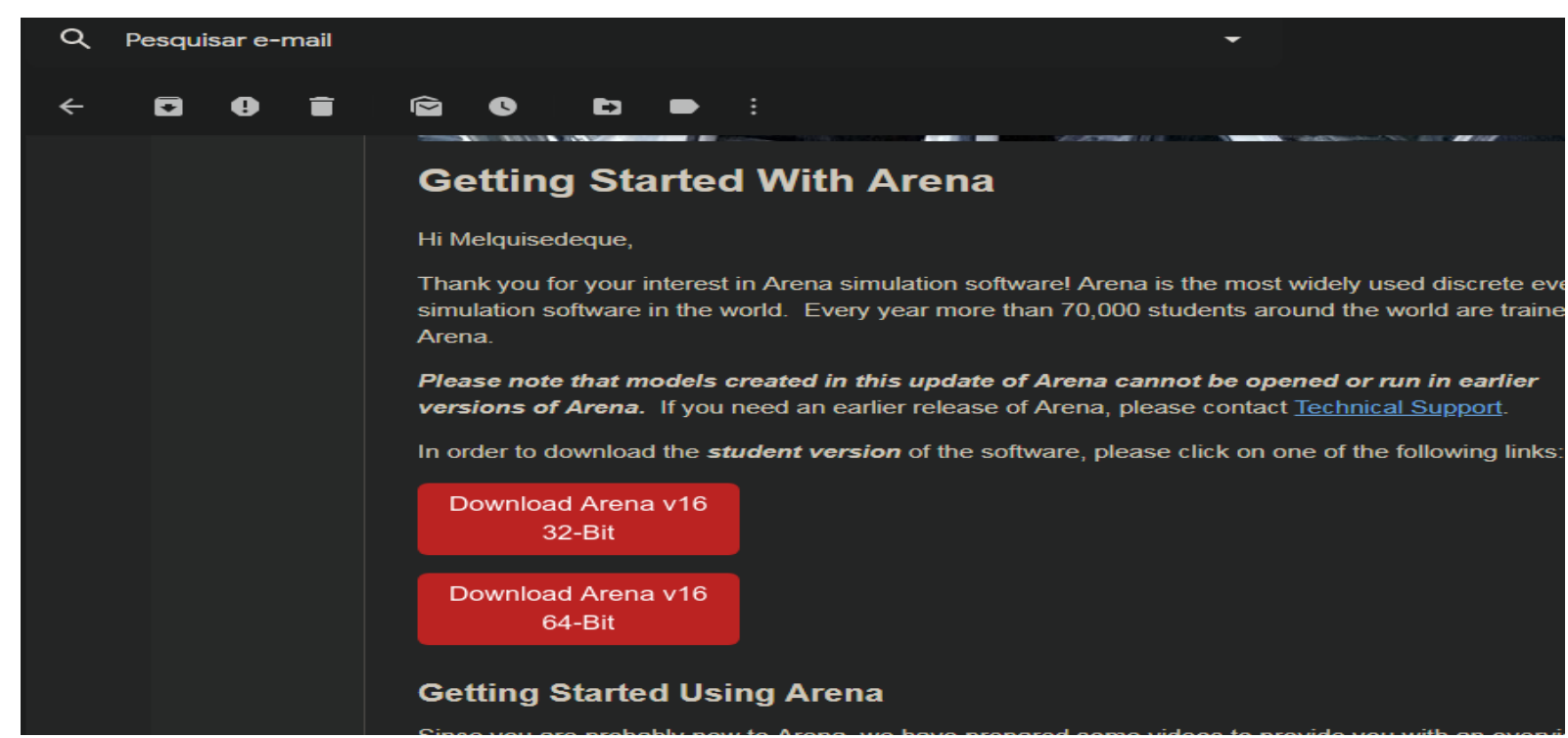

Figura A1.4. Iniciando o Arena.

Duas opções de download são enviadas, a versão a ser escolhida deve ser de acordo com o sistema operacional utilizado. No Windows 7, por exemplo, pode ser verificado a versão do programa seguindo os seguintes passos: Menu iniciar (Ícone do Windows); Clique com o botão direito do mouse no item "Computador" e depois clique em "Propriedades", Figura A1.5

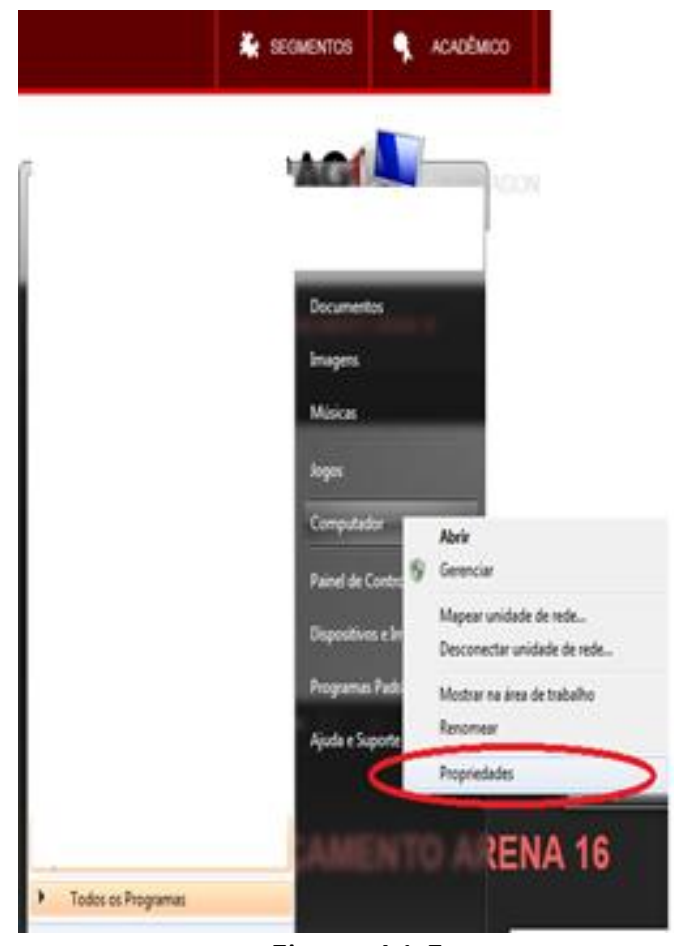

Figura A1.5

Após clicar em propriedades, será apresentada várias informações do computador, entre elas, na seção "Sistema", como é mostrado o tipo do sistema, Figura A1.6. 


\section{Sistema}

Fabricante:

Modelo:

Classificação:

Processador:

Memória instalada (RAM): 6กم GR (utilizável. $589 \mathrm{GR}$ )

Tipo de sistema: Sistema Operacional de 64 Bits

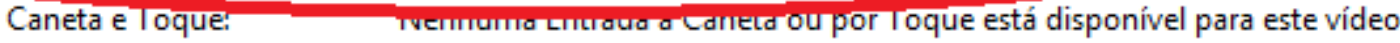

Figura A1.6.

Logo após o programa correspondente a versão do computador ser baixado, pode-se descompactar a pasta baixada no lugar de escolha do usuário, Figura A1.7.

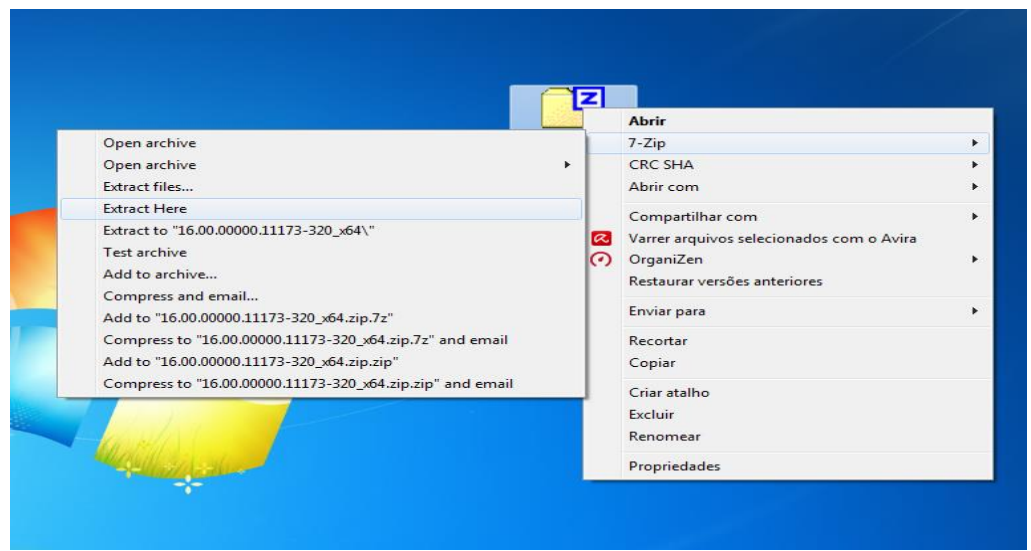

Figura A1.7

Feito isso, deve-se clicar na pasta "Medialmage", Figura A1.8.

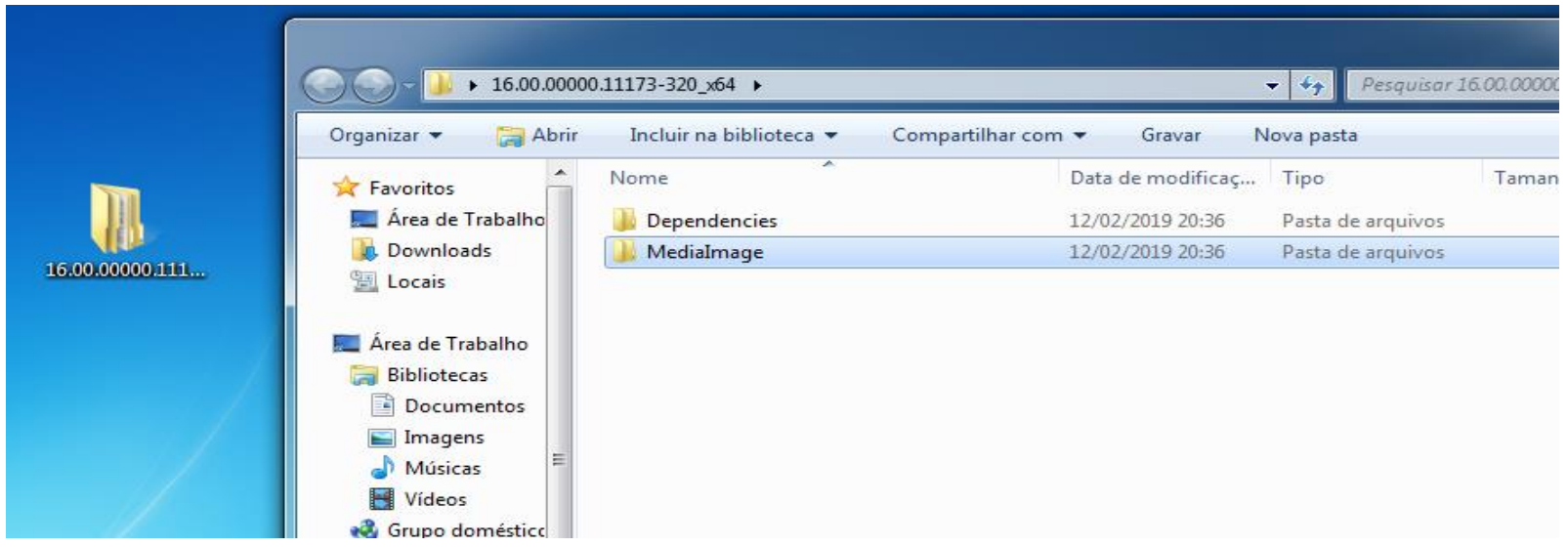

Figura A1.8.

Em seguida, clicar no item "autorun.exe", Figura A1.9. 
FILAS: conceitos, novos enfoques de abordagem e aplicações em Transportes

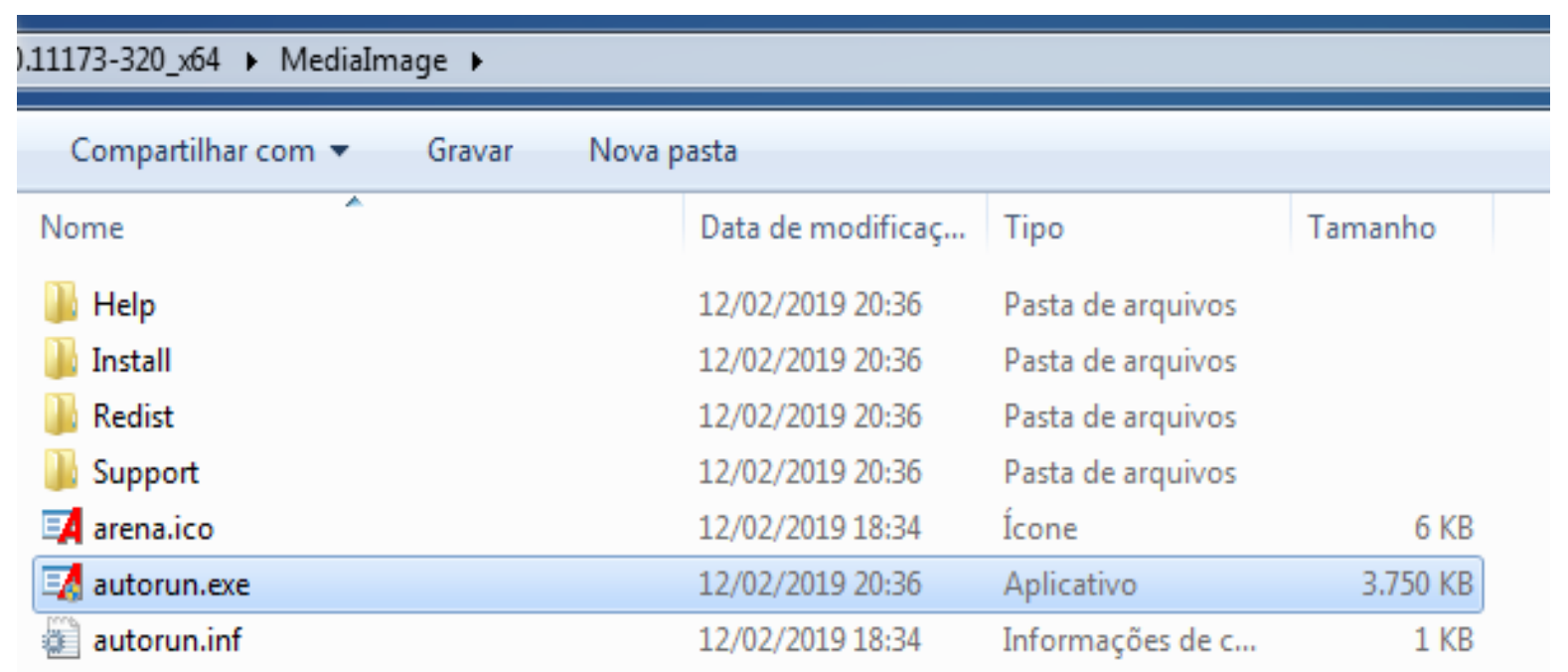

Figura A1.9.

Será aberta uma janela com algumas opções. Para prosseguir a instalação, deve-se clicar no item "Install Arena 64-Bit", no exemplo a versão baixada foi a de 64-Bit. Figura A1.10.

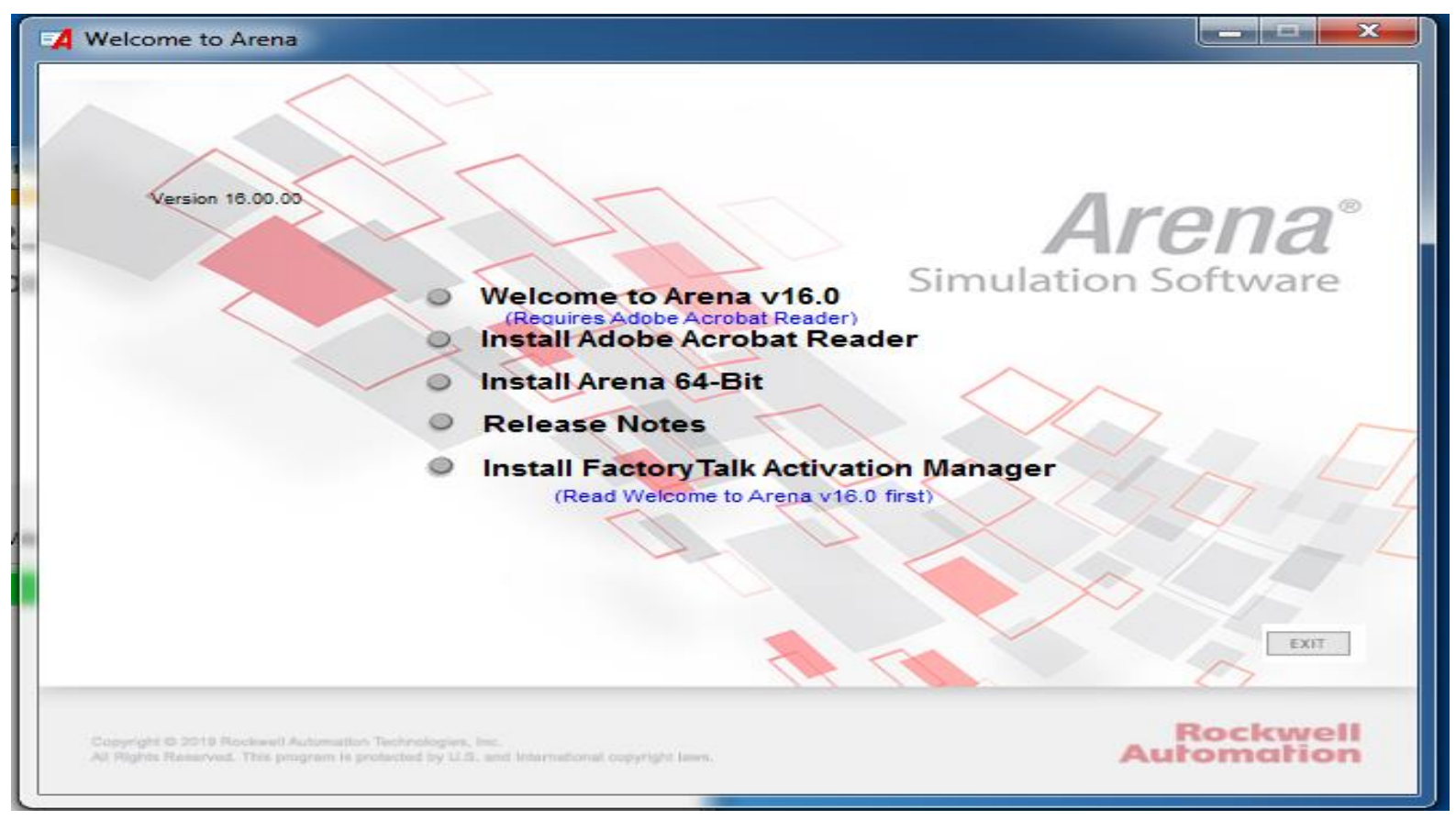

Figura A1.10.

Em seguida poderá aparecer uma janela pedindo que se instale alguns programas que são prérequisitos, caso o sistema operacional do usuário ainda não os possua. Nesse caso, a instalação dessas pendências é efetuada automaticamente, cabendo ao usuário clicar em Avançar e Concluir, quando for pedido, Figura A1.11. 
FILAS: conceitos, novos enfoques de abordagem e aplicações em Transportes

Arena Prerequisite Installer

Please wait while the Arena prerequisite installation program examines your system and determines if there are any required system updates that need to be installed and installs them.

D System Requirements
$\square$ MDAC 2.8
$\square$. NET Framework 2.0
$\square$ Visual Basic for Applications
$\square$ Visual Basic for Applications 1033
$\square$ A.ccess Database Engine
$\square$ Crystal Reports Runtime
$\square$. NET Framework 4.0

Passed

Passed

Passed

Updated

Updated

Updated

Updated

Figura A1.11.

Será apresentada a tela de boas-vindas da instalação, clicar em "Next", Figura A1.12.

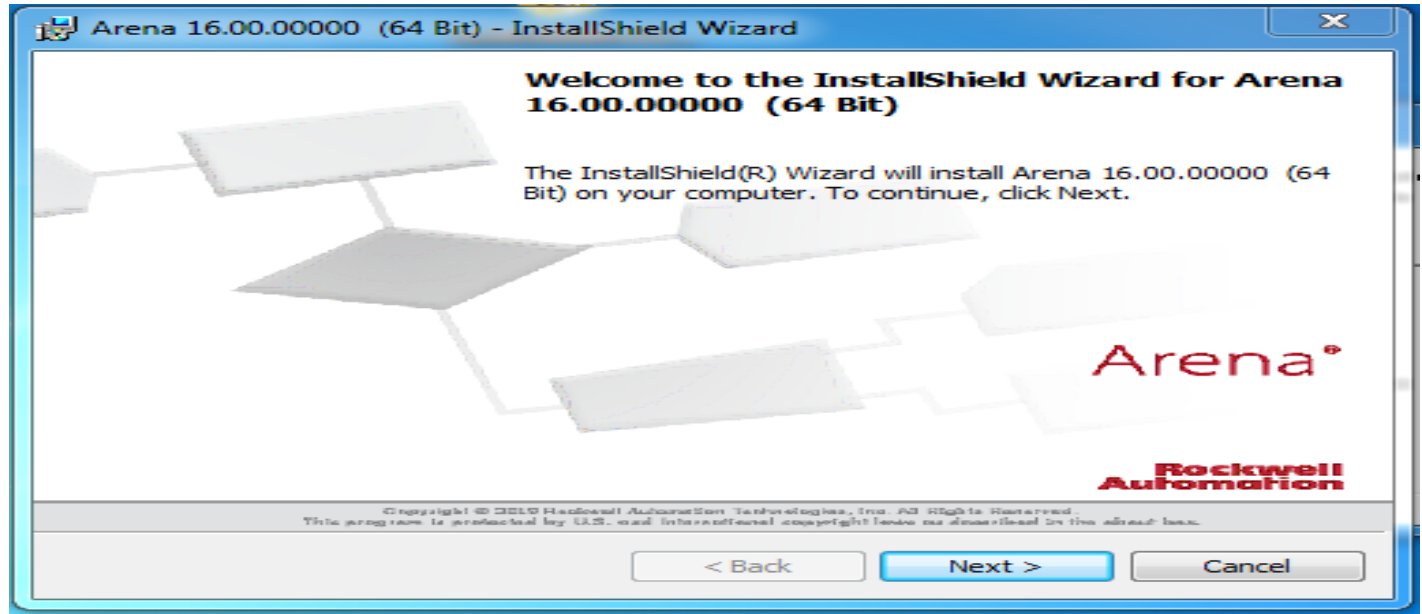

Figura A1.12.

Na sequência, são apresentados os termos de uso, que deve ser lido e, em seguida, aceito, clicando na opção "I accept the terms in the license agreement", Figura A1.13.

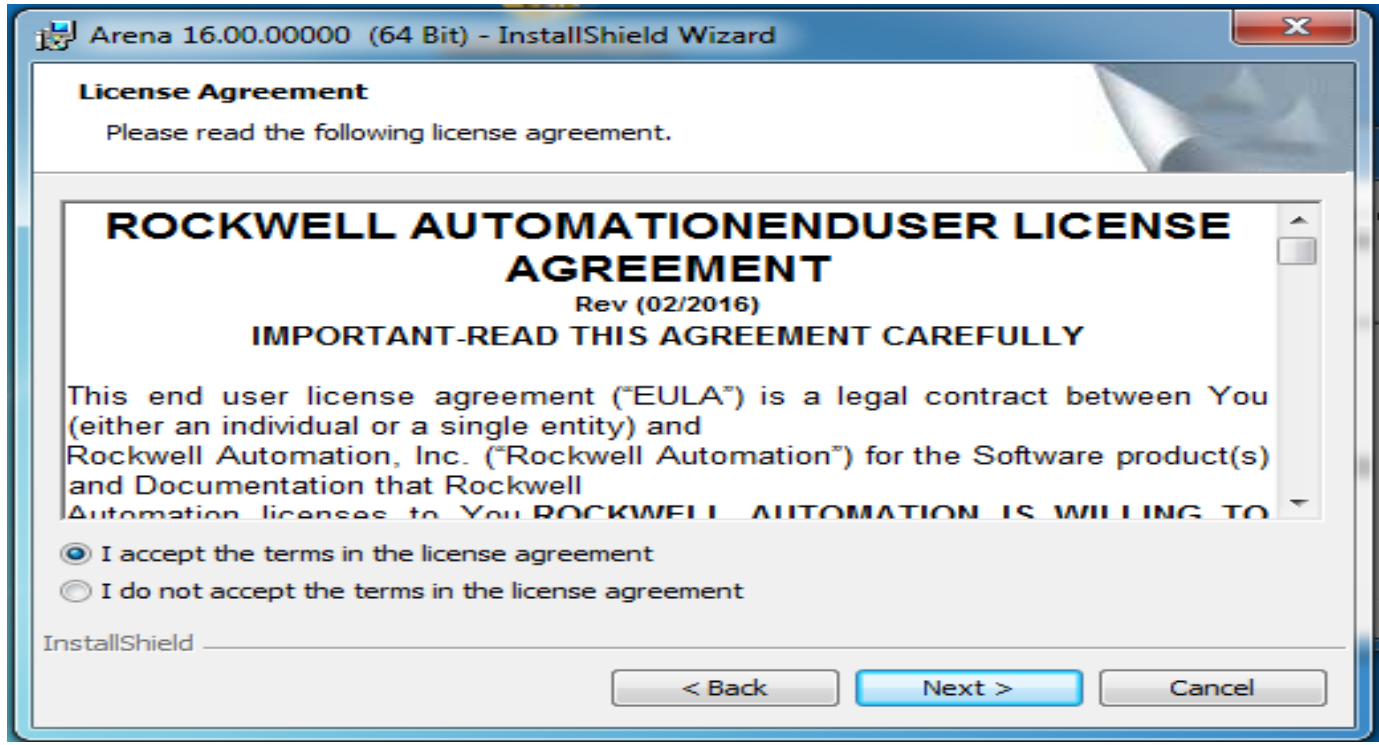

Figura A1.13. 
Logo em seguida será mostrada a janela da licença de uso: na primeira caixa, deve ser colocado um nome de usuário, na caixa abaixo o nome da organização e na última deve-se escrever "STUDENT" para obter a licença acadêmica, Figura A1.14.

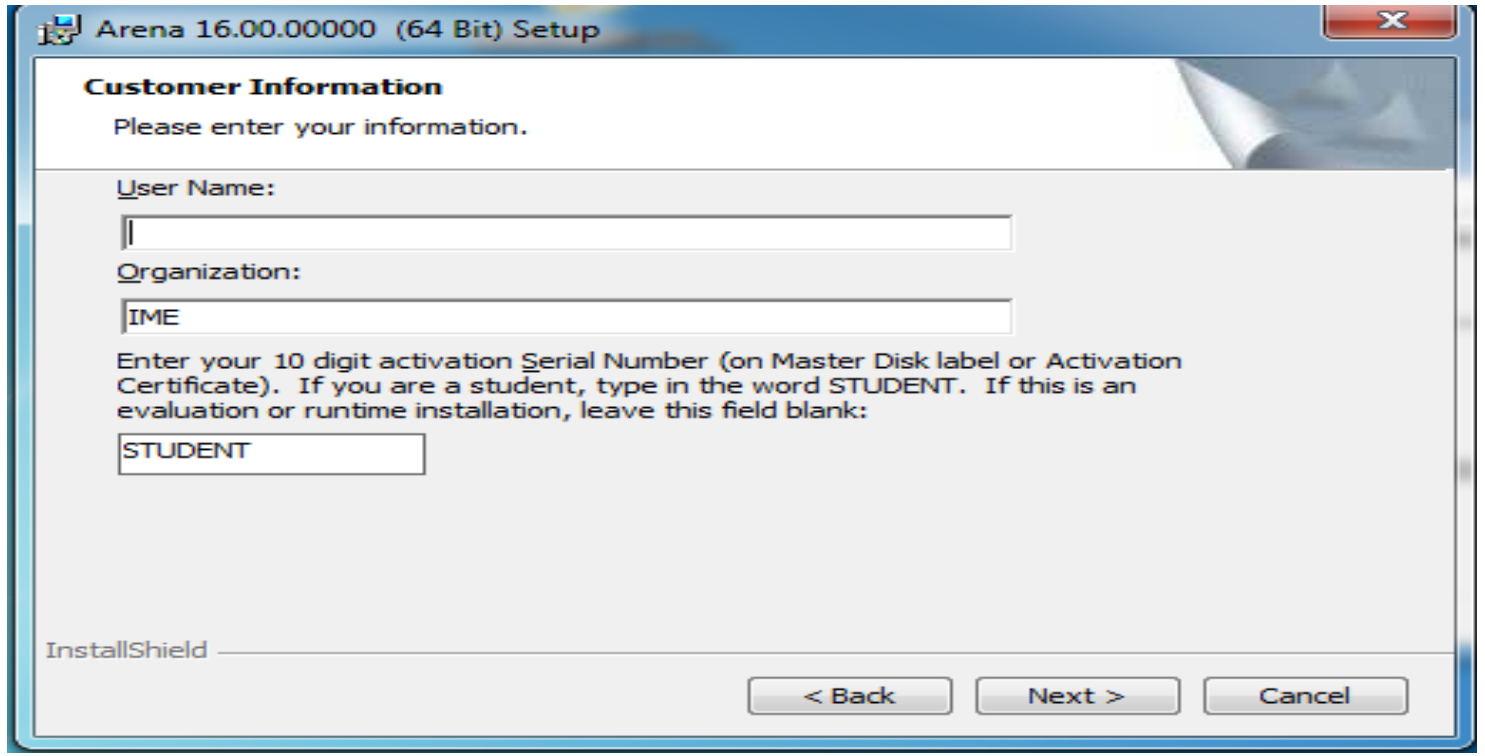

Figura A1.14.

Feito isso, aparecerá a opção de instalação personalizada ou padrão, clique na primeira para instalar a versão no modo padrão, Figura A1.15.

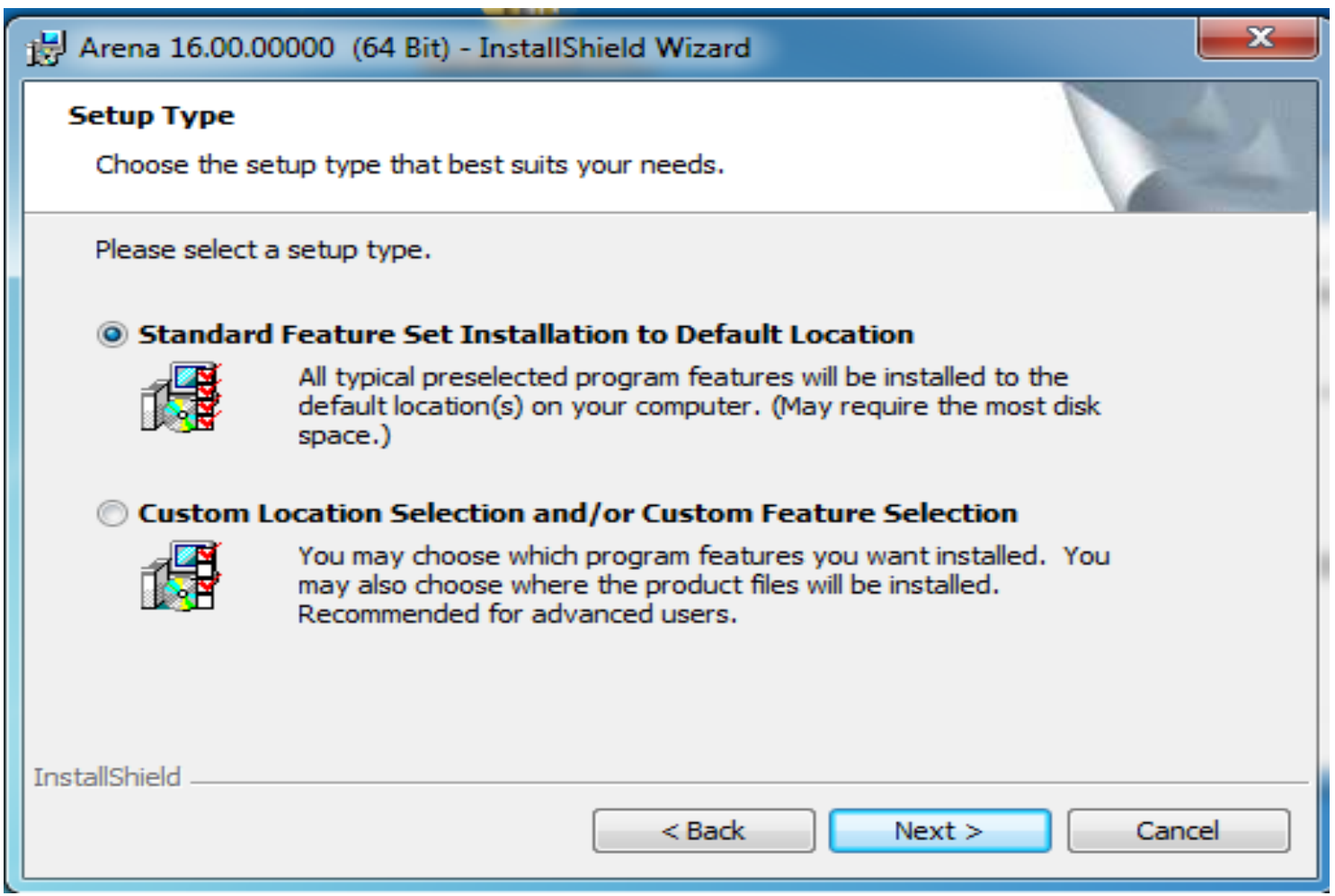

Figura A1.15. 
Após isso, irá ser apresentada a janela da Figura A1.16. Para começar a instalação deve-se clicar em "Install".

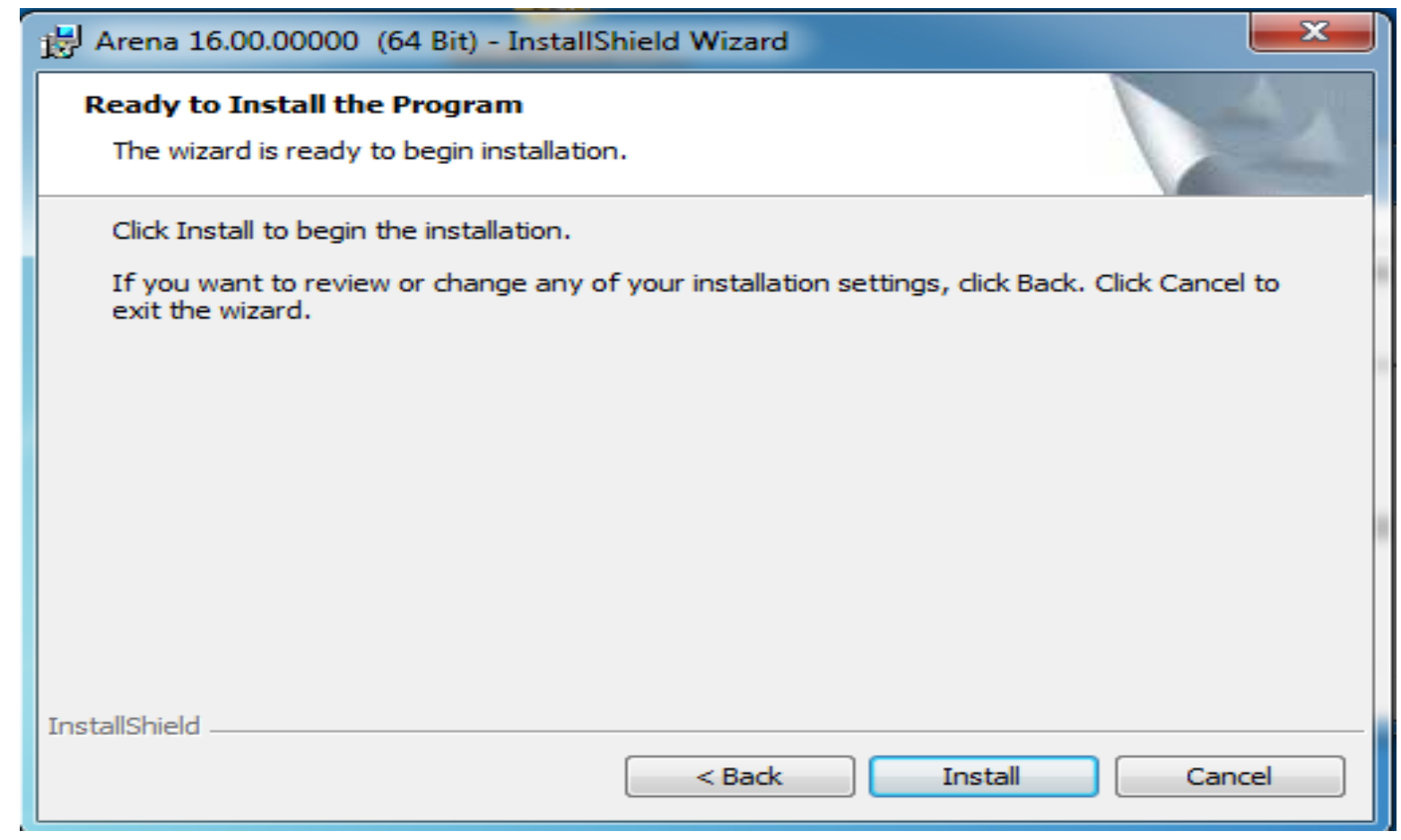

Figura A1.16.

Será iniciada a instalação, sendo mostrada a barra de progressão, Figura A1.17.

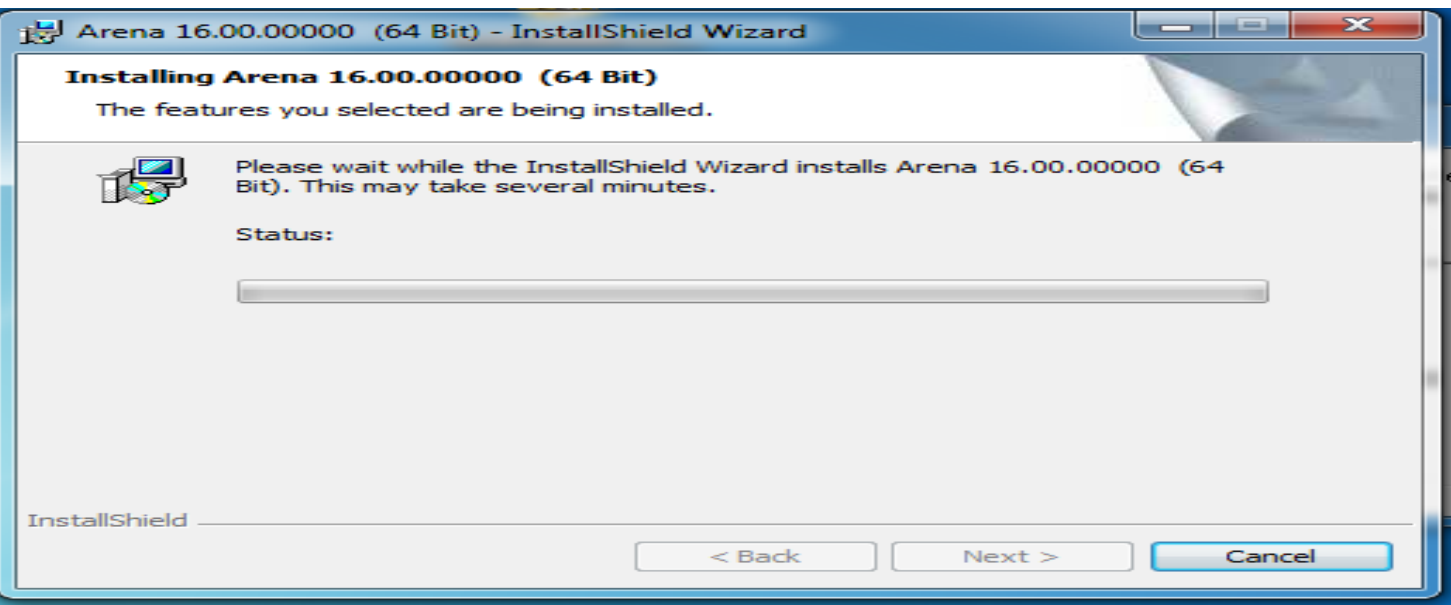

Figura A1.17.

Durante esse processo, poderá aparecer uma janela informando que alguns arquivos precisam ser atualizados. Se isso ocorrer, mantenha a opção "Automatically close and attempt to restart applications" marcada e clique em "OK", Figura A1.18. 
1녕 Arena 16.00.00000 (64 Bit) - InstallShield Wizard

Files in Use

Some files that need to be updated are currently in use.

The following applications are using files that need to be updated by this setup.

Intel(R) Management and Security Application Local Management Service

- Automatically close and attempt to restart applications.

Do not close applications. (A reboot will be required.)

Installshield

Figura A1.18.

Depois de clicar em "OK" a barra de progresso retornará e a instalação continuará como visto na Figura A1.19.

\section{눙 Arena 16.00 .00000 (64 Bit) - InstallShield Wizard}

\section{Installing Arena 16.00.00000 (64 Bit)}

The features you selected are being installed.

Please wait while the InstallShield Wizard installs Arena 16.00.00000 (64

Bit). This may take several minutes.

Status:

Updating component registration

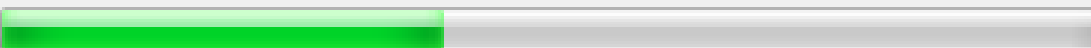

InstallShield

Figura A1.19.

Ao final da instalação será apresentada a janela abaixo, devendo-se clicar na opção "Finish", Figura A1.20. 
FILAS: conceitos, novos enfoques de abordagem e aplicações em Transportes

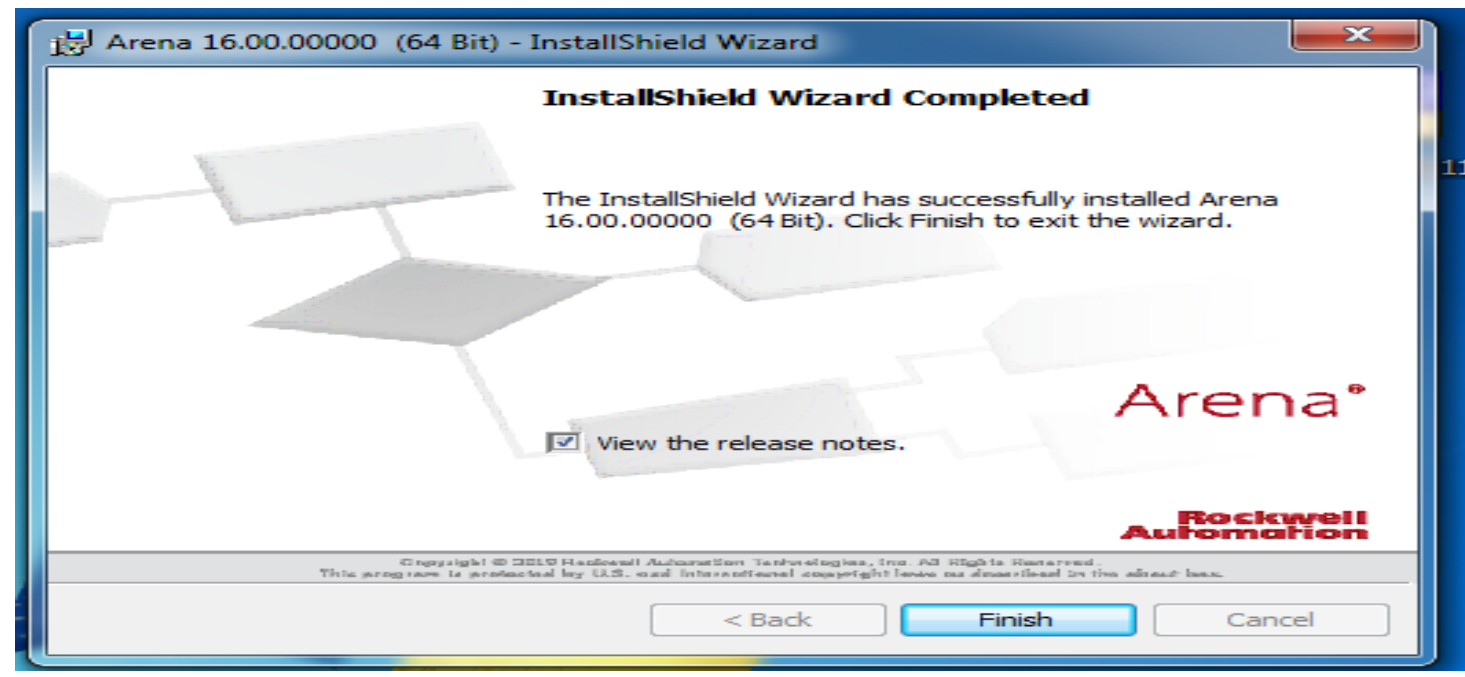

Figura A1.20.

Será aberta uma janela com algumas informações do Arena e o ícone do programa poderá ser visto no menu Iniciar, Figura A1.21. Caso o ícone não esteja visível. pode ser encontrado em: Menu iniciar; Rockwell Software; Arena.

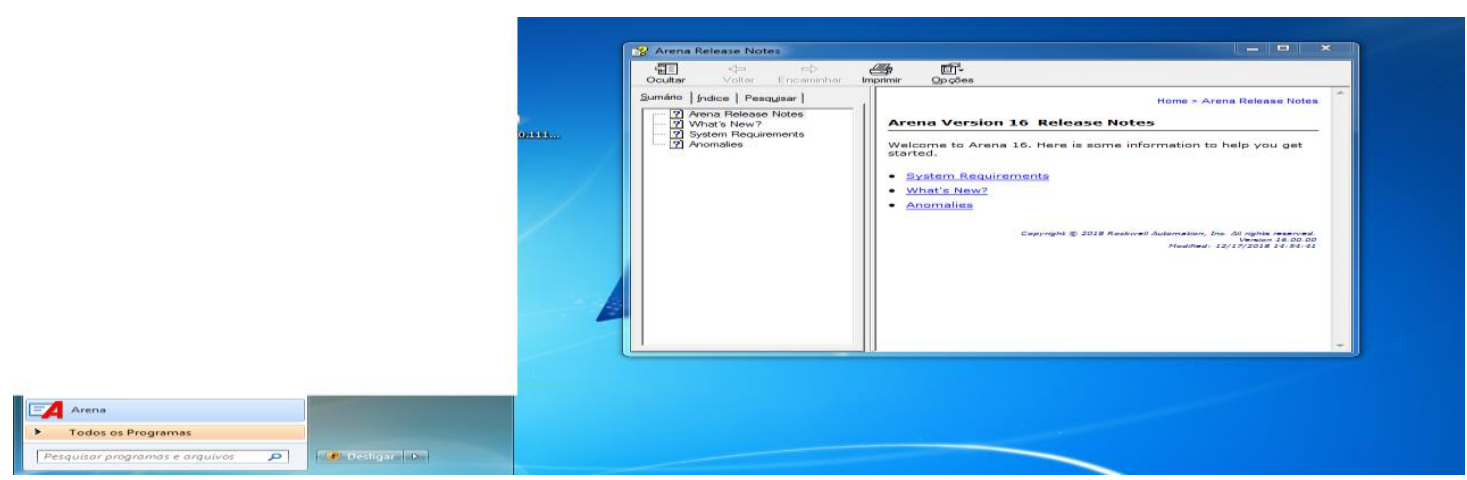

Figura A1.21.

Ao abrir o Arena pela primeira vez, será mostrada uma janela contendo algumas informações sobre a versão de estudante. Essa versão não possui limite de tempo para uso, porém é limitada no tamanho do modelo que pode ser construído no software, Figura A1.21.

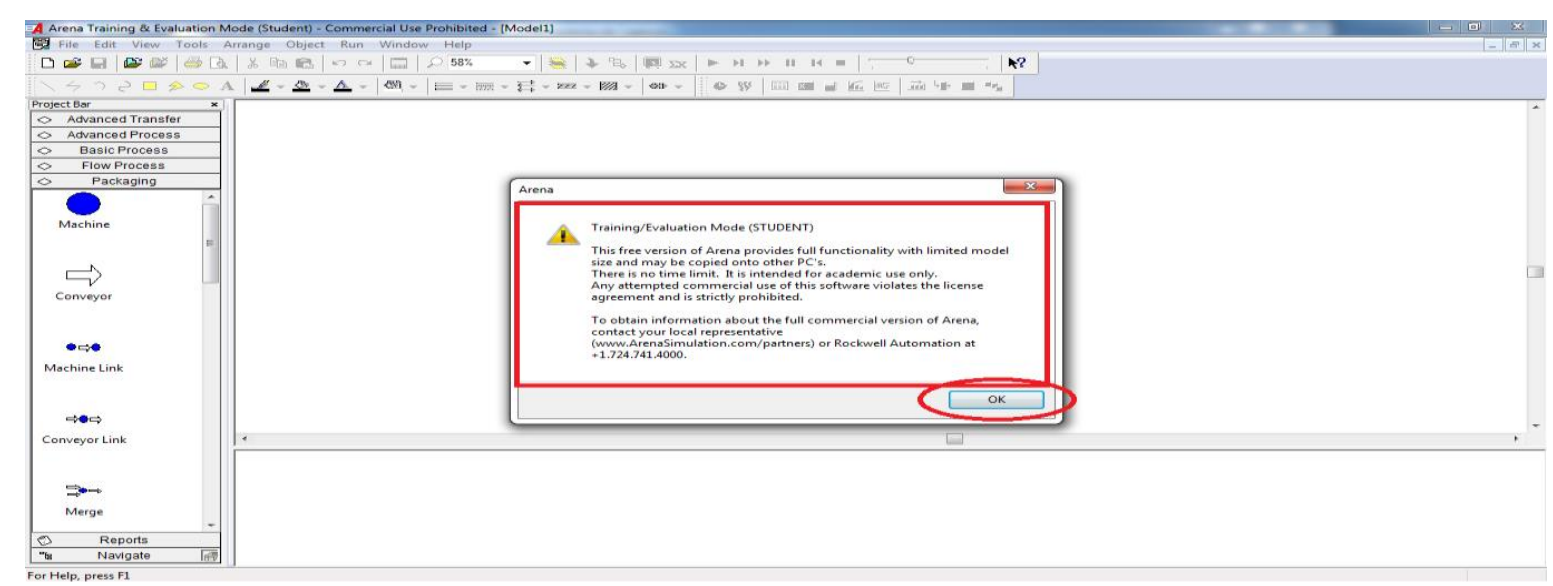

Figura A1.21. 


\section{Como identificar a distribuição de probabilidades das taxas de chegada e de atendimento}

Nesse tutorial será apresentado uma forma de identificar uma distribuição de probabilidade no ARENA, partindo de uma massa de dados coletados.

Vamos supor que foram obtidas 100 medições automáticas de tempos de chegada a uma estação de atendimento, Tabela A1.1

Tabela 1.1. Dados do exemplo

\begin{tabular}{|r|r|r|r|r|r|r|r|r|r|}
\hline \multicolumn{10}{|c|}{ TEMPO EM MINUTOS } \\
\hline 0,504491 & 0,355598 & 0,642691 & 1,223715 & 0,520564 & 0,469512 & 2,126337 & 2,835193 & 0,209905 & 1,188198 \\
\hline 1,430811 & 5,020071 & 0,316684 & 0,722051 & 0,60673 & 3,181953 & 2,93449 & 0,257771 & 0,380774 & 0,758811 \\
\hline 1,376195 & 0,490491 & 0,495025 & 0,82945 & 0,799916 & 1,28362 & 1,177524 & 0,346378 & 0,313207 & 0,481282 \\
\hline 0,261665 & 0,92356 & 0,622497 & 2,248512 & 0,7497 & 0,686245 & 0,676218 & 2,703005 & 2,575282 & 0,354767 \\
\hline 1,269151 & 0,967212 & 0,876704 & 1,280494 & 0,360471 & 2,044147 & 0,423899 & 1,055691 & 0,377527 & 0,356401 \\
\hline 1,438538 & 1,196127 & 0,209673 & 0,262164 & 1,120306 & 1,537063 & 0,64615 & 1,370212 & 1,163559 & 1,106227 \\
\hline 1,277754 & 1,303157 & 0,727596 & 0,50249 & 1,750318 & 0,417316 & 0,865912 & 0,682869 & 0,767713 & 5,46225 \\
\hline 0,532083 & 2,156432 & 0,975001 & 0,489678 & 2,398159 & 1,325395 & 1,20493 & 0,836157 & 0,364557 & 1,735272 \\
\hline 0,810399 & 0,693226 & 0,495253 & 1,722741 & 1,19839 & 1,028925 & 1,919315 & 1,795118 & 1,095142 & 0,212702 \\
\hline 0,35899 & 0,310262 & 0,244434 & 2,248052 & 0,399974 & 2,171119 & 0,258915 & 1,781006 & 1,056129 & 0,573956 \\
\hline
\end{tabular}

Deve-se salvar esses dados em um arquivo de formato ".txt" de modo que cada tempo medido ocupe uma linha do arquivo.Para criar o arquivo na área de trabalho do Windows, clique com o botão direito do mouse na área de trabalho, vá até a opção Novo e clique em Documento de Texto, Figura A1.22.

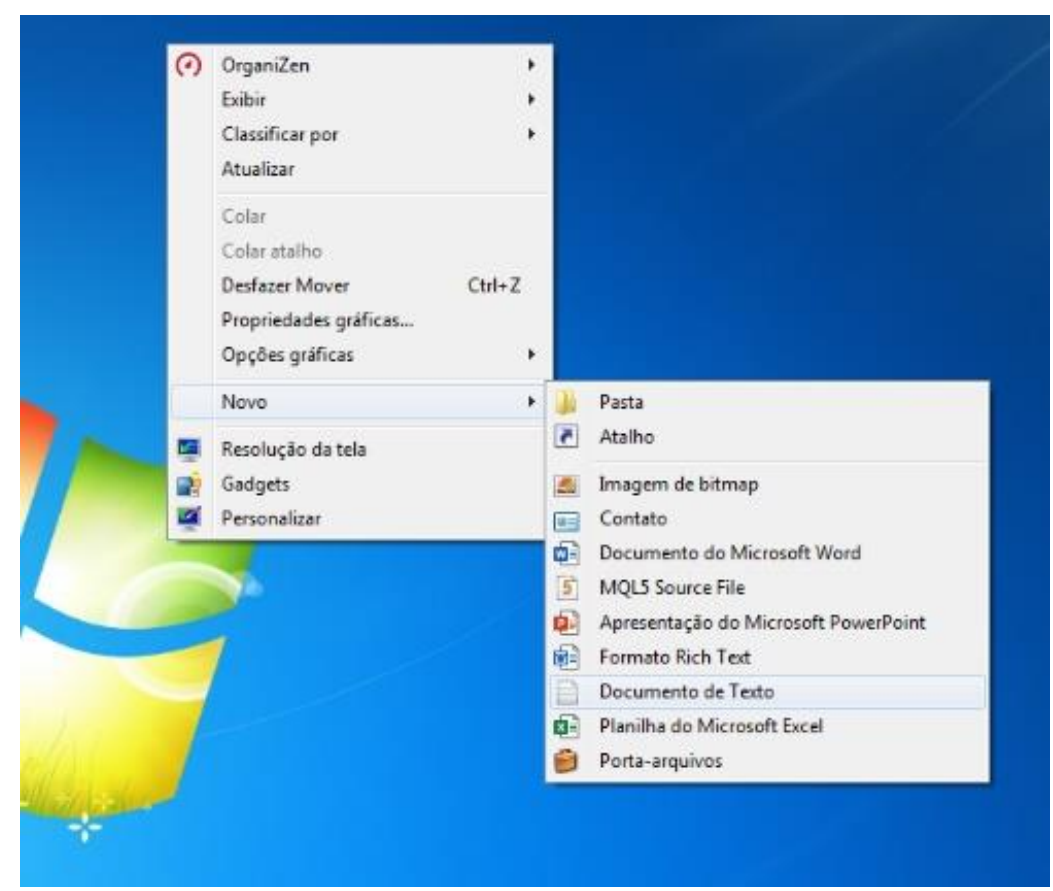

Figura A1.22.

Feito isso, inclua os dados no arquivo criado, Figura A1.23. 


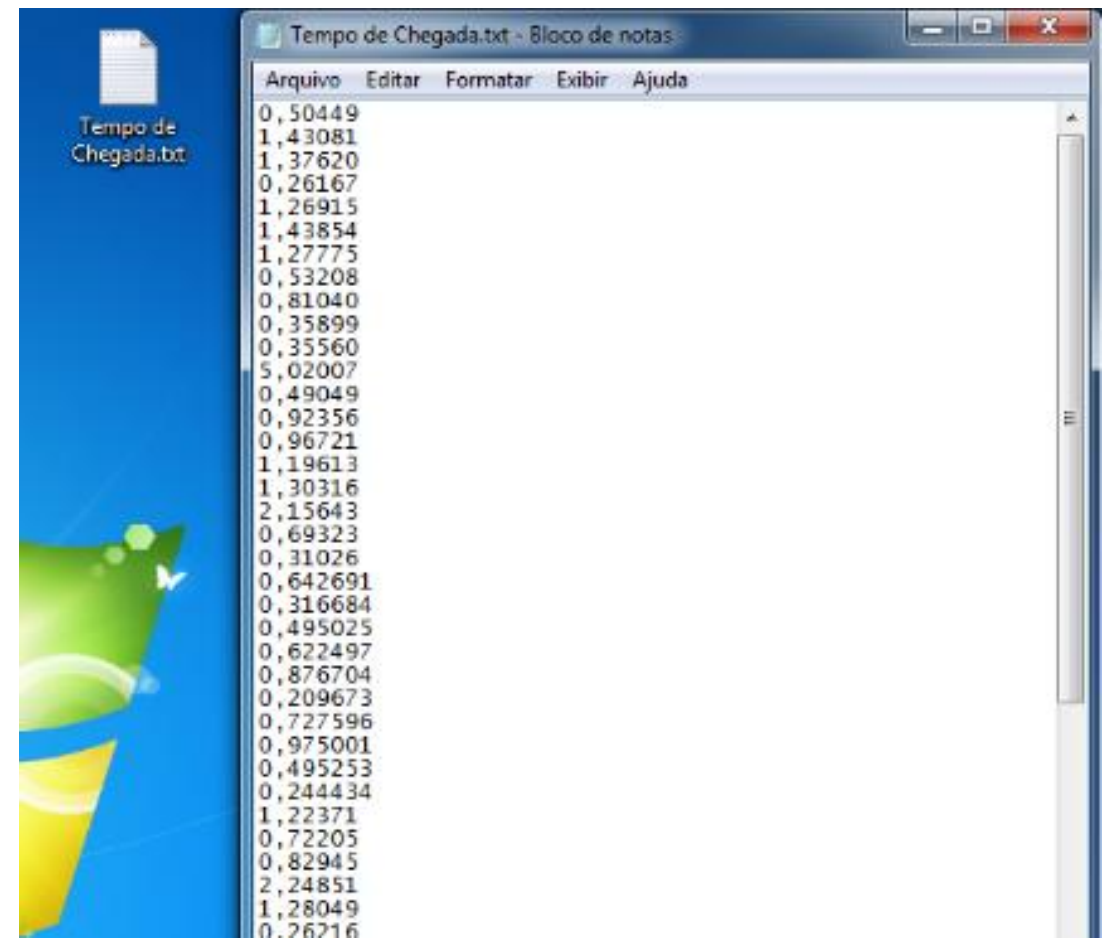

Figura A1.24.

O ARENA utiliza o padrão americano de pontuação, portanto, as virgulas devem ser substituídas por pontos ("," por "."). Para isso, com o arquivo .txt aberto no bloco de notas, basta apertar as teclas $\mathrm{Ctrl}+\mathrm{H}$, e aparecerá uma janela para substituir esses elementos, Figura A1.24. Na caixa "Localizar", digite a virgula "," e na caixa "Substituir por" digite o ponto ".". Após isto, clique em "Substituir Tudo" e salve as mudanças antes de fechar o arquivo.

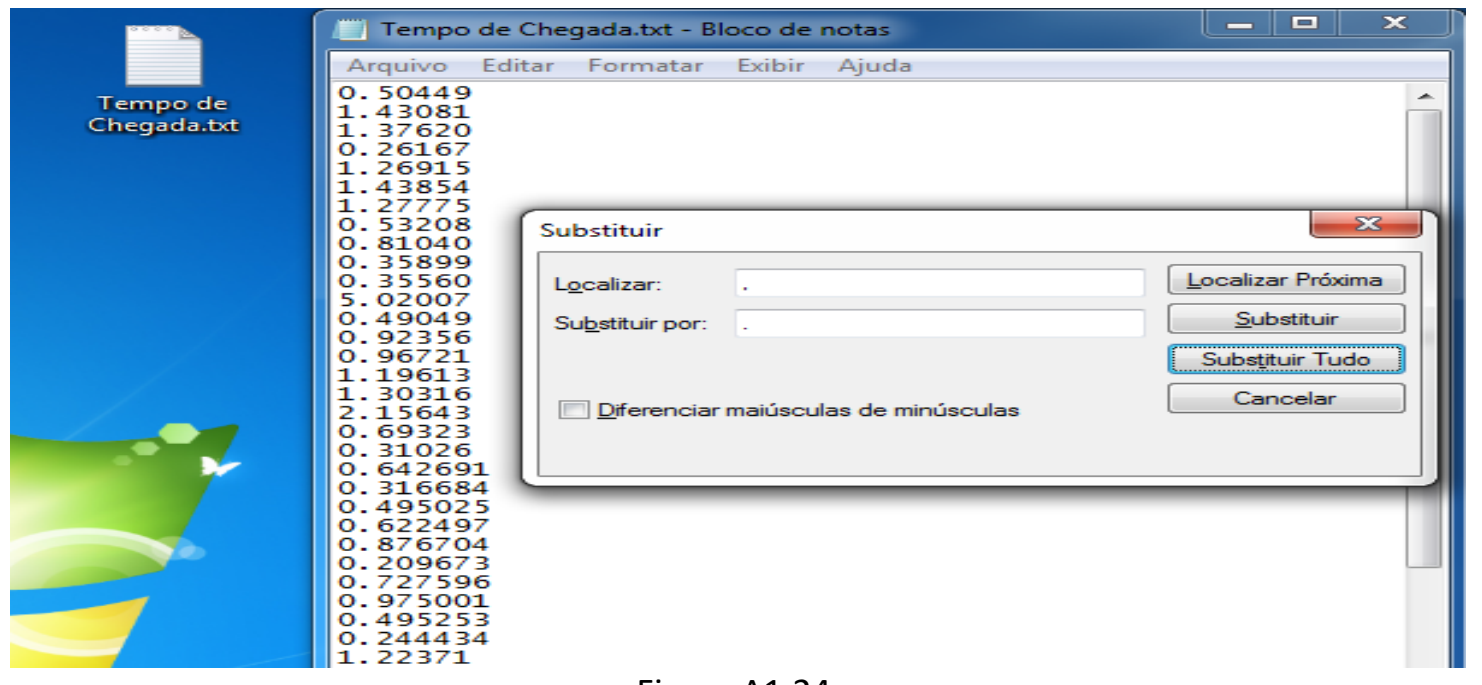

Figura A1.24.

Depois disso, abra o ARENA e localize a opção "Input Analyzer" que fica localizado na barra superior dentro da opção "Tools", Figura A1.25. 
FILAS: conceitos, novos enfoques de abordagem e aplicações em Transportes

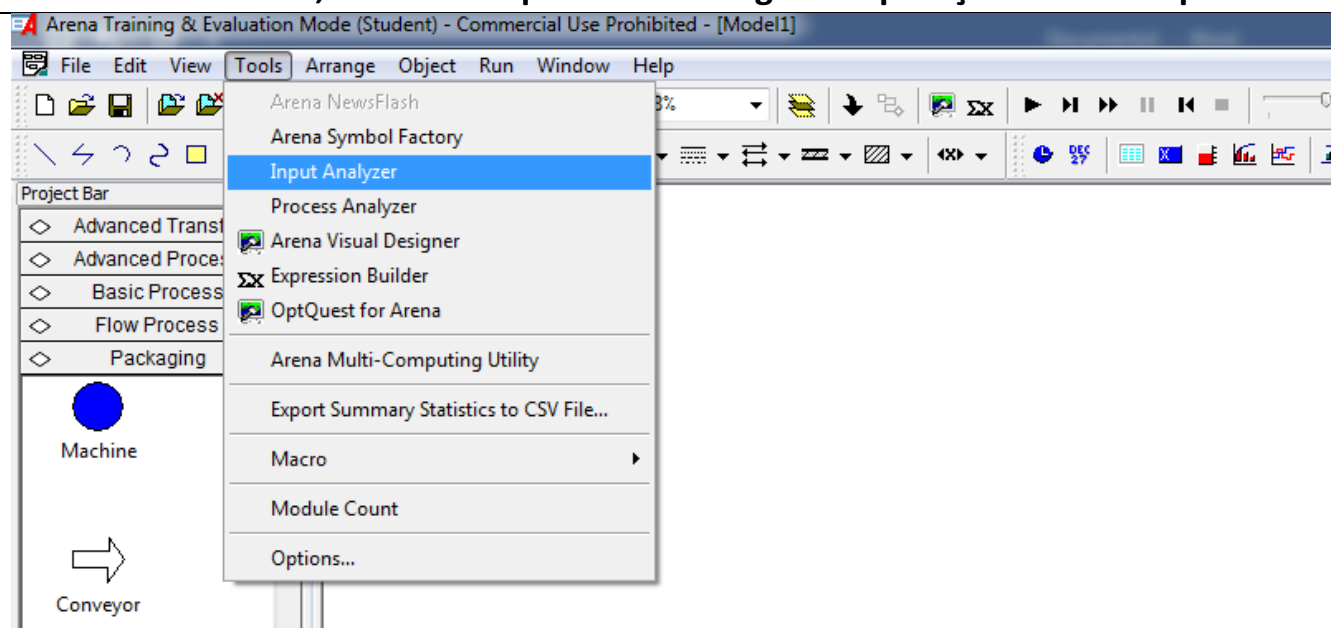

Figura A1.25.

Após abrir a ferramenta Input Analyzer é necessário criar um arquivo novo. Nesse caso clique no ícone "New" na barra superior, Figura A1.26.

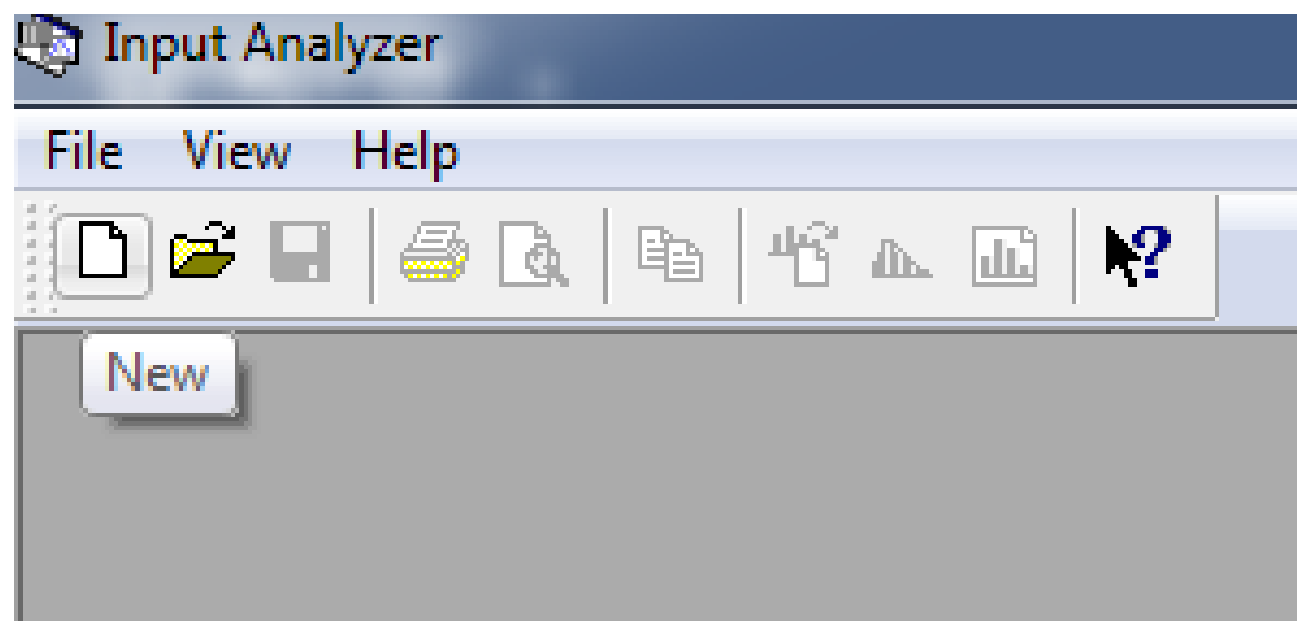

Figura A1.26.

Em seguida clique no ícone "Use Existing Data File" que fica localizado na barra superior, Figura A1.27.

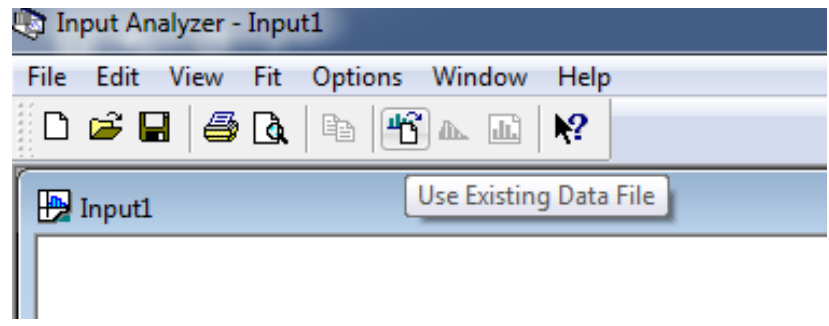

Figura A1.27.

Selecione o arquivo salvo e clique em Abrir, Figura A1.28. 


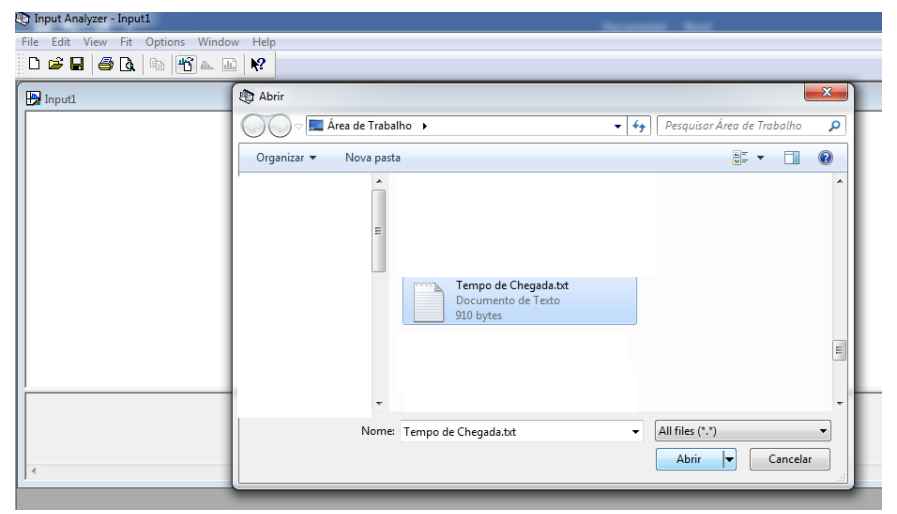

Figura A1.28.

Após abrir o arquivo, o Input Analyzer mostra algumas informações sobre os dados, Figura A1.29.

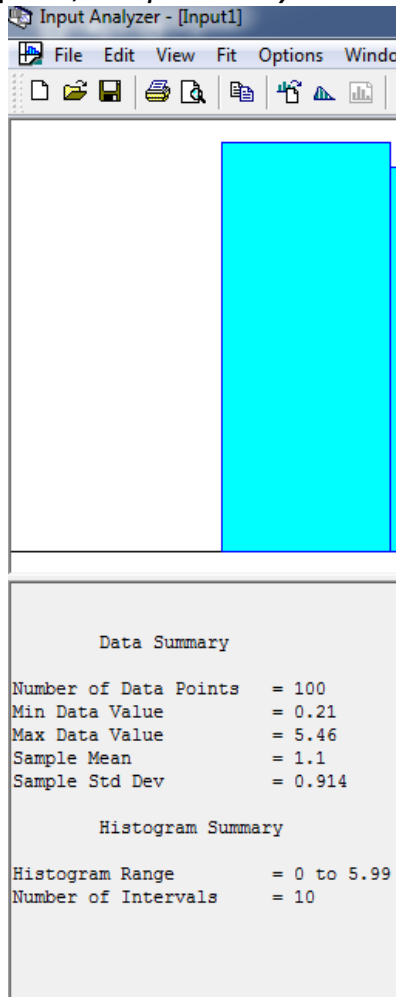

Figura A1.29.

Apresentado o número de amostras no arquivo, valor mínimo e máximo dentre outros. E por fim, um histograma das medidas dividido no intervalo que o Input Analyzer escolhe.

Para identificar a distribuição de probabilidade baseado nos dados inseridos, basta clicar no ícone "Fit All" na barra superior do programa, Figura A1.30. 


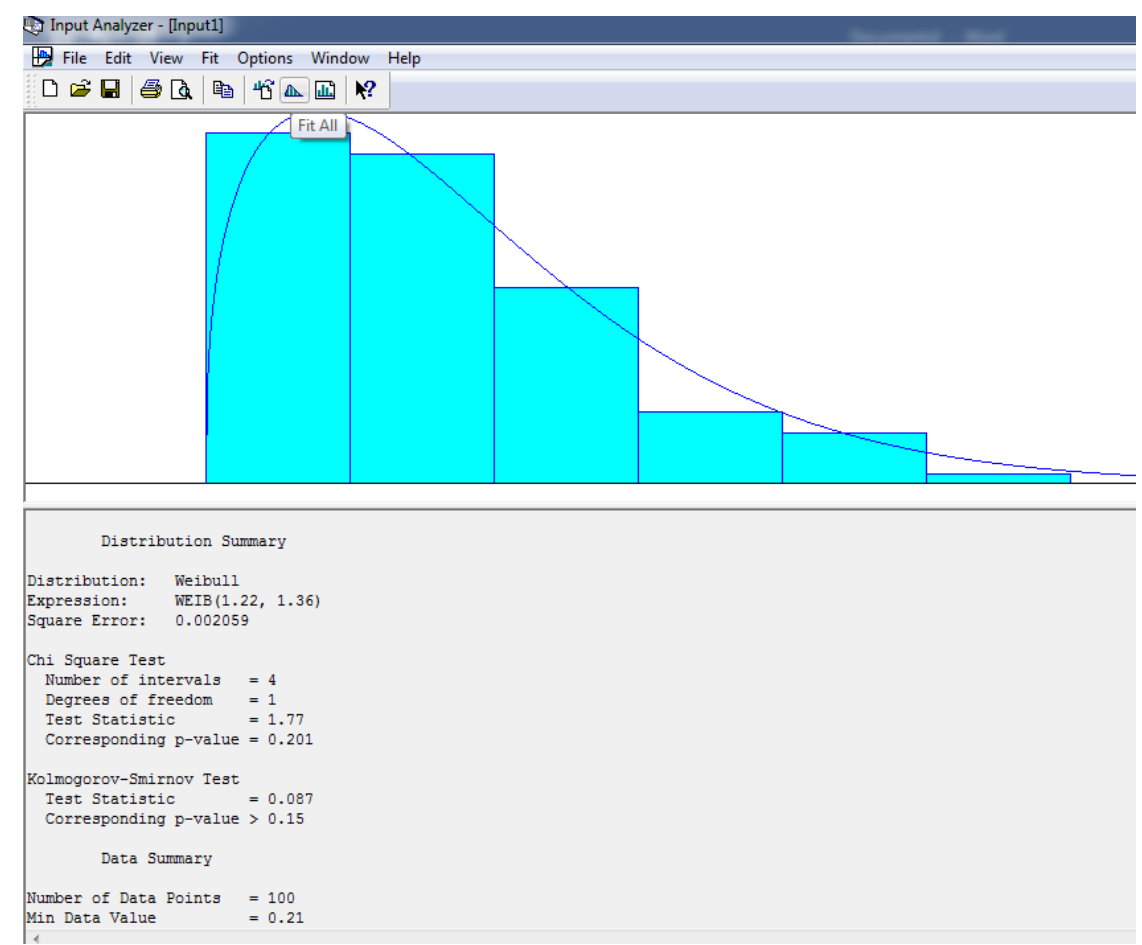

Figura A1.30.

Com isso, o Input Analyzer escolhe a que melhor modela os dados, dentre os parâmetros do programa, distribuição que representa os dados amostrais. Nesse exemplo, foi a Weibull. A expressão que pode ser utilizada na modelagem desse processo no ARENA é "WEIB $(1.22,1.36)$ ".

Caso o usuário queria escolher outra distribuição de probabilidade nos dados basta clicar na opção "Fit" e escolher a nova distribuição, Figura A1.31.

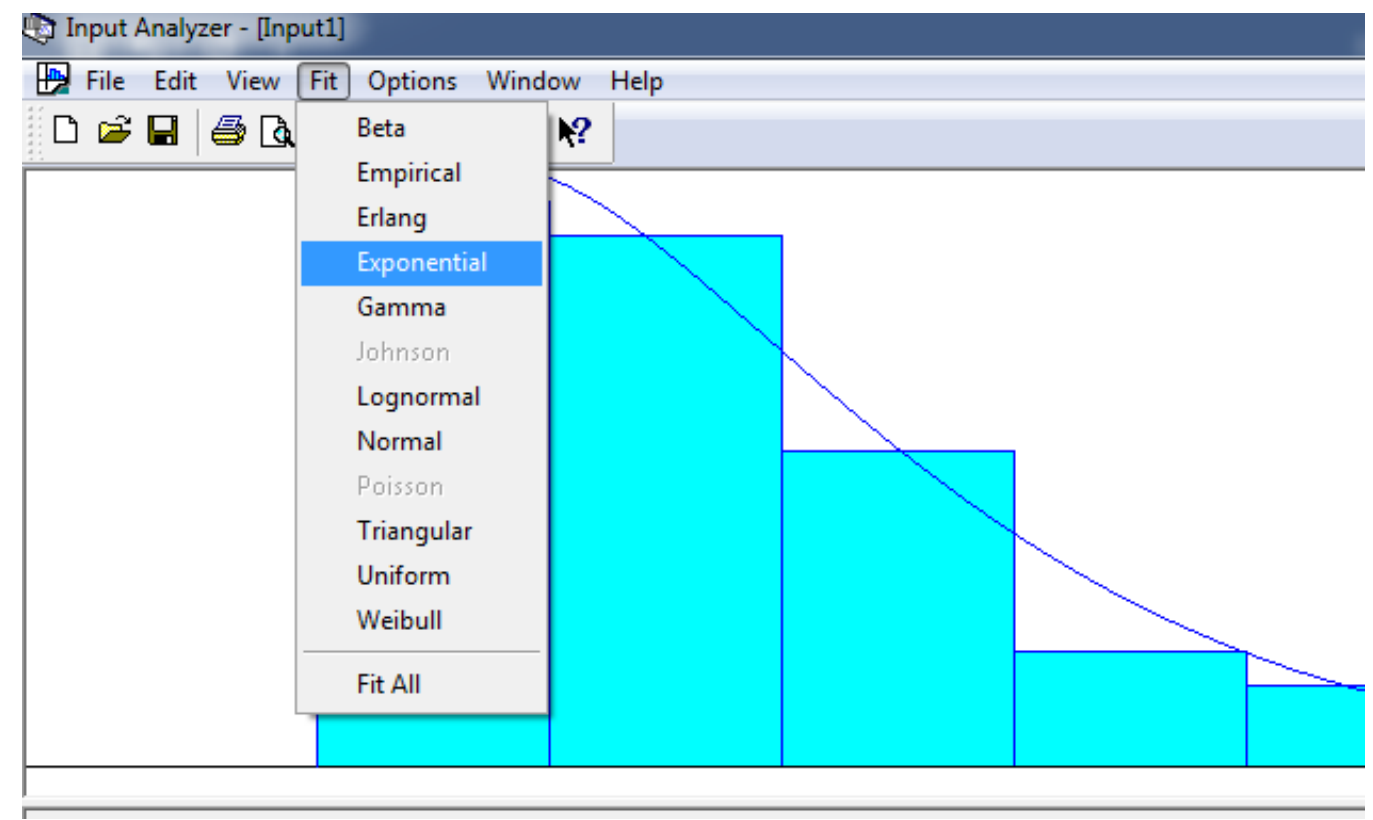

Figura A1.31.

Se o usuário quiser usar a distribuição Exponencial, por exemplo, basta clicar na opção "Exponential" e usar os dados exibidos no programa, como visto na Figura A1.32. 


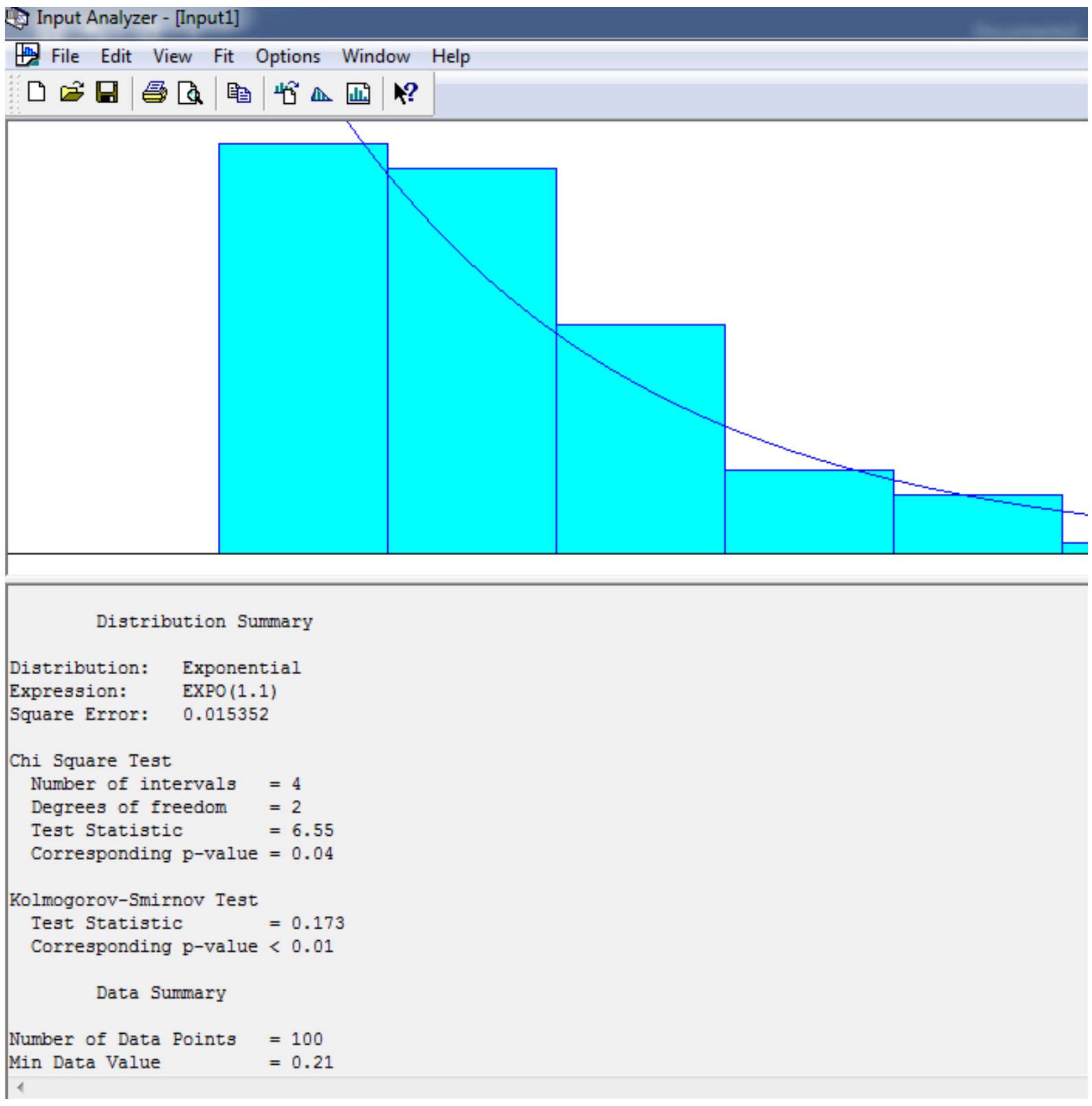

Figura A1.32.

\section{Exemplo de simulação}

Vamos supor que desejamos medir o tempo médio de uma fila, juntamente com o tamanho médio de um processo de atendimento de 100 passageiros que chegam a 1 atendente, obedecendo a uma distribuição exponencial cuja a média é 1 minuto e o tempo de atendimento é regido pela distribuição triangular, onde o tempo mínimo é de 5 , a média é 6 e o tempo máximo é de 7 (tempo em minutos).

Será apresentado a seguir como modelar esse processo.

Primeiramente abra o programa ARENA, Figura A1.33. 


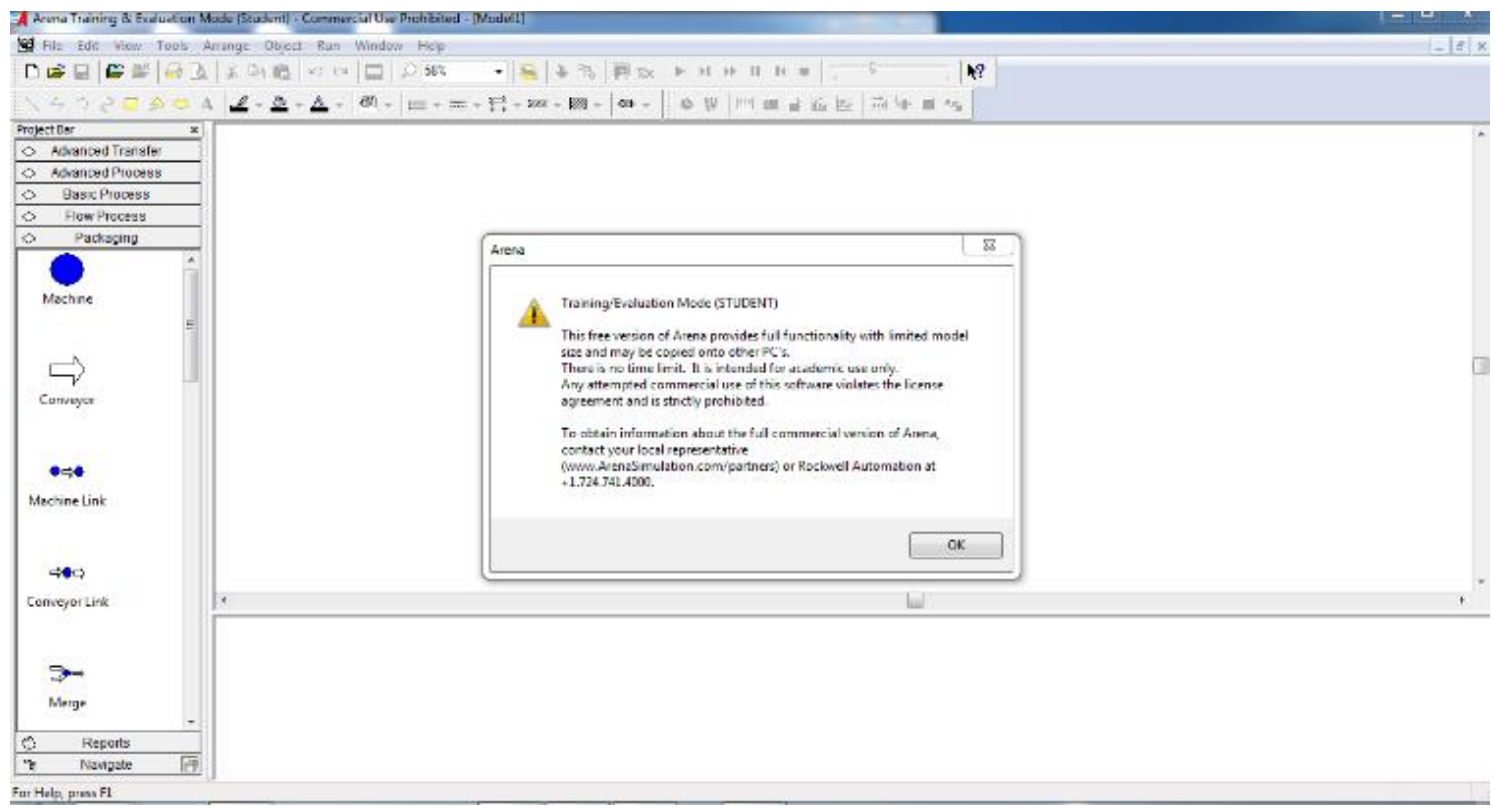

Figura A1.33.

Se a licença utilizada for a de estudante, irá aparecer um aviso ao iniciar o programa, nesse caso clique em OK para prosseguir. Em seguida, localize na aba da esquerda a opção "Basic Process". Clique nessa aba para abri-la, Figura A1.34.

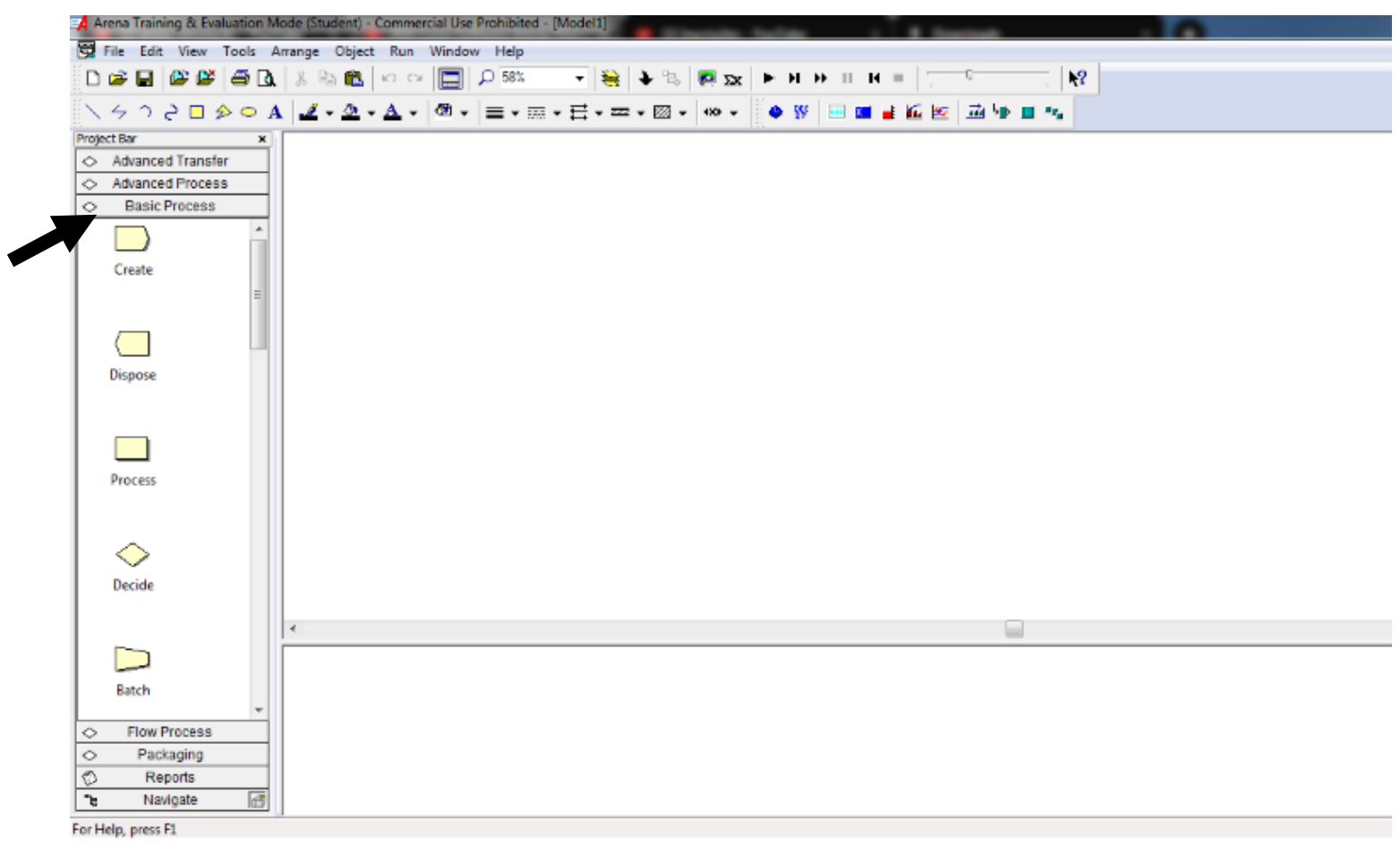

Figura A1.34.

Para dar início à modelagem. é necessário clicar e arrastar o bloco "Create" da aba da esquerda para a parte em branco do centro da tela, que é a área de trabalho do ARENA, Figura A1.35. 


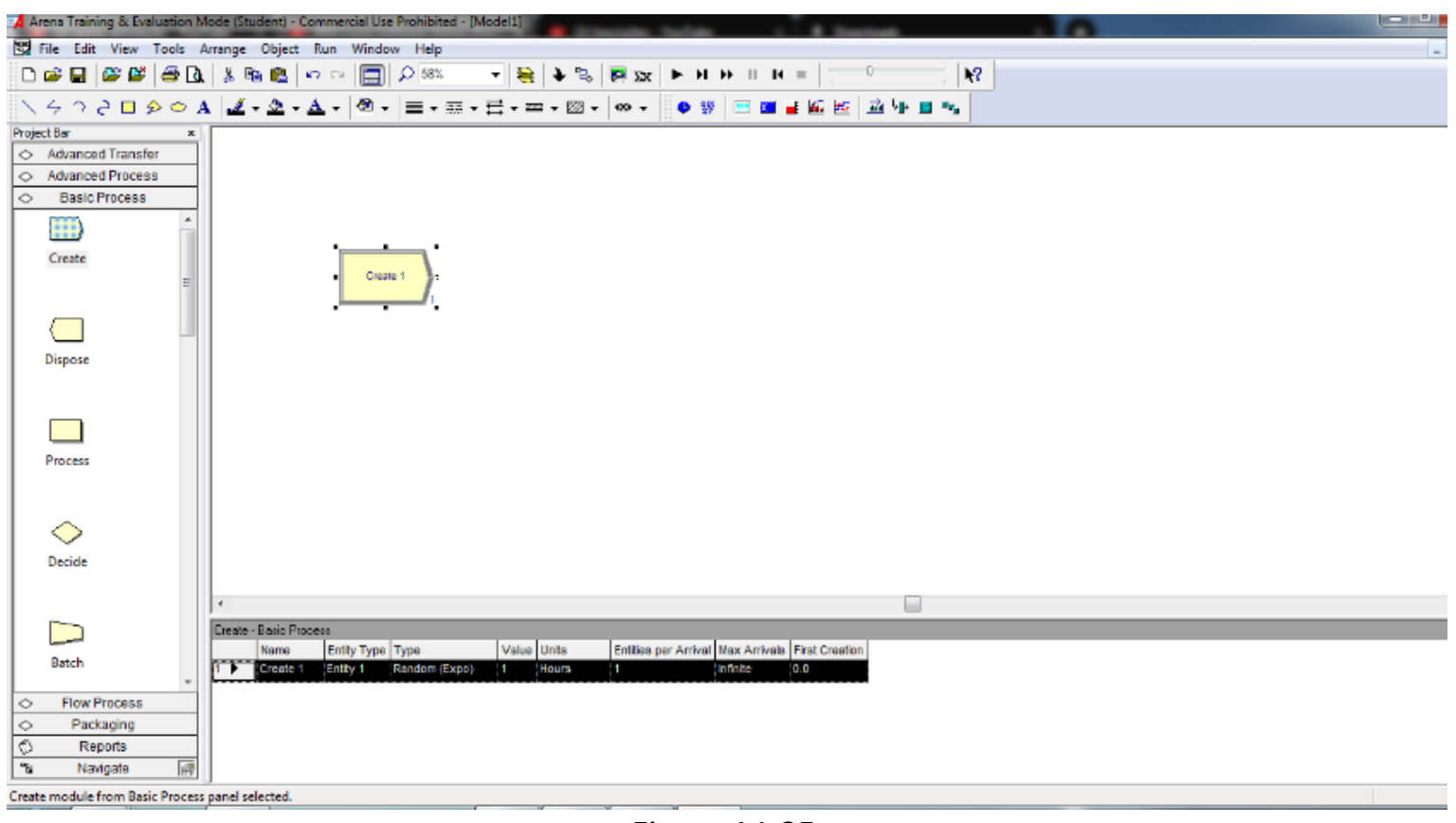

Figura A1.35.

Assim sendo, é possível editar alguns parâmetros desse bloco, para isso basta clicar duas vezes sobro o bloco "CREATE" adicionado, Figura A1.36.
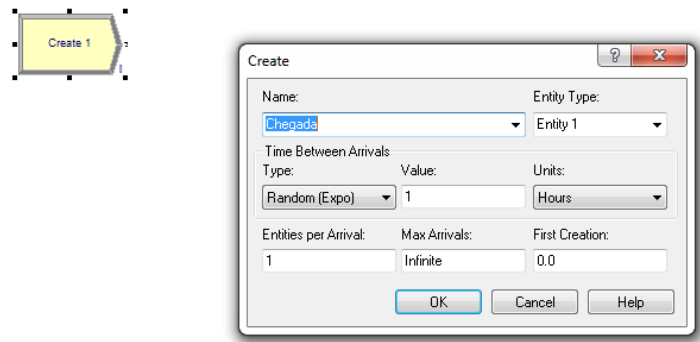

Figura A1.36.

Irá aparecer uma caixa onde será possível mudar o nome do bloco; nesse exemplo. o nome dado será de "Chegada", representando a chegada de novos usuários no processo, Figura A1.37.
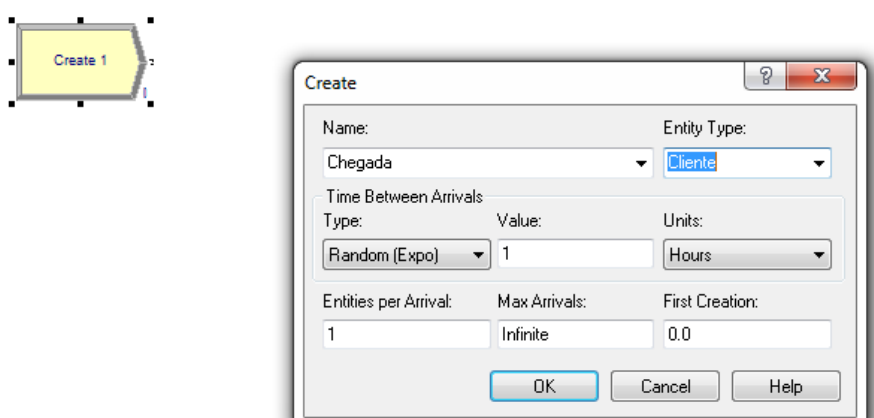

Figura A1.37. 
Em "Entily Type" será colocado a palavra "Passageiro" para representar o tipo de chegada do bloco, Figura A1.38.

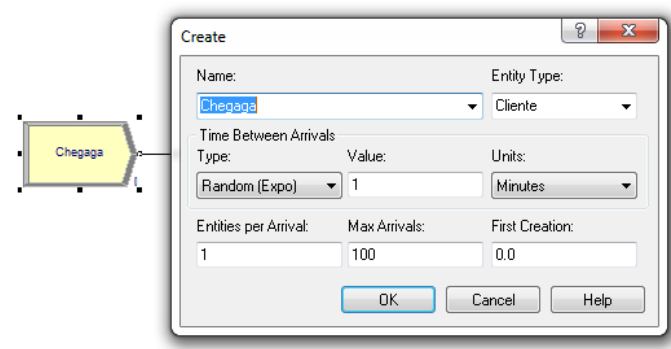

Figura A1.38.

Em "Type" será mantido a função "Random(Expo)" que corresponde a distribuição exponencial cuja a média é dada pelo valor "Value", nesse caso, 1 minuto. Em "Units" deve-se trocar de "Hours" para "Minutes".

De semelhante forma, para adicionar o processo de atendimento, clique e arraste o bloco "Process" para frente do bloco "Chegada". É normal que o ARENA ligue os blocos automaticamente, porém, se isso não ocorrer é possível ligar os blocos indo na opção "Object" da barra de tarefas e clicando na opção "Connect". Em seguida basta clicar nos pontos pretos das extremidades dos blocos para conectá-los, Figura A1.39.

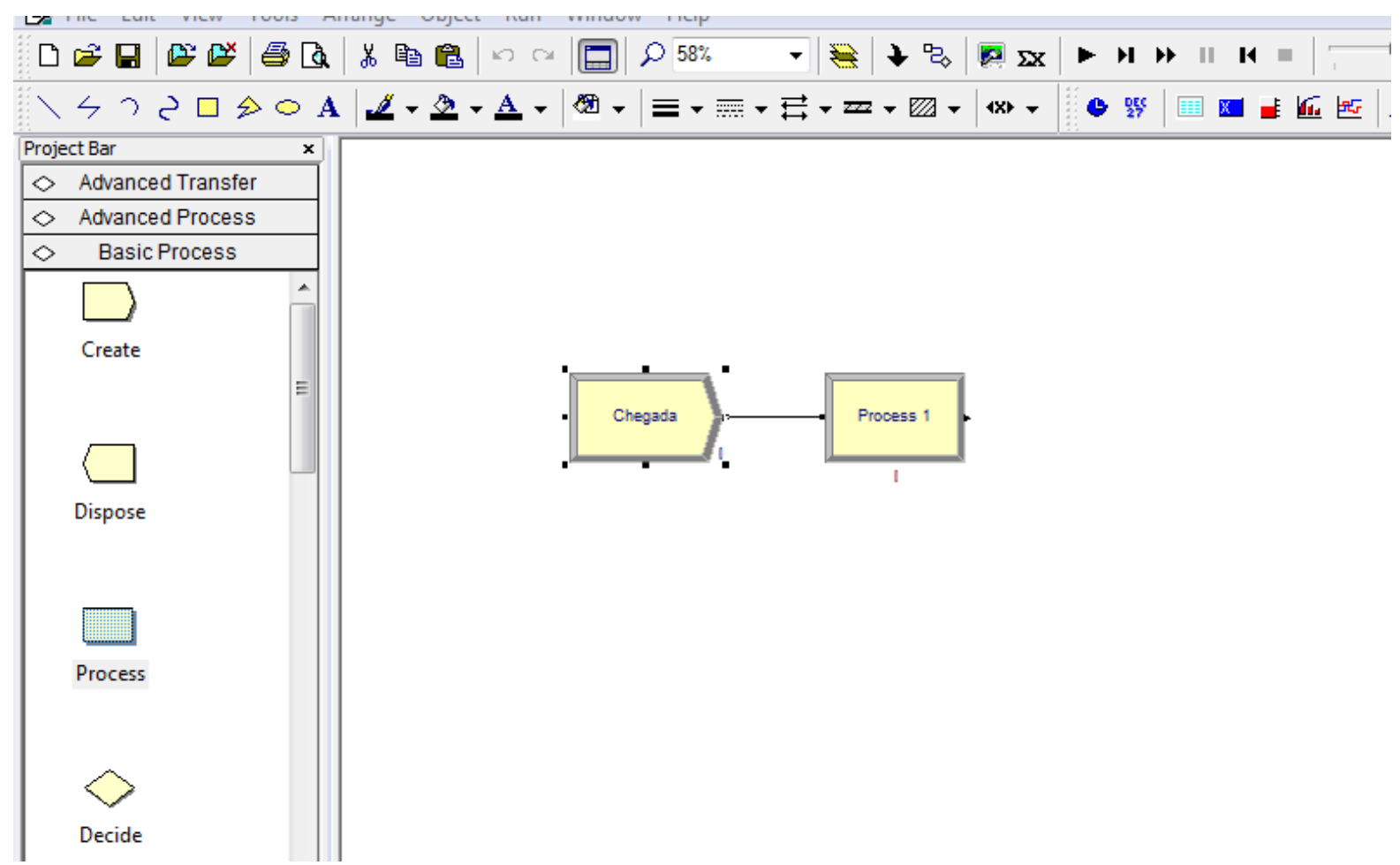

Figura A1.39. 
Clicando duas vezes sobre o bloco "Process" irá aparecer uma janela como mostrado na Figura A1.40.

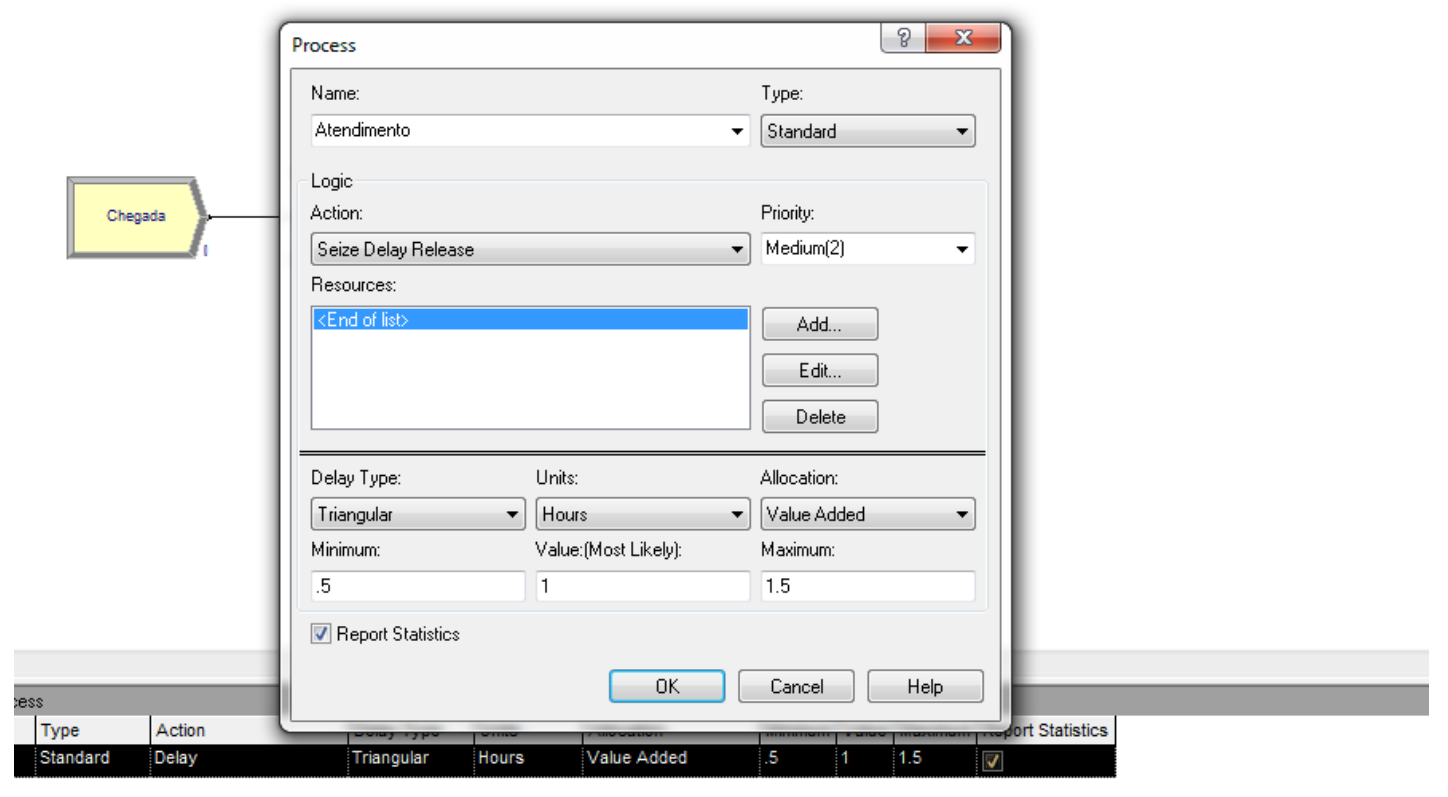

Figura A1.40.

Na caixa "Name" será colocado o nome "Atendimento". Em seguida, deve-se clicar na caixa "Action" e escolher a opção "Seize Delay Release" que irá reter o elemento passageiro na fila e atrasar a saída dele até que o tempo do atendimento termine. Depois, em "Resources" deve-se clicar no botão "Add..." para adicionar um atendente no bloco. O nome será "Atendente" e a opção "Unitis to Seize/Release" será mantida 1, Figura A1.41.

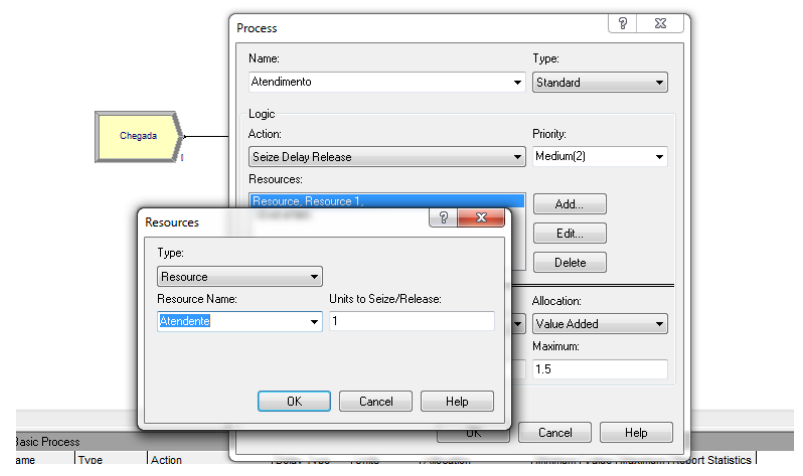

Figura A1.41.

Após clicar em OK para adicionar o atendente, será configurado o tempo de atendimento. Clicando na caixa abaixo de "Delay Type" deve-se escolher a opção "Expression" e na caixa "Expression" será selecionada a opção "TRIA" que corresponde a distribuição triangular. Sendo TRIA $(5,6,7)$ para as especificações do exemplo, colocando "Minutes" na caixa de "Units", Figura A1.42. 
FILAS: conceitos, novos enfoques de abordagem e aplicações em Transportes

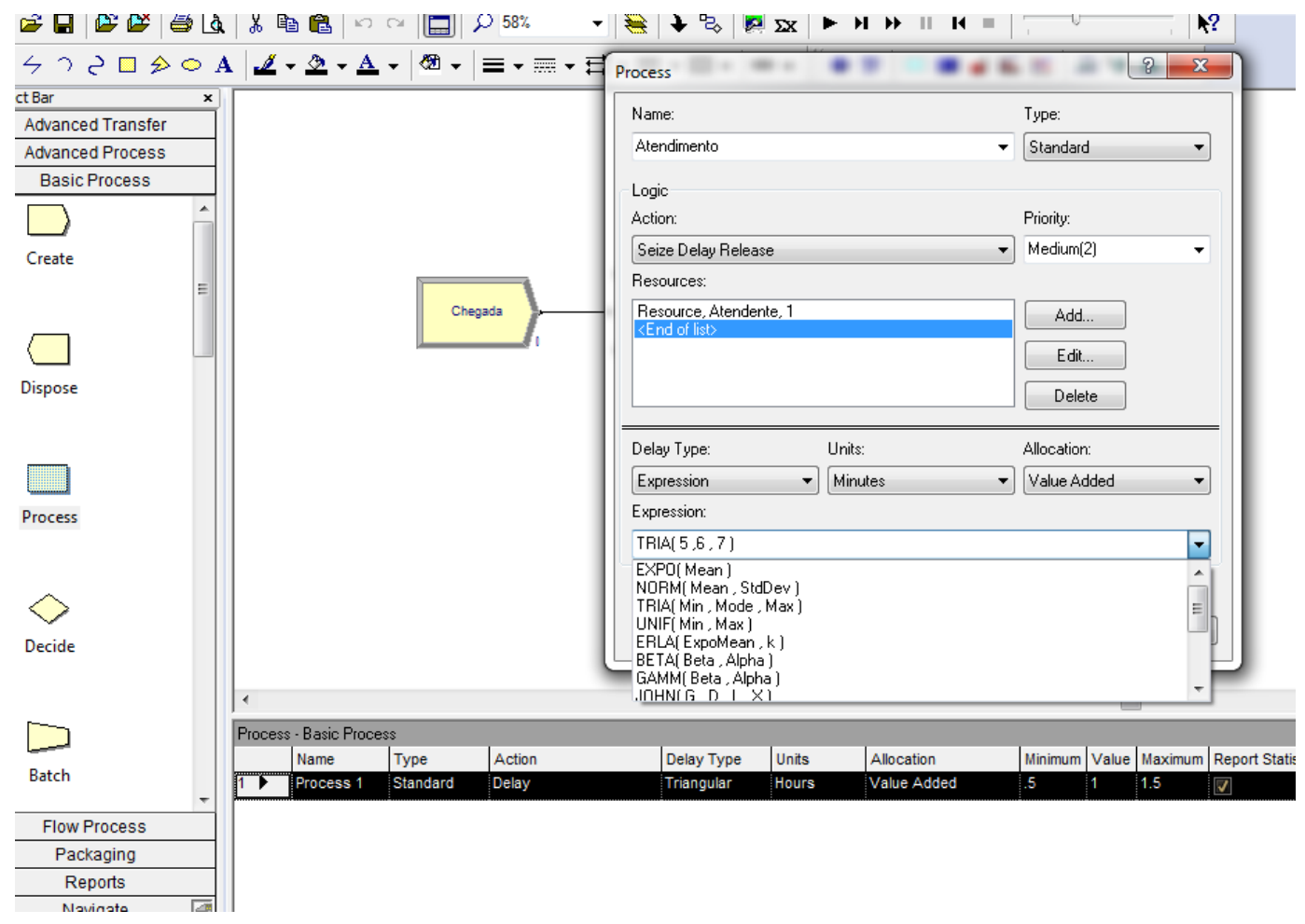

Figura A1.42.

Logo após deve-se clicar em OK para fechar essa janela de "Process".

No ARENA possui algumas funções de distribuições de probabilidade, cada uma delas é indicada para alguns tipos processos, Quadro A1.1.

Quadro A1.1. Abreviaturas das distribuições de probabilidade

\begin{tabular}{|l|l|l|l|}
\hline Distribuição & Abreviatura & Parâmetros & Melhor Aplicação \\
\hline Poisson & POIS & Média & Chegada \\
\hline Exponencial & EXPO & Média & Chegada \\
\hline Triangular & TRIA & Min/ Média/Max & Atendimento \\
\hline Uniforme & UNIF & Min/ Média/Max & Atendimento \\
\hline Normal & NORM & Média/Desvio & Atendimento \\
\hline Johnson & JOHN & $\mathrm{G}, \mathrm{D}, \mathrm{L}, \mathrm{X}$ & Atendimento \\
\hline Log Neperiano & LOGN & Média Logrtm. & Atendimento \\
\hline Weibull & WEIB & Beta, Alfa & Atendimento \\
\hline Discreta & DISC & P1, V1, .. & Cheg/Atendim \\
\hline Contínua & CONT & P1, V1, $\ldots$ & Cheg/Atendim \\
\hline Erlang & ERLA & Média / K & Atendimento \\
\hline Gamma & GAMM & Beta, Alfa & Atendimento \\
\hline
\end{tabular}

Seguindo no exemplo, o último bloco a ser adicionado será o "Dispose" que representa a saída do processo. Clicando duas vezes nesse bloco, o único parâmetro que será alterado é o "Name" que será trocado para o nome "Saída", Figura A1.43. 


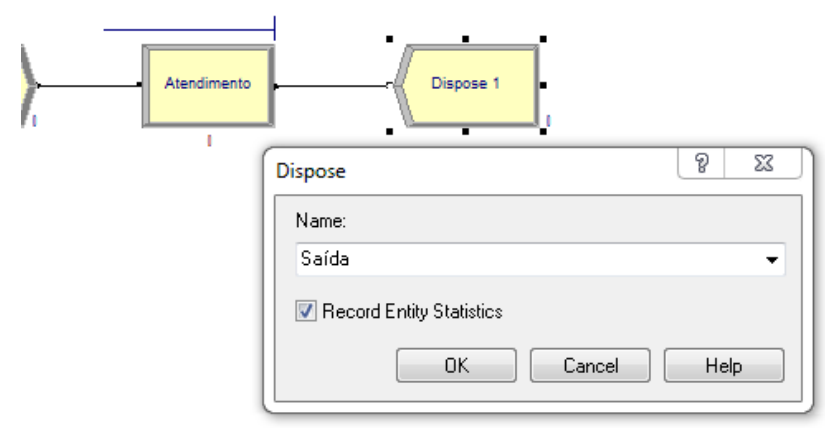

Figura A1.43.

Após apertar OK o modelo já estará pronto para ser simulado. Para isso, é necessário clicar no botão "GO" que possui um ícone triangular, localizado na barra superior, Figura A1.44.

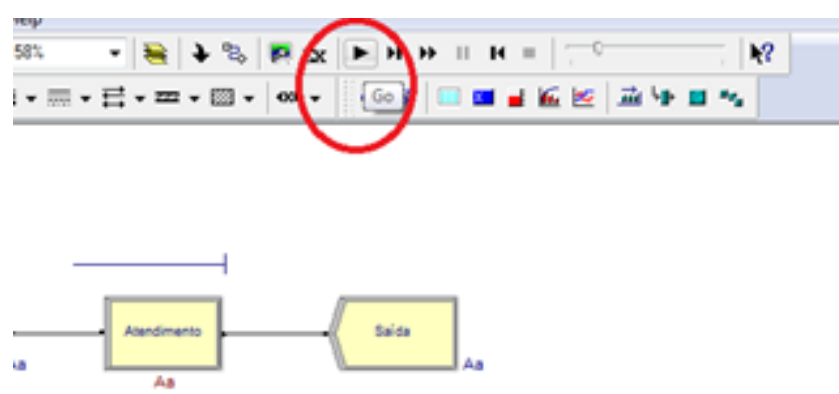

Figura A1.44.

Conforme a simulação se desenvolve, é possível observar uma animação no modelo representando os passageiros entrando e saído do sistema, Figura A1.45.

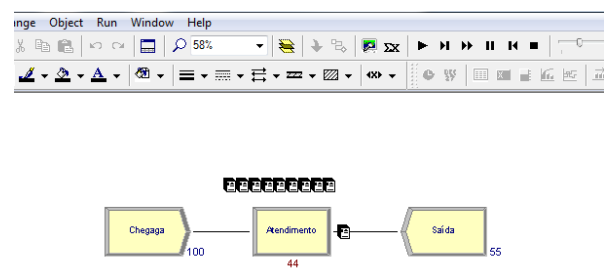

Figura A1.45.

Por fim, ao findar a simulação o ARENA exibirá uma janela para exibir o relatório gerado. Para isso é necessário clicar em "Sim", Figura A1.46. 


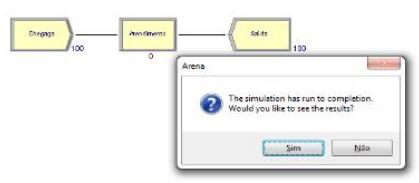

Figura A1.46.

A primeira parte do relatório exibido e o "Category Overview" que mostra o Número de saída do sistema, como foi predefinido 100 no início do problema o número de saída é o mesmo, Figura A1.47.

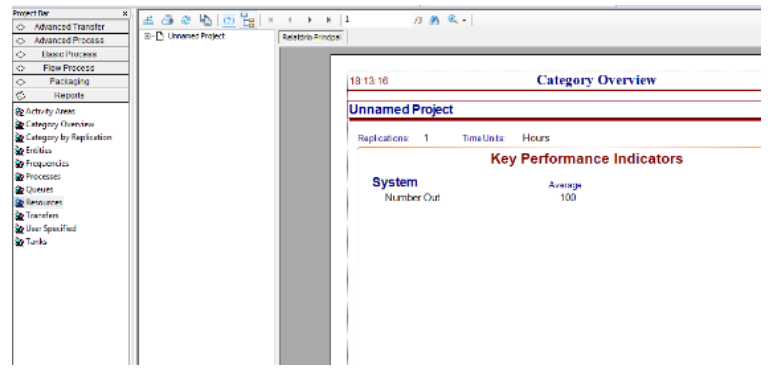

Figura A1.47.

Clicando em "Queues" é possível extrair o número médio de espera na fila e abaixo o número médio de passageiros esperando na fila, obtendo-se os resultados, Figura A1.48.

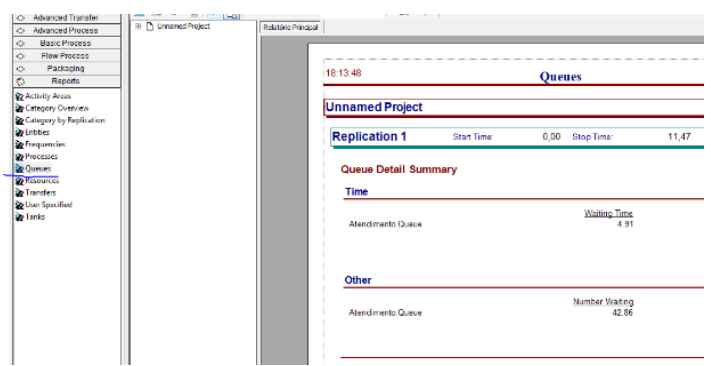

Figura A1.48.

Também é possível ver a taxa de ocupação do atendente clicando em "Resources" e observando o "Sched Util", nesse caso é 1 representando 100\%, indicando que não ouve ociosidade no atendimento, Figura A1.49.

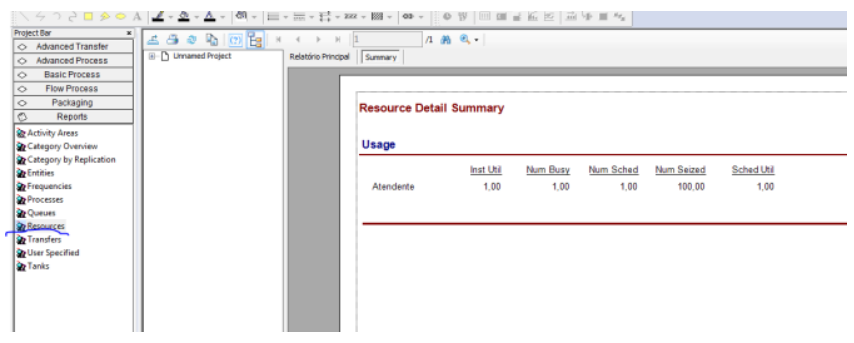

Figura A1.49.

\section{REFERÊNCIA}

ARAíJO et al,. Manual do Arena 9.0. Santa Catarina, v 2, 2006. Disponível em: <http://mz.pro.br/simulacao/32-APOSTILA_ARENA_9.pdf> Acesso em: 23 jun 2019. 


\section{Anexo \\ 2 \\ 50 ou mais \\ vídeos sobre teoria das filas}

ADONIS CARNEIRO DA SILVA

a) em português:

a. Teoria das filas: vídeo com maior número de visualizações

https://www.youtube.com/watch?v=ybZe4spMFfk\&t=53s

b. Teoria das filas: desenho de problemas

https://www.youtube.com/watch?v=qN91ULD25So

c. Teoria das filas: Faculdade Pitágoras

https://www.youtube.com/watch?v=PcBNwK8J7Gg

d. Teoria das Filas - Luiza Prates

https://www.youtube.com/watch?v=imrlJ8rxNiY

e. Estudo da teoria das filas aplicado a uma casa lotérica

https://www.youtube.com/watch?v=Z joG7 yvHO

f. Debate sobre o artigo - Teoria das filas e da simulação

https://www.youtube.com/watch?v=rhfumdaHDGw

g. TCC Teoria das Filas aplicado ao estacionamento da Universidade Positivo

h. https://www.youtube.com/watch?v=RsGdlx3|NeO

b) em inglês:

a. Queueing Theory, In Practice: Performance Modelling in Cloud-Native Territory https://www.youtube.com/watch?v=yf6wSsOFqdl

b. Discrete event simulation example for queueing theory $\mathrm{M} / \mathrm{M} / \mathrm{C}$ queue https://www.youtube.com/watch?v=MhVQzem-t6g

c. How queueing theory can improve wait times https://www.youtube.com/watch?v=SRql Ntrcnc

d. Queueing Theory in practice: Performance Modeling for the Working Enginner https://www.youtube.com/watch?v=Hda5tMrLJqc

e. Queueing Modeling in Excel https://www.youtube.com/watch?v=irMhkCGXOXs

f. Queueing Theory https://www.youtube.com/watch?v=FXiZfpldqEY

g. Queueing Theory Application: Starbucks

https://www.youtube.com/watch?v=jHHRzodiHzQ

h. Queueing Theory https://www.youtube.com/watch?v=PZtbYzuUbMQ

i. Customer Queueing Systems https://www.youtube.com/watch?v=YlUJ4qPjt10 
FILAS: conceitos, novos enfoques de abordagem e aplicações em Transportes

j. Queueing Theory Presentation

https://www.youtube.com/watch?v=2IXtauTMJz|

k. Queueing Theory in 10 minutes

https://www.youtube.com/watch?v=6Qd5WKhG6Z0

I. Queue Modeling Basics

https://www.youtube.com/watch?v=Wgkcrtirr7s

m. Queueing Theory - Sharon Buhs

https://www.youtube.com/watch?v=ktVITuLJ ic

n. Queueing Example

https://www.youtube.com/watch?v=WaaZDGW7 Q4

o. Queueing Theory - Morgan Maglich

https://www.youtube.com/watch?v=CPntVloNG0O

p. Problems on Probability and Queuing Theory

https://www.youtube.com/watch?v=kUZ93kdpx6o

q. Queueing Theory - Blanca Alcaraz

https://www.youtube.com/watch?v=dPBmrEO52YM

r. Queueing Theory Presentation

https://www.youtube.com/watch?v=A0s5K3ZNjFA

s. Queueing theory

https://www.youtube.com/watch?v=t2S5grl It0

t. Queueing theory basics

https://www.youtube.com/watch?v=hJ2CmtDvmv8

u. Queueing theory-Michele McGarry

https://www.youtube.com/watch?v=gBxFNRjS4Dw

v. Queueing

https://www.youtube.com/watch?v=9kJUw2DSFKI

w. The queueing theory

https://www.youtube.com/watch?v=8JvnsXUw75U

x. Impact of queueing theory

https://www.youtube.com/watch?v=fVBMcim8p31

y. Impact of queueing theory

https://www.youtube.com/watch?v=fVBMcim8p31

z. Queueing Theory-Chris Browne

https://www.youtube.com/watch?v=oAuYMHgS7oO

c) em espanhol:

a. Teoría de Colas Conceptos Básicos

https://www.youtube.com/watch?v=ib3 zvjOw c

b. Teoria de Colas

https://www.youtube.com/watch?v=WILHqODOmLM

c. ¿Cuál es la fila más rápida del supermercado? I Teoría de colas

https://www.youtube.com/watch?v=VPuRoEOVogo

d. Teoria de filas

https://www.youtube.com/watch?v=i7PDUWWOWZE 
FILAS: conceitos, novos enfoques de abordagem e aplicações em Transportes

e. Teoría de colas (Líneas de espera)

https://www.youtube.com/watch?v=fCr6SKWlpAk

d) em francês:

a. La théorie des files d'attente

https://www.youtube.com/watch?v=KNLxLWV IYM

b. Les files d'attente

https://www.youtube.com/watch?v=8hoEX qPNHo

c. Episode la théorie de la file d'attente Markov

https://www.youtube.com/watch?v=2giLFXIlzYk

d. Théorie de la file d'attente

https://www.youtube.com/watch?v=qxLsyFuR3dY

e. La gestion de file d'attente

https://www.youtube.com/watch?v=Gh QMDIB8U0

f. No Queue est un système intelligent pour la gestion des files d'attente

https://www.youtube.com/watch?v=OfrKsHLoVQA

g. Fini les files d'attente

https://www.youtube.com/watch?v=OsAd-TME1uw

h. Théorie des files d'attente: Pour être bien servi, il faut savoir attendre comme le soldat Adkins

i. https://www.youtube.com/watch?v=QvNYXTtNe20

e) em alemão:

a. Warteschlangentheorie - mit weniger Auslastung mehr schaffen https://www.youtube.com/watch?v=RQ5Jdp7TJHk

b. Warteschlange

https://www.youtube.com/watch?v=FvWOG6YR7b|

c. Wie du die richtige Warteschlange wählst - LIFE HACK

d. https://www.youtube.com/watch?v=jpgAOepvkEk 


\section{Anexo \\ Teoria das Filas \\ 3 em três universidades estrangeiras}

ADONIS CARNEIRO DA SILVA

Quando se pensa nas melhores universidades do mundo, certamente alguns nomes nos vêm à mente automaticamente. Harvard, Cambridge, Oxford, MIT, Stanford são instituições lembradas mundo a fora por causa da excelência em ensino e pesquisa.

Entretanto, para listar quais são as principais referências universitárias no campo da Engenharia de Transportes devemos analisar alguma fonte que classifique as instituições pela qualidade deste curso, e não pela qualidade de toda instituição em geral.

Por exemplo, a Universidade de Stanford, localizada no estado americano da Califórnia, é internacionalmente respeitada, sendo classificada pelo QS World University Rankings como a segunda melhor universidade do mundo. Todavia. a mesma não possui nenhum curso de Engenharia de Transportes no seu quadro.

Sendo assim, para otimizar o contato com as melhores instituições foi tomado como base o ShanghaiRanking's Global Ranking of Academic Subjects 2018, que fornece as melhores universidades do mundo no campo Engineering e na cadeira Transportation Science \& Technology.

Para obter informações sobre o ensino de Teoria das Filas nos programas de Engenharia de Transportes das melhores universidades, foram consultados os websites das instituições, bem como foram solicitados relatos diretamente dos docentes responsáveis pela transmissão destes assuntos.

Dessas, obteve-se sucesso nas respostas somente nas seguintes:

\section{a. California University, Berkeley}

Na Universidade da Califórnia Berkeley, nos Estados Unidos da América, o departamento de Engenharia Civil e Ambiental oferece, entre seus programas de pós-graduação, mestrado e doutorado em Engenharia de Transportes. Entretanto, uma vantagem de frequentar a Universidade da Califórnia é o acesso a uma ampla variedade de departamentos acadêmicos. Você é incentivado a realizar estudos em áreas de foco fora de Transportes. O programa de Mestrado em Engenharia é ideal para este propósito. Um exemplo é a divisão de Análise de Tráfego e Foco de Controle, onde é ministrada a disciplina de Teoria das Filas, sob o código IEOR 267, pertencente ao departamento de Engenharia Industrial e Pesquisa Operacional.

Com duração de 15 semanas e 3 horas de leitura semanais, a ementa da disciplina consiste nos seguintes assuntos: Resultado de " $L=$ (lambda) $w "$ e outras leis conservadoras. Modelos elementares de filas; comparar filas de servidor único e múltiplo. PASTA. Work. Markovian queues; product form results. Modelos de transbordamento. Cadeias de Markov embutidas. Passeios aleatórios e filas GI / G / I. Conservação do trabalho; prioridades. Limites e aproximações. 


\section{b. Sydney University}

Na Universidade de Sydney, na Austrália, o departamento de Engenharia Civil da Faculdade de Engenharia e Tecnologias da Informação oferece um mestrado interdisciplinar em Transportes com foco na engenharia, planejamento urbano e gestão de negócios de transporte. No primeiro semestre do segundo ano do curso é oferecida a disciplina de Engenharia de Tráfego, sob o código CIVL5702. Com 13 semanas de duração, 6 créditos, e tendo como coordenador o professor Mohsen Ramezani, esta disciplina de estudo visa fornecer uma compreensão avançada dos fundamentos da engenharia de tráfego, teoria do fluxo de tráfego, modelagem de tráfego, e operações. Os tópicos incluem: fundamentos da teoria do fluxo de tráfego; Análise de Schock Wave, micro-modelagem; modelagem macro; teoria das filas; interseção ao controle; medição de rampa; simulação de tráfego; coleta e análise de dados de tráfego; e dinâmica de multidões. A Teoria das Filas é aplicada conjuntamente com fluxo de tráfego para desenhar e otimizar sistemas de tráfego.

Como requisitos para realizar a matrícula nesta disciplina os alunos devem assumir que já possuem os seguintes conhecimentos: Estatísticas básicas através de análise de regressão, cálculo diferencial e integral, programação de computadores. A disciplina que é ministrada presencialmente por 2 vezes na semana, requer também um tempo de leitura semanal de 4 horas e estudo independente de 6 horas. A avaliação é realizada através de tarefas semanais individuais ou em grupo.

\section{c. National University of Singapore}

O departamento de engenharia civil e ambiental da Universidade Nacional de Singapura oferece cinco programas de mestrado, dentre eles uma especialização em Engenharia de Transportes. Na disciplina de Engenharia de Transportes, sob o código CE3121 e com 4 créditos, o assunto de Teoria das Filas é abordado em duas aulas e através de leituras. Este módulo introduz princípios básicos e ferramentas para projetar, planejar, avaliar, analisar, gerenciar e controlar sistemas de transporte. O objetivo é capacitar os alunos para identificar, formular, examinar e resolver problemas de engenharia de transporte. Os principais tópicos incluem sistema de transporte, planejamento e gerenciamento, projeto geométrico de estradas e interseções, projeto estrutural do pavimento, materiais de pavimentação, fluxo de tráfego e análise e gerenciamento e controle de tráfego. 


\section{REFERÊNCIAS ADICIONAIS}

WINSTON, W. L. Operations Research: applications and algorithms. Cengage Learning; 4.ed. California Thomson 2004. xvi, 1418p. ISBN 0534380581, capítulo 20.

SHORTLE, J.F., THOMPSON, J.M. GROSS, D. e HARRIS, C. M. Fundamentals of Queueing Theory, 5th edition, Wiley, 2018, $548 \mathrm{p}$.

COOPER, R.B. Introduction to queueing theory. New York: Macmillan, 1981. 3477 p.

COSTA, Luciano Cajado. Teoria das Filas:

http://www.deinf.ufma.br/ mario/grad/filas/TeoriaFilas_Cajado.pdf

LARSON, R.C. e ODONI, R. Urban Operations Research. Prentice-Hall, NJ, 1981.

1. Livro: http://web.mit.edu/urban_or_book/www/book/

2. Suplemento: http://web.mit.edu/urban_or_book/www/

3. Filas: http://web.mit.edu/urban_or_book/www/book/chapter4/contents4.html

NOVAES, A. G. - Pesquisa Operacional e Transportes: Modelos Probabilísticos, São Paulo, Editora.da USP e McGraw-Hill do Brasil Ltda., 1975.

PRADO, Darci Santos do, Teoria das Filas e da Simulação, Série Pesquisa Operacional, volume 2, Nova Lima: Falconi Editora, 6ạ. edição, 2014.

COGAN, Samuel, Gerenciando as percepções nas filas de espera, Rio de Janeiro: Qualitymark, 1998 
Este livro apresenta os conceitos introdutórios referentes à Filas, com uma linguagem de fácil compreensão para as pessoas que estão tendo o primeiro contato com o tema.

Os exemplos e exercícios resolvidos apresentados consolidam a teoria e as aplicações reais e estimulam compreender a viabilidade de aplicação dos conhecimentos adquiridos.

Destina-se aos estudantes de pós-graduação e de graduação em diversas áreas, notadamente Administração e Engenharia de Produção, nas disciplinas que enfatizam aplicações em Transportes, como Pesquisa Operacional, Logística e Otimização de Sistemas. 